ORNL/M--2500

DE93 004291

\title{
U.S. - EC FUEL CYCLE STUDY: BACKGROUND DOCUMENT TO THE APPROACH AND ISSUES
}

\author{
Prepared By \\ Oak Ridge National Laboratory \\ And \\ Resources For The Future
}

\section{Report No. 1 on the EXTERNAL COSTS AND BENEFITS OF FUEL CYCLES: \\ A Study By The \\ U.S. Department of Energy \\ And The \\ Commission of the European Communities}

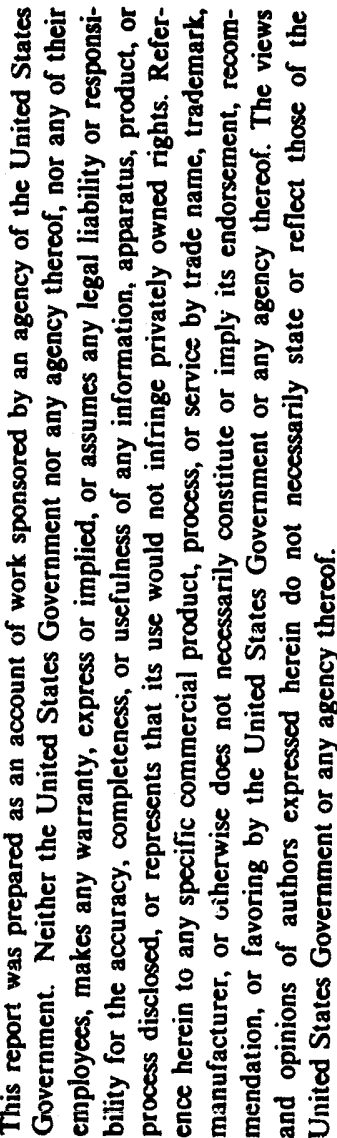

\author{
November 1992 \\ OAK RIDGE NATIONAL LABORATORY \\ Oak Ridge, Tennessee 37831 \\ is managed by \\ MARTIN MARIETTA ENERGY SYSTEMS, INC. \\ for the \\ U.S. DEPARTMENT OF ENERGY \\ under Contract No. DE-AC05-840R21400
}

WCoun

Se 
U.S. - EC FUEL CYCLE STUDY:

BACKGROUND DOCUMENT TO THE APPROACH AND ISSUES

\section{CONTRIBUTORS}

Project Managers: Robin Cantor* and Russell Lee

Executive Summary

Chapter 1

Chapter 2

Chapter 3

Chapter 4

Chapter 5

Appendix A

Appendix B

Appendix C
Introduction

Analytical Tools

Identifying Ecological

Impacts from the Coal

Fuel Cycle

Identifying Health Impacts from the Coal Fuel Cycle

Economic Valuation for Fuel Cycle Analysis

Typical Environmental Interactions of the Coal

Fuel Cycle for Electricity

Production

Accounting Framework Matrices for the Coal Fuel Cycle

The Social Costing Debate:

Issues and Resolutions
Robin Cantor* Alan Krupnick***

Russell Lee

Robin Cantor* Hilary Smith** Alan Krupnick***

Robin Cantor* Alan Krupnick** A. Schaffhauser $\mathrm{Jr}$.

Larry Barnthouse Glen Cada Roger Kroodsma Robb Turner

Clay Easterly Troyce Jones

Alan Krupnick***

ORNL Staff

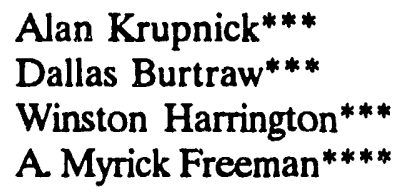

*Now with the U.S. National Science Foundation

**U.S. Department of Energy

**"Resources for the Future

****Bowdoin College 


\section{ACKNOWLEDGEMENTS}

This report has benefitted considerably from the careful reviews and detailed comments that were made on earlier drafts of this report. The authors would especially like to thank the U.S. Department of Energy's Offices of Domestic and International Energy Policy; Fossil Energy; Nuclear Energy; and Conservation and Renewable Energy for their reviews. In addition, the Federal Energy Regulatory Commission, staff at Oak Ridge National Laboratory, and our colleagues on the European Communities research team all contributed valuable review comments and other input to this report.

The authors would also like to thank Teresa Ault, Virginia Bolinger, Karen Bowman, Brenda Bush, Brenda Cleaves, Glenda Hamlin, and Pam Witcher for their word processing of the numerous drafts; Vicki Conner for the cover design; Kerri Ballew for technical editing; and Miranda Talley and Chris Dummer for assisting in the production of the report.

The views expressed in this report are solely those of the authors (refer to the list of contributors). They do not necessarily reflect the views of the U.S. Department of Energy, The Commission of the European Communities, Martin Marietta Energy Systems Inc. or Oak Ridge National Laboratory. 
TABLE OF CONTENTS

CONTRIBUTORS $\ldots \ldots \ldots \ldots \ldots \ldots \ldots \ldots \ldots \ldots \ldots \ldots$

ACKNOWLEDGEMENTS $\ldots \ldots \ldots \ldots \ldots \ldots \ldots \ldots \ldots$ ii

LIST OF TABLES $\ldots \ldots \ldots \ldots \ldots \ldots \ldots \ldots \ldots \ldots$ vii

LIST OF FIGURES $\ldots \ldots \ldots \ldots \ldots \ldots \ldots \ldots \ldots \ldots \ldots$ vii

EXECUTIVE SUMMARY .................... viii

E.1 BACKGROUND AND PURPOSE OF THE STUDY . . . v viii

E.2 TERMINOLOGY $\ldots \ldots \ldots \ldots \ldots \ldots \ldots \ldots \ldots \ldots \ldots \ldots$

E.3 SCOPE ....................... xii

E.4 ANALYTICAL TOOLS $\ldots \ldots \ldots \ldots \ldots \ldots \ldots \ldots$ xvi

E.5 IMPACT-PATHWAYS $\ldots \ldots \ldots \ldots \ldots \ldots \ldots \ldots \ldots$ xviii

E.6 ECONOMIC VALUATION $\ldots \ldots \ldots \ldots \ldots \ldots \ldots \ldots$ xix

1. INTRODUCTION $\ldots \ldots \ldots \ldots \ldots \ldots \ldots \ldots \ldots \ldots \ldots \ldots \ldots \ldots$

1.1 BACKGROUND $\ldots \ldots \ldots \ldots \ldots \ldots \ldots \ldots \ldots \ldots 1-1$

1.1.1 Overview of the Study $\ldots \ldots \ldots \ldots \ldots \ldots \ldots \ldots 1-3$

1.1.2 Terminology ..................... 1-4

1.2 SCOPE OF THE STUDY $\ldots \ldots \ldots \ldots \ldots \ldots \ldots \ldots 1-8$

1.2.1 Choice of Theoretical Foundation .......... 1-9

1.2.2 Investment or Operational Perspective . . . . . . 1-12

1.2.3 Static or Dynamic Model . . . . . . . . . . . . 1-13

1.2.4 Stages of the Fuel Cycle ................ 1-14

1.2.5 Scale of Generating Facility ............. 1-15

1.2.6 Time Period .................... 1-15

1.2.7 Non-environmental Externalities . . . . . . . . 1-15

1.3 OUTLINE OF THE REMAINDER OF THE REPORT 1-16

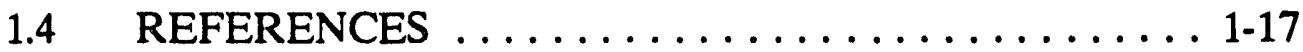

2. ANALYTICAL TOOLS ................... 2-1

2.1 THE DAMAGE FUNCTION APPROACH ....... 2-2

2.1.1 Alternative Approaches to Valuing

Damages in a PUC Context ............ 2-6

2.1.2 The Issue of Thresholds and Standards . . . . . 2-10

2.2 THE ACCOUNTING FRAMEWORK . . . . . . . . . 2-14

2.3 THE IMPACT-PATHWAY APPROACH $\ldots \ldots \ldots \ldots .2-20$ 
2.4 THE UNCERTAINTY AND QUALITY MESSAGE SYSTEM $\ldots \ldots \ldots \ldots \ldots \ldots \ldots \ldots \ldots \ldots \ldots .2-23$

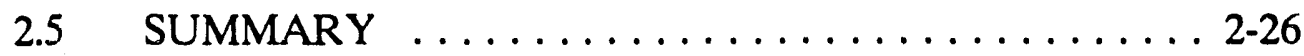

2.6 REFERENCES $\ldots \ldots \ldots \ldots \ldots \ldots \ldots \ldots \ldots \ldots .2-26$

3. IDENTIFYING ECOLOGICAL IMPACTS FROM THE

COAL FUEL CYCLE . . . . . . . . . . . . . . . . . . . 3-1

3.1 AQUATIC RESOURCES AND COAL FUEL CYCLE . . 3.1

3.1 .1 Coal Mining . . . . . . . . . . . . . 3-1

3.1.2 Coal Cleaning and Beneficiation . . . . . . . . 3-3

3.1.3 Generation ................... 3-3

3.2 TERRESTRIAL RESOURCES AND THE COAL

FUEL CYCLE . . . . . . . . . . . . . . . 3-5

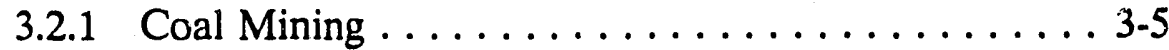

3.2.2 Coal Cleaning and Beneficiation . . . . . . . 3.6.

3.2.3 Coal Transportation . . . . . . . . . . . . . 3-6

3.2.4 Generation ..................... 3-7

3.2.5 Power Transmission . . . . . . . . . . . 3-7

3.3 DEFINITIONS OF IMPACT CATEGORIES . . . . . . . 3-7

3.3.1 Crops and Suburban Landscape . . . . . . . . . 3-8

3.3.2 Livestock . . . . . . . . . . . . . . . . . 3-12

3.3.3 Timber $\ldots \ldots \ldots \ldots \ldots \ldots \ldots \ldots \ldots \ldots . . \ldots \ldots .12$

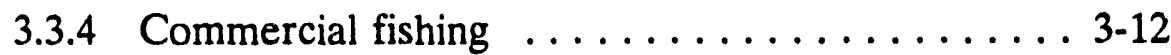

3.3.5 Recreational fishing $\ldots \ldots \ldots \ldots \ldots \ldots \ldots . \ldots .14$

3.3.6 Hunting ....................... 3-15

3.3.7 Recreation . . . . . . . . . . . . . . . . 3-15

3.3.8 Biodiversity . . . . . . . . . . . . . 3-15

3.4 QUANTIFICATION METHODS $\ldots \ldots \ldots \ldots \ldots \ldots .3-16$

3.5 REFERENCES . . . . . . . . . . . . . . . 3-18

4. IDENTIFYING HEALTH IMPACTS FROM THE COAL

FUEL CYCLE . . . . . . . . . . . . . . . . . 4-1

4.1 HEALTH RESOURCES AND THE COAL

FUEL CYCLE . . . . . . . . . . . . . . . 4 4-1

4.1 .1 Coal Mining . . . . . . . . . . . . . .

4.1.2 Coal Cleaning and Beneficiation . . . . . . . 4-2

4.1.3 Transportation . . . . . . . . . . . . . . . 4-3

4.1.4 Generation ................... 4-3

4.1.5 Transmission and Distribution ........... 4-4

4.2 PROCEDURES FOR CALCULATING

HEALTH IMPACTS $\ldots \ldots \ldots \ldots \ldots \ldots \ldots \ldots . \ldots 4-4$

4.2.1 Source Terms $\ldots \ldots \ldots \ldots \ldots \ldots \ldots \ldots \ldots 4.5$

4.2.2 Transport $\ldots \ldots \ldots \ldots \ldots \ldots \ldots \ldots \ldots .4 .6$ 
4.2.3 Sources of Exposure-Response

Information . . . . . . . . . . . . 4-7

4.2.4 Previous Assessments of Fuel Cycle

Impacts . . . . . . . . . . . . . . . . 4-11

4.2.5 Threshold Levels of Pollution . . . . . . . . . . . . 4-12

4.3 POTENTIAL HEALTH ENDPOINTS . . . . . . . . . . 4-12

4.3 .1 Cancer .................... 4-13

4.3.2 Asthma Attacks (increased airway

resistance), Irritation Symptoms,

Respiratory Insufficiency (breathing

difficulty), and Mortality . . . . . . . . . 4-16

4.3.3 Neurological Effects ............... 4-18

4.3.4 Cardiovascular Effects . . . . . . . . . . 4 4-19

4.3.5 Reproductive Effects . . . . . . . . . . . 4-20

4.4 UNCERTAINTY ISSUES FOR HEALTH IMPACTS . . 4-21

4.5 REFERENCES .................. 4-23

5. ECONOMIC VALUATION FOR FUEL CYCLE ANALYSIS . . 5-1

5.1 THEORY OF VALUE $\ldots \ldots \ldots \ldots \ldots \ldots \ldots$. . . . . .

5.2 VALUATION APPROACHES ............. $5-3$

5.2.1 Comparison of Approaches ........... 5-6

5.3 SPECIFIC ENDPOINTS ............... . 5-7

5.3.1 Mortality Risk Reductions to

Individuals . . . . . . . . . . . . . 5-7

5.3.2 Morbidity Reductions . . . . . . . . . . . . . . 5-11

5.3.3 Occupational Health and Safety ... . . . . . 5-12

5.3 .4 Production Impacts ... . . . . . . . . . . . 5-13

5.3.5 Benefits to Economic Assets .......... 5-14

5.3.6 Impacts to Environmental Assets . . . . . . . . 5-15

5.4 SUMMARY AND RESEARCH ISSUES . . . . . . . . 5 5-23

5.5 SPECIAL ISSUES IN VALUATION . . . . . . . . 5-25

5.5 .1 Transferability .................. 5-25

5.5 .2 Aggregation . . . . . . . . . . . . . . . 5-29

5.5 .3 Nonlinearities . . . . . . . . . . . . 5 5-33

5.5.4 Temporal Perspective in Analysis ......... . 5-33

5.5 .5 Discounting .................. . 5-34

5.6 MATCHING IMPACT ENDPOINTS AND

ECONOMIC VALUES ... . . . . . . . . . . 5-34

$5.7 \quad$ REFERENCES $\ldots \ldots \ldots \ldots \ldots \ldots \ldots \ldots \ldots \ldots$

APPENDIX A TYPICAL ENVIRONMENTAL INTERACTIONS

OF THE COAL FUEL CYCLE FOR

ELECTRICITY PRODUCTION 


\section{APPENDIX B ACCOUNTING FRAMEWORK MATRICES}

FOR THE COAL FUEL CYCLE . .......... B-1

APPENDIX C THE SOCIAL COSTING DEBATE:

ISSUES AND RESOLUTIONS ........... C-1

C.1 THE BASIC THEORY OF ENVIRONMENTAL POLICY ..................... C-2

C.2 OPTIMAL ENVIRONMENTAL POLICY VS SOCIAL COSTING AS COST-EFFECTIVE POLICY . . . . . . . C-4

C. 3 IS SOCIAL COSTING A GOOD IDEA? ......... C-5

C.4 HOW SHOULD DAMAGES BE MEASURED? ...... C-9

C.5 WHEN IS DAMAGE OR BENEFIT AN EXTERNALITY? . . . . . . . . . . . . . C 9

C.5.1 Criteria ..................... C-10

C.5.2 Rules of Thumb ................. C-12

C.5.3 A More Sophisticated Approach . . . . . . . . C-19

C.6 IMPLEMENTATION ISSUES $\ldots \ldots \ldots \ldots \ldots \ldots \ldots \ldots$, C-20

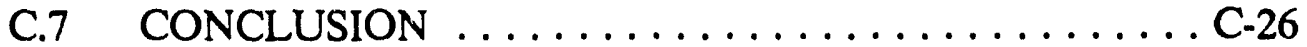

C.8 REFERENCES $\ldots \ldots \ldots \ldots \ldots \ldots \ldots \ldots \ldots \ldots \ldots$ C- 27 


\section{LIST OF TABLES}

Table 1 Impact Categories and Valuation Approaches . . . . . . 2-7

Table 2 Mappings important to the Externalities Problem ........................ 2-15

Table 3 Reference Data and Model Requirements for an Impact-Pathway Analysis $\ldots \ldots \ldots \ldots \ldots \ldots .2-22$

Table 4 Summary of Ecological Impact Categories . . . . . . . . . 3-9

Table 5 Potential Health Effects from Coal Fuel Cycle . . . . . . 4-15

\section{LIST OF FIGURES}

Fig. 1 Impact-Pathway Damage Function Approach $\ldots \ldots \ldots$ xxi

Fig. 1 Impact-Pathway Damage Function Approach $\ldots \ldots \ldots$ 2-5

Fig. 2 Mapping of Stages of the Coal Fuel Cycle into Emissions and other Residuals ........... 2-16

Fig. 3 A Mapping of the Emissions and Resulting Changed Concentrations into Ecological, Health, and Other Impacts for the Coal Mining Stage $\ldots \ldots \ldots \ldots \ldots \ldots \ldots \ldots \ldots . \ldots \ldots$ 2-19

Fig. 4 A Mapping of Impacts into Marginal Economic Damages ...................... 2-21

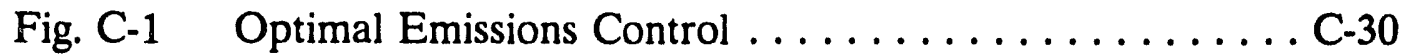

Fig. C-2 The Market for Electricity $\ldots \ldots \ldots \ldots \ldots \ldots \ldots$ C-31

Fig. C-3 A Hypothetical Utility's Sources of Electricity Generation under an Environmental Costing Program of Social Cost Dispatch . . . . . C -32 


\section{EXECUTIVE SUMMARY}

\section{E.1 BACKGROUND AND PURPOSE OF 'THE STUDY}

Since the writings of A.C. Pigou in 1932, economists have recognized that the price of something may not reflect its true cost to society. This situation occurs when there are inadvertent and unaccounted for effects of one or more parties on the welfare of another (i.e. the presence of "externalities"). The classic example is unregulated pollution from a smokestack. Here, a factory produces products which are priced by taking into account the demand for the products and labor, land, materials, capital, and other costs; but the damages (and benefits) from the factory's emissions--health and other effects-are true costs to society that are unaccounted for in the prices of the products. In the absence of a means of "internalizing" these costs in the factory's decisions, the prices of the products will be too low and too much of them would be produced or consumed relative to prices and production in a "socially efficient" economy.

Much of modern environmental policy, i.e., command and control regulation, tradable permits, and emissions fees and subsidies, is an attempt to have polluters account for these externalities to one degree or another. Literally hundreds of books and articles detail how to set optimal regulations or design optimal policy, in the sense of "getting the prices right," i.e. equal to social costs at the margin. Another huge literature details how to estimate external costs for use in the design of such policies. Governments -particularly the federal government - have tried to address this problem of external costs and benefits. The federal government in the United States has responded largely through regulation. Successive waves of legislation - the Clean Water Act of 1972, the Clean Air Act of 1970, and, most recently, the Clean Air Act Amendments of 1990 - sought to restrict (or raise the cost of) use of the environment as a repository for residual emissions.

Against the backdrop of the pursuit of optimal environmental policy is a recent and controversial movement led by U.S. Public Utility Commissions (PUC's). This movement seeks to address external costs of pollution as part of the utility planning process, primarily with respect to choices about investment in new generation capacity and demand side management. This movement does not address itself to the question of optimal regulation but seeks to make choices about new investments and operations that result in the lowest possible social costs, given the existing set of regulations and policies affecting the utility. More than half the states in the U.S. have laws, PUC regulations, or proposals to require external costs to be explicitly 
Executive Summary

recognized in some form in utility planning (Cohen et al. 1990). Some states limit the inclusion of external costs to qualitative consideration of environmental effects in least-cost planning. Others (New York, Massachusetts, California, and Nevada) require that procedures such as bidding, which are used to expand generation capacity, incorporate environmental costs through a system of pollutant-specific "adders." The idea is that adders will address the external costs - that is, those costs incurred and not accounted for in market transactions - and force these consequences to be accounted for in investment decisions, by what is called "internalizing" these costs. Unfortunately, comprehensive estimates of external costs consistent with knowledge about environmental and health impacts, as well as with economic theory, are non-existent; and confusion exists over whether PUC's should be involved and exactly how.

The U.S. has increasingly recognized that the lack of high-quality information on externalities was distorting decision making both at the federal level, in terms of allocating energy research and development budgets, and at the state PUC level, in terms of conservation and technology choice. Both sets of decisions have large implications for the Nation's energy future. In addition, it was recognized that credible estimates of external costs (and benefits) could aid in decisions about future environmental policies. Consequently, the U.S. Department of Energy (DOE) launched a major initiative to provide the foundation for sound decision making concerning the external costs (and benefits) of energy. The European Communities had come to much the same realization - that external costs of fuel usage could not be understood, computed, and correctly applied given the current state of knowledge.

In February 1991, DOE and the Commission of the European Communities (EC), signed a joint statement regarding the external costs of fuel cycles. This 18-month agreement committed their respective organizations to "develop a comparative analytical methodology and to develop the best range of estimates of external costs from secondary sources" for eight fuel cycles and four conservation options. In our study, a fuel cycle is defined as the series of physical and chemical processes and activities that are required to generate electricity from a specific fuel or resource.

Lead responsibilities for the fuel cycles were distributed between the two research teams as follows: both teams to undertake the coal fuel cycle and conservation options; the U.S. to lead on the biomass, oil, natural gas, and small hydroelectric energy; and the EC to lead on the uranium, photovoltaic energy, and wind cycles. The Federal Energy Regulatory Commission is also a participating co-sponsor in the U.S. study. A study team was created in the 
U.S. by bringing together research staff at Oak Ridge National Laboratory (ORNL) and Resources for the Future (RFF). A similar study team was organized for the EC effort.

The primary objectives of the study as defined by the teams were:

1. To create a unified conceptual design for quantifying the various costs and benefits associated with the production and consumption of energy from different fuel sources;

2. To demonstrate an accounting framework that can be used to estimate the static measures of a broad range of costs (and benefits) that result from incremental use of different fuel types and use this information in a comparative analysis of fuel types;

3. To identify critical methodological issues and information needs that will affect the expanded efforts to develop comprehensive assessments of the costs of energy use.

Given time and budget constraints, it soon became apparent that it would not be possible to completely reach the goals of the agreement. So the U.S. and EC study teams, with the full agreement of the study principals, moved to construct the foundation for eventually reaching the study goals.

This foundation phase of the study is primarily limited to developing and demonstrating methods for estimating impacts and their monetized value, what we term "damages" or "benefits," leaving aside the extent to which such damages have been internalized. However, Appendix C provides the conceptual framework for evaluating the extent of internalization. In addition, this appendix places the "social costing debate" involving PUC's and electric utilities into a conceptual economic framework, examining whether such involvement on the part of the PUC can be justified and the consequences associated with alternative types of involvement.

Instead of fully examining all "secondary source" fuel cycle damages and benefits and private costs, the study concentrates mainly on the incremental or marginal nonmarket damages and benefits from additions to electrical generation capacity. However, in cases where upstream or downstream activities would be largely dedicated to the increment in generating capacity, the study addresses their impacts and damages as well. In addition, the study recognizes that non-environmental as well as environmental impacts should be included among the "hidden" benefits as well as the hidden costs of energy. 
Complete analysis of the external costs and benefits ultimately requires an equally balanced assessment of abatement technology and costs. This assessment is not part of the scope of this study. Furthermore, the study team is not addressing the purely private-cost component of social costs, as this activity is appropriately covered by individual DOE programs and involves a very different body of literature and analysis.

This report is a background document to introduce the study approach and to discuss the major conceptual and practical issues entailed by the incremental damage problem. As a background document, the report seeks to communicate an overview of the study and the important methodological choices that were made to conduct the research. In successive sections of the report, the methodological tools used in the study are discussed; the ecological and health impacts are reviewed using the coal fuel cycle as a reference case; and, in the final chapter, the methods for valuing impacts are detailed.

\section{E.2 TERMINOLOGY}

In this report, a number of terms are used that have created much confusion in public and professional discourse. Some of these terms have been used imprecisely and others have had their meaning changed in use over time. Thus, clear definitions of key terms are prerequisites for the discussions on concepts and policy contexts that follow in later sections of the document.

- EMISSION: The byproducts of production and con.umption processes (defined broadly) are called emissions. Emissions may be transported in air and water media and deposited on aquatic and terrestrial resources. Abatement processes used to control emissions also generate emissions.

- IMPACT: This term is taken from the phrase "environmental impact assessment," meaning the physical or socioeconomic effect of some activity. Examples of physical impacts are changes in crop yields, human health, and recreation resources. Examples of socioeconomic impacts are changes in aesthetics, noise nuisance, and employment conditions.

-DAMAGES: Following legal terminology, damages are the nonetized value of detrimental impacts which accrue to society from the activities of producers and consumers. A related term, benefit, refers to the monetary value of positive impacts. 
- EXTERNALITY: This term refers to the economic consequences of private activities (such as energy production and use) that accrue to society, but not explicitly accounted for in the decision making of activity participants. Where these consequences are detrimental, they are called external costs; where these consequences are positive, they are called external benefits.

-INTERNALIZING AN EXTERNALITY: This expression means to create social conditions where the damages (or benefits) from production and consumption are taken into account by those who produce these effects. These social conditions can be created by government regulation, a tort system, bargaining between private parties, or other policy and inctitutional arrangements. Benefits and damages can exist even when all externalities have been internalized.

-ECONOMIC EFFICIENCY: This term refers to the condition that is achieved when society's resources (technological, ecological and human) are allocated to their highest-valued uses. For society, this means that the difference between total consumption benefits and total production costs is maximized. A benefit-cost criterion can be used to judge whether a considered action (such as building a particular type of power plant) improves economic efficiency relative to the status quo or to some other investment. An optimal policy for addressing externalities is one that balances the costs of reducing damages with the benefits and is generally not one that would lead to zero pollution, impacts, or damages.

\section{E.3 SCOPE}

The first phase priorities were chosen with the pressing needs at the state level in mind: (1) select, develop and demonstrate a rigorous methodology for estimating the damages and benefits for each of the fuel cycles through electricity generation; (2) undertake a state-of-the-art assessment of the most relevant scientific and economic literature; and (3) develop an economic framework capable of applying external cost estimates in a realistic PUC setting. Follow-on efforts are likely to include development of a database and information system that can be accessed by PUCs and other users, and extension of the methodology to distribution and end-use stages including transportation. 
At the outset, we emphasize that our analysis is framed by economic considerations of decision making to select fuel cycle options: this means that economic theories and models from welfare economics are used to structure the organization and scope of the analysis and that the analysis of physical phenomena, such as emissions, concentrations, and impacts, is driven by concern for estimating monetary values.

Valuation Paradigm. We begin with the following valuation paradigm. Were a new plant to be built in a particular area, the individuals located in that area would be offered a package of both positive and negative impacts. These impacts would be experienced simultaneously to a large with one or another impact reinforcing or mitigating the effects of others in the individual's valuation function. Our conceptual task is to estimate damage (or benefit), i.e., to determine the aggregate willingness to pay (WTP) of individuals to avoid (or obtain) this package of impacts.

In fact, there are no studies that come close to the ideal damage estimate and mounting such a study is beyond the scope of this project. Rather, we have organized existing studies in a variety of disciplines according to the damage function approach (see below): first, characterizing fuel cycle activities and their residuals; second, estimating impacts for each "impact pathway" while accounting to the extent possible for areas of double-counting; and third, valuing these impacts.

Welfare economics suggests that non-environmental externalities are no less important than environmental externalities to the determination of social costs. Some potential non-environmental externalities may have physical impacts and pathways that are similar to environmental effects, but others may have direct economic effects.

We identify three potential sources of non-environmental externalities. One is the failure of markets and closely related public goods problems. If markets work imperfectly, then the prices of goods and services will not be equal to their opportunity cost for society, which is the economic values of their alternative use. One prominent example are the potential benefits that may stem from the employment of people who were previously involuntarily unemployed or underemployed. Similarly, public goods such as public infrastructure are typically not priced at their opportunity cost. Consequently, users such as transporters of fuels along public highways may not consider the opportunity cost that stems from the deterioration and congestion of these resources. 
A second category for potential non-environmental externalities is termed energy security. This category encompasses a number of topics including strategic consumption behavior in international markets, reliability of energy resources and related national security, military and foreign policy issues, and macroeconomic issues including balance of trade effects.

A third category includes externalities associated with government intervention in the economy. Frequently, government intervention is motivated by the desire to remedy a pre-existing market failure and therefore may be efficiency enhancing. Nonetheless, governmental policies may create other external costs that are amplified or diminished by specific energy investments. Examples include administrative costs, deviations from marginal cost pricing associated with public utility regulation, liability limits, or indirect effects of policy actions that result in the complex environment for most governmental policy. This study addresses some of the potentially significant non-environmental externalities and attempts to estimate their economic value in a common metric with environmental and health effects.

Marginal Perspective. The perspective of our study is strictly forward looking; we wish to understand the incentives faced by current and future decision makers and the ramifications for economic welfare. Therefore, our analysis is geared to estimating changes in activities, pollution, values, etc., from some baseline determined, in part, by conditions associated with a particular location, which we call a reference environment. The analysis is therefore focused on estimating the marginal consequences of a fuel cycle creating spillovers at particular locations, as opposed to estimating average consequences at particular or "average" locations.

Reference Environments. To motivate the development and demonstration of methods as well as to permit some sensitivity tests of results, we chose two sites (called reference environments) for the location of each type of generation plant. To provide comparability across fuel cycles and to the extent practical, the same two sites were used for each plant. For the fossil and nuclear plants, these were a site in Tennessee at the loration planned for the Clinch River breeder reactor, and at a New Mexico site near the Four Corners region of the Southwest. These sites were chosen because they had been the object of major data collection and site characterization efforts, not because they are in any way "representative" of future power plant sites. For the biomass and hydro sites, a southwest site is physically impossible, so we choose an area in southwest Washington state.

Investment Perspective. For practical reasons, we limit our scope to an investment view of utility operations, as opposed to an operations view. The 
investment view addresses questions about the new incremental capacity in the fuel cycle activity (e.g., an addition or investment in new electricity generating facilities). The operating view addresses questions about displacements, reconfiguration, or increased use within an existing system (e.g., displacing a peak load plant with more output from a marginal base load plant). Investment and operation activities are not mutually exclusive but involve substantially different information requirements to examine pollution emissions and other effects. The operations focus requires a complete characterization of the existing production system's activities to capture the change in emissions and other effects from an increase in output or capacity. The investment strategy, however, begins with the base level environmental and health conditions and examines the change to the base from the additional increment in, for example, generating capacity assuming that the use of existing units is uncilanged. These additions are defined by current and future technologies used at each stage of the fuel cycle that are reasonably well characterized for their input and output consequences. Specifically, the study considers activities associated with a single power plant--not regional or nationwide energy programs, or even the effect of the single plant on a utility's other supply and demand alternatives.

Static Model. Likewise, for practical considerations, we limit our scope to a static view of the physical and economic consequences of externalities. The term static describes the lack of feedback and other interaction that would normally be active in any systems approach for a given incremental change in generating capacity. Thus, changes in health and the environment do not affect prices in the labor market, which might affect the private costs of mining, for example.

Fuel Cycle Stages. We also limit considerations of certain stages in the fuel cycle. A total energy cycle includes: (1) primary resource extraction and preparation, (2) transport and storage of resources and materials, (3) conversion and processing, (4) end-use services, and (5) disposal. With the exception of the conservation options, this fuel cycle study concentrates on the first three stages and on disposal. End-use activities are highly varied; consider, for example, the difficulty in determining how kilowatt hours are used, much less determining the impacts from that use.

Scope of Impacts. The scope of impacts includes local, regional, and global consequences. However, the U.S. and EC teams have agreed to examine local and regional impacts first. The global impacts will be presented by the study as potential impacts, rather than as impact assessments, due to the highly limited knowledge base in this area. 
Additional Fuel-Cycle Assumptions. We assume that existing capacities in other stages of the fuel cycle will be sufficient to meet the needs of the incremental generation investment. For example, we assume that existing coal mines are adequate to supply coal to the new investment. Second, we estimate damages for direct effects only, i.e., effects arising directly from a stage of the fuel cycle, ignoring secondary effects (e.g., from the cement used to pour the foundation of the generation plant), unless the argument can be made that these secondary processes and outputs are unique (e.g., emissions from the production of certain chemicals used only to produce solar fuel cells), or unless they are calculated to be comparable in magnitude to primary emissions.

An appropriate scale of the incremental investment is designated for each fuel type. Power plants come in many sizes which influences their use in an existing electricity system. A review of current U.S. utility expansion plans suggested that, for commercial feasibility, coal, nuclear, oil and many gas plants corresponded to medium - to large-scale investment needs; and that hydro, biomass photovoltaic, and wind might satisfy smaller scale needs. Medium to large scale is about 300 megawatts electric (MWe) or larger, while smaller scale is under $50 \mathrm{MWe}$.

The benchmark for each fuel cycle reflects 1990 investment options. Future technologies in the coal, nuclear, and biomass fuel cycles, however, significantly alter their respective benchmark environmental impacts. For 2010, investment alternatives are examined for these three fuels to provide balance between current conditions and pending commercial opportunities.

\section{E.4 ANALYTICAL TOOLS}

\section{Damage Function Approach}

A number of analytical tools are to be developed to implement the study approach. These tools are necessary to name impacts, quantify what has been named, translate physical quantities to damages, and finally, distinguish damages from external costs. These steps essentially operationalize the Damage Function Approach (DFA).

The DFA attempts to combine natural science and economics to reveal as many changed relationships as possible from the incremental investment (see Chapter 2 for more discussion of the DFA). For incremental damage or benefit estimates, the DFA begins with residual emissions from each fuel-cycle activity necessary to support the incremental investment and considers (1) the 
transport, deposition, or chemical transformations of these emissions to derive changed concentrations of pollutants that are spatially and temporally distributed; (2) the physical response of ecological, human, and social resources (which are also spatially and temporally distributed) to changed concentrations; and (3) how these responses are valued by the individuals affected.

The U.S.-EC team believes that the DFA is the most appropriate approach for the foundation phase of the study. First, it highlights how technological and descriptive factors (such as environmental baseline and resource locations) influence the residual damages (and benefits). These aspects are important for actual siting decisions as well as for planning energy strategies. Second, it requires full information about physical and behavioral processes to quantify impacts and residual damages (and benefits). The knowledge generated by the DFA provides an essential building block to any of the other more aggregate or compound approaches. It also identifies fundamental gaps in our understanding of technologies, physical processes, and economic behavior. Finally, the DFA provides pollutant-specific information that is useful for research and development planning and responds to the information needs of the PUCs.

Fig. 1 shows a flow chart that captures the DFA process and is a good guide to how the study approach is organized. Each stage of each fuel cycle implies a limited number of technical options given our scenario assumptions. Once abatement technology and locational conditions are considered, particular activities and their residual emissions are listed or named. To the extent these emissions can be disaggregated into meaningful pollutant species and their rates quantified, the next step is to use transport modelling (via air or water) and the physical characteristics of the site to quantify changed concentrations, doses, and resource responses. These responses then define the set of physical impacts. Next, monetary values are assigned to the physical or social impacts. Finally, the last step of the analysis, which is not emphasized in this first phase of the project, considers the distinction between damages and external costs by referencing, for instance, existing regulatory and civil law arrangements that may act to internalize externalities.

In addition, other tools are to be developed to organize and to help clarify both information and uncertainty related to the assessment of incremental damages and benefits.

Accounting Framework. The Accounting Framework organizes and builds the information base for the DFA through a series of sequential matrices. These matrices are a way of organizing information on: (a) the different emissions 
matrices are a way of organizing information on: (a) the different emissions from the various fuel-cycle activities, (b) the impact of each emission on physical and social conditions, and (c) the economic value of each impact. The matrices will generally be "sparse," i.e. most entries will be blank either because they are not applicable or because the base of scientific knowledge is not well-developed. Missing or inadequate information can be highlighted explicitly with this framework. Accounting framework entries reflect two objectives: first, to organize a state-of-the-art assessment of best practices or best data for a generic fuel-cycle problem; and second, to demonstrate knowledge-in-use when applying the information to particular case studies.

Conveying Uncertainty. Uncertainty refers to the spread of plausible values for a cell entry and the level of confidence placed in a quantitative statement. Quality refers to both an entry's worth as a piece of information and the credibility of the theory, data, and methods used to generate the entry. Few of the accounting framework entries will be known with certainty or even generally agreed upon as the prevalent quantity or relation. To leave cell entries standing alone without signaling the uncertainty and quality of the entries would overstate the precision with which the entries are known. In addition, signalling the uncertainty and quality for cell entries will indicate the areas where further study is most needed. Accordingly, the analysis will include NUSAP, a notational message system designed to assess systematically the uncertainty and quality of records in the study.

In addition to this uncertainty message system, uncertainty in estimates will be conveyed at each stage of the analysis using statistical or judgmental confidence intervals as warranted. Although sophisticated Monte Carlo simulation techniques are available for propagating errors through the links in the damage function, these techniques will not be used in this phase of the study; they require a computerized model simulation package that is currently underdevelopment by the EC research team. For the present time, we will follow the ad hoc procedure of combining low estimates from one step of the calculations with low estimates of the other steps to estimate a low estimate of damage (or benefit), following the same procedure to estimate mid and high values. In general, this procedure creates final damage confidence intervals far wider than any of the intervals applicable to a particular step.

\section{E.5 IMPACT-PATHWAYS}

In practice, a fuel cycle generally has too many stages, emissions, impacts, damages and benefits for a comprehensive analysis of all of them. Thus, implementation of the Damage Function Approach requires that a 
limited number of impact-pathways be selected for detailed analysis. These priority impact-pathways are generally those thought to have potentially the greatest damages or benefits. This assessment is based on an initial assessment of the scientific and economics literature.

This Background Document generally describes impacts and impactpathways in the context of the coal fuel cycle. However, much of the discussion applies more generally to impact analysis for all fuel cycles.

Categories of impact endpoints to be considered by the study include:

- Health effects: mortality; acute morbidity; and increased risk of developing chronic disease;

- Changes in ecological resources; and

- Output or production effects.

The preliminary reviews of ecological and health impacts for the coal fuel cycle provide information on impact categories, exposure processes that link emissions to endpoints, the feasibility of existing dose-response information to quantify endpoint changes, and various measurement and quantification issues.

\section{E.6 ECONOMIC VALUATION}

The discussion of economic valuation for fuel cycle analysis highlights conceptual and practical issues that must be addressed to combine impact and valuation information. In the study approach, value is intimately connected to opportunity costs - i.e., the concept that there is no free lunch, that something must be given up to gain something else. Thus, values are determined in the context of constraints, be they money, time, health, or something else that is valued. These constraints imply that a thing has value to the extent that individuals are willing to pay for it - the so-called willingness to pay criterion in economics that underlies modern benefit-cost analysis.

The concept of value is based on decades of research in neoclassical microeconomic analysis. At the core of this notion is consumer sovereignty i.e., that each individual in society is the best judge of his or her value for a good or resource. 
When damages show up in nonmarketed commodities, values are estimated as the individual's willingness to pay (WTP) for an improvement in the state of nature (in terms of reductions in pollution or its physical consequences) or by the individual's willingness to accept (WTA) compensation to tolerate a worsening of the state of nature.

Standard economic methods to valuing changes in welfare may be taken when damages show up in marketed products. Standard methods include using demand and supply models to derive price and quantity changes, which, in turn, provide the basis for damages.

When impacts occur in nonmarketed commodities, two broad approaches have been developed to estimate damages: the contingent value (CV) and indirect approaches. The CV methods involve asking either open or closed-ended questions of individuals for their willingness to pay in response to hypothetical scenarios involving reductions in health or environmental risks or effects. The indirect approaches (sometimes called revealed preference approaches) seek to uncover values for the nonmarketed environmental goods by examining market or other types of behavior that are related to the environment as substitutes or complements.

There are a number of special issues that limit the interpretation or applicability of valuation research for this study: transferability of the results from one location or concept to another; aggregation of the results across temporal or geographic boundaries, endpoint categories, or individuals; andnonlinearities in impacts or valuation responses.

The success and effort of economic research in this area have been unevenly distributed among the valuation categories. The most effort has clearly gone into the theory and estimation of recreation and mortalityreduction benefits. Mortality-reduction benefit studies have derived values for reducing risks of accidental death. Although there is a substantial range in results, they are generally consistent with one another. However, very few studies have obtained values for reducing mortality risks associated with environmental exposures. Substantial research has also addressed the valuation of pollution effects on morbidity, visibility, and economic production, particularly on the effects of ozone exposure on field crops. Valuation of damages to materials and to ecosystems (including endangered species) is largely unexplored, although even here much effort is currently being placed on estimating damages under the natural resources damage assessment process. 
Figure 1. Impact-pathway damage functio", approach

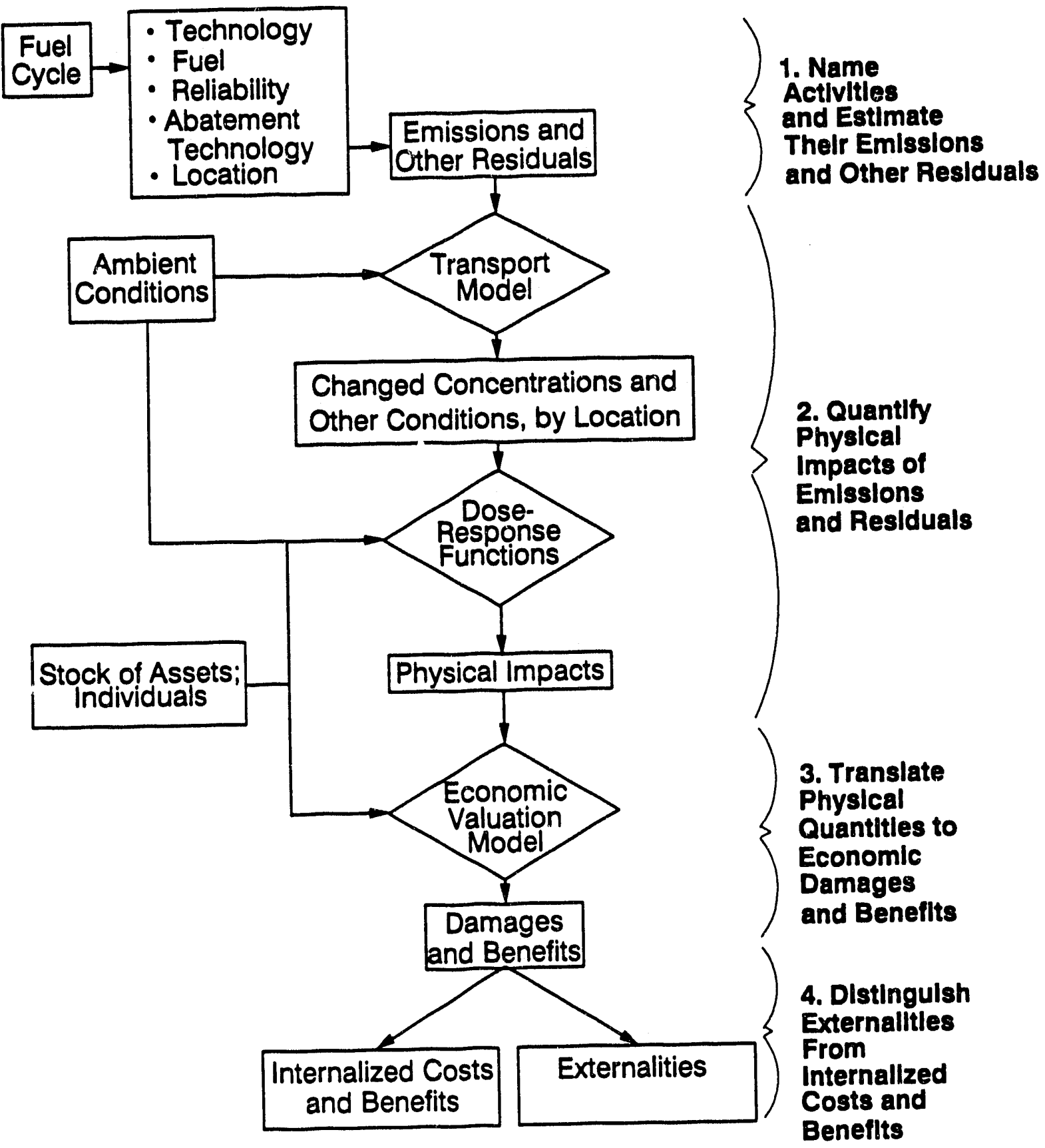




\section{INTRODUCTION}

\subsection{BACKGROUND}

Since the writings of A.C. Pigou in 1932, economists have recognized that the price of something may not reflect its true cost to society. This situation occurs when there are inadvertent and unaccounted for effects of one or more parties on the welfare of another (i.e. the presence of "externalities"). The classic example is unregulated pollution from a smokestack. Here, a factory produces products which are priced by taking into account the demand for the products and labor, land, materials, capital, and other costs; but the damages (and benefits) from the factory's emissions--health and other effects-are true costs to society that are unaccounted for in the prices of the products. In the absence of a means of "internalizing" these costs in the factory's decisions, the prices of the products will be too low and too much of them would be produced or consumed relative to prices and production in a "socially efficient" economy.

Much of modern environmental policy, i.e., command and control regulation, tradable permits, and emissions fees and subsidies, is an attempt to have polluters account for these externalities to one degree or another. Literally hundreds of books and articles detail how to set optimal regulations or design optimal policy, in the send of "getting the prices right," i.e. equal to social costs at the margin. Another huge literature details how to estimate external costs for use in the design of such policies. Governments particularly the federal government - have tried to address this problem of external costs and benefits. The federal government in the United States has responded largely through regulation. Successive waves of legislation - the Clean Water Act of 1972, the Clean Air Act of 1970, and, most recently, the Clean Air Act Amendments of 1990 - sought to restrict (or raise the cost of) use of the environment as a repository for residual emissions.

Against the backdrop of the pursuit of optimal environmental policy is a recent and controversial movement led by U.S. Public Utility Commissions (PUC's). This movement seeks to address external costs of pollution as part of the utility planning process, primarily with respect to choices about investment in new generation capacity and demand side management. This movement does not address itself to the question of optimal regulation but seeks to make choices about new investments and operations that result in the lowest possible social costs, given the existing set of regulations and policies affecting the utility. More than half the states in the U.S. have laws, PUC regulations, or proposals to require external costs to be explicitly recognized 
1. Introduction

in some form in utility planning (Cohen et al. 1990). Some states limit the inclusion of external costs to qualitative consideration of environmental effects in least-cost planning. Other (New York, Massachusetts, California, and Nevada) require that procedures such as bidding, which are used to expand generation capacity, incorporate environmental costs through a system of pollutant-specific "adders." The idea is that adders will address the external costs - that is, those costs incurred and not accounted for in market transactions - and force these consequences to be accounted for in investment decisions, by what is called "internalizing" these costs. Unfortunately, comprehensive estimates of external costs consistent with knowledge about environmental and health impacts, as well as with economic theory, are nonexistent; and confusion exists over whether PUC's should be involved and exactly how.

The lack of high-quality information about externalities can distort decision making both at the federal level, in terms of allocating energy research and development budgets, and at the state PUC level, in terms of conservation and technology choice. Both sets of decisions have large implications for the Nation's energy future. In addition, credible estimates of external costs (and benefits) can aid in decisions about future environmental policies. In 1991, the U.S. Department of Energy (DOE) launched an initiative to provide a foundation for sound decision making concerning the external costs (and benefits) of energy. The Europec'n Cummunities had come to much the same realization - that external costs $r_{f} f$ fuel usage could not be understood, computed, and correctly applied given the current state of knowledge.

In february 1991, DOE and the Commission of the European Communities (EC), signed a joint statement regarding the external costs of fuel cycles. This 18-month agreement committed their respective organizations to "develop a comparative analytical methodology and to develop the best range of estimates of external costs from secondary sources" for eight fuel cycles and four conservation options. In our study, a fuel cycle is defined as the series of physical and chemical processes and activities that are required to generate electricity from a specific fuel or resource. Lead responsibilities for the fuel cycles were distributed between the two research tearns as follows: both teams to undertake the coal fuel cycle and conservation options; the U.S. to lead on the biomass, oil, natural gas, and small hydroelectric energy; and the EC to lead on the uranium, photovoltaic energy, and wind cycles. The Federal Energy Regulatory Commission is also a participating co-sponsor in the U.S. study.

Given time and budget constraints, it would not be possible to reach the goals of the agreement, so the U.S. and EC study teams, with the full 
agreement of the study principals, moved to construct the foundation for eventually reaching the study goals. This foundation phase of the study is limited to developing and demonstrating methods for estimating impacts and their monetized value, what we term "damages" or benefits," leaving aside the extent to which such damages have been internalized. Further, instead of fully examing all "secondary source" fuel cycle damages and benefits and private costs, the study concentrates mainly on the incremental or marginal nonmarket damages and benefits from additions to electrical generation capacity. However, in cases where upstream or downstream activities would be largely dedicated to the increment in generating capacity, the study addresses their impacts and damages as well. In addition, the study recognizes that nonenvironmental as well as environmental damages should be included among the "hidden" benefits as well as the hidden costs of energy.

The remainder of this chapter contains a brief overview of the study, definitions, and consideration of methodological choices made to conduct the study. In successive chapters, the methodological tools used in the study are discussed; the ecological and health impacts are reviewed using the coal fuel cycle as a reference case; and, in the final chapter, the methods for valuing impacts and deriving damages are detailed.

The body of this document is concerned with methods for estimating damages. It is also recognized that state PUC's and others are seeking guidance on the application of such estimates to utility decision making. While offering this guidance is not the major thrust of the study, an analysis of the subject is appended to this report as answers to a series of questions: (i) Is "social costing," as it is being considered and practiced by PUC's, a good idea? (ii) How should damages and benefits be measured? (iii) When does a "damage" that is already regulated need internalization? and (iv) Given that (iii) is clear and that estimates of such costs are available, what implementation issues must be faced? In addition, the basic theory of environmental policy design is discussed and distinguished from the part of the theory that is applicable to "social costing" in the PUC case.

\subsubsection{Overview of the Study}

The study identifies the residual burdens (emissions, land use changes, etc. remaining after controls and regulations are met) and other nonenvironmental effects (examples include changes in employment conditions and road damages) that results from the extraction, transportation, and conversion of fuels into electricity. The "fuels" considered in the study are biomass, coal, hydroelectric (small), natural gas, oil, photovoltaic, uranium, and wind. Once the residual effects are identified, their impacts are estimated, 
and monetary values are determined for these impacts (i.e., the willingness to pay to avoid or obtain these impacts). The approach of the study is to hypothetically place a new electricity generating facility for each of the comparable fuel types at the same site, if technically plausible, to hold the geographical environment constant so that the residual effects of the different fuels can be compared. These effects are cataloged only within a defincd region. Impacts are generally site specific. Conservation options will be analyzed to determine their impacts and what monetary values should be placed on them. The output of the current phase of the study will consist of the methodology, the assessment of relevant knowledge, the creation of databases, and the demonstration of that knowledge in generating some marginal damage/benefit estimates. It cannot be overemphasized that the primary objectives of the study are to develop and demonstrate the application of the methodological framework. Any numerical calculations are intended as examples, not as generic representative estimates.

Although developing a methodology to compute external costs and benefits is the eventual goal of this study, external cost and benefit estimates will generally not be made in this phase. If externalities are thought of as those costs and benefits not already incorporated into consumption and production decisions, then measures are needed of marginal damages and benefits from residual emissions and other consequences. The first phase of this study will concentrate on the marginal damages and benefits.

Externalities are a highly important and contentious issue for both the state-level PUCs and national-level governments concerned with energy and environmental policy. Appendix $\mathrm{C}$ presents a separate analysis that addresses the fundamental questions about treatment of external costs in a policy setting.

\subsubsection{Terminology}

In this report, a number of terms are used that have created much confusion in public and professional discourse. Some of these terms have been used imprecisely and others have had their meaning changed in use over time. Thus, clear definitions of key terms are prerequisites for the discussions on concepts and policy contexts that follow in later sections.

We start with the least ambiguous term: impact. We take this term from the phrase "environmental impact assessment," meaning the physical or chemical effect of some activity, as distinguished form an economic or monetary effect. Examples of impacts are: land disturbance from the clearing of the land to build a new electric power plant, and an increase in days of a certain health symptom in the population exposed to the plant's air pollution. 
These two examples of impacts are treated very differently by our study when it comes to their valuation or monetization. The first impact may very well be captured in the costs of building and operating the plant, and, therefore, already be taken into account in the costs of producing electricity form the plant. Landscaping costs, for instance, would be included in capital and operating costs. To the extent that these impacts do not spill over the borders of the plant, we exclude them from the purview of this study. Of course, the plant manager or systems planner will attend to them in conventional accounting practices.

The second impact is clearly a case where there are spill-overs. ${ }^{1}$ The monetary value of this second type of impact may be termed damages, following legal terminology. Freeman (1979) and others use damage to refer to the value of what is lost by pollution starting from a "clean slate" up to the current "dirty" baseline. We use damages as the monetized impacts form increasing pollution at the baseline a small (i.e., marginal) amount. Note that the term damages only refers to the value of impacts that would not normally (in the absence of government regulation, a tort system, bargaining between private parties, or some other policy or institutional setup) be taken into account by the plant manager. Thus, the cost to the firm of impacts to land it owns in the example above would not be called a damage. We use the term benefits, as does Freeman, to mean the value of marginal improvements to the environment from the dirty baseline. Thus, benefits are damages avoided or actual spillover improvements due to the plant's construction or operation.

The term, damage function approach, has come to mean an approach to valuing environmental impacts that integrates the necessary science and economics in a step-by-step fashion (form emissions, to concentrations, to impacts, to damage), sometimes skipping steps where possible and desirable. The damage function approach is one of the main tools for analysis selected for this project, and Section 2.1 contains a more complete discussion of its scope and operation.

So far, we have been avoiding use of the term externality, which we use synonymously with external cost or external benefit. The term externality has a long and confusing history in the economics literature. Much of this literature has tried to explain the conditions under which an externality persists, but there is general agreement on when it is present. Following is the definition from Baumol and Oates (1975):

\footnotetext{
${ }^{1}$ We ignore for the moment that electric utilities are regulated and that these regulatory commissions may force the utility to take such spill-overs into account. See Appendix C.
} 
An externality is present whenever some individual's (say, A's) utility (satisfaction) or production relationships include real (that is, nonmonetary)variables, whose values are chosen by others (persons, corporations, governments) without particular attention to the effects on A's welfare (p. 18).

For instance, if Mr. A's satisfaction depends on seeing a clear sky (a "real variable"), but Mr. B's production activity creates pollution that makes the sky hazy, then Mr. B is creating an externality and Mr. A bears an external costs. Similarly, an external benefit is created if Mr. B cleans up a site by the location of his factory in what was formerly an unsightly town waste area near Mr. A; this creates an increase in Mr. A's welfare.

External costs are often referred to in concert with the terms private costs and social costs. When economic activity takes place in markets, inputs to production and consumption activities have prices which, assuming competitive conditions, reflect the value of resources given up by producing a given product rather than something else. These costs are private costs, meaning they are costs observed in markets and therefore are taken into account in the economic decisions of producers and consumers. But, some activity takes place outside of, or external to, markets. For the most part, pollution is one such activity. These activities result in costs (or benefits) to society, such as ecological and health effects from air pollution, that are not necessarily counted in the economic decisions of those whose activities cause these costs (or benefits) (e.g., the managers of a plant).

We divide externalities into two types, often labeled "environmental" and "non-environmental." These labels do not convey much about the functional distinction between the two types. In general, environmental externalities have physical impacts as their first-order effect (for example, ecological or health impacts may imply environmental externalities). Nonenvironmental externalities have economic impacts as their first-order effect. Examples of this type would include externalities tied to employment loss or creation, energy security, and natural monopoly. Beyond the first-order effects, the two types may have second-order affects that look very much the same, e.g., both health externalities and employment externalities may result in second-order changes in regional growth. The first-order distinction becomes important for our project because our approach tends to concentrate on first-order effects.

We now distinguish between damage and external costs. The economics literature makes no distinction between these two terms but defines a third term, Pareto-relevant externality, to distinguish between welfare losses 
from pollution and the subset of these that would be eliminated if pollution were optimally reduced. This is, Pareto-relevant externalities are the damages (externalities) that have not been (but should be) reduced to obtain the optimal pollution level. (See Buchanan and Stubblebine 1962). We depart from this jargon-laden taxonomy, by eliminating the "pareto-relevant" phrase, calling non-internalized damages externalities. Joskow (1992) also follows this typology. With these definitions, damage is always present when there is an external cost, but the reverse is not always true, i.e., one may have damage without having an external cost. ${ }^{2}$

The distinction between external cost and damage turns on the concept of internalizing an externality. To internalize an externality means to create social conditions where the damages from production and consumption are taken into account in decisions of those producing these effects. These conditions may be based on incentives or property right policies. However, the command and control policies (represented by regulatory limitations on pollutants that cause damages) generally do not fully internalize damage.

To internalize externalities fully, one option which economists recommend to government and regulators is an incentive-based strategy that charges a price for the use of the environment, called a Pigouvian tax. This tax forces producers of the externality to take into account the value of its impact on the environment into account in the productive decisions, in the same way that labor costs force the firm to "economize" on how much labor they can use efficiently. Without a tax (or some other policy forcing consideration of damage) on the environment, it is viewed as a free good, and will be used without regard to the consequences of this use to others. Pricing forces the firm to take these consequences into account.

The "right" Pigouvian tax is not the one that would lead to zero pollution, impacts, or damages. Reducing emissions is expensive, increasingly so as more emissions are reduced. ${ }^{3}$ This expense, expressed in dollars, represents resources diverted form other uses to pollution reduction (i.e., opportunity costs). On the other hand, reducing emissions may have several benefits at first, but additional benefits will diminish as the environment

\footnotetext{
${ }^{2}$ The EC team uses somewhat different terminology. The U.S. uses the term externality to mean that portion of damage (or benefit) that has not been accounted for in eccnomic decisions. The EC uses the term relevant externality to mean the same thing. The standard welfare economic jargon for this concept is Pareto-relevant externality.

${ }^{3}$ What is being described here is the marginal abatement cost curve which is normally assumed to rise with additional cleanup.
} 
approaches a pristine state. ${ }^{4}$ The optimal tax is one that balances the costs of reducing pollution with the benefits, bringing pollution to the point that marginal abatement costs and marginal benefits are equal. At this point the pollution has been reduced to its efficient level (i.e., the net benefits to society of reducing pollution are maximized).

At this efficient point, the damages from the pollution have been fully internalized into decisions made by the polluting firm. The damages eliminated in cleanup, or through other changes in production techniques (e.g., fuel switching or new investment), are obviously incorporated in electricity costs, while paying the tax provides a signal to the firm that there is a cost of using the environment related to the pollution that remains. The key point is that after optimal control of pollution is reached and all externalities are internalized into decisions, damage will remain (as long as the optimal level of pollution is not zero).

Given estimates of private costs and damages that reflect true external costs generated by a fuel-cycle activity, the two costs can be combined to yield an estimate of social costs. If the external effects are positive, such as cleaning up the town waste area, social costs would be less than private costs. Even though the theory sounds very deterministic; the truth is that uncertainty and ignorance pervade any actual quantification. This issue will be addressed later in this chapter.

\subsection{SCOPE OF THE STUDY}

This study requires, like any other study, a logical sequence to reach the study objectives. Further, all studies must decide how much of real-world complexities is critical to include in the study and how much can be held fixed, or beyond the scope of the study. Given the relatively unexplored territory faced by this study, many choices had to be made. The first-phase priorities were chosen with the pressing needs at the state level in mind: (1) select and develop a rigorous methodology for estimating the monetary values of damages and benefits for the fuel cycle through electricity generation; (2) undertake a state-of-the-art assessment of the most relevant scientific and economic literature; and (3) develop an economic framework capable of applying external cost estimates in a realistic PUC setting. Follow-on efforts

\footnotetext{
This is the marginal benefit curve, which is normally assumed to fall with additional cleanup. The logic for the fall in marginal benefit with greater cleanup is somewhat controversial and is not needed for appropriately setting the Pigouvian tax. Marginal benefits may just as well be constant for all pollution reductions, for instance.
} 
are likely to include development of a database and information system that can be accessed by PUCs and other users, and extension of the methodology to distribution and end-use stages including transportation.

\subsubsection{Choice of Theoretical Foundation}

to begin, we emphasize that our analysis is framed by economic considerations of decision making to select fuel cycle options: this means that economic theories and models from welfare economics are used to structure our organization and scope of analysis. The perspective is strictly forward looking; we wish to understand the incentives faced by current and future decision makers and the ramifications for economic welfare. Our analysis is geared to estimating changes in activities, pollution, values, etc., from some baseline determined, in part, by conditions associated with a particular location.

Social costs are conceptualized to represent the diminution of (or increase in) individual welfare ${ }^{5}$ resulting from activities associated with a particular fuel cycle, appropriately aggregated across all individuals and expressed in monetary values. Some of these costs are private and are represented in the price of commodities and services that are employed in each particular fuel cycle. As noted, some costs are external and are not included in market prices. Private costs plus external costs equal social costs.

Social costing may bear a close relationship to materials-balance investigations and environmental impact assessments (EIAs). Materialsbalance studies catalog each material (or resource) used and produced through a particular chain of energy-cycle activities. ElAs catalog impacts to physical, biological, and socio-economic resources that results from a specified investment, operation, or policy decision. Appendix A contains figures on the coal fuel cycles as viewed from an EIA perspective. When combined, material balances and environmental assessments generate complete input-output accounts of all physical consequences expected to follow from a defined set of decisions. This set of accounts is specific to the chain of activities and the location of all activities and corresponds generally to the information needs of a Total Energy Cycle (TEC) analysis.

Social costing is the full benefit-cost translation of this ledger of physical consequences. However, for this project, the translation is

\footnotetext{
${ }^{5}$ Economists are actually interested in changes in individual utility or the level of satisfaction that individuals obtain from goods and services. Goods may provide satisfaction either through use or through existence.
} 
conceptually based on theories of welfare economics (form which benefit-cost analysis is derived), which implies two major departures from other accounting approaches.

First, resource effects or impacts have value only because they affect individual welfare, not because they represent so many energy units, labor units, or land units. ${ }^{6}$ Chapter 5 provides detail on the underlying concepts of economic valuation, but for now, it is sufficient to emphasize that damage assessment, as defined by welfare economics, reflects both location-specific impacts and the monetary value of these impacts.

Second, the benefit-cost translations of resources and impacts reflect economic efficiency considerations; physical quantities are assigned value by prices that balance marginal costs and marginal benefits (in competitive markets) and determination of externalities is made. Techniques for valuing non-market impacts are designed to provide prices that also perform this role. In reality, this determination often represents a difficult evaluation, and these evaluations ultimately rest on the sponsor's interest or policy context.

These difficulties imply that the benefit-cost translation is not a straightforward modification of the physical ledger. Rather, the physical account of impacts is being redefined in economic dimensions. A further departure from TEC studies that we impose on our project is to investigate damages and benefits only. We have chosen to ignore the private cost component of full social costing because this activity is appropriately addressed at the program level of DOE, and the two components involve very different bodies of literature and analyses.

Basically, four perspectives are recognized by economists as legitimate means to frame the incremental damage problem: national economic sectors, programmatic or regional, composite pollutant or compound impact, and lamage function. The first two may be regarded as macro-approaches and the latter two as micro-analytic in their focus. Other accounting approaches exist but are either inconsistent with many of the concepts of welfare economics or have no deliberate economic component at all.

\footnotetext{
${ }^{6}$ Over the centuries, society and economics have struggled with defining the "right" unit of values. Readers may be familiar with the BTU theory of value, the labor theory of value, and the land theory of value. Modern practitioners of benefit-cost analysis argue that value reflects changes to individual utility or satisfaction, which may not correlate to the composition of goods and services.
} 


\section{National Economic Sectors}

An approach based on national models of economic sectors could be used to understand the national implications of furl-cycle impacts and residual damages. Unfortunately, no current models at this level of aggregation exist that accovnt for all the sectors of the economy that represent nonmarket ecological and health resources that are of paramount interest in the residual damage question.

A second problem with the national perspective is that there is no direct connection from emission sources and local environment descriptions to the national consequences. The level of aggregation in these models precludes such an in-depth understanding.

\section{Programmatic or Regional Perspective}

These approaches suffer less from the aggregation problem but still require a predefined production scenario for analysis. A programmatic or regional approach is appropriate to analyze a regional energy strategy that suggests a combination of fuel cycle contributions to meet energy demand. Utilities perform such analyses for the private cost component of their energy systems. The primary difficulty of this approach for residual damage estimates is the results cannot easily be transferred from one utility to another and interregional effects may be ignored. All results are scenario and system specific. Furthermore, to get residual damage estimates, a very large amount of information on impacts from new increments of capacity and the existing capacity in the system is needed. For older capacity this information may not exist.

\section{Composite Pollutant or Compound Impact}

Composite pollutant and compound impact approaches are empirical in nature, so that an understanding of any of the science or behavioral responses is not necessary to compute residual damage estimates. Only observed responses to composite indicators are needed, which are then used to gauge the incremental change from the new investment.

Approaches based on composite pollutants use empirical data on different levels of pollution in various areas to estimate different impacts. For example, different levels of ozone concentration may be used to estimate changes in crop yields or health impacts without any particular reference to a single contributory source of pollution. Thus, the process by which incremental emissions are transported and change the observed concentrations of pollution is not evaluated. 
Compound-impact approaches use empirical data to estimate specific damages from total impacts. For example, if the location of hazardous facilities is used to explain property-value changes in surrounding neighborhoods, the damages done cannot be apportioned to specific impacts (such as health concerns, aesthetic changes, and so on).

\section{Damage Function Approach (DFA)}

This approach attempts to combine natural science and economics to reveal as many changed relationships from the incremental investment as possible (see Chapter 2 for more discussion of the DFA). For incremental damage or benefit estimates, the DFA begins with residual emissions from each fuel-cycle activity necessary to support the incremental investment and considers (1) the transport, deposition, or chemical transformations of these emissions to derive changed concentrations of pollutants that are spatially and temporally distributed; (2) the physical response of ecological, human, and social resources (which are also spatially and temporally distributed) to changed concentrations; and (3) how these responses are valued by the individuals affected.

The U.S.-EC team believes that the DFA is the most appropriate approach for the foundation phase of the study. First, it highlights how technological and descriptive factors (such as environmental baseline and resource locations) influence the residual damages (and benefits). This is important for actual siting decisions as well as planning energy strategies. Second, it requires full information about physical and behavioral processes to quantify impacts and residual damages (and benefits). The knowledge generated by the DFA provides an essential building block to any of the other more aggregate or compound approaches. It also identifies fundamental gaps in our understanding of technologies, physical processes, and economic behavior. Finally, the DFA provides pollutant-specific information that is useful for research and development planning and responds to the information needs of the PUCs.

\subsubsection{Investment or Operational Perspective}

The investment view addresses questions about the new incremental capacity in the fuel cycle activity (e.g., an addition or investment in new electricity generating facilities). The operating view addresses questions about displacements, reconfiguration, or increased use within an existing system (e.g., displacing a peak load plant with more output from a marginal base load plant). Investment and operation activities are not mutually exclusive but do involve substantially different information requirements to examine pollution 
emissions and other effects. The operation focus requires a complete characterization of the existing production system's activities to capture the change in emissions and other effects from an increase in output or capacity. The investment strategy, however, begins with the base level environmental and health conditions and examines the change to the base from the additional increment in, for example, generating capacity assuming use of existing units is unchanged. These additions are defined by current and future technologies used at each stage of the fuel cycle that are reasonably well characterized for their input and output consequences.

In practical terms, it is easier and more consistent with existing literature to frame the incremental needs of a new power plant than the incremental needs of a new extraction process. Activities performed within other stages are assumed to be based on increments to existing capacity. In essence, we are employing a rule of "all else remains the same." Limiting the analysis goals in the near term to examining current baseline activities at other stages does not diminish the application as long as additions are made to the research base. For example, one assumes that, during the coal fuel cycle, incremental coal mining occurs at an existing mine rather than at a new mining site that would be developed. Where this limitation is difficult to justify given knowledge on existing capacity, high priority has been placed on documenting information that would ultimately contribute to expanding the assumptions about non-generation stages.

Largely for reasons of ease of analysis, the U.S. and EC teams have adopted an investment view, leaving the operations view to be applied in further extensions of the work. Furthermore, investments and their resulting impacts are considered in different regional reference environments reflecting the importance of how differences in resource assumptions affect DFA results. For the U.S., the Southeastern and Southwestern regions provide case study descriptors.

The Southeastern site is near Oak Ridge in eastern Tennessee. The Southwestern site is near Farmington, New Mexico in the Four Corners Region of the U.S. These locations are not intended as being representative sites for the U.S. or even for their respective regions. Also, the sites are not necessarily economically viable locations for some (or even all) of the fuel cycles. Where the sites are not physically plausible for a particular fuel cycle, however, other sites are analyzed.

\subsubsection{Static or Dynamic Model}

In the abstract, estimating residual damages requires information on the comprehensive and dynamic responses to fuel cycle emissions and impacts. 
1. Introduction

It also requires a complete understanding of how the impacts are translated into damages. No existing model or analytical effort has captured the dynamic interactions of the energy, environmental, and socioeconomic systems in enough detail to fully satisfy the information needs of estimating residual damages. A very large amount of information and understanding of existing economic activities is necessary simply to describe the baseline environmental and health conditions.

Given the extreme challenges posed by dynamic modeling at the given level of knowledge in terms of both data and understanding of the physical and economic processes, the U.S.-EC team chose to develop a static set of data and relationships. The term static describes the lack of feedback and other interactive channels that would normally be active in any systems approach for a given incremental change in generating capacity. For example, consider the operating perspective once again. A utility bringing a new generating facility on-line would surely rearrange the operation of its system of plants to account for the new one. Emissions, resulting impacts, and eventual damages would change for the system as a whole. But to account for all those feedback effects, the generating system and the economy in which it resides would have to be modeled at enormous costs in time and money.

The static choice avoids all those complications by holding the generating system and economy fixed despite the addition of capacity. Although static development is an admittedly unrealistic assumption it has the virtue of being a precondition for any more complicated model, and it allows the methodology to be tested. Any quantitative results, however, would have to be treated as illustrative. Given the study requirement to achieve proof of concept and demonstrate knowledge in use, the U.S.-EC team decided to undertake a static presentation initially while making plans for more realistic modeling efforts to follow.

\subsubsection{Stages of the Fuel Cycle}

The joint U.S.-EC studies are based on the fuel cycle concept with a primary emphasis on fuel conversion for the generation of electricity. TEC analysis considers all stages and all activities of an energy cycle including primary resource extraction and preparation, transport and storage of resources and materials, conversion and processing, and end-use services (Placet and Humphreys 1991). A fuel cycle analysis may be thought of as a subset of the TEC analysis in that fuel cycle analyses have traditionally concentrated on the first three stages. With the exception of conservation options, the end-use stage of the energy cycles is excluded. End-use activities are highly varied; consider, for example, the difficulty in determining how kilowatt hours are used, much less determining the impacts from that use. 


\subsubsection{Scale of Generating Facility}

Power plants come in many sizes which influences their use in an existing electricity system. There is a history of debate regarding the large versus small scale plant and optimal investment. A review of current U.S. utility expansion plans suggests that, for commercial feasibility, coal, nuclear, oil and gas plants corresponds to larger-scale investment needs; small hydro, biomass photovoltaic and wind might satisfy smaller scale needs. Larger scale is 300 and more megawatts electric (MWe), and smaller scale is less than 50 MWe. There seems little reason to consider plant sizes significantly outside the utilities' planning set. For example, there seems to be little benefit in examining a one megawatt nuclear plant or a 1,000 megawatt wind farm. Scale has implications for detectable levels of impacts, which are addressed in the next chapter.

\subsubsection{Time Period}

The time frame for investment must also be selected. The benchmark for each fuel cycle reflects 1990 investment options. Future investment options in the coal, nuclear, and biomass fuel cycles in particular, however, significantly alter their respective benchmark environmental impacts. For 2010, investment alternatives are examined for these three fuels to provide balance between current conditions and pending commercial opportunities.

Impacts also may have a temporal dimension. If impacts are distributed unevenly over time and damages are expressed in annual terms, the corresponding damages must reflect placement in time: conventionally, this is done by using a discount rate to derive present values and then levelized. No particular discount rate enjoys universal acceptance. Rates of $2 \%$ and $10 \%$ (in real terms) are generally thought to define reasonable range. Users of the methodology to be developed in this study will want to use their own appropriate rates. For the purpose of the calculations, in this study a $3 \%$ (real) interest rate is used where possible to compute an annual levelized value expressed as cents/KWh. A levelized cost (for example) is the annual value which when spread evenly over the life of the facility and summed equals the present value of the total cost--expressed in real dollars.

\subsubsection{Non-environmental Externalities}

The theoretical foundation of welfare economics suggests that nonenvironmental externalities are no less important than environmental externalities to the determination of social cost. Some potential nonenvironmental externalities may have physical impacts and pathways that are similar to environmental effects, but others may have direct economic effects. 
We identify three potential sources of non-environmental externalities. One is the failure of markets and closely related public goods problems. If markets work imperfectly, then the prices of goods and services will not be equal to their opportunity cost for society, which is the economic values of their alternative use. One prominent example are the potential benefits that may stem from the enipiojment of people who were previously involuntarily unemployed or underemployed. Similarly, governmentally provided public goods such as public infrastructure are typically not priced at their opportunity cost. Consequently, users such as transporters of fuels along public highways may not consider the opportunity cost that stems form the deterioration and congestion of these resources.

A second category for potential non-environmental externalities is termed energy security. This category encompasses a number of topics including strategic consumption behavior in international markets, reliability of energy resources and related national security, military and foreign policy issues, and macroeconomic issues including balance of trade effects.

A third category includes externalities associated with government intervention in the economy. Frequently, government incervention is motivated by the desire to remedy a pre-existing market failure and therefore may be efficiency enhancing. Nonetheless, governmental policies may create other external costs that are amplified or diminished by specific energy investments. Examples include administrative costs, deviations from marginal cost pricing associated with public utility regulation, liability limits, or indirect effects of policy actions that result in the complex environment for most governmental policy. This study addresses some of the potentially significant non-environmental externalities and attempts to estimate their economic value in a common metric with environmental and heal effects.

\subsection{OUTLINE OF THE REMAINDER OF THE REPORT}

The remainder of this report introduces the reader to our process of analysis. Chapter 2 is a detailed discussion of the tools of the analysis, including important definitions, the DFA and measures of value, the accounting framework, the knowledge-base library, and a notation system for knowledge-base data to signal uncertainty and quality information.

Chapters 3 and 4 are preliminary reviews of a number of ecological and health impacts that have been more thoroughly addressed in the individual fuel cycle documents. They illustrate the "naming" function of our approach. They are tailored to the coal fuel cycle and our regional reference 
environments to limit the list of "names." Readers may be familiar with similar discussions from EIA work or physical impact inventories. A review of the economic valuation literature is presented in Chapter 5 and in Appendix $\mathrm{C}$.

\subsection{REFERENCES}

Baumol, W. J. and Oates, W. E., 1975. The Theory of Environmental Policy, Prentice Hall, Englewood Cliffs, New York.

Buchanan, J. M. and Stubblebine, W. C., 1962. "Externality," Economica, 29(116), 371-384.

Cohen, S. D., et al. 1990. "A Survey of State PUC Activities to Incorporate Environmental Externalities into Electric Utility Planning and Regulation," National Association of Regulatory Commissioners, Washington.

Freeman, A. M. III, 1979. The Benefits of Environmental Improvements, Resources for the Future, Washington, D. C.

Joskow, P. L., 1992. "Dealing with Environmental Externalities: Let's Do It Right!" Edision Electric Institute Issues and Trends Briefing Paper No. 61.

Pigou, A. C., 1932. Economics of Welfare, MacMillan, London, England.

Placet, M. and Humphreys, K. K., 1991. "Environmental Tradeoffs Associated with Various Energy Pathways: A Total Energy Cycle Analysis Approach," Pacific Northwest Laboratory, Richland, Washington. 


\section{ANALYTICAL TOOLS}

The previous chapter reviewed the alternative analytical approaches that could be used to investigate the external costs (and benefits) of fuel cycles. While there are a number of approaches to assess externalities, the damage function approach (DFA) was selected to guide this study. The DFA provides the greatest emphasis on the relationships between natural and economic science to reveal the sequence of marginal changes which result in damages. Examining these relationships builds a knowledge base useful for comprehensive modeling at the national level as well as policy or technological analysis at the level of specific activities.

Identifying the best point of policy or regulatory intervention to recognize externalities in the energy services sector has been confounded by the lack of comprehensive information about the magnitude of these effects. Thus, the policy response at the state and federal level has tended to pursue assessments of the externalities or methodologies for incorporating external costs into production decision making (DeAngelis and Raskin 1989). Regulatory responses, however, have been more aggressive. Over half of the state Public Utility Commissions (PUCs) in the United States are considering options to modify current regulatory accounts for environmental and health externalities (Cohen et al. 1990, Ottinger et al. 1990).

Despite the PUC responses, correction for externalities in practice is a highly complicated problem that requires careful attention to both the physical consequences and economic valuations. Realistically, any attempt to make optimal adjustments to account fully for the external effects of all the stages of all fuel cycles is beyond the scope of current information capabilities. However, building the information base that is necessary for understanding the big and small effects and indicating where information is lacking is a task that can be pursued with more optimism.

This chapter presents the major tools to implement the DFA in the context of fuel cycle activities. These tools are necessary to name impacts, quantify what has been named, translate physical quantities to damages, and finally, distinguish damages from external costs. The sections that follow will describe in more detail important definitions and the various tools developed to conduct the analysis. The DFA is the primary analytical tool to assess the marginal damages of fuel cycles. The accounting framework organizes and builds the information base for the DFA. A message system is also proposed to assess systematically the uncertainty and quality of the data. 


\subsection{THE DAMAGE FUNCTION APPROACH}

In this project we estimate impacts for each priority impact-pathway associated with a generating plant being located in each of two reference environments (refer to Section 2.3 on impact-pathways). Then we obtain willingness to pay (WTP) estimates specific to a particular impact and use them to obtain an estimate of damage for that pathway. These damage estimates are then added to obtain the overall WTP to avoid the plant relative to a no-change baseline. ${ }^{1}$

However, it must be recognized that this approach has conceptual limitations. In reality, were a new plant to be built, affected individuals would be offered a package of both positive and negative impacts. Thus, many impacts would be experienced simultaneously. Ideally we could obtain estimates of individual WTP to avoid (or obtain) this package of impacts. For our practical approach to be valid, we must assume that the WTP for (or to avoid) a given impact is independent of that for (or to avoid) any other impact. That is, we must assume that the WTP to avoid the sum of these impacts equals the sum of the WTP to avoid each impact.

In fact, there is a body of economic literature suggesting that adding independently measured WTP estimates across different commodities (i.e., impacts) may overestimate total damage. The reasoning is that money spent on avoiding one impact cannot be spent on avoiding another. Consequently, estimates of the willingness to pay to avoid a single impact will be less constrained by income than such estimates for a set of impacts together. In addition, to the extent that environmental commodities are complements (like good health and recreation), reducing the quality of one will make the quality of the other less valuable to pieserve. Thus, adding separate WTP estimates for avoiding these two changes would overestimate damage. At the same time, some environmental commodities may be seen as substitutes. If, say two different but substitutable types of recreation sites are degraded, WTP estimates taken from each site separately would take the quality of the other site as given and assume that the other site would be available as a substitute. Degrading both sites together would reduce substitution options and result in a higher WTP to avoid the simultaneous impacts than the WTP to avoid each impact separately, i.e., on this account, our approach would underestimate damage.

\footnotetext{
${ }^{1}$ We make some attempts to avoid double-counting of impacts (e.g., by netting out the symptom-days that double-count RAD's).
} 
To further appreciate the conceptual limitations of our approach to valuing marginal damages, it is helpful to consider an ideal study as a benchmark. An example of an ideal study would be a "perfectly designed" contingent valuation study that addressed how much more a person would be willing to pay to avoid a new coal power plant being located in a particular region against an alternative (hypothetical) source of power with no externalities. These people could be those physically or economically affected or the general population that might hold existence values for natural resources that might be affected. This survey would detail all of the impacts predicted for this coal cycle, their time phasing, etc., presenting them as a package. These effects would then be evaluated as a package, with WTP to avoid the coal plant emerging directly. Any interdependencies in people's preferences over the elements of the package would, in theory, be taken into account in their WTP responses.

Whether the full set of environmental commodities are more generally complements, substitutes, or unrelated in the individual's utility function is unknown. In any event, the limitations on WTP imposed by an income constraint argues that our damage estimates, were they complete (i.e., for all damage/benefit categories), would overestimate total damage.

Measuring the marginal damages for a specific energy fuel cycle with the DFA involves two components. First is the estimation of the quantities of all resources injured or enhanced by producing and consuming the fuel source (most importantly, the nonmarketed resources such as air and water quality). It is important to note that the focus is confined to residual emissions and burdens because abatement technologies or waste management act to internalize the costs of physical impacts; thus these costs are already reflected in market prices. The loss (or gain) of nonmarketed resource quantities fall outside the normal transactions in fuel cycle markets.

The second component of measuring damages involves the estimation of the value of the injured (or enhanced) resource quantities. This value may be reflected by opportunity costs. Opportunity costs reflect the value of goods and services forgone by applying resources to one use rather than alternative uses. For market goods, under generally competitive conditions and with only incidental effects on nonmarketed resources, a value for the incremental use of a marketed resource can be directly observed as the market clearing price for this resource. In such cases, private costs can be interpreted to reflect social costs. However, there may be instances where markets for energy resources in the United States fail to be generally competitive. Furthermore, energy production and consumption often affect nonmarketed resources significantly. For nonmarket goods, such as health and environmental quality, 
the production and consumption of energy is often claimed to have significant effects. Chapter 5 considers how value is determined for goods and services that are not traded in conventional markets.

Environmental damages are derived by considering impacts and how individuals value these impacts. For example, considering the electric power generation stage of a fuel cycle, and limiting the discussion to air pollution for simplicity, the proposed technologies for producing and transmitting power and abating air emissions, together with the location of the proposed project (including transmission lines), determine the types of emissions, the receiving media, and, along with weather patterns and existing ambient pollution levels, the effect on air pollution concentrations at various locations in the region. Similar statements can be applied to emissions to water and land, and use of land. In addition, the location of transmission lines can directly effect land use and aesthetics (sight lines) that do not involve emissions per se. Given local environmental quality, and its susceptibility to pollution damage [captured in "dose-response" (D-R) functions], any additions to the levels of concentrations would cause environmental impacts. A flow chart of the damage function approach and the important analytical steps are shown in Fig. 1. Both the technological and the site-specific considerations play an important role in the determination of physical impacts.

Ecological and health impacts are generally believed to dominate the environmental damages of fuel cycles. The pollutants can be identified (in terms of ambient concentrations) and impacts categorized that, based on what is known in the scientific literature, are likely to have significant effects. Typical external impacts include (1) health effects (increased risk of mortality and two forms of morbidity, including acute effects, to healthy people and those with chronic diseases, and increased risk of developing chronic disease), (2) effects on output or production (such as effects of air pollution on reducing crop yields), (3) effects on assets that are linked to markets (such as air pollution effects on building materials and soiling of clothes), and (4) effects on environmental assets (such as effects of water pollutants on recreation, and effects of air pollution on visibility). The identification and measurement issues of these impacts are discussed in more detail in Chapters 3 and 4.

Methods to estimate the damages associated with physical external effects have gained broader acceptance in the last two decades as theoretical valuation issues have been resolved and the body of literature pertaining to specific applications has grown. However, much controversy remains regarding the appropriate valuation method. 
Fig. 1 Impact-pathway damage function approach

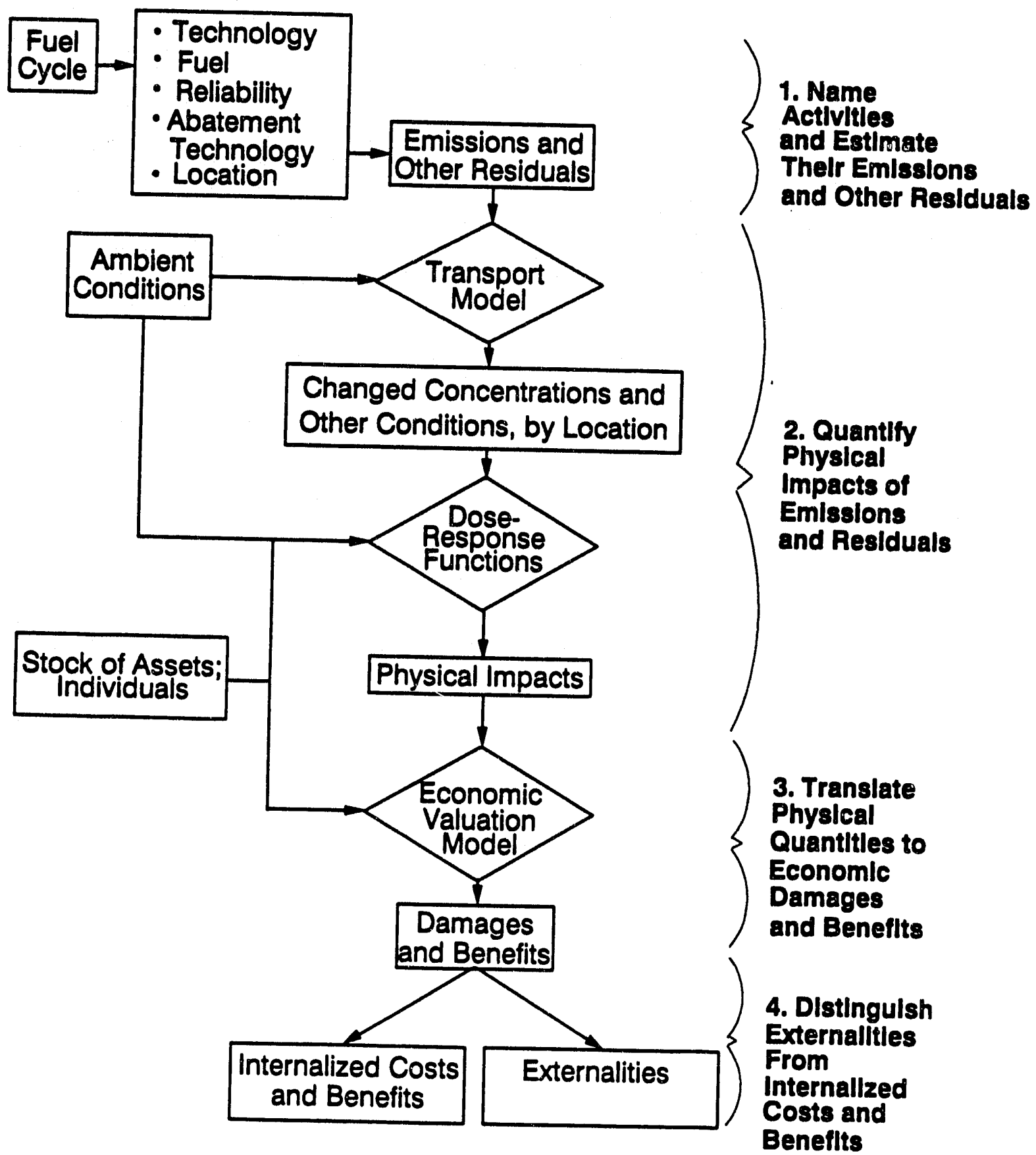




\subsubsection{Alternative Approaches to Valuing Damages in a PUC Context}

To move towards social cost-effective investment decisions, externalities must be valued and incorporated into producers' decision making. Three approaches have been or are being taken to estimate environmental costs of electricity generation-generic adders, abatement costs, and damage functions. Several states (e.g. Wisconsin), being direct and pointed about the difficulties in valuing damages to health and the environment, have adopted arbitrary rules (such as a percentage adder) for granting credit to clean generation technologies or penalizing dirtier technologies. Other states are at least temporarily using the costs of reducing pollution as a measurable proxy for the benefits of such reductions (e.g., New York and Nevada). California has recently decided to use estimates of damages instead of abatement costs. And all of the other states that have some form of quantified "adders" are considering a switch to estimates using the damage function approach. In several of these states (New York, Nevada, Wisconsin, and California) studies to provide such estimates are ongoing.

Which of these approaches is preferable? The approach of using an admittedly arbitrary adder has the advantages of being immediately and inexpensively implemented while avoiding any pretense of being "right." Thus, as new information comes along, the adder can be easily changed. Its obvious disadvantage is that it is purely a judgmental approach and, therefore, may be quite off the mark. The adder doesn't vary by location, either, although the effects of a given generation technology can be very different depending on its location.

To distinguish between the abatement cost and damage function approaches requires careful consideration of what is being measured as well as the value of obtaining measurements. With the damage function approach, estimates of damages are obtained by using the aggregate value individuals place on reductions in their welfare - that is, the amount individuals would be willing to pay or would need to be compensated - to leave them indifferent to the welfare loss. Changes in individual welfare are then measured by a variety of techniques, some relatively straightforward (when one is concerned with effects on marketed goods, damages to crops can be an issue), and others less so (when nonmarketed commodities, such as recreation, health, and aesthetic beauty, are affected).

There is a large body of information and research that can be used to value health and environmental damages. While difficulties remain, the usefulness and relevance of measuring direct damage costs has largely been 
settled as a policy matter. Leaving aside the enormous research effort in estimating the physical effects of pollution, benefit analysis has become an integral part of environmental economics and government decision making. Environmental benefit analysis has been institutionalized at the federal level in the Regulatory Impact Assessment process under Executive Order 12291, the natural resource damage assessment provisions of the Comprehensive Environmental Response, Compensation, and Liability Ačt (Superfund), and the 1990 Clean Air Act Amendments. The newest survey of the field (Cropper and Oates 1990) bears out the enormous effort, success, and popularity of the field. Table 1 lists various market and nonmarket resources that might be affected by energy services and the valuation methods (based on benefit estimation) that have been used to measure damages. The table illustrates the breadth of impacts considered by the literature; see Chapter 5 for more details on the particular valuation methods listed.

When damages show up in marketed assets (e.g., what has been termed "impact to production" in Table 1) standard approaches to valuing changes in welfare may be taken. Standard approaches include using demand and supply models to derive price and quantity changes, which, in turn, provide the basis for damages.

Table 1. Impact categories and valuation approaches

\begin{tabular}{ll}
\hline \multicolumn{1}{c}{ Impact category } & \multicolumn{1}{c}{ Valuation approaches } \\
\hline TO INDIVIDUALS: & \\
Mortality & $\begin{array}{l}\text { Wage compensation } \\
\text { Contingent valuation } \\
\text { Averting behavior }\end{array}$ \\
& Human capital (foregone earnings) \\
& $\begin{array}{l}\text { Averting behavior } \\
\text { Contingent valuation }\end{array}$ \\
Morbidity & Cost of illness \\
& Contingent valuation \\
Anxiety & Contingent valuation \\
Aesthetics & General Equilibrium Models \\
Other &
\end{tabular}


TO PRODUCTION:

Crops/forests/fisheries

Consumer plus producer surplus

Water-using industry

Consumer plus producer surplus

Municipal water supply authorities

Opportunity cost (alternative aquifer)

Service replacement (municipal

treatment, bottled water)

TO ECONOMIC ASSETS:

Materials (corrosion)

Replacement cost

Service values

Property values

Hedonic price models*

TO ENVIRONMENTAL

ASSETS:

Use

Recreation

Unit day

Contingent valuation

Property value

Travel cost

Random utility

Other

Service replacement

Contingent valuation

Property value

Nonuse (existence)

Contingent valuation

Stewardship

Inherent

Bequest

Vicarious consumption

-Will involve double-counting if health, visibility, and materials damages are estimated independently.

Source: Adapted from "Project IV: The Benefits and Cost of Superfund Cleanups: An Information Assessment," Coalition on Superfund, September 1989 
When damages show up in nonmarketed commodities, valuation may be computed by the individual's willingness to pay (WTP) for an improvement in the state of nature (in terms of reductions in pollution or its physical consequences) and the individual's willingness to accept (WTA) compensation to tolerate a worsening of the state of nature.

Indirect and direct approaches have been developed to estimate values. Direct approaches, called contingent valuation methods (CV), involve asking individuals for their WTP in response to hypothetical scenarios involving reductions in health or environmental risks or effects. The indirect approaches (sometimes called revealed preference approaches) seek to uncover values for the non-marketed environmenta! goods by examining market or other types of behavior that are related to the environment as substitutes or complements. Another indirect approach is the resource cost approach. By tracking spending on goods used to avoid pollution or its effects, one can gain some idea of WTP. For a description of these techniques, see Chapter 5.

The abatement cost approach takes the complexity of applying either direct or indirect valuation approaches as the point of departure. In this view, direct damage costs can never be adequately measured and valued and that, assuming regulations are set "efficiently"-to equalize environmental benefits and abatement costs at the margin-compliance costs are a reasonable proxy for damage costs. However, there are reasons to believe that environmental regulations may not be set at economically efficient levels. For instance, the Clean Air Act (CAA) specifically precludes the EPA Administrator from considering abatement costs in setting standards, and the process of estimating and valuing environmental damages (while not precluded under the CAA) is given little weight because the CAA requires standards to be set to protect sensitive individuals with a margin of safety. This involves estimating risks for sensitive individuals from air pollutants but not the population risks and damages (or benefits) that would be reeded to set "efficient" air quality standards. Even if costs and benefits were considered in setting regulation, many other issues are routinely taken into account, such as the distribution of effects (across states or income groups, for instance) and implementation problems.

It must be emphasized, where regulations are not set at economically efficient levels, abatement cost is generally a poor indicator of damages. Moreover, its use implies that the value of reducing emissions can be the same in locations where damages from such reductions are clearly very different. For instance, assume that the costs of reducing $\mathrm{SO}_{2}$ emissions are identical for a power plant located on the Atlantic Ocean (where the plume normally blows 
out to sea) and another plant in Ohio. This implies that, with the abatement cost approach, environmental costs would be identical for the two plants. Yet, the reductions in darnages from reducing emissions of the coastal plant are obviously less valuable than those from the Ohio plant.

As policy, the abatement cost approach creates problems. In New York, for example, application of this approach has led to reduced competitiveness of coal relative to oil in electric generation. Coal-fired plants are primarily located in the sparsely populated northern areas of the state, while the oil units are in and around New York City. Without an approach that takes population densities into account in the assessment of social costs, the unfortunate result may be that net health damages could be improved by switching system capacity from oil to coal.

Moreover, abatement costs are unlikely to be even a lower bound to the benefits of control, which requires the assumption that regulators always err on the side of too weak regulations. Serious doubt has been cast about this assumption (Krupnick and Portney 1991).

Perhaps the most potent argument against the abatement cost approach is that the approach may well harm or protect the environment at far higher economic costs than are necessary. These effects may result because the "wrong" mix of electricity generation capacity may be put in place, based on a flawed methodology. Indeed, placing too high a value on environmental damage can be just as undesirable as placing too low, or even a zero, value on impacts.

\subsubsection{The Issue of Thresholds and Standards}

A major area of confusion regarding the application of the DFA is associated with the estimation of damages for areas meeting applicable ambient quality standards, e.g., the National Ambient Air Quality Standards (NAAQS) set under the Clean Air Act. Lave (1991) asserts that as such standards must be set by law to "protect health with a margin of safety," by definition there are thresholds at or above the current standard. According to this position, there are no health effects from the air emissions of a new power plant in areas in compliance with such standards.

However, this position is based on the assumptions that: (a) the NAAQS are actually set solely on the basis of this criterion, and (b) doseresponse functions relating air emissions to health generally have thresholds. In fact, there is evidence of non-trivial health effects below standards for particulates and ozone, and no presumption that non-health effects are zero 
below the health-based standard (a secondary standard, which is more for guidance, is supposed to address the non-health effects). Standards for ozone, particulates, and lead effects have become more stringent over time indicating a recognition of health effects below some previous (and thus possibly current) standards.

The process of setting the NAAQS is EPA's multimillion dollar process to develop a Criteria Document, a Staff Paper summarizing and drawing conclusions from the Criteria Document, a review of these documents by the Clean Air Scientific Advisory Committee (CASAC), and a subsequent decision by the Administrator on what the standard will be. Why may this process not issue NAAQSs that ensure that there are no health effects in areas in compliance?

The simplest explanation is one of timing. The NAAQS process is so costly and cumbersome that Congress asked for review of the standards only every five years. Thus, between rounds of this process, health scientists have at least five years (in the case of ozone they have had 12 years) to develop evidence of the health effects of air pollutants. Any interim analysis, such as ours, can portray a more accurate picture of the state of research by relying on the Criteria Documents and Staff Papers as a starting point, and supplementing these documents with research performed since the latest round of standard setting. As, in practice, the five year phasing may be prolonged considerably, there is plenty of time for new research.

For both ozone and particulates, there has been significant new research since the standards were set. It has now been established with clinical studies that there are effects of ozone on acute health endpoints at concentrations below the standard and for longer averaging times. Effects in the lab have been found at $0.08 \mathrm{ppm}$ for six-hour exposures. A one-hour standard offering protection with a margin of safety would be lower than the current standard of $0.12 \mathrm{ppm}$. For particulates, research relating daily pollution exposures to daily mortality rates in a city has been replicated for five cities/regions, with strikingly comparable results found across the cities. Most of these areas are in attainment with the particulates standard. This research supplants earlier, far-less satisfactory cross-sectional studies, which until recently were the only studies to rely on for information on this critical pathway.

The second explanation relates to the purpose of standard setting versus the purpose of a damage estimation exercise. Many arguments during the NAAOS process relate to the definition of an "adverse" health effect, for it is only these that merit protection with a margin of safety. Medical 
considerations (and probably legal ones as well) are salient during these debates. In practice, EPA has often taken a very liberal interpretation of this word, counting a two-hour cough event as an adverse effect, for example. But, in theory, a tighter interpretation could be taken. For a benefits/damage analysis, on the other hand, all effects are counted so long as someone would be willing to pay to have avoided them. Thus, differences between a medical and an economic interpretation of "adverse" effect could lead, quite directly, to a finding of an economic effect but not necessarily a medical/legal one (and vice-versa).

These first two explanations are not controversial. A third explanation is compelling to anyone who follows this process. The EPA staff and the key people on CASAC favor clinical studies (if they exist) rather than epidemiological studies as the basis for standard-setting, probably because of the former type of study's greater certainty in terms of cause and effect and for the difficulty of challenging the clinical study findings in the courtroom. The clinical studies receive greater attention in the EPA review, with epidemiological studies generally relegated to the status of providing "qualitative" evidence of effects, while clinical studies provide "quantitative" evidence.

For the purpose of estimating the damages to a population from pollution, however, clinical studies are frequently less reliable than epidemiological studies. The former sometimes suffer from small and biased samples (old people, very young people, ill people, blacks, and women are typically under-represented) and from ignoring how people avoid pollution or mitigate its effects (by slowing their exercise, for instance). In contrast, epidemiological studies identify associations between health effects and changes in air pollution, taking into account all groups in the population and the way these people behave (although this type of study suffers from showing only statistical associations, not cause and effect).

The important point is not whether the NAAQS process is deficient. It is simply that the purpose of this process is to find thresholds in response (even if applied to a very small and unrepresentative group) not to measure effects on the general population by deriving dose-response functions. Thus, the analyses in the Criteria Documents and Staff Papers are done for the purpose of damage/benefit assessments and it is not surprising that these analyses rely more on epidemiological studies.

A fourth explanation is the evidence for setting the NAAQS. An example is the current ambient ozone standard. As detailed in Landy, 
Roberts, and Thomas (1990), factual evidence for setting the $19790.12 \mathrm{ppm}$ ozone standard was limited.

Two clinical studies were highlighted in the Staff Paper as justification for the recommendation that the standard be set at $0.12 \mathrm{ppm}$. One of the clinical studies (DeLucia and Adams 1977) provided unreplicated and ambiguous evidence on only six subjects. The other clinical study (von Nieding 1977) exposed 11 young men to various air pollutants while engaged in light exercise, showing changes in some measures of lung function and blood chemistry to only $0.10 \mathrm{ppm}$ ozone after two hours of exposure. This study was criticized for unorthodox measurement methods by the Criteria Document. Other clinical studies found effects at $0.20 \mathrm{ppm}$, and above 0.25 ppm, some showed effects on asthmatics, while others did not even at relatively high ozone concentrations.

Epidemiological and animal studies were also available to provide additional information, but none of the former directly addressed issues of thresholds and their analytical methods were sufficiently questionable that they were not relied on to any great extent. The animal studies suffered, then, as they do now, from questions about translating results from animals to humans.

A fifth explanation goes still further, asserting that politics, economic considerations, and a host of other factors play a role in standard setting. It is clear that even the framers of the Clean Air Act came to recognize that the concept of health dose-response function thresholds was difficult to defend on scientific grounds, but argued for its continued use on practical grounds. Senator Muskie, one of the primary architects of the Clean Air Act of 1970, said:

There was no other way to [set the NAAQS than to use a threshold model]... The statute clearly prohibits the use of economic considerations in the setting of health standards... We couldn't use a technology handle [in setting the NAAQS]...we had to find a threshold. Even with practically minimal emissions there are health effects to someone....It may be an oversimplification, (BNA Environmental Reporter, Feb 2, 1979, 1813).

As has already been experienced with respect to regulating cancer risks, we may find that there are no "safe" exposure levels to ozone and other air pollutants. In this case, the CAAA taken literally would require a zero standard. But who would subject the economy to the consequences? 
Therefore, without thresholds, the process of setting standards becomes one of judgment, albeit informed by underlying health science, but also influenced by the costs of attaining standards (even though formally costs can not be considered) and by public and political attitudes. In addition, without thresholds, there may be effects on the general population that are judged to be too small to warrant protection. But a damage assessment cannot overlook them, so long as people would be willing to pay to avoid them. Indeed, the NAAQS process could, in theory, ignore small effects to a very large number of people in the general population, setting standards to protect against much more significant effects that occur only at higher ambient levels. This may be a perfectly defensible public policy decision, but one that is irrelevant for assessing damages.

\subsection{THE ACCOUNTING FRAMEWORK}

The accounting framework is an organizing principle to: (1) identify the emissions or burdens from a fuel cycle stage, (2) name or identify the impacts, and quantify what has been named, and (3) translate physical quantity changes into damages or benefits. Table 2 lists first the series of mappings defining the problem at the broadest level. The second listing shows that supporting the general series of mappings is a number of more specific relationships and translations.

The analysis of damages from fuel cycle activities involves the search for information to quantify all of the relationships in Table 2. However, underlying this simple organization of information is all the necessary information on emission transport and dose-response that leads to a measurement of physical impacts. The figures in Appendix A illustrate how stages in the coal fuel cycle are characterized by the residual emissions that are linked to physical impacts following the practices of environmental impact analysis. Figure 2 illustrates the matrix format used to display the relationships between fuel-cycle activities and residual emissions and burdens. Figure 2 represents part of the larger, actual matrix which is given in Appendix B.

The appropriate level of activity within any stage of a fuel cycle is determined by setting the scale and technology for electricity generation and then deriving all the requisite inputs and outputs to support that particular generation option. For the current project, several options for coal-generating facilities will be considered in 1990 and 2010 time frames; however, as we indicated in Chapter 1, there will be less diversity in the analysis of other stages. The technologies or activities are characterized by their residual 
Table 2 Mappings important to the externalities problem

\begin{tabular}{ll}
\hline & Broad-Level Mappings \\
Fuel cycle stages & $\rightarrow$ activities \\
Activities & $\rightarrow$ emissions and other residuals \\
Emissions & $\rightarrow$ transport and changed concentration \\
Transport and changed & $\rightarrow$ physical impacts \\
concentration & $\rightarrow$ economic damages and benefits \\
Impacts & $\rightarrow$ external costs and external benefits \\
Damages and benefits & $\rightarrow$ More Specific Mappings \\
& $\rightarrow$ source terms \\
Emissions & $\rightarrow$ concentrations \\
Source Terms & $\rightarrow$ exposures \\
Concentrations & $\rightarrow$ doses \\
Exposures & $\rightarrow$ responses \\
Doses & $\rightarrow$ physical impact endpoints \\
Responses & $\rightarrow$ valuation startpoints \\
Impact endpoints & $\rightarrow$ damages and benefits \\
Valuation startpoints & $\rightarrow$ external costs and external benefits \\
Damages and benefits & \\
\hline
\end{tabular}


Fig. 2 Mapping of stages of the coal fuel cycle into emissions and other residuals

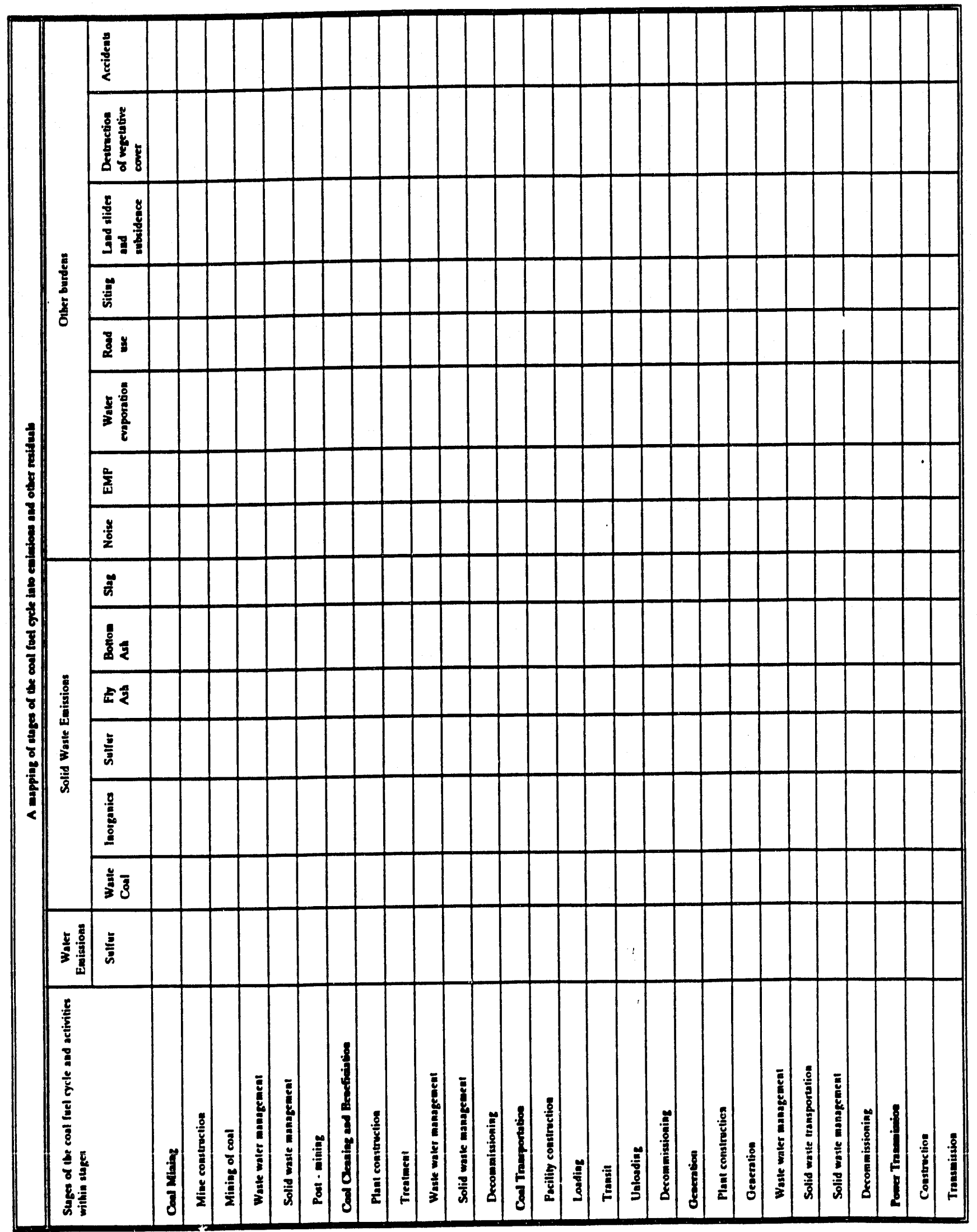


Fig. 2 (continued)

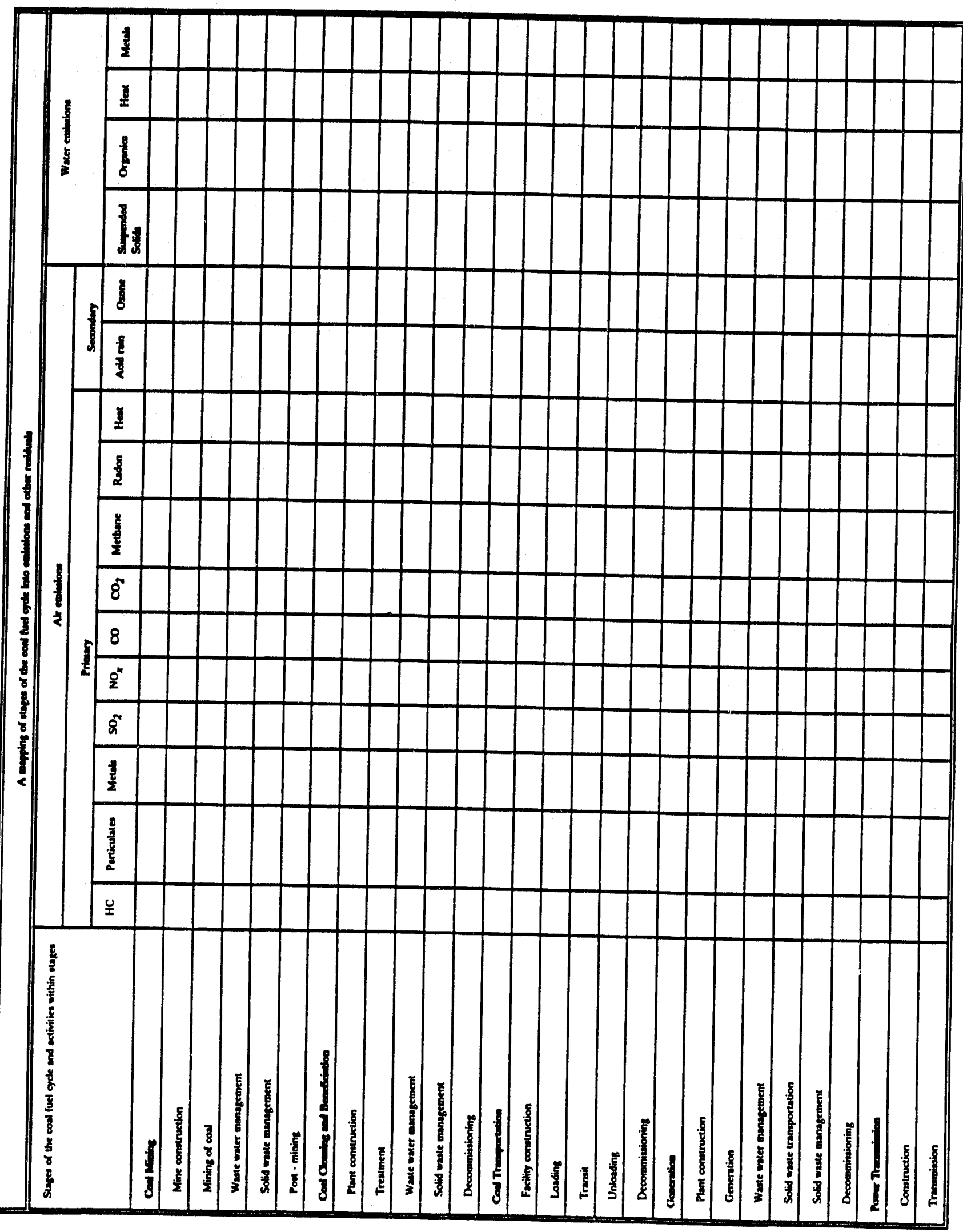


emissions appropriate for the scale of the incremental investment. All data for these characterizations are extracted from existing literature.

Once emissions and burdens are characterized for each stage of the fuel cycle, the next set of relationships for the framework is the mapping of emissions into concentrations. Atmospheric transport models can be used to estimate concentrations of pollutants in the air. Gaussian plume models are available for primary pollutants, such as particulate matter, $\mathrm{NO}_{2}, \mathrm{SO}_{2}$, and air toxics. More complex models are needed to address chemical transformations, such as the link between $\mathrm{NO}_{2}$ emissions to ozone concentrations and $\mathrm{SO}_{2}$ to sulphate concentrations. Key issues to address in this set of relationships are the geographical extent of the analysis and the temporal and spatial detail required. The greater the spatial and temporal detail, the greater the nonlinearities in the dose-(or concentration) response functions, particularly with respect to their dependence on baseline ambient concentrations.

The next set of relationships links concentrations to physical impacts. Fig. 3 shows part of the matrix for the coal-mining stage. Matrices for all coal fuel-cycle stages can be found in Appendix B. As noted, many complicated links are expected to be embedded in the entries of the impact matrices. The ecological and health impacts are addressed more fully in Chapters 3 and 4, respectively. The socioeconomic impacts of interest include building materials, stigma effects (perception of contamination) on land and water resources, visibility (and visual insults), noise, public services (community services and public institutions that must resolve conflicts derived from the presence of other burdens), and other quality of life impacts (e.g., increased traffic congestion). The scope of impacts includes local, regional, and global consequences. However, the U.S. and EC teams have agreed to examine local and regional impacts first. The global impacts will be presented as impact potentials rather than as impact assessments due to the highly limited knowledge base in this area. As an aid to the reader, we will convert estimates of damage from global warming to its mills $/ \mathrm{kWh}$ equivalent. However, we emphasize that such estimates are too questionable for use at this time.

The next mapping in the accounting framework represents the translation of physical impacts into marginal damages. Fig. 4 shows the matrix for the mining stage. Underlying the entries in Fig. 4 are the links necessary to match physical impacts and monetary values. This mapping relies on information to define the appropriate valuation startpoints from the impacts literature. In addition, valuation measures must be available to derive the marginal damages. Chapter 5 of this report contains detailed discussions of 
Fig. 3 A mapping of the emissions and resulting changed concentrations into ecological, health, and other impacts for the coal mining stage (only a part of the overall matrix is shown)

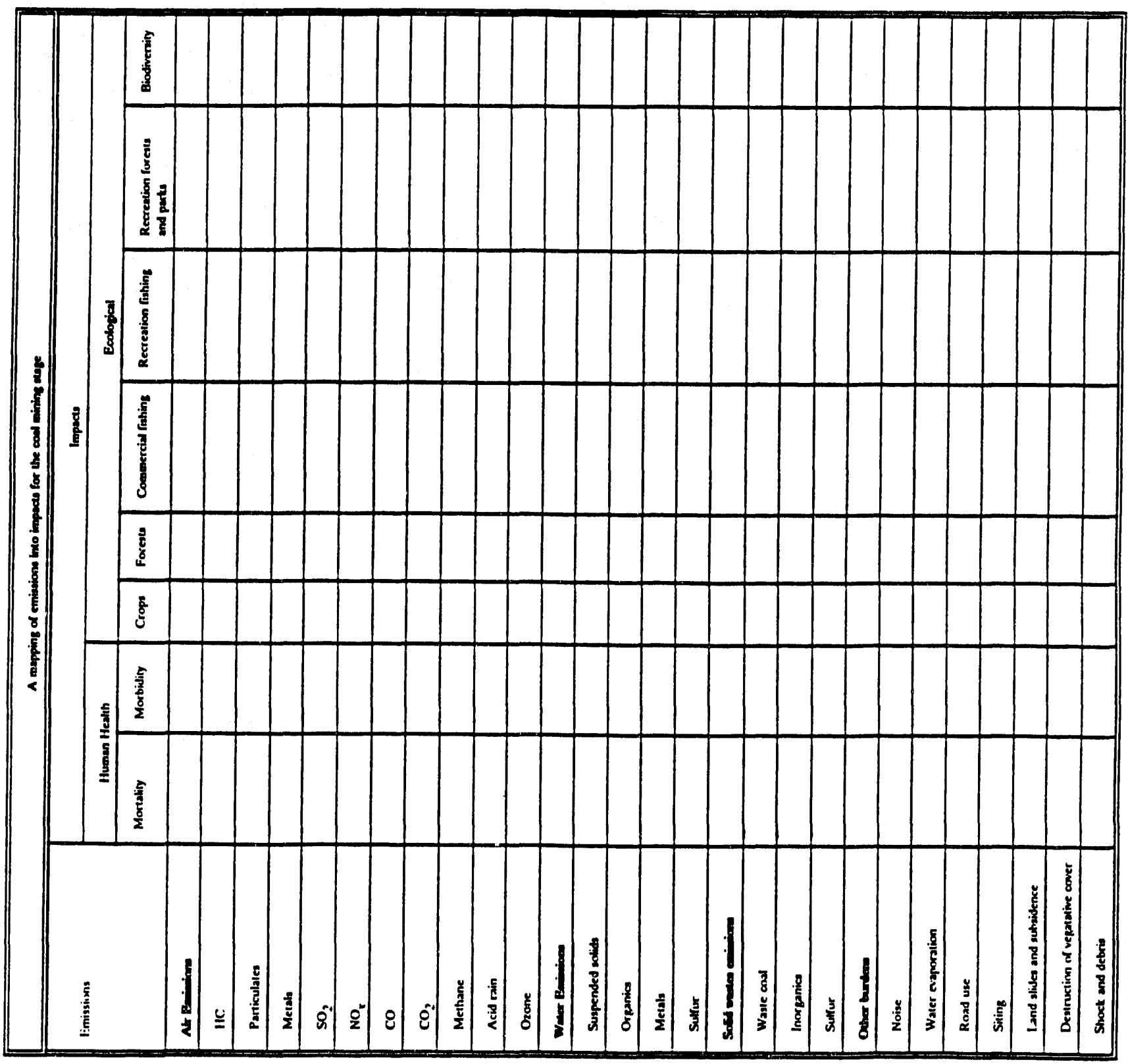


the key issues regarding the use of techniques from economic valuation in the context of the U.S. and EC projects.

\subsection{THE IMPACT-PATHWAY APPROACH}

In theory, the Damage Function Approach (DFA) can be applied to try to estimate values for every cell in all of the accounting matrices. In practice, however, this approach turns out to be more complex than just filling in data for sets of cells for any damage that would be investigated. Intermediate transformation processes which take place have to be addressed. This analysis is carried out in practice via the Impact-Pathway Approach.

The Impact-Pathway Approach starts from the primary emissions identified in the first matrix of the accounting framework. It describes the route which is taken from the source of contamination or burden to the endpoint or receptor (human or the environment). It therefore includes the chemical transformation of primary emissions into secondary type emissions (if any). Ozone and acid rain formation are typical examples. Pollutant dispersion is the next step of the impact-pathway analysis. It results in estimates of the changes in ambient concentrations to which receptors will react. The impacts are estimated by dose-response relationships. From these, one obtains a quantification of the physical impacts resulting from the residuals under consideration. The association of the impacts with the corresponding residuals defines the second matrix of the accounting framework, the impact matrix for each of the fuel cycle stages. Assigning opportunity costs to the injured or enhanced resources is the next and final step of the approach. Table 3 shows an example of data and model requirements for this impact-pathway approach.

There are too many stages in the fuel cycle, and too many emissions impacts and values to be able to address all of them in detail. Furthermore, limitations in knowledge pose significant constraints on the number of calls that can be analyzed. Thus practical implementation of the DFA requires the identification of a limited number of "priority" impact-pathways to analyze in greater detail. 
Fig. 4 A mapping of impacts into marginal economic damages (only part of the overall matrix is shown)

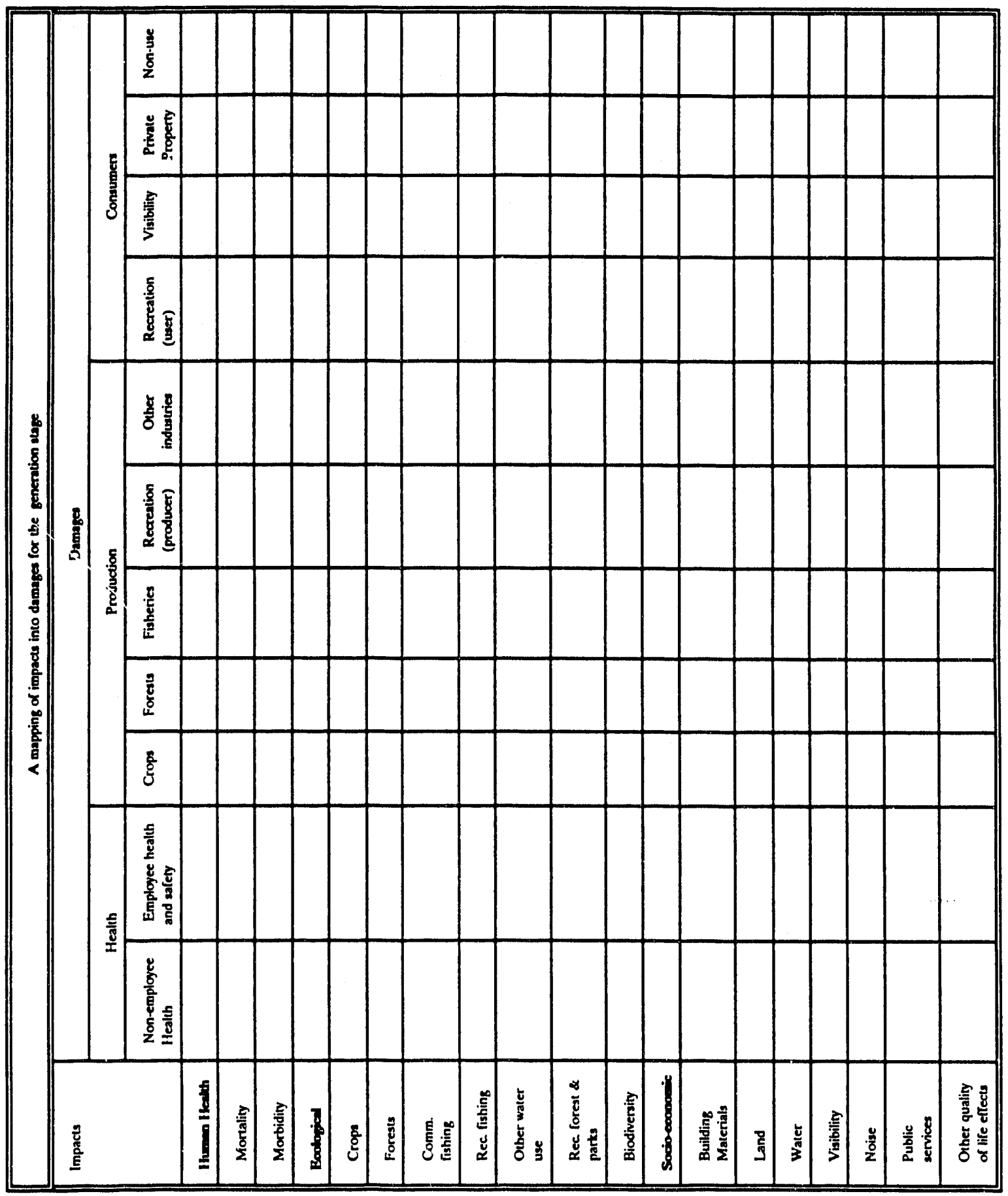




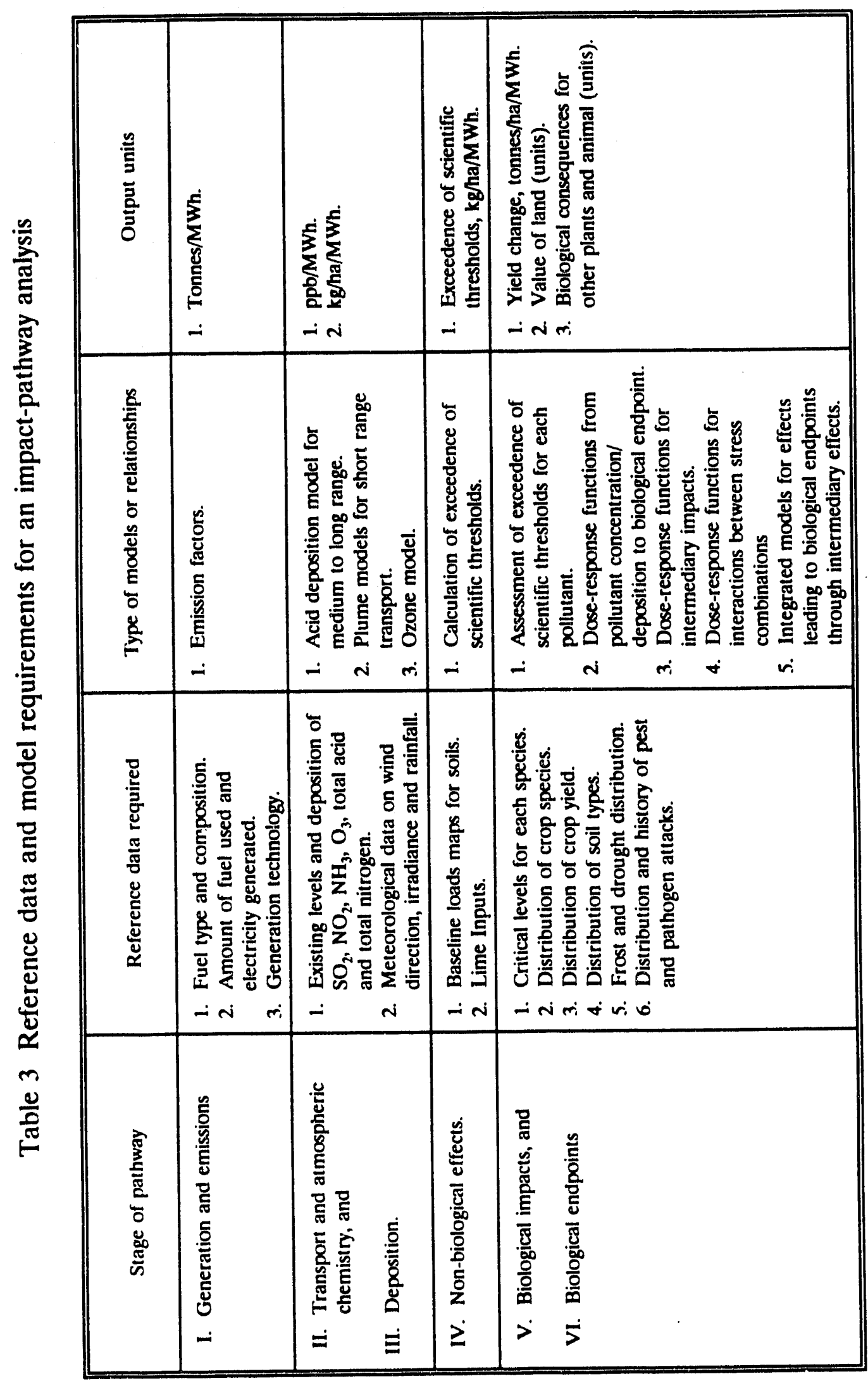

हैं 
Impact-pathways are given "priority" in this study on the basis of three criteria:

(1) The extent of the impact as reflected in its potential economic value, based on an assessment of the scientific and economics literatureimpacts thought to be more significant are more likely to be selected;

(2) A comparison of emissions of the same pollutant from different stages of the fuel cycle-impact-pathways with comparatively high emissions are more likely to be selected;

(3) A review of the literature on the impacts and on the damages or benefits - those with more quantitative information about them are more likely to be selected.

\subsection{THE UNCERTAINTY AND QUALITY MESSAGE SYSTEM}

Data which are used to estimate the impacts, damages, and benefits of different impact-pathways require a system for study team members to signal the uncertainty and the quality of these data to other users. Few of the accounting framework entries will be known with certainty or even generally agreed upon as the prevalent quantity or relation. For example, the magnitude of ecological or human health responses to energy-related pollutants cannot be known with certainty given current knowledge of the relationships. The monetary valuations associated with the imperfectly known impacts are also uncertain and at times, controversial. To leave cell entries standing alone without signaling the uncertainty and quality of the entries would overstate the precision with which the entries are known. In addition, signalling the uncertainty and quality for cell entries will indicate the areas where further study is most needed.

Uncertainty and quality are signaled through a notational system named NUSAP as an acronym for its categories. NUSAP was developed by Funtowicz and Ravetz (1990) to provide a quality control of quantitative information in science for policy studies. Application of the system relies first on the judgments of the study team and then on the peer review process. The NUSAP system has been adapted for signaling the uncertainty and quality of quantitative information to be used in estimating the emissions, impacts, and damages of fuel cycles. Uncertainty refers to the spread of plausible values for a cell entry and the level of confidence placed in a quantitative statement. Quality refers to both an entry's worth as a piece of information and the credibility of the theory, data, and methods used to generate the entry. 
The NUSAP system signals uncertainty by stating the spread of values associated with a numerical entry. A number standing alone falsely suggests that it is known with certainty. Thus, the uncertainty must be signaled. Where the element itself is a piece of quantitative information, as with a numerical cell entry, the uncertainty of the element explicitly is signaled in its own numerical terms: this is done by designating a restricted interval of values. The interval of all possible values may be immense, making such an interval of possible values uninformative. Thus, the bounds of the interval are constrained by designating a level of confidence. This "confidence interval" is called a spread.

The spread of NUSAP is not necessarily generated by statistical analysis. If a statistical distribution does not exist or fails to fully represent all significant uncertainty about a value, then the NUSAP spread will be generated by the subjective judgment of experts. Also, a statistical distribution may not fully capture the uncertainty about a value. Probability distributions are generated from all sorts of activities besides those envisioned by probability theory. Many times distributions are simply assumed. Standard manipulations of probability distributions to derive uncertainty measures are based on ideal situations and therefore they cannot completely represent uncertainty in less-than-ideal cases. Thus, a statistical confidence interval may not fully capture the uncertainty involved.

In addition to signaling uncertainty, NUSAP also signals the quality of entries. Quality pertains to the state of knowledge about an element. In evaluating the qualitative aspects of an entry, the questions "What is known?" and "What is not known?" The term "qualitative" here means both "nonnumerical" and "goodness." Signaling uncertainty alone does not assess the goodness of an entry. The quality of entries is signaled in the assessment and pedigree categories of NUSAP. The assessment category evaluates an entry's worth as a piece of information and the pedigree category evaluates the source of the piece of information.

The assessment is made for each entry based on its worth for providing information on the emissions, impacts, and marginal damages of fuel cycles. Entries will be assessed on four aspects: informative value based on spread, informative value based on application, generalizability to other applications or sample spaces, and robustness over time. Each of these aspects will be rated low, medium, or high. Informative Value Based on Spread provides an assessment of the incremental ignorance that is overcome by the studies, methods, or works which generated the entry. Informative Value Based on Application provides an assessment of how much the uncertainty about the 
entry affects the quality of the result of analysis using the entry. Generalizability to Other Applications provides an assessment of the usefulness of the entry for other potential applications other than the application for which the value was originally generated. Robustness of Value over Time provides an assessment of how valid the value is expected to remain.

Pedigree signals the quality of entries by evaluating their sources. In other words, the pedigree exhibits an evaluation of the mode of production of the quantitative information. Pedigree contains four categories: theoretical basis, data inputs, estimation methods, and estimation metric. (Estimation metric refers to the measurement of the estimate. Is it the object itself, or a proxy for something immeasurable? If it is a proxy, how good is the proxy?) Entries' quality levels are assessed on these categories by indicators. The indicators have specific definitions but in general are assigned a value between 1 (unacceptable) and 5 (excellent).

One of the strengths of the NUSAP system is that uncertainty and quality can be signaled in a brief cryptic and systematic format. However, this is also be a disadvantage when a user wants to know why an entry received a particular rating. Thus, brief comment fields accompany each assessment and pedigree aspect. The comments explain why a particular rating was received. The NUSAP scheme is summarized as follows.

The NUSAP Scheme

Numerical entry (i.e., information on quantification)

Numeral, or

Notation, or

Variable Name, or

Note on practice

Unit:

U1: Units of measurement

U2: Statistic used for value [e.g., mean (ME), mode (MD), median (MN), lower bound (LB), upper bound (UB), expected value (EV), or no distribution (ND)]

Spread of value

S1: Level of confidence

S2: $\quad$ Spread lower and upper bound (S[LB, UB]) 
Assessment of value:

I1: Informative value based on spread

I2: Informative value based on application

G: Generalizability to other applications

R: Robustness of value over time

Pedigree:

T: Theoretical basis (and application of theory)

D: Data inputs

E: Estimation methods

M: Estimation metric

Notation:

(N, U1, U2): (S1, S2[LB, UB], A[I1,I2,G,R]): (P[T,D,E,M])

\subsection{SUMMARY}

The complexities and multi-disciplinary nature of the marginal damages problem demand appropriate tools. There is a need to organize and analyze a very large amount of information. The DFA provides the main organizational structure and highlights how physical impacts are translated into damages with measures of value. The accounting framework organizes the natural science and economic valuation relationships underlying the DFA. The selection and analysis of impact-pathways provide an operational way of using the DFA. Finally, uncertainty is addressed explicitly by employing a notation system that conveys to the reader or user judgments about the statistical and quality aspects of the knowledge base entries.

\subsection{REFERENCES}

Cohen, S. D., et al. 1990. "A Survey of State PUC Activities to Incorporate Environmental Externalities into Electric Utility Planning and Regulation," National Association of Regulatory Commissioners, Washington.

Cropper, M. L. and Oates, W. E., 1990. "Environmental Economics: A Survey," Resources for the Future Discussion Paper QE90-12 (forthcoming in $J$ of Econ Lit). 
DeAngelis, M. and Raskin, S., 1989. "The Social Benefits and Costs of Electricity Generation and End-Use Technologies," California Energy Commission, Sacramento, Calif.

DeLucia, A. J. and W. C. Adams, 1977. "Effects of $\mathrm{O}_{3}$ Inhalation During Exercise on Pulmonary Function and Blood Biochemistry." Joumal of Applied Physiology, 43:75-81.

S. Funtowicz and J. Ravetz, Uncertainty and Quality in Science for Policy, Kluwer Academic Publishers, Dordrecht, The Netherlands .

Krupnick, A. J. and Portney, P. R., 1991. "Controlling Urban Air Pollution: A Benefit-Cost Assessment," Science, 252:522-528.

Landy, M. K., M. J. Roberts and S. R. Thomas, 1990. The Environmental Protection Agency: Asking the Wrong Questions, Oxford University Press, Inc.

Lave, L. B., 1991. Testimony given to the Department of Public Utilities, D.P.U. 91-131.

Ottinger, R. L., Wooley, D. R., Robinson, N. A., Hodas, D. R., and Babb, S. E., 1990. Environmental Costs of Electricity, Oceana Press, New York, New York.

Von Nieding, G., 1977. "The Acute Effects of Ozone on the Pulmonary Function of Man," VDI Berichte 270, 123-129. 


\section{IDENTIFYING ECOLOGICAL IMPACTS FROM THE COAL FUEL CYCLE}

This chapter summarizes ecological impacts with particular emphasis on all phases of the coal fuel cycle, but is not a state-of-the-art literature review, which is forthcoming. Rather, the chapter uses selected studies to identify impacts and methodologies. These studies cover most types of impacts that would apply to other fuel cycles as well. Coal was selected as the initiating fuel cycle because it was the first studied by the project team. Considerable controversy exists about the potential ecological consequences of its use, and a very broad scope of potential damages or benefits have been referenced from its use. Aquatic and terrestrial resources of interest having been defined, ecological impact categories being used in the project "accounting framework," are defined, and alternative approaches to quantification are discussed. This information, along with data specific to the site and regional locations of the case-study power plants, will later be used to estimate the environmental impacts of concern.

The ecological impacts that would be of interest for an analysis of environmental externalities are highly diverse. Ecological resources are generally categorized as either aquatic or terrestrial. The sources of marginal damages include gaseous and aqueous emissions, solid waste generation and disposal, electromagnetic fields, and physical disturbance. In most cases impacts of land use changes are not included, because the commercial or recreational value of the converted land is assumed to be reflected in the market price. For nonuse categories such as biodiversity, however, land use change may have external costs.

\subsection{AQUATIC RESOURCES AND THE COAL FUEL CYCLE}

Mining, transportation, and energy production from coal have a variety of potential impacts on aquatic resources. Principal concerns have historically included impacts of mining and coal cleaning on water quality, impacts of combustion-related aqueous discharges, and impacts of power plant cooling systems on fish and other biota. More recently, regional and global effects of acid deposition, $\mathrm{CO}_{2}$ release, and heavy metals have become major concerns.

\subsubsection{Coal Mining}

Coal mining impacts are addressed by the Surface Mining Control and Reclamation Act (SMCRA) of 1977. Any conclusions about the extent of 
impacts from current practices depend on assumptions about compliance with SMCRA. Unclaimed, non-compliance surface mining alters the topography and vegetative cover of land, which in turn affect the volume and rate of surface water runoff. Storm water runoff may exceed surface water effects and carries a larger load of suspended materials where vegetation has been reduced. On the other hand, surface discharges may be reduced during non. storm periods, especially if streams flow into mining-induced fractures or subsidence areas.

Cushman, Gough, and Moran (1980) reviewed the extensive literature on potential hydrologic and water quality effects of existing coal mining. Surface water quality effects of coal mining were characterized in terms of acid drainage, increases of other dissolved constituents (e.g., alkaline drainage and trace substances), and increased suspended solids loads. Mining-induced alterations in $\mathrm{pH}$ and dissolved contaminants can degrade groundwater as well, making the water unsuitable for consumption. Acid drainage from mines may continue long after their closure, and alkaline drainage is a problem in western coal fields that is often compounded by the low dilution potential of many western streams.

The increased variability in streamflows can affect aquatic biota by reducing habitat; floods will increase bottom scouring, and sedimentation will fill pools and degrade riffle habitat needed by bottom-dwelling organisms. Damage to aquatic life from acid mine drainage is attributed to a combination of low $\mathrm{pH}$, high levels of metals and sulfates, and the deposition of a blanket of iron hydroxide precipitates which smother bottom-dwelling organisms (Dvorak and Lewis 1978). Biotic impacts from alkaline mine drainage, on the other hand, result from turbidity, sedimentation and osmotic stress from high concentrations of dissolved solids. Often, these water quality and biotic impacts associated with mine drainage are most pronounced in small streams, and are more likely to affect recreational fishing and biological diversity than commercial fishing.

Although underground mining generally has less effect on soils and vegetation than surface (strip) mining, subsidence of shallow, mined out spaces can also have major effects on topography and surface water runoff. Underground coal mining often causes greater quantities of acid or alkaline drainage than surface mining, but the relatively smaller amount of soil disturbance results in less soil erosion and sedimentation. 


\subsubsection{Coal Cleaning and Beneficiation}

Coal cleaning and beneficiation produces both solid wastes and liquid effluents although this waste stream may be treated as a product stream by fluidized bed plants capable of burning coal wastes. Effects of coal processing are similar to those of mining, although of lesser magnitude (Cushman, Gough, and Moran 1980). Air and water can percolate through refuse piles, resulting in acidic or alkaline leachates. For example, processing and refuse leachates have been estimated to contribute $7.5 \%$ of the acid drainage in Appalachia (Dvorak et al. 1977). Uncontrolled discharges from refuse piles and holding lagoons can degrade the quality of both surface and ground waters. As with mining effects, waters affected by coal processing operations may also exhibit altered $\mathrm{pH}$ and increased dissolved solids, including contamination by heavy metals and hydrocarbons. Recreational fishing, biodiversity, and consumptive water uses could all be constrained by water quality degradation resulting from coal processing facilities.

\subsubsection{Generation}

Water quality in receiving streams could be affected by operation of the condenser cooling system, discharges from air pollution control equipment, and runoff from coal storage and residual waste disposal areas. Operation of the power plants' heat dissipation (condenser cooling) system requires large amounts of water that are usually withdrawn directly from surface waters and subsequently discharged with an added load of heat and chemical contaminants. These surface waters contain aquatic organisms that may be injured or killed through their interactions with the power plant. Because such losses could adversely impact recreational and commercial fisheries, power plant condenser cooling system operations are strictly regulated. Alternatively, the added load of warm water discharge may extend fishing seasons in northern climates.

Aquatic organisms too large to pass through the intake debris screens and that cannot swim away from them, may be impinged against the screens. Impingement can affect large numbers of fish and shellfish, and results in mortality if the organisms are held against the screens for long periods of time (Langford 1983).

Aquatic organisms small enough to pass through the screens will travel through the entire condenser cooling system and be exposed to heat, mechanical and pressure stresses, and possibly biocidal chemicals before being discharged back to the water body. This process, called entrainment, is potentially fatal to a wide variety of small plants, invertebrates, fish eggs, and larvae (Schubel and Marcy 1978). 
When poorly controlled, discharges from the condenser cooling system may also affect the receiving water body through heat loading and chemical contaminants, most notably chlorine or other biocides. Sporadic heated effluents may cause direct mortality among aquatic organisms by either heat shock or cold shock. In addition, there are a number of indirect or sublethal stresses, associated with heated discharges, that have the potential to alter aquatic communities, for example, increased incidence of disease, predation, or parasitism, as well as changes in dissolved gas concentrations (Langford 1983).

Coal pile runoff is a potential problem at coal-fired power plants. If runoff is not carefully monitored and controlled, coal fines as well as leachates containing organic compounds, heavy metals, and other contaminants may degrade surface waters or groundwater. Water quality degradation from coal pile runoff can have effects similar to those of acid mine drainage (for highsulfur coals) or alkaline mine drainage (for low-sulfur coals) (Dvorak and Lewis 1978).

Coal combustion produces ash and slag that require disposal. The ash is often slurried to a holding pond and the slurry water recycled, evaporated, or discharged. Potential effects on water quality from solid waste collection and disposal stem from increases in trace contaminants, $\mathrm{pH}$, chemical oxygen demand, and dissolved and suspended solids (Cushman, Gough, and Moran 1980). Ash pond overflow, dike failure, ash-slurry pipeline rupture, and site erosion may introduce high levels of dissolved and suspended solids into surface waters. Leachates from stored or land-filled ash or scrubber sludge may also have chronic effects on both surface and groundwater quality, the extent of which is related to such factors as soil type, depth of the water table, effectiveness of pond sealing, dilution, and element mobility (Cushman, Gough, and Moran 1980).

Aquatic resources can be indirectly affected by atmospheric emissions from coal-fired power plants. Sulfur and nitrogen oxides contribute to acidic deposition; surface waters may become acidified from either direct deposition (both wet and dry fallout) or runoff of acidic water. The resulting lowered $\mathrm{pH}$ and elevated heavy metals concentrations have effects on aquatic communities similar to those of acid mine drainage. Acidic deposition is believed to have contributed to the reduction of biotic diversity and the reproductive failure of fish species in some lakes in the northeastern United States (NAPAP 1990). 


\subsection{TERRESTRIAL RESOURCES AND THE COAL FUEL CYCLE}

Activities associated with the various stages of the coal fuel cycle can have impacts on terrestrial biota and other land resources (for example, crops, pasture, forests, orchards, threatened and eridangered species, game animals, and public and private recreation lands). The principal concerns are the impacts of power-plant gaseous emissions on plants and the impacts resulting from occupation of land by surface mines, generating facilities, and solid waste disposal areas.

\subsubsection{Coal Mining}

Underground mines have relatively little effect on terrestrial resources because only small areas are typically disturbed. Impacts of surface mining can, however, be substantial.

The principal types of surface mining of coal are contour mining and mountain top removal, in mountainous terrain, and area strip mines in nonmountainous areas. Contour mining and mountaintop removal in mountains (e.g., the Cumberland Mountains of Tennessee) usually result in a loss of forested area on the mine itself and reduced productivity of adjacent downslope areas that receive discarded stripped material (spoil). Historically, if spoil was deposited downslope from a contour mine, an area usually more than twice the size of the mine itself was directly impacted (Dvorak et al. 1977). Extensive downslope erosion and gullying may also result, particularly where timber cuts occur near the mines. Many currently active contour and mountaintop mines and some old ones are being reclaimed; the mines are being revegetated or the land is being restored to original contour before being revegetated (Vogel 1981). However, even reclaimed areas usually have significantly lower productivity and biodiversity than undisturbed areas.

Contour mines usually occupy only a small fraction of mountainous land. Therefore, they may have minimal impact on forest wildlife of the mountains and, when reclaimed, may provide herbaceous and brushy habitats of value to game species such as ruffed grouse and white-tailed deer (Samuel et al. 1978; Vogel 1981). However, impacts may be relatively adverse if mining occurs in areas where particularly important wildlife resources are located (Honig, Olson, and Mason 1981). Contour mining often results in increased recreational activities (e.g., hunting, motorcycling) in the mountains, because roads to such mines allow increased access. This may be a net positive impact depending on local and regional interests. Although contour mining usually does not occur within parks, mines within the viewshed of mountain parks can have aesthetic impacts on park visitors. 
Large area strip mining is conducted in relatively level or gently sloping terrain, both in the eastern and western United States. The topography is altered, and former land uses (forest, crops, pasture, and rangeland) are displaced until the mines are reclaimed (Haynes et al. 1979). Land at the mines is also replaced by buildings, railroad spurs, and access roads. Soils on reclaimed mines are not usually very productive, and 10 to 30 years may pass before row-crop agriculture can resume in the eastern U.S. (Dvorak et al. 1977).

In the Southwest, lands that are surface mined are less productive than lands in the eastern U.S., and in some areas rangelands are less productive because of overgrazing. Because of low rainfall, it can be very difficult to establish vegetative cover and reclaim a mine without irrigation (Dvorak et al. 1977).

\subsubsection{Coal Cleaning and Beneficiation}

Coal cleaning, with its attendant generation of refuse, is done primarily in the central interior and eastern areas of the U.S. where high-sulfur coal is mined. The primary impact on terrestrial resources is the displacement of land by refuse disposal areas (gob piles and slurry lagoons). Terrestrial environments near such disposal areas can be impacted by windblown coal fines and acid drainage from the refuse. Proper reclamation of the disposal areas can minimize impacts, producing land suitable for wildlife cover, pasture, or recreation.

\subsubsection{Coal Transportation}

Potential sources of transportation impacts on terrestrial resources include the following:

- land requirements and disruption for new railroad spurs and haul roads to the mine sites,

- land requirements and disruption for new loading and unloading facilities for barges,

- accidental spillage and windblown dusts of coal associated with moving coal cars and coal trucks.

Terrestrial resource impacts of coal transportation, aside from impacts of transportation emissions, will be minimal if existing transportation facilities are adequate and little construction of new transportation facilities is required. Most disturbance will occur in the vicinity of new mines requiring the construction of roads and railroads from the mine site to existing roads and railroads. 


\subsubsection{Generation}

The generation stage would probably impact terrestrial resources through the replacement of land by generating facilities and the release of gaseous emissions (Dvorak et al. 1977, Dvorak and Lewis 1978, DOE 1989). At or near the generation site, land will be occupied by the plant facility itself and by various support facilities, including electrical substations, coal storage yards, ash and slag disposal areas, and disposal areas for limestone scrubber sludge. Air pollution can both damage plant tissue and cause decreases in production of crops and native vegetation and add fertilizer to soils which then enhances crop and forest growth. Compared to crops, less is known about the impacts of gaseous pollutants on forests and other natural plant communities.

Gaseous and particulate emissions can also decrease visibility over vast areas. Aesthetic quality at parks in the Southeast and the Southwest has been adversely affected by pollution-caused decreases in visibility; although natural haze, humidity, and automobile exhaust play an important contributory role.

\subsubsection{Power Transmission}

New power lines may be required for new generating facilities, but the impact would be relatively minimal (Kroodsma and Van Dyke 1985; Lee et al. 1989). The greatest impact occurs when a new line is routed through forest, which must be cleared to accommodate it. Because power-line corridors through forests are narrow and usually support dense, brushy vegetation, impacts on wildlife and forest land uses are minimal. In open areas such as pasture and cropland, existing land uses can continue beneath the new lines except in spots occupied by support towers. The towers occupy relatively little land and have minimal economic impact on agriculture. Extensive studies of electromagnetic fields produced by power lines have not shown significant impact on wildlife or livestock. Where power lines cross residential or recreational areas, there may be aesthetic or other siting impacts.

\subsection{DEFINITIONS OF IMPACT CATEGORIES}

This section defines the ecological impact categories to be used in the accounting framework (i.e., the column headings in the matrices used to map emissions into impacts). The categories are defined in terms of the biological resources valued by society, rather than by medium or path. Using this scheme, soil or water quality are intermediate impacts rather than resource categories, because they affect the suitability of the environment for valued 
organisms or for other human uses. A particular resource such as agriculture can be affected by multiple emissions and by multiple environmental pathways; both through the direct effects of air pollutants on plants and the indirect effects of degraded soil quality. The impact categories are defined below and summarized in Table 4 .

\subsubsection{Crops and Suburban Landscape}

Crops include both conventional row crops, such as corn and soybeans and orchards, and other plants harvested for direct economic value. Crops can be affected by direct phytotoxicity (toxic effects of contaminants on plant tissue), by soil degradation due to contaminant deposition or disturbance, or by irrigation with contaminated water. Common crops in the southeastern United States include corn, soybeans, and cotton. Although the acreage is smaller, similar crops are grown in the southwest on irrigated land. Suburban landscape includes grass, trees, and shrubs, and may show effects similar to those of crops from air pollutants.

The extensive literature on the effects of air pollutants on plants has been summarized by Shriner et al. (1990). The impact of specific pollutants decreases in the following order: ozone $\left(\mathrm{O}_{3}\right)>$ sulfur dioxide $\left(\mathrm{SO}_{2}\right)>$ acidic deposition $>$ nitrogen dioxide $\left(\mathrm{NO}_{2}\right)$. Reductions in production of various crops is decreased up to $56 \%$ by $\mathrm{O}_{3}$, depending on the crop species, location, and exposure. No effects on regional crop yield have been shown to result from the other pollutants. Reductions of crop production may rarely or occasionally be caused by $\mathrm{SO}_{2}$ in the vicinity of $\mathrm{SO}_{2}$ point sources.

Available data are generally adequate to quantify the impact of a power plant's emissions on crop production, provided that one can quantify the ozone concentrations within the emissions. Shriner et al. (1990) conclude that empirical models are currently adequate for assessment of air pollution impacts on crop yield and provide a case-study assessment. The acreage and production of each type of crop in each appropriate region can be determined from data available in United States Department of Agriculture and state reports on agricultural statistics. The quantitative relationships between crop production and ozone concentration can be obtained from existing literature for a large number of crop species and cultivars (Heck, Heagle, and Shriner 1986; Shriner et al. 1990). Then, the acreage and dose-response data can yield estimates of each crop's production losses resulting from power plant emissions. Impacts of other coal emission sources and stages of the fuel cycle other than power generation would only be minor, but could be quantified provided that their respective air pollutant concentrations could be quantified. 
Table 4. Summary of ecological impact categories.

Impact Impact pathways Definition
Category

Crops and suburban landscape

Livestock
Contaminant deposition on plant surfaces (phytotoxicity)

Soil contamination (phytotoxicity or nutrient

leaching)

Disturbed or lost acreage

Contaminated irrigation water

Fertilization

Increase in crop yield

Loss of livestock productivity due to reduced production or availability of pasture

Soil

contamination

Lost acreage 
Table 4. (continued)

\begin{tabular}{|c|c|c|}
\hline $\begin{array}{l}\text { Impact } \\
\text { Category }\end{array}$ & Impact pathways & Definition \\
\hline \multirow[t]{4}{*}{ Timber } & $\begin{array}{l}\text { Contaminant } \\
\text { deposition of } \\
\text { plant surfaces } \\
\text { (phytotoxicity) }\end{array}$ & \multirow[t]{3}{*}{$\begin{array}{l}\text { Loss of timber yield due to reduced } \\
\text { tree growth or acreage loss }\end{array}$} \\
\hline & $\begin{array}{l}\text { Soil } \\
\text { contamination } \\
\text { (phytotoxicity or } \\
\text { nutrient } \\
\text { leaching) }\end{array}$ & \\
\hline & Lost acreáge & \\
\hline & Fertilization & Increase in forest growth \\
\hline $\begin{array}{l}\text { Commercial } \\
\text { fishing }\end{array}$ & $\begin{array}{l}\text { Water quality } \\
\text { degradation }\end{array}$ & $\begin{array}{l}\text { Loss of commercially harvestable fis } \\
\text { to reduced production or contamina } \\
\text { above regulatory standards }\end{array}$ \\
\hline \multirow[t]{2}{*}{$\begin{array}{l}\text { Recreational } \\
\text { fishing }\end{array}$} & $\begin{array}{l}\text { Water quality } \\
\text { degradation } \\
\text { Flow reduction }\end{array}$ & \multirow[t]{2}{*}{$\begin{array}{l}\text { Loss of opportunity or quality of } \\
\text { recreational fishing due to reduced } \\
\text { production or contamination above } \\
\text { regulatory standards }\end{array}$} \\
\hline & Habitat loss & \\
\hline Hunting & $\begin{array}{l}\text { Habitat/landscape } \\
\text { destruction or } \\
\text { disturbance }\end{array}$ & Loss of opportunity to hunt \\
\hline
\end{tabular}


Table 4. (continued)

Impact Impact pathways Definition
Category

Recreational Habitat/landscape Loss of opportunity for touring, hiking, use of destruction or forests or disturbance birdwatching, swimming, and other nonparks

Reduced visibility

Impaired air/water quality

Biodiversity Impaired air quality Impacts on threatened and endangered

Water quality species; impacts on other aesthetically valued plants or wildlife; altered

Soil quality community structure/function

Habitat destruction or disturbance

Buildings and materials

Deposition of particles, aerosols, and containinated rainwater

Nonecological land use Land disturbance or contamination

Nonecological water use Impaired water quality or quantity

Visibility

Enhanced weathering of exposed metal and stone consumptive uses

$$
\text { community structure/function }
$$

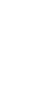


3. Ecological Impacts

\subsubsection{Livestock}

Livestock includes animals and poultry raised for meat or dairy products. Animals and poultry could theoretically be directly impacted whenever they inhale air pollutants or consume vegetation contaminated by air pollutants. Ambient air pollution levels in rural areas are, however, usually far below levels that could cause significant decreases in livestock productivity. No data demonstrating such direct impacts are available. Cattle and poultry are the principal livestock raised in the southeast. Cattle and sheep grazed on open range are predominant in the southwest.

\subsubsection{Timber}

Timber refers to wood products harvested from managed natural forests or tree plantations. Irrigation of forest land is rare in the United States. Otherwise, timber production is subject to the same sources of environmental impacts as is crop production. Extensive pine plantations grown for pulp production are present in the southeast. National Forests in the southern Appalachians provide some hardwood production. Commercial timber harvest is negligible in the Southwest.

In contrast to the availability of data for crop production, data are generally unavailable to show the responses of whole trees or stands of trees (e.g., mixed hardwood forests or pine plantations) to air pollutant stress. Consequently, empirical models and conclusive quantitative estimates of such responses do not exist. Existing process models relate to responses of tree seedlings and branches to air pollutants. These models are being modified to provide preliminary estimates of whole tree response, which could then be used to extrapolate to stand response, but this work has not been completed. The review by Shriner et al. (1990) provides no estimate of stand response.

\subsubsection{Commercial fishing}

Commercial fishing refers to the harvest of fish and shellfish for sale. Fishery value can be affected (1) by changes in water quality that affect the survival, growth, or reproduction of the organisms, or (2) by accumulation of contaminants in the harvested product. The term "water quality" encompasses a variety of characteristics that influence the suitability of a water body for use by man or by the resident biota. Among these are temperature, $\mathrm{pH}$, dissolved materials such as plant nutrients (phosphates and nitrates), degradable organic pollutants, metals and other toxic chemicals, oil, grease, and suspended sediment. Commercial fishing is not a major industry in coal-bearing regions of the United States. A small mussel industry (primarily for pearl production) 
still exists in the southeast, and aquaculture for trout and catfish production is common in this region. Commercial harvest of finfish from southeastern rivers and reservoirs is negligible. Crawfish aquaculture is common in Louisiana, a source of oil. Commercial fishing is negligible in southwest regions.

Effluents from coal mining, beneficiation, and combustion all have the potential to adversely impact water quality and, in turn, aquatic communities. Water quality impacts from coal mining primarily result from soil erosion (which increases turbidity and sedimentation in surface waters) and contaminated mine drainage (sulfur, heavy metals, and organic compounds). These potential impacts could also occur at beneficiation and generation sites, but are more localized and thus more easily controlled. The amount of sediment and contaminated drainage produced per hectare of mined land can be estimated for each coal mining region (DOE 1981), but the consequent biological effects are more difficult to quantify, especially on a regional basis.

Solid wastes (coal fines, non-coal mineral refuse, ash, and slag) can enter surface waters as suspended solids and impact both water quality and aquatic biota. In addition to the physical effects of turbidity and sedimentation, leaching of dissolved contaminants (toxic organic compounds and heavy metals) from these solid wastes could degrade surface waters. Volumes and chemical characteristics of leachates from solid wastes piles have been estimated (e.g., DOE 1981).

Fish and wildlife resources having significant problems in specific geographic areas have been identified and mapped (e.g., Honig, Olson, and Mason 1981), so that the coincidence of the distribution of coal fuel cycle impacts with the distribution of threatened or endangered species can be studied. Alternatively, the measured biological effects of estimated levels of pollutants (e.g., ppm of suspended solids, concentrations of metals, or particular $\mathrm{pH}$ values) can be coupled with information about biological resources (e.g., abundance or yield to the fishery) to estimate a reduction in the resource. Because biological populations are highly variable from site to site, this approach would best be applied to either a specific site (for which the species and numbers are known) or a hypothetical case study (in which reasonable values that reflect regional resources are assumed).

The emissions of $\mathrm{CO}_{2}, \mathrm{~S}$, and $\mathrm{NO}_{\mathrm{x}}$ by coal combustion may have significant effects on some aquatic resources. Although beyond the scope of this phase of the study, global warming, which may result from increased concentrations of carbon dioxide, is predicted to increase surface water temperatures, which in turn would change the distribution of commercially and recreationally important fish species. In addition, regional changes in precipitation may lead to droughts, which would reduce the amount of habitat 
available to aquatic biota and limit fisheries production. Potential changes in distribution have been modeled for a few species; see Regier, Magnuson, and Coutant (1990). Impacts would be gradual but widespread.

Acidification of surface waters as a result of acid precipitation could also limit diversity and production of aquatic communities. Although lake acidification experiments indicate that biotic effects of acid rain can be severe, causal linkages between acidic deposition, acidification of surface waters, and the loss of biological resources are poorly quantified on a national or continental scale. As a result, projection of potential impacts to aquatic resources are difficult (DOE 1989).

Atmospheric deposition from coal plants has recently been identified as a principal source of heavy metal pollution in some water bodies (Mitra 1986). No quantitative estimates of biological impacts are available at this time.

\subsubsection{Recreational fishing}

Recreational fishing refers to harvest of fish for sport or for consumption by the fisherman. Recreational fishing is common in ponds, rivers, and reservoirs of the southeast, and is affected by the same sources of impact as commercial fishing. Dozens of species are fished. The most important recreational fisheries in warmwater reservoirs, rivers, and ponds involve the families Centrarchidae (largemouth and smallmouth bass, bluegills, crappie), Ictaluridae (catfishes), Esocidae (pike, muskellunge), and Percidae (perches, walleye, sauger). Striped bass fisheries exist in many large reservoirs. Coldwater streams in the southern Appalachians and on the Cumberland Plateau support fisheries for rainbow trout, brown trout, and brook trout. Recreational fishing is less common in the southwest, however, tailwaters below the major dams on the Colorado River support significant trout fisheries. Cold water fisheries are also important resources outside the regional environments addressed in this study.

Recreational fisheries are subject to the same sources of damage as are commercial fisheries. Compared with commercial fisheries, recreational fisheries are more likely to be located in close proximity to coal fuel cycle activities, and are therefore more likely to be affected by runoff and aqueous effluents than are commercial fisheries. Although exposures to coal-derived contaminants are more easily estimated, recreational fish populations are generally less intensively studied than are commercial stocks, so biological damage may be more difficult to quantify. 


\subsubsection{Hunting}

Hunting refers to noncommercial harvesting of game birds and mammals. These animals can be affected by air and water pollution and by physical disturbances (habitat destruction, noise) related to energy production. Hunting is common on private and public land throughout the southeast and southwest.

Reduced wildlife populations clearly result in reduced hunter success but may not cause significantly reduced hunting activity. Wildlife populations in hunting areas may be reduced by surface mining and may remain at reduced levels until reclamation is fully effective in restoring original conditions, however, little information is available for quantifying the reduction of either wildlife populations or hunting activity. Air pollution resulting from the coal fuel cycle is not likely to have direct toxic effects on wildlife.

\subsubsection{Recreation}

Recreational use of forests and parks refers to nonconsumptive activities such as touring, boating, swimming, hiking, camping, and trail-biking. Recreation can be affected by adverse changes in forest composition or wildlife abundance, by reduced visibility, or by noise and visual impacts of mining or electricity generation. Changes in water quality, related to energy production or other industrial facilities, can affect the recreational value of rivers and lakes, and all rivers and reservoirs in the southeast support intensive recreational use. National forests and the Great Smoky Mountains National Park are also important recreational resources. The southwest contains several important national parks and monuments that are especially vulnerable to reduced visibility due to haze formation.

\subsubsection{Biodiversity}

The term "biodiversity" has been defined in many different ways. Biodiversity and the threats to it were recently discussed in the proceedings of the National Forum on Biodiversity (Wilson 1988). We define impacts on biodiversity to include all ecological effects not directly related to exploitation or recreational use. Specific impacts addressed in this project include (1) those to threatened or endangered species or legally protected systems (e.g., Wild and Scenic Rivers), and (2) those to other aesthetically valued natural ecosystems (e.g., wetlands, pine barrens, bogs) of the types that are protected by organizations such as the Nature Conservancy. Although greatly affected by civilization, the southeastern United States still supports a number of endangered and threatened species as well as relict examples of a number of 
previously common ecosystem types. Despite similar human influence, the southwest continues to sustain moist riparian habitats as especially important reservoirs of biodiversity.

To some degree, emissions from all components of the coal fuel cycle can affect biodiversity. Because biodiversity (as used here) reflects non-use aspects of the environment, this is one category for which physical habitat destruction can lead to external costs based on existence values.

\subsection{QUANTIFICATION METHODS}

In general, there are three types of approaches to deriving quantitative relationships between levels of environmental stress and ecological responses: empirical modeling, mechanistic (or process) modeling, and expert judgement. The appropriate choice for a given circumstance depends on the quantity of data available, the degree of understanding of underlying processes, the similarity of the new situation to previous situations, and the amount of extrapolation required beyond existing conditions.

Empirical relationships are relationships derived through statistical analysis of measured data. In ecology, statistical models, including regression analysis, discriminant analysis, and other multivariate techniques, are often used to summarize and interpret field observations (Green 1980). In environmental impact assessment, statistical models are a fundamental component of the design of monitoring programs to detect differences between (1) control and affected sites (Thomas 1977, Loehle and Smith 1990) and (2) pre-impact and post-impact observations (Vaughan and Van Winkle 1982, Loehle and Smith 1990). In assessments of impacts of acidification on surface waters, empirical models have been used extensively to extrapolate from observations on subsamples of lakes and streams to impacts on regional surface water resources (Baker et al. 1990). Empirical models have also been used to estimate reductions in regional crop yield due to $\mathrm{O}_{3}, \mathrm{SO}_{2}$, and $\mathrm{NO}_{2}$ (Shriner et al. 1990).

Empirical models do not explain observations in terms of causal relationships between the independent and dependent variables; they simply summarize observed relationships between variables. Such models can be used for predictive purposes (e.g., predicting responses of crop production to air pollution), provided that (1) independent evidence of causal relationships is established, and (2) the range of expected stress and response levels lies within (or at least close to) the range over which the observations used to develop the model were made. These conditions were met in both the surface 
water and crop-yield examples above. In many important assessment problems, however, empirical modeling is inadequate or unfeasible. In assessments of the ecologica? effects of global climate change, for example, the major interest is in predicting long-term responses to climatic regimes well outside of the historically observed range. Long-term management of fisheries (Walters 1986) and prediction of environmental responses to PCB remediation (Limburg 1986) are similarly inappropriate for empirical modeling.

As an alternative, dose-response relationships may be estimated using mechanistic models derived from the fundamental principles of physics and chemistry. The purpose of a mechanistic model is to describe in quantitative terms the relationship between some phenomenon and its underlying causes. Whereas in a statistical model the fitted coefficients such as the slope and intercept of a regression line have no intrinsic meaning, the parameters in a mechanistic model have real operational definitions and are (at least in principle) amenable to independent measurement. The classical laws of physics, such as Newton's Laws and Maxwell's equations, are mechanistic models. Contaminant transport models used to predict deposition patterns or concentrations of contaminants in terms of the physical and chemical processes are also mechanistic.

Mechanistic models can be generally categorized as (1) steady-state models that predict a final endpoint (e.g., surface water chemistry) given certain inputs (e.g., atmospheric sulfur deposition) and known geochemical relationships, without regard to the time it takes for the changes to occur, and (2) dynamic models that take into account factors such as rates of change that indicate how long it will take to reach an endpoint, or what pathway it may follow to get there. Dynamic models provide more information concerning responses to stress, but predictions about steady states are usually more reliable. Examples of mechanistic models used in acidic deposition assessment of aquatic effects include the MAGIC and ILWAS models and others described by Thornton, Marmorek, and Ryan (1990). Kiester et al. (1990) discuss mechanistic models used for predicting effects of air pollutants on trees and crops, and Walters (1986) has discussed the use of mechanistic models of fish population dynamics in fishery management.

If the mechanisms are correctly represented, and the parameters have been adequately measured, then predictions should be possible outside as well as within the range of observations. However, the degree of validity of mechanistic models is often unknown. Empirical approximations and simplifying assumptions are always required, and experimenial or observational testing of assumptions and predictions is often impossible. For this reason, there is no clear-cut rule for selecting between empirical and 
mechanistic approaches to prediction. If data are limited or large extrapolations are required but causal mechanisms are reasonably understood, mechanistic modeling may be preferable. If a large amount of relevant data exist and extrapolation beyond the range of observations is not required, then empirical approaches may be superior. If both large data sets and mechanistic understanding exist, then mechanistic models may again be preferable, but this is a matter of judgment.

In many cases data and understanding are insufficient to support either empirical or mechanistic prediction. For these situations, subjective stressresponse relationships derived from expert judgement provides a third means of characterizing stressor-response relationships. For example, existing data are insufficient for developing rigorous statistical estimates of the decline in forest productivity per unit ozone or sulfur released. However, experts in plant physiological ecology could probably use the large data base for crops, together with general understanding of the differences between crop plant and tree physiology, to develop simple coefficients for use in impact assessments.

All three approaches to prediction will be required to assess the ecological consequences of alternative fuel cycle technologies. Particularly well-understood effects, such as effects of air pollutants on crops, and the effects of acid deposition on water quality and fish community structure, will be quantified using existing empirical and mechanistic models. Poorly documented effects, such as changes in biodiversity or recreational opportunity will be addressed through expert judgement. Intermediate cases, such as effects of acid mine drainage or aqueous effluents on fish production, will employ mixes of modeling and expert judgement.

\subsection{REFERENCES}

Baker, J. P., Bernard, D. P., Christensen, S. W., and Sale, M. J., 1990. "Biological Effects of Changes in Surface Water Acid-Base Chemistry," NAPAP Report 13, Acidic Deposition: State of Science and Technology. National Acid Precipitation Assessment Program, Washington.

Cushman, R. M., Gough, S. G., and Moran, M. S., 1980. Overview of the Effects of the Coal Fuel Cycle on Hydrology, Water Quality and Use, and Aquatic Ecology, ORNL/TM-7152, Oak Ridge National Laboratory, Oak Ridge, Tenn.

Dvorak, A. J., Brown, C. D., Dettman, E. H., Hinchman, R. A. Jastrow, J. D., Kornegay, F. C., LaFrance, C. R., Lewis, B. G., Lundy, R. T., Olsen, R. D., Parker, J. I., Pentecost, E. D., Saguinsin, J. L., and Vinikour, W. S., 1977. The Environmental Effects of Using Coal for Generating Electricity. NUREG-0252. Argonne National Laboratory, Argonne, Ill. 
Dvorak, A. J. and Lewis, B. G. (eds.), 1978. Impacts of Coal-Fired Power Plants on Fish, Wildlife, and Their Habitats, . FWS/OBS-78/29, U.S. Fish and Wildlife Service, Washington.

Green, R. H., 1980. "Multivariate Approaches in Ecology: the Assessment of Ecological Similarity," Annual Review of Ecology and Systematics 11,1-14.

Haynes, R. J., McBrayer, J. F., Cushman, R. M., and Roop, R. D., 1979. Environmental Impacts of Coal Extraction in Alabama: 1978-85. ORNL/TM-6793, Oak Ridge National Laboratory, Oak Ridge, Tenn.

Heck, W. W., Heagle, A. S. and Shriner, D. S., 1986. "Effects on Vegetation: Native Crops, Forests," pp. 247-350 in A. S. Stern (ed.) Air Pollution, vol. 6, Academic Press, Inc., N.Y.

Honig, R. A., Olson, R. J., and Mason, W. T. Jr. 1981. Atlas of Coal/Minerals and Important Resource Problem Areas for Fish and Wildlife in the Conterminous United States. FWS/OBS-81/06, U.S. Department of the Interior, Washington.

Kiester, A. R., Droessler, T. D., Amateis, R., Avery, A., Barton, C., Bassow, S., Beloin, R., Burkhart, H., Chen, C., Cothern, S., Dougherty, P., Ford, E. D., Ford, R., Gherini, S., Gomez, L., Jarvis, P., Ladd, L., Teskey, R., Webb, C., and Weinstein, D., 1990. "Development and Use of Tree and Forest Response Models," NAPAP Report 17, Acidic Deposition: State of Science and Technology, National Acid Precipitation Assessment Program, Washington.

Kroodsma, R. L. and Van Dyke, J. W. 1985. Technical and Environmental Aspects of Electric Power Transmission, ORNL-6165, Oak Ridge National Laboratory, Oak Ridge, Tenn.

Langford, T. E. 1983. Electricity Generation and the Ecology of Natural Waters, Liverpool University Press, Liverpool, England.

Lee, J. M. Jr. et al., 1989. Electrical and Biolcgical Effects of Transmission Lines: $A$ Review. DOE/BP-945, U. S. Department of Energy, Washington

Limburg, K. E., Moran, M. A., and McDowell, W. H., 1986. The Hudson River Ecosystem, Springer-Verlag, N.Y. 
Loehle, C., and Smith, E. P., 1990. "An Assessment Methodology for Successional Systems. II. Statistical Tests and Specific Examples," Environ Manage 14,259-268.

Mitra, S., 1986. "Mercury in the Ecosystem: Its Dispersion and Pollution Today," Technomic: Lancaster PA.

National Acid Precipitation Assessment Program (NAPAP), 1990. "Integrated Assessment External Review Draft, August/September 1990," National Acid Precipitation Assessment Program, 722 Jackson Place, NW, Washington.

Regier, H. A., Magnuson, J. J., and Coutant, C. C., 1990. "Introduction to Proceedings: Symposium on Effects of Climate Change on Fish," Transactions of the American Fisheries Society 119(2),173-175.

Samuel, D. E., Stauffer, J. R., Hocutt, C. H., and Mason, W. T. Jr. eds., 1978. Surface Mining and Fish/Wildlife Needs in the Eastern United States. U.S. FWS, FWS/OBS-78/81.

Schubel, J. R. and Marcy, B. C. Jr., 1978. Power Plant Entrainment: $A$ Biological Assessment, Academic Press, Inc., N.Y.

Shriner, D. S., Heck, W. W., McLaughlin, S. B., Johnson, D. W., Irving, P. M., Joslin, J. D., and Peterson, C. E. 1990. Response of Vegetation to Atmospheric Deposition and Air Pollution, National Acid Precipitation Assessment Program, State of Science and Technology, Report 18 (NAPAP SOS/T 18).

Thomas, J. M., 1977. "Factors to Consider in Monitoring Programs Suggested by Statistical Analysis of Available Data," pp. 243-255 in W. Van Winkle (ed.), Assessing the Effects of Power-Plant-Induced Mortality on Fish Populations, Pergamon Press, N.Y.

Thornton, K. W., Marmorek, D. R., and Ryan, P. F. 1990. "Methods for Projecting Future Changes in Surface Water Acid-Base Chemistry," NAPAP Report 14, in Acidic Deposition: State of Science and Technology, National Acid Precipitation Assessment Program, Washington.

DOE (U.S. Department of Energy), 1981. Energy and Water Resources, DOE/EV/10154-4, Washington. 
DOE (U.S. Department of Energy), 1989. Final Programmatic Environmental Impact Statement, Clean Coal Technology Demonstration Program. DOE/EIS-0146, Washington.

Vaughan, D. S., and Van Winkle, W., 1982. "Corrected Analysis of the Ability to Detect Reductions in Year-Class Strength of the Hudson River White Perch Population", Canadian Journal of Fisheries and Aquatic Sciences 39,782-785.

Vogel, W. G., 1981. A Guide for Revegetating Coalmine Soils in the Eastern United States, U.S. Forest Service General Technical Report NE-68.

Walters, C. J., 1986. Adaptive Management of Renewable Resources. McGrawHill, N.Y.

Wilson, E.O., ed. 1988. Biodiversity, National Academy Press, Washington. 


\section{IDENTIFYING HEALTH IMPACTS FROM THE COAL FUEL CYCLE}

This chapter provides a brief overview of potential health impacts of the fuel cycle phases and describes the basic sources of information and methods for evaluating health impacts and the three steps involved. Also in this chapter, selected literature is evaluated for emissions and health impact categories and a set of health impact endpoints recommended. In future work, this information will be augmented to include a greater level of detail for each health endpoint and will include a proposed exposure-response relationship that can be credibly used in the assessment. In the latter stages of this project, the exposure-response relationship, along with detailed data on the reference site, will be used to quantify the impacts of concern; these in turn will be used to calculate the health effects portion of the external costs (i.e., numbers of persons with a particular effect resulting from exposure to a particular pollutant).

This chapter is not a state-of-the-art literature review, which is forthcoming, but rather uses selected studies to identify impacts and methodologies. An overview of the coal fuel cycle from the health impact perspective will be presented, followed by discussions of health impact needs relative to emissions, transport of the pollutant source to the receptors, and general exposure-response relationships. Potential health endpoints will then be presented along with a general discussion of sources of data and models that could be used to quantify these endpoints. All models and data contain uncertainty, so the topic of uncertainty will be reviewed for its relevance in both previous and present efforts to evaluate incremental damages.

\subsection{HEALTH RESOURCES AND THE COAL FUEL CYCLE}

Previous attempts to examine the health impacts of the coal fuel cycle have been rather limited in scope. Efforts have focused largely on evaluating occupational deaths and injuries. A few authors have attempted to estimate health impacts to members of the public for the generation phase of the fuel cycle. These estimates usually focused on only $\mathrm{SO}_{x}, \mathrm{NO}_{x}, \mathrm{O}_{3}$, and particulates. In addition, the previous emphasis on occupational health effects will be of limited usefulness to the current study except to the extent that these effects can be considered external to existing wage and benefits agreements.

The following narrative briefly describes the stages of the coal fuel cycle as they pertain to potential health impacts. As the study progresses, the 
relative importance of stages or pollutants within stages may take on slightly different perspectives, in which case this document will be updated.

\subsubsection{Coal Mining}

Both surface or underground mining methods are subject to mining accidents resulting in injuries or death. Additionally, miners are exposed to dust and engine fumes and in underground mining, radon gas. The traditional coal mining diseases, black lung (pneumoconiosis) and progressive massive fibrosis, are accounted for in the cost of coal to the extent that wages and benefits reflect the identified health risks, ${ }^{1}$ but other impacts such as those from exposure to engine fumes and radon may not be. Radon impacts have received scant attention. Further, the extent to which disabled miners have been supported by the coal industry has not been addressed in previous studies of external costs.

Exposures to members of the public are limited to engine fumes, storm water runoff, and acid or alkaline drainage. Federal and local statutes have resulted in better dust control in recent years. Engine fumes dissipate quickly and are produced in only small amounts, so their effects should be minor in an overall analysis. Storm water runoff and acid or alkaline drainage may affect a small number of people, either directly through drinking water or indirectly. Surface water could become so acidic that certain sources would be unusable. Likewise, trace metals in areas disturbed by mining may reach toxic levels in water or the food chain. Finally, although the radon $\left({ }^{226} \mathrm{Ra}\right)$ content of coal is comparable to that of natural soil, the effect of acid or alkaline leaching on radon mobilization is poorly understood. Changing the $\mathrm{pH}$ of natural waters could increase exposures to natural radioactivity and toxic metals through indirect pathways of exposure. For example, one indirect means could be the food supply. In some remote areas, fish are a major source of protein.

\subsubsection{Coal Cleaning and Beneficiation}

Coal cleaning and beneficiation may be performed physically or chemically. Based on our evaluations to date, effluents should be qualitatively

\footnotetext{
${ }^{1}$ Compensation and benefits vary considerable from state to state and company to company. In a review of the situation in one east Tennessee county, Watson (1984) determined that the annual cost for supporting disease-disabled miners exceeds that of operator payments into the Black Lung Benefits Trust Fund by a factor of five. Also, further evidence suggests that large external costs may be associated with mining, the Social Security Administration and the U.S. Department of Labor have verified that the coal industry paid only $0.03 \%$ of all black lung compensation between 1970 and 1979 (OTA, 1979). Supporting disease-disabled miners may be among the greatest external costs for coal technology.
} 
similar to those resulting from mining. Hazards and direct impacts to occupational personnel from coal cleaning and beneficiation should be less minor than those for mining. Beneficiation would create wastes containing sulfur compounds, natural radioactive materials, and toxic trace metals. Especially in areas with abundant rainfall, these materials could leach into nearby surface water, where even a small quantity of ${ }^{226} \mathrm{Ra}$ could cause a significant radiological impact (Gotchy 1987). As with mining, public health impacts from leaching caused by coal cleaning and beneficiation have not been explored in much detail.

\subsubsection{Transportation}

Health impacts from coal transportation would result mostly from accidents, some of which would involve members of the public. Other than accidents, most of the effects on workers would derive from operation of heavy machinery (resulting in constant vibration). Effluents would result mostly from transportation engines and would be qualitatively similar to the generation stage but much less extensive.

\subsubsection{Generation}

Operation of a power plant would result in occupational accidents and a wide range of effluents to the atmosphere. Effluents generally include trace elements (many of which are carcinogens, radioactive, or otherwise highly toxic) found originally within the raw coal, hydrocarbons (as products of incomplete combustion of coal, which can be carcinogens), and combustion gases. (A large portion of these individual effluents would be such small concentrations that they would have negligible influences on human health.) Historically, studies of health impacts from coal have focused on the combustion gases, primarily $\mathrm{NO}_{x}, \mathrm{SO}_{x}$, and $\mathrm{CO}$. Gaseous effluents also are precursors for additional hazardous substances such as ozone and acidic aerosols. Combined, gaseous products are associated with a wide range of health endpoints, from the most insignificant cough to possibly premature mortality. Many trace elements are known or suspected carcinogens; hazards from uncovering naturally occurring radioactive materials and producing wastes from incomplete combustion can range from slight to very high.

The generation stage is also associated with a large coal pile as well as a large waste stream. The principal exposure from these sources is through water runoff, where the water would carry products from coal, acidic or alkalinie materials, organic compounds, and trace metals. Organic materials would include carcinogens; metals include carcinogenic trace heavy metals and radioactive elements. In addition, radon gas would emanate from the piles. 
Literature from which the extent of health impacts from these sources can be inferred is very sparse.

\subsubsection{Transmission and Distribution}

Transmission and distribution refer to moving electrical energy from the location of generation to the location of use. Transmission and distribution are accomplished through the use of metal conductor wires carrying electrical currents. The distribution and use of electrical energy result in production of electric and magnetic fields. These fields surround conductor wires and may be detected beyond the rights-of-way boundaries. Persons may be exposed to these fields because of occupation or casual proximity to transmission or distribution sources. Experts disagree on the potential effects of electric and magnetic fields. At the present time, the U.S. Environmental Protection Agency is reviewing literature to develop a hazard designation of electric and magnetic fields. Information is unavailable to derive an exposure-response relationship at this time.

\subsection{PROCEDURES FOR CALCULATING HEALTH IMPACTS}

Estimation of the type and number of health impacts from the various stages of the fuel cycle just briefly reviewed requires an understanding of the hazard, the pathways by which humans may come into contact with the hazard, and humans' biological response to the hazard, once exposed. Two broad categories may be identified for segregating effects: accidents and health effects. Each of these categories may have affected persons who fall under the definition of "external effects" as well as persons who, though affected by the technology, are compensated by existing wage and benefits agreements.

In the health impacts literature, the most well categorized impacts are accidents. Accidents mostly affect persons engaged in handling the coal and are often expressed in days of work lost. Actuarial data are usually available to support analyses. Health impacts from accidents are internalized to the extent that they occur to persons employed in the hazardous activity and wages and that benefit plans reflect these risks; occupational accidents will be further examined as the project proceeds.

The least well categorized impacts are the health effects that result from exposure to pollutants associated with one or more phases of the fuel cycle. Because actions taken today may result in environmental consequences throughout a long period of time (decades or more), we must make a decision 
on the time aggregation of effects for our assessment. For example, slag waste contains toxic metals and ${ }^{226} \mathrm{Ra}$. Because of its chemical and physical form, however, leachate and emissions from the slag may not affect people until many (i.e., 50 to 100) years after its production. Then, it may continue to be hazardous for hundreds of years. A precedent has been set for dealing with this type of situation for radioactive materials but not for stable toxic materials. A critical need exists for this project to develop a strategy for incorporating such long-range effects into cost analyses. Health effects may occur for either occupational personnel or members of the public; the effects may be acute (with an expression of biological response soon after a shortterm exposure) or chronic (with an expression of disease after a protracted period of exposure and possibly many years after the exposure period has ceased) and may range in seriousness from conditions of which the affected individual is unaware to death. Specific effects (biological endpoints) will be discussed in Section 4.3. In the remainder of this section, we will discuss the three main elements required to arrive at an estimate of health impacts.

\subsubsection{Source Terms}

Initial detailing of the emission characteristics of all of the stages in the fuel cycle is required. Emission characteristics will need to include all major effluent constituents, their rates of release, and their chemical and physical forms. The presently available emissions and burdens (i.e., source terms) are a start but will require expansion. It is inadequate, for example, to have just a notion of the total mass of hydrocarbons in the generation effluents. These materials exhibit a wide range of chemical forms and toxicities. Thus, to assist our efforts in characterizing health effects, we expect, for example, that emission characteristics will be developed in more detail. To evaluate those health impacts, we must have a better definition of hydrocarbon classes, or at least, an identification of the most prevalent chemicals. Particulates must be described in terms of size distribution. Finally, naturally occurring radioactive materials in the effluents may also be important and warrant a column in the emissions matrix.

Once emission characteristics of combustion are developed, they must be followed through the various pathways to the point of human exposure. Impacts from specific source terms depend on exposed populations. In addition to the immediate combustion source term, which is limited to atmospheric releases, toxic materials leaching from the several sources of waste ash and from slag. These materials can contain much higher concentrations of toxic metals and naturally occurring radioactive elements than the original coal and may, by their physical and chemical form, be subject to low release rates initially. However, analysis of health effects needs to 
consider these sources of exposure. Considerable additional source term descriptions for the fuel cycle are required.

\subsubsection{Transport}

Transport characteristics, a critical link in health impact evaluations, include all pathways for the effluents (source terms) to reach humans. ${ }^{2}$ The major pathways include air, water, soil, and the food chain. In addition to physical transport, chemical and biochemical transformation, concentration in plants or animals, and the production of secondary products may contribute significantly to the overall estimate of health effects. Most pollutants will have different transformation and transport rates for each pathway. Classes of health effects are numerous and include direct health effects and indirect health effects. Direct health effects include those related to exposure to ambient air, water, or food contaminated by the pollutants or reaction products of the pollutants (e.g., ozone). Indirect health effects (Grant et al. 1990) include those arising from the influence of acidic deposition on water quality in streams, lakes, other bodies of water, cisterns, and drinking water supply pipes (e.g., through $\mathrm{pH}$ changes, etc). These include health effects ultimately caused by (1) the mobilization of pollutants (mainly metals) from soils or sediments into bodies of water and their entry into the human food chain and (2) the leaching of pollutants from pipes or other drinking water sources consequent to acidic deposition phenomena.

Two general methods are available for providing the "transport to receptor" link: mathematical models and measurement. Measuring pollutants in the environment is a good way to identify pathways from emitter to receptor when the pollutant has a unique source. However, pollutants associated with the coal fuel cycle are also derived from a wide range of other human activities and endogenous sources. The multiple sources for the pollutants with which we are concerned and the inability of measurement to distinguish between these sources cause us to rely on mathematical modelling to determine source-to-receptor links. However, no generalized transport models are available for all of the effluents and pathways that will be present during the coal fuel cycle. In fact, significant efforts in previous studies of fuel cycle externalities have focused only on the inhalation pathway, primarily for gaseous pollutants. Nonetheless, there is a significant body of literature from which to draw.

\footnotetext{
2 In many assessments of health impacts, where environmental releases have point sources of origin, it is appropriate or required that the highest exposed individual be identified and the exposure characterized in detail. This analysis will focus on population effects, not necessarily the most sensitive individuals. To that end, more effort should be focus on developing the information that would allow an accurate assessment of exposure to large numhers of people rather than a precise assessment for the sensitive group or individual.
} 
Mathematical models use systems of equations to quantify and explain the relationship between air-pollutant concentrations and important variables such as emission rates from contamination sources. These models are derived from a knowledge of atmospheric dispersion and, sometimes, knowledge of important chemical and physical interactions as well as from assumptions and approximations that permit complex physical-chemical reactions to be represented by mathematical formulations. (The physical-chemical behavior of the pollutants we have in the source terms depends on the ambient conditions. The temporal characteristics of ambient conditions may be relatively important in the production of health impacts, especially for the $\mathrm{NO}_{x}, \mathrm{SO}_{x}, \mathrm{O}_{3}$, and particulates. Therefore, this assessment will require atmospheric modelling assistance by personnel familiar with the chemistry issues.) Atmospheric transport models can be classified into two broad categories: those that predict exposure (in units of concentration multiplied by time) and those that predict concentration (in units of mass per unit volume).

Atmospheric transport modelling has traditionally focused on predicting pollutant concentrations in outdoor air at required distances and times. One problem, that arises for our application is that the majority of people spend more time indoors than out. However, with the exception of a few of the criteria pollutants, little is known about the relationship between indoor air quality and outdoor air quality. More work is needed to model the relationship of indoor-air quality to the composition of outdoor air for coal and other fuel cycles.

Previous attempts to quantify costs associated with fuel cycles have focused on the inhalation pathway for the coal fuel cycle. The gaseous emissions are clearly important in the inhalation pathway of exposure. However, an examination of the effluents from incineration of hazardous wastes suggests that, at least for some of the pollutants, such as some heavy metals and polyaromatic hydrocarbons, the major pathway to humans may be through the food chain (Travis et al. 1986). The degree to which the food chain influences health impacts depends to a great degree on the proportion of food grown in the region to be examined. The types and quantities of foods produced in the reference area must be identified. Information about the distribution of food producers will be needed, not information about the person nearest the facility.

\subsubsection{Sources of Exposure-Response Information}

Once the source term characteristics have been identified and the materials have been transported to the point of human exposure, the issue of identifying the exposure-response relationships for health impacts becomes 
paramount. For a given exposure, health impact assessment depends on exposure-response information. Information required to convert exposures to biological responses comes from several sources, including in-vitro (cellular) studies, whole animal toxicological assays (in-vivo), and human epidemiological (including clinical) studies. Each of these main categories contains numerous sub-categories. When performing health impact assessments, the information of greatest interest is at the human level and preferably for the conditions of interest. Thus, we would prefer to have human exposure-response studies for exposure levels near the expected level for this assessment and with the same mix of co-exposures; less favorable data would be taken under much higher levels of exposure or taken otherwise out of context. Out of context refers to conditions that are very different from the exposure conditions to be analyzed. For example, if the human exposure to be analyzed is a mixture of $\mathrm{NO}_{2}, \mathrm{SO}_{2}, \mathrm{O}_{3}$, acid aerosols, and PM-10 but the data are taken in a clinical setting, with $\mathrm{O}_{3}$ being the only chemical under study, the conditions are clearly very different. The data are certainly valuable, but we would have to make a series of assumptions to apply the data to our evaluation context. Assumptions could include a variety of factors such as independent action of pollutants and similarity of response between the subjects providing the data and the persons to be assessed.

Epidemiological studies are concerned with the patterns of disease in human populations and the factors that influence these patterns (Lilienfeld and Lilienfeld 1980). In general, scientists view well conducted epidemiological studies supported by physiological analysis as the most valuable source of information from which to draw inferences about human health risks. For example, a study of chemical carcinogens conducted by the Office of Science and Technology Policy came to the conclusion that "a positive finding in a well-conducted epidemiological study can be viewed as strong evidence that a chemical poses a carcinogenic risk to humans" (OSTP 1979).

Unlike the other approaches (in vitro and laboratory animal studies), epidemiological methods can be used to study the direct effects of hazardous substances on human beings. Epidemiological studies also help identify actual hazards to human health without prior knowledge of disease causation and can complement and validate information about hazards generated by animal laboratory studies. Compared with other techniques used in risk analyses, epidemiology is relatively well suited to situations where (1) exposure to the risk agent is high (such as cigarette smoking), (2) adverse health effects are unusual (such as rare forms of cancer), (3) the symptoms of exposure to the risk agent are known, (4) the link between the causal risk agent and adverse effects in the affected population is direct and clear, (5) the risk agent is 
present in the bodies of the affected population, and (6) high levels of the risk agent are present in the environment (e.g., in the soil or drinking water). However, many of the environmental health risk agents currently subject to regulatory and societal concern do not fall into these categories. As a result, epidemiological studies used in risk analysis have important limitations that constrain their usefulness. These limitations arise not from epidemiology per se but rather from the nature of the specific risk analysis needs to which epidemiology is sometimes applied. For example, one limitation of epidemiological studies is that they can be conducted only for hazards to which people already have been exposed. They generally are not useful for predicting effects of new substances or technologies that have previously unstudied emissions. Notwithstanding these potential limitations, several pollutants of interest to our evaluation, notably sulfates, ozone, $\mathrm{NO}_{\mathbf{x}}$, particulates, and $\mathrm{CO}$, have been the focus of epidemiologic study, often in both the clinical and environmental settings.

A second limitation of epidemiology is the lack of experimental controls. For obvious moral, ethical, and practical reasons, researchers can neither control nor account completely for subjects' behavior which may affect their health and therefore influence the study results. To the extent possible, "control" or "unexposed" populations are identified and used in most such studies. However, true controls, in the laboratory sense cannot be achieved. A third limitation is that epidemiological studies may fail to account for the effects of multiple sources of exposure. If both the experimental and control groups in a study (of a chemical in the water supply, for example) are exposed to a risk agent from another unidentified source or medium (such as air), the study results midy not show an association although one is actually present.

A final limitation of epidemiological studies is that they have poor sensitivity and are generally unable to detect small increases in risk unless very large populations are studied. At low exposure levels, adverse effects or false positives may be very difficult to detect. For example, to identify any change in the number of genetic defects that could be caused by one additional $X$ ray (which causes a 3-mrem dose) per person per year, a study would need to observe a population of approximately 700 million people for three generations. Even then, a positive result would not prove 100 percent certainty of harm, and a negative effect would not prove certainty of zero risk.

In spite of the desirability of human data, most toxicological information is obtained from animal bioassays. One is then immediately faced with the need to extrapolate results from animal to humans. Further, larger doses (than expected ambient levels) are generally used in animal studies to elicit toxic effects at levels and frequencies which are measurable in a limited 
4. Health Impacts

number of animals. For example, to study an adverse effect at a low concentration level which might affect one animal in 1000 would require several thousand animals to be studied for the risk to be measured with precision for each exposure condition. Such resources are rarely available for toxicological studies. Hence, higher exposures are used in animal studies to measure high levels of risk, which can be accomplished with adequate precision with perhaps 50 animals of each sex and two species. This creates the problem of extrapolating results to lower doses to estimate the risks that might occur in humans exposed to much lower concentrations. Such studies also require a conversion to a human equivalent exposure. Extrapolation to humans and extrapolation to low exposure levels are subjects of considerable interest in risk assessment (Gaylor 1988) and inevitably lead to the introduction of additional uncertainties.

In the past decade, there has been explosive increase in the quantity, variety, and quality of laboratory tests using in vitro cell and tissue cultures to study the effects of risk agents on biological organisms. (In vitro literally means "in glass." In our context, this term is meant to signify a biological test that can be conducted in a test tube or other experimental container. Thus, in vitro tests do not use live or whole animals.) This increase has resulted primarily from (1) demand for quicker and less expensive techniques to screen chemicals for potentially adverse effects; (2) rapid and revolutionary advances in biological techniques for manipulating genetic material, monitoring cellular behavior, and initiating tissue culture growth; and (3) pressure from animal welfare activists and others to develop alternatives to live animal assays.

The predictive value of in vitro genetic toxicity tests for carcinogenicity tests in vivo is controversial. Most of the debate has centered around the predictive value of the Ames test, which is the most widely used mutagenicity assay. (In vivo literally means "in life." Thus, an in vivo test would be one with a whole, live animal.) A report on the in vivo and in vitro test results of 73 chemicals studied in the National Toxicology Program (Tennant 1987) revealed that $83 \%$ of chemicals with positive Ames tests results were also rodent carcinogens. However, $51 \%$ of the chemicals with negative results were noncarcinogens. In general, the accuracy of in vitro tests for carcinogenicity is compromised by (1) the lack of direct correspondence between mechanisms of genetic toxicity used in the assays and current understanding of carcinogenesis; (2) the difficulty of extrapolating from simple cellular systems to complex, higher organisms; and (3) a long list of differences between whole cells and laboratory animals. On a brighter side, Glass et al. (1991) recently completed a study suggesting that short-term in-vitro assays 
could be used to rank carcinogenic potencies similarly to long-term animal assays. Using a similar perspective, Jones et al. (1988) have developed a method for ranking toxicity that uses both in vitro and in vivo data.

\subsubsection{Previous Assessments of Fuel Cycle Impacts}

Many studies have attempted to compare health impacts of air pollutants deriving from different fuel cycles. Selected examples include: Hamilton (1974); Morgan et al. (1978); Morris et al. (1979); Inhaber (1979); El-Bassioni (1980); OECD (1982); NAS-NRC (1982); Novak, Bozzo, and Hamilton (1984); Gotchy's analysis reported in NUREG-0332 (1987); EPRI (1987); Holdren (1987); Fritzsche (1989); Cox and Ricci (1990); Ottinger et al. (1990); and Senior Expert Symposium (1991). Thus, one might assume that exposure-response models for health effects from various fuel cycles are reasonably well known and adequately catalogued. However, many of the studies have focused on premature death or days of life lost due to accident or injury. These are, for the most part, internal costs and are embodied in the discussion of accidents.

Few of the studies listed above have attempted to consider other health endpoints or even potential health effects from environmental contaminants beyond one or a few nonradiological pollutants. Morgan et al. (1978) describe "A Probabilistic Methodology for Estimating Air Pollution Health Effects from Coal-Fired Power Plants" in which they limited their discussion to mortality effects from sulfur air pollution and more specifically to the effects from power plant-generated sulfates. While Morgan et al. (1978) focus on sulphur emissions, they cautioned readers to remember that significant mortality may also result from nitrates, heavy metals, and interaction among power plant effluents and with other pollutants in the environment.

Ricci (1990) discusses epidemiological studies and analyses upon which risk coefficients for fossil pollutants are based. In reviewing existing epidemiological studies and related analyses, Ricci noted that suspended particulate and at least one form of sulfur compounds were included by almost all researchers; only five included $\mathrm{NO}_{x}$, and only one included ozone. A proxy for smoking was included by only six; three treated trace metals; one included benzo(a)pyrene [B(a)P]; and the socioeconomic, demographic, and other variables ranged from none to more than 10 . Only the few most comprehensive fuel cycle assessments have given any consideration to morbidity or injary. Exceptions include Gotchy (1987) and Fritzsche (1989).

The NRC published a report (NUREG-0332) authored by R.L. Gotchy in 1987 on the "Potential Health and Environmental Impacts Attributable to 
the Nuclear and Coal Fuel Cycles." Work described was first issued for comment in 1977 and seems to have undergone exhaustive review between 1977 and 1987. Potential health effects from the coal fuel cycle were evaluated through mining, benefication and cleaning, transportation, generation, and ash and waste handling activities. This document describes reasonably well (1) knowns, (2) unknowns, (3) and likely associations with regard to health effects deriving from the coal fuel cycle as of 1977.

Previous works on fuel cycle externalities have focused more on what was known already in terms of accident or injury, and no comprehensive evaluation has been made for a wide range of biological endpoints and for the suite of available pathways. A major objective of future work will be to determine if credible source-term pathways and exposure-response relationships can be identified in the literature or if they can be synthesized from the literature.

\subsubsection{Threshold Levels of Pollution}

Many attempts by governments to force the incorporation of externalities into private decision making were frequently driven by the presumption there were threshold levels of pollution, below which there would be no effects, primarily on human health, secondarily on the ecosystem.

The threshold approach has energy policy implications because (1) it may be inconsistent with the current science on dose-response relationships; (2) regulatory lag may imply a continual obstacle for matching science and regulations; and (3) there has been little consideration of how costs and benefits are balanced below the standards.

\subsection{POTENTIAL HEALTH ENDPOINTS}

A wide range of health endpoints may be affected by pollutants from coal-fueled electrical generating plants. These endpoints consist of immediate and unambiguous ones, such as those deriving from accidents, and those of a very subtle nature, such as more frequent coughing. Health endpoints, for our purposes, are those identified through scientific studies on the emissions listed in Fig. 2 of Chapter 2. These studies, both prospective and retrospective, have been performed on humans, and some clinical studies are reported. Other studies have been performed on laboratory animals and cellular systems. For some pollutants, scientists have inquired about a wide range of potential endpoints and it is likely that many pollutants will contribute to several health endpoints in our final analysis. For example, cadmium is 
implicated in cancer, cardiovascular disease, neurotoxicity, developmental toxicity, etc. Studies of health effects from the coal fuel cycle, however, are derived from actuarial information coliected on industrial accidents and occupational disease.

Morbidity (disease state) and mortality (death) rates from occupational exposures occur mostly from black lung (i.e., coal worker's pneumoconiosis), progressive massive fibrosis, and accidents. For occupational exposures, these rates are thought to be the most important (first-order), identifiable and predictable from existing records on exposure, disease and injury or death. (The extent to which these conditions are compensated for in wages and benefits will determine the proportion of these conditions that are "internal.") Thus, many of the important factors of occupational risk or occupational health endpoints are probably well known for mining, benefication, and transportation. Other (second-order) and possibly externalized hazards such as cancer, neurotoxicity, cardiovascular disease, and reproductive disorders may potentially occur but individually are expected to affect fewer people and to be less severe that effects resulting from accidents, black lung and progressive fibrosis.

Collectively, however, the second-order effects may be more important than the first-order effects in terms of total numbers of persons affected and the particular health endpoints. The main source for this information would be additional epidemiological studies of persons employed in the coal supply industries to reveal information on the health effect endpoints of interest. Information for occupational personnel could also be derived through knowledge of levels of exposure to toxic materials on the job and exposureresponse information for these materials. This latter process will also be required for most of the endpoints of interest with respect to members of the public.

Potential health effects from the coal cycle are presented in Table 5. We expect to obtain a considerable portion of our information on accidents and occupational diseases from standard sources of data collection. The key part of our interpretation and projection for accidents and occupational diseases will be to determine the extent to which current rates will continue to the time of interest for this study and the extent to which they are compensated for by wages and benefits.

\subsubsection{Cancer}

There is some degree of controversy as to which compounds are carcinogenic to man. The smallest and most conservative list derives from the 
Carcinogen Assessment Group (CAG) of the Environmental Protection Agency. It is our assessment at this time that many of the hydrocarbons and the trace metals are candidates for evaluation as carcinogens. The CAG evaluations are useful because risk coefficients (exposure-response probabilities) are given and because they serve as the seeds for EPA promulgated statutes. Other lists of carcinogens are likely to include hundreds of substances, but generally risk coefficients are left to the imagination of the user. About 50\% of all substances tested to date are carcinogenic (DHHS, 1989), but we and others have posited that the major consideration is that toxicity-induced compensatory cell proliferation (regeneration of cells killed by the toxic exposure) is likely to potentiate (cause expression of) cancers initiated by other pollutants or spontaneous causes. There is much coutroversy regarding what agents are carcinogenic under which conditions. In spite of the amount of research ongoing and completed, the definition of carcinogens and cancer requires operational definitions; theory and mechanistic understanding are inadequate. Jones, Griffin, and Walsh (1983) discuss how theory and application can be used in risk and hazard assessments. On this basis, a practical relative potency approach is presented by Jones et al. (1983 and 1988).

Chemicals vary $10^{7}$-fold in toxic potency. For this and other reasons described, we used a chemical-scoring system developed for the U.S. Air Force that is currently being used in the Environmental Restoration Program of the U.S. Department of Defense [Fed. Regist. 52 (Pt.222), 44204 (1987); Fed. Regist. 54 (Pt.202), 43104 (1989)]. The method, called RASH (Rapid Screening of Hazard), is well documented for 278 chemicals (Jones et al. 1988). The objective is to use robust statutory concentrations to transfer experience from one chemical to another. In so doing, a more complete picture derives from a series of incomplete overlays. Statutes for chemicals are based on concentrations in air, water, or food. In some instances, the EPA considers an agent carcinogenic only if the agent has been demonstrated to cause cancer by the identical route of exposure. This study will seek to clarify these issues by assessing the literature on effects, such as the case of formaldehyde (Owen et al. 1990). 
Table 5. Potential health effects from the coal fuel cycle

Health effect

Possible source term(s)

Public and Occupational

Accidents

Cancer

Mortality

Respiratory disease

Asthma attacks Irritation symptoms

Respiratory insufficiency

Neurological (including learning deficit)

Cardiovascular

Reproductive

Immunological

Occupational

Mining accidents

Black lung (pneumoconiosis)

Progressive massive fibrosis coal transport, explosions

hydrocarbons, trace metals, radioactive effluents

acidic precipitation precursors, particulates

acidic precipitation precursors, particulates

cadmium, lead

$\mathrm{CO}, \mathrm{NO}_{\mathrm{x}}$ compounds, ozone

lead, ionizing radiations

ozone, heavy metals, hydrocarbons coal transport, explosions

coal dust

coal dust 
Historically, noncarcinogens have been controlled individually and without concomitant interactions with carcinogens [Fed. Regist. 51 (Pt.185), 344014-2 (1986)]. If a chemical is lacking one intrinsic trait needed to be a carcinogen, it has not been permitted to borrow that trait from other pollutants. But, noncarcinogens are commonly used experimentally to promote carcinogenesis initiated by other agents. Historically, incomplete carcinogens have been identified as carcinogens based on epidemiological findings. Dichlorodiphenyl-trichloroethane (DDT), benzene, arsenic, and tetrachlorodibenzo-p-dioxin (TCDD) may be examples. The National Council on Radiation Protection and Units (NCRP 1989) has suggested that promoters induce cell proliferation and support the position of the American Council of Governmental Industrial Hygienists (ACGIH 1989), who note that physical irritation may initiate, promote, or accelerate physical impairment through interaction with other chemical or biologic agents. Many noncarcinogens may thereby eventually be regulated as carcinogens.

\subsubsection{Asthma Attacks (increased airway resistarce), Irritation Symptoms,} Respiratory Insufficiency (breathing difficulty), and Mortality

This discussion is limited to the health effects of the gaseous air pollutants. Principle secondary sources for the discussion in this section are NAPAP State of Science and Technology Report 22, EPA 600/8-88/105A, EPA 600/8-90/045A, and EPA 600/8-88-005A, supplemented with recent publications (e.g., Schlesinger et al. 1990, Pope, 1989). A very large array of pollutants related to acidic precipitation could be considered for direct health effects including the gaseous air emissions, sulfur oxides, particulates, and nitrogen oxides. Although hydrocarbons help produce ozone they are otherwise not considered to contribute to respiratory morbidity.

Most $\mathrm{SO}_{\mathrm{x}}$ compounds in the ambient air result from emissions of sulfur dioxide. The predominant $\mathrm{SO}_{\mathrm{x}}$ compounds in the air include $\mathrm{SO}_{2}$, ammonium sulfate, ammonium bisulfate, and sulfuric acid. The latter two are key components of acidic aerosols. Thus, $\mathrm{SO}_{2}$ and acidic aerosols are selected for our health impact evaluation. Most $\mathrm{NO}_{\mathrm{x}}$ compounds in the ambient air result from the emissions of nitric oxide (NO) or nitrogen dioxide $\left(\mathrm{NO}_{2}\right)$, depending on the source. These emissions undergo transformations, ultimately resulting in the presence of $\mathrm{NO}, \mathrm{NO}_{2}$, nitric acid, nitrous acid, nitrous oxide, nitrites, nitrates, and other $\mathrm{NO}_{\mathrm{x}}$ compounds in the ambient air. 
Photochemical oxidation plays a major role in air quality by causing reactions that result in pollutants of health concern, predominantly $\mathrm{O}_{3} \cdot \mathrm{O}_{3}$ is not related directly to acid precipitation, but its ambient levels are influenced significantly by precursors of acid precipitation, such as $\mathrm{NO}_{\mathbf{x}}$. In addition, if combined with acidic aerosols and $\mathrm{NO}_{2}, \mathrm{O}_{3}$ can be additive or synergistic in causing health impacts.

To facilitate interaction with the valuation part of this project, some of the general findings and endpoints that seem to have relevant scientific support will be enumerated. A great deal of evaluation work must take place before any conclusion is firm or supported by an exposure-response equation. The following endpoints described in the EPA NAPAP Report \#22 reflect results of scientific reports but, in several cases, will not be complete enough to match a defined valuation startpoint. The following points are made in the EPA report and summarized here with some clarification:

1. Epidemiological studies indicate that increased mortality among the elderly, the very young, and individuals with preexisting respiratory disease has been associated with elevated 24-h long acidic precipitation precursor levels in the presence of elevated levels of particulate matter (Mendelsohn and Orcutt 1979; Ozkaynak and Spengler 1985; Ozkaynak and Thurston 1987). Analyses of epidemiology data from London during the 1950s to 1970s indicate that acute exposures to acidic aerosols in air pollutant mixtures were likely associated with increased mortality and morbidity. More recent epidemiologic evaluations also suggest, but have not clearly demonstrated, that acute or chronic exposures to more contemporary air pollutant mixtures containing acidic aerosols may be associated with increased morbidity and, perhaps, mortality. This issue is receiving considerable scrutiny because of the particulars of both data and analyses used in the major studies as well as the potentially large external costs.

2. Short-term peak levels of $\mathrm{SO}_{2}$ may pose some risk to asthmatics. The health implications of this risk vary, but typically include breathing discomfort during exercise and other symptoms that may result in the need to discontinue exercise and, in some cases, the need for medication.

3. Acute experimental exposure to acidic sulfates, primarily $\mathrm{H}_{2} \mathrm{SO}_{4}$, can cause pulmonary function changes and reactivity responses in some asthmatics. 
4. Acute experimental exposure to $\mathrm{H}_{2} \mathrm{SO}_{4}$ can alter mucociliary clearance of the lungs in normal and asthmatic humans, and chronic exposures can alter it in animals.

5. There is some experimental evidence to suggest that chronic exposure to $\mathrm{H}_{2} \mathrm{SO}_{4}$ or to elevated acidity may contribute to the development of chronic bronchitis.

6. Acute ozone exposures cause trarsient decrements in pulmonary function that result in rapid, shallow breathing and a decrease in the ability to inspire maximally. Other symptoms related to ozone are cough, pain upon deep inspiration, and nose and throat irritation.

7. Acute exposures to ozone can cause lung inflammation.

8. Acute exposure to ozone can decrease host defenses against infectious respiratory disease.

9. Animal studies have shown that chronic exposure to ozone can cause chronic changes in the lungs, raising significant concern about the potential for the causation of chronic lung disease in humans.

10. Acute exposure to elevated levels of $\mathrm{NO}_{2}$ may alter airway responsiveness to a variety of nonspecific stimuli (e.g., cold air, histamine, and a bronchoconstrictor drug) in some asthmatics. $\mathrm{NO}_{2}$ can also affect pulmonary function in these subjects.

11. The results of some epidemiological studies have demonstrated an association between long-term $\mathrm{NO}_{2}$ exposure and an increase in respiratory symptoms in young children.

12. In-patient admissions for both children and adults with respiratory related illnesses that include simple pneumonia, pleurisy, bronchitis, and asthma are associated with chronic exposure to fine particulate pollution (PM-10).

\subsubsection{Neurological Effects}

The coal-fuel cycle also is associated with several pollutants linked with nervous system disorders. The human nervous system coordinates behavior, it perceives and responds to external stimuli, is responsible for mediating communication with the external environment, and coordinates the activities of all other organ systems and thus plays an essential role in maintaining 
metabolic balance. Many kinds of injury to the nervous system are irreversible, because, after initial growth and development, the system has little capacity to repair itself or to regenerate, and resulting losses of function can be permanent as well as debilitating. Effects that are difficult to detect in an individual, such as a decline in intelligence quotient, are of great concern when they occur throughout large portions of a population.

Beginning with Hippocrates' observation in 370 B.C. that lead miners experienced disfunction, numerous associations between neurologic impairment and environmental exposures have been noted. Exposure to low concentrations of environmental lead is correlated with reduced scores on tests of mental development (Bellinger et al. 1987, Needleman 1989), and exposure to manganese can produce a dyskinetic motor syndrome (Cook, Fahn, and Brait 1974). Also, exposures to environmental chemicals may contribute to clinical neurodegenerative disorders seen later in life. Calne et al. (1986) have hypothesized that various environmental agents contribute to Alzheimer's disease, Parkinson's disease, or amyotrophic lateral sclerosis by depleting neuronal reserves to an extent that becomes observable in the context of natural aging. While much study has taken place, it is safe to say that the extent to which environmental neurotoxicants contribute to chronic neurologic and psychiatric disease is not yet known.

In summary, neurological damage could be caused by toxic exposures to certain effluents associated with the coal fuel cycle, but existing data supporting quantitative analyses for symptoms studies in the willingness-to-pay paradigm (see Chapter 5) are rare. One notable exception is lead, which has been characterized with respect to decrements of intelligence (ATSDR 1990, Winneke et al. 1990). Cadmium is also suspect for this same endpoint (Thatcher et al. 1982).

\subsubsection{Cardiovascular Effects}

Similar to neurological toxicity, evaluation of the effects of pollution on the cardiovascular system remains more an art than a science. Generally, quantitative models are not available. Cardiovascular disease (CVD) is the single greatest cause of death in the United States and in Western Europe. There is strong epidemiologic evidence for an interaction of environmental and genetic factors in the development of clinically significant episodes of CVD. However, the specific contributions of each of these components to the onset and development of CVD are poorly understood. Environmental factors such as cigarette smoke anc agents that elevate blood pressure have been associated with the development of clinically significant episodes of CVD. However, evidence linking these factors to CVD in a causal way, let alone the 
demonstration that these factors are directly involved in the molecular events that underlie development of CVD, is lacking. One of the interesting directions being taken in current research is the development of evidence consistent with the view that somatic cell alterations are critical to plaque development in humans (Penn 1989). Such a perspective would provide a link between environmental carcinogens and the development of CVD. However, sufficient evidence is lacking at this time to construct a risk assessment directly relating such chemical agents and CVD. One direction that has received recent attention is the relationship between lead, blood pressure, and CVD.

Lead is associated with elevated blood pressure in several large epidemiologic studies. Schwartz (1991) reviews and analyzes information that confirms the expected association of lead with left ventricular hypertrophy. This evidence of an association with permanent cardiovascular changes supports the blood pressure and lead findings.

Other recent work on cardiovascular effects has focused on exposures to $\mathrm{CO}$ and combined exposure to $\mathrm{O}_{3}$ and $\mathrm{NO}_{2}$; evaluation of such data may yield some exposure response relationships. Presently, most concern has been centered on aggravation of angina symptoms with exposure to CO (Allred 1991).

\subsubsection{Reproductive Effects}

Reproduction may be affected by toxic materials. These materials may affect the process of development from fertilization through birth. Although effects are difficult to quantify, the toxic effects of legal drugs and environmental chemicals on the human reproductive system are an important health concern. The extent of the hazard of chemicals to reproduction and the risks to humans from chemical exposure are difficult to assess because of the complexity of the reprod :rtive process, the unreliability of laboratory tests, and the quality of human data (Dixon, 1982). There are numerous underlying biologic processes that effluents from the coal fuel cycle might alter to produce reproductive dysfunction. Effluents associated with a small increment to the current base load will probably be too small to observe effects in the population. Effects may be direct, as on some subcellular molecule such as a receptor that alters the ability of the cell to divide, differentiate, or otherwise function normally. Toxicity may also result from an effect that is mediated indirectly, for instance, by altering the presence or effectiveness of a hormone. Fairly reliable human data are available for agents such as cigarette smoke, lead, ethyl alcohol, and ionizing radiations. Of these, only lead is identified in the coal fuel cycle effluent streams. Many of the other agents identified in the effluents of coal (particularly the metals) are 
potentially involved in reproductive toxicity but are less well studied (Barlow and Sullivan, 1982; Schrag and Dixon 1985). Impacts can be evaluated in terms of decreased fecundity, increased infant mortality, decreased birth weight, and infertility.

\section{Immunological}

The immune system functions to recognize and eliminate agents that are harmful to normal health. The immune system is a highly evolved organ system deriving from the pluripotent stem cells in the bone marrow. Maturation of most of the cell types derived from the pluripotent stem cells generally occurs within the bone marrow. However, lymphoid progenitor cells are disseminated by the blood system to the primary lymphoid organs where they differentiate under the influence of the microenvironment of these organs. At these organs, the lymphocytes are produced from which the other cell lines involved in immune response are derived. When the immune system functions properly, the foreign agents are eliminated quickly and efficiently. Occasionally, the immune system responds adversely to environmental agents, resulting in an allergic reaction (Coombs and Gell, 1975). A single immune function assay cannot be used to comprehensively evaluate deleterious effects on the immune system following exposure to chemicals (Dean et al, 1982). However, the problem of occupational and environmental sensitivity is now widely recognized. Hypersensitivity has been noted for a variety of metals. The list includes nickel, beryllium, platinum, chromium, mercury and gold (Kazantiz, 1978). Suppression of the immune system, which can lead to adverse health responses, has been associated with some effluents from the coal cycle. In particular, benzene is a noted myelotoxin (Wierda et al, 1981). Other immunosuppressants identified are polycyclic aromatic hydrocarbons (Stjernsward, 1966); Ozone (Coffin and Gardner, 1972), and $\mathrm{NO}_{2}$ (Ehrlich et al, 1977). Impacts can be evaluated in terms of increased frequency of infectious diseases.

\subsection{UNCERTAINTY ISSUES FOR HEALTH IMPACTS}

The health impact discussion is concluded with some specific concerns about the uncertainty aspects of the health impacts problem. Exposures, projected environmental concentrations, and accidents can generally be treated as knowns, but most other health considerations must be classified as "unknowns" or "likely associations." Likely association describes a correspondence between an exposure and an effect, but uniqueness of the cause-effect relationship cannot be demonstrated. A recent report (Fritzsche 
1989) on fuel cycle externalities has identified some concerns relative to the uncertainty issue that are worth noting.

First, it is important to distinguish between health effects based on extrapolation models and those based on actuarial data. Not to do so would confuse information having a low degree of certainty with information having a high degree of certainty. Second, although health and accident statistics register the incidence of injuries, illnesses, and mortality, environmental risk assessments are often restricted to premature deaths because it is hard to evaluate the severity of nonlethal effects. At present, not enough is known about the incidence of the latter effects caused by the many chemical substances emitted from power plants, so a balanced risk assessment is difficult.

Nonetheless, work within this project will attempt to evaluate the effects of each of the source term pollutants. The practic 1 difficulty with the damage-function approach requiring complete disaggregation is that many of the health effects associated with air pollution are linked to numerous pollutants. For example, there is a general debate on how to distinguish the effects of acid aerosols from particulates. While our approach strives to be more precise, we cannot ignore issues such as synergistic interactions among pollutants.

Similar views of the intrinsic uncertainty underlying health risk analysis for fossil energy fuel cycles have been expressed by most other objective investigators who have attempted to quantify risks and hazards. On the more optimistic end of the distribution of opinions is a remark by Gotchy (1987) that pollution versus health effect correlations, such as used by Lave and Seskin, are not adequate without other toxicological and epidemiological data but when interpreted as a whole, ca:- provide order-of-magnitude precision. Somewhat more pessimistic views have been expressed by others, such as Cox and Ricci (1990), who note that uncertainty is intrinsic and unavoidable in risk assessment and the choice of a dose-response function relating ambient levels of emissions from a power plant to resulting public-health consequences may be determined by regulatory fiat tempered by scientific hypotheses, theory, and empirical data. House (1981) similarly expressed that the high levels of uncertainty in health-related statistics add a dimension of confusion to pollution or safety information that only confuses the decision maker. Also, Ricci (1990) noted that airborne pollutants are generic and cannot be traced to a single source and that the $95 \%$ confidence interval for excess deaths in 1985 from airborne pollutants ranges from 0 to 250,000: "Such data are so primitive that it is questionable whether they can truly be considered 
information." However, for health effects other than mortality, the exposureresponse relationships are more promising.

Many investigators have attempted to define very precisely the exact exposure-response curve for a particular pollutant for a particular scenario. We believe that, in many cases, this type of process will need to be modified for our analysis. The transferability of exposure-response results will ultimately depend on the original study design and idiosyncracies of the sample population. In some cases, there may be several credible estimates of the exposure-response relationship to be included in the projec: snowledge base. Furthermore, many investigators face problems when attempting to extrapolate biological data to concentrations well below the original data. For example, although precise models of radiological risk are commonly used, the health effects from the nuclear cycle are not known more accurately than those from nitrogen oxides in the atmosphere. Yet, most hea risk assessors consider that radiological risk is known accurately while risi from chemical pollutants is often treated as unknown or absent. Both estimates depend on data taken much out of context from where they were collected and depend on mathematical extrapolation models.

The choice of the exposure-response model used to extrapolate highly reliable epidemiological data at high exposures can induce an uncertainty range of $10^{6}$ when extrapolated to low exposures (Jones and Walsh 1990). This tendency is exemplified in an EPRI (1987) example for arsenic that has been characterized by four common dose-response models and leads to health-effects estimates that differ by eight orders of magnitude. This type of uncertainty issue has led some researchers (Fritzsche 1989) simply to gauge health risks as a fixed proportion of emission levels. However, rather than be defeated by a wide spread in the potential health impacts, our analysis will assess how the spread affects the external costs problem.

\subsection{REFERENCES}

ATSDR (Agency for Toxic Substances and Disease Registry), 1990. Toxicological Profile for Lead, ATSDR/TP 88/17. U.S. Department of Health and Human Services, Public Health Service, Atlanta.

Alred, E. N., 1991. "Effects of Carbon Monoxide on Myocardial Ischemia," Env. Hlth. Perspectives 91, 89-132.

ACGIH (American Conference of Governmental Industrial Hygienists), 1989. Threshold Limit Values and Biological Exposure Indices for 1989-1990. Cincinnati. 
Barlow, S. M., and Sullivan, F. M., 1982. Reproductive Hazards of Industrial Chemicals, Academic Press, London.

Bellinger, D., Leviton, A., Waternaux, C., Needleman, H., and Rabinowitz, M., 1987. "Longitudinal Analyses of Prenatal and Postnatal Lead Exposure and Early Cognitive Development." N. Eng. J. Med. 316(17), 1037-1043.

Calne, D. B., Eisen, A., McGreer, E., and Spencer, P., 1986. "Alzheimer's Disease, Parkinson's Disease, and Motoneurone Disease: A Biotrophic Interaction Between Aging and Environment?" Lancet II(8515) 10671070.

Coffin, D. L., and Gardner, D. E., 1972. "Interaction of Biological Agents and Chemical Air Pollutants," Ann. Occup. Hyg. 15, 219-35.

Cook, D. G., Fahn, S., and Brait, K. A., 1974. "Chronic Manganese Intoxication," Arch. Neurol. 30, 59-71.

Coombs, R. R. A., and Gell, P. G H., 1975. "Classification of allergic reactions responsible for clinical hypersensitivity and disease." In Gell, P. G. H., Coombs, R. R. A., and Lachman, P. J. (eds.) Clinical Aspects of Immunology p. 761.

Cox, L. A., Jr. and Ricci, P. F., 1990. "Health-Risk Assessment: Production of Electricity," J. of Energy Engineering 116(3), 130-147.

Dean, J. H., et al., 1982. "Procedures Available to Examine the Immunotoxicity of Chemicals and Drugs," Pharmacol. Re. 34, 137-48.

Dixon, R. L., 1982. "Potential of Environmental Factors to Affect Development of Reproductive Systems," Fund. Appl. Toxicol. 2, 5-12.

Ehrlich, R., et al., 1977. "Health Effects of Short-Term Inhalation of Nitrogen Dioxide and Ozone Mixtures," Environ. Res. 14, 223.

El-Bassioni, A. A., with contributions from other SAI staff members, 1980. $A$ Methodology and A Preliminary Data Base for Examining the Health Risks of Electricity Generation from Uranium and Coal Fuels, NUREG/CR1539 U.S. Nuclear Regulatory Commission report, Washington.

EPRI (Electric Power Research Institute), 1987. Risk Assessment of Toxic Pollutants from Fossil Fuel Power Plants, EPRI EA-5358, Palo Alto, Calif. 
Fritzsche, A. F., 1989. "The Health Risks of Energy Production," Risk Analysis 9(4), 565-577.

Gaylor, D. W., 1988. "Quantitative Risk Estimation," In Risk Assessment and Risk Management of Industrial and Environmental Chemicals, eds. C. R. Cothern, M. A. Mehlman and W. L. Marcus, eds. Princeton Scientific Publishing Co., Inc., Princeton, N.J.

Glass, L. R., Jones, T. D. Easterly, C. E., and Walsh, P. J. 1991. "Use of Short-Term Test Systems for the Prediction of the Hazard Represented by Potential Chemical Carcinogens," Environmental Auditor 2(3), 103-169.

Gotchy, R. L., 1987. Potential Health and Environmental Impacts Attributable to the Nuclear and Coal Fuel Cycles. NUREG-0332.

Grant, L. D., Elias, R. W., Goyer, R. A., Nicholson, W. J., Olem, H., Bertsch, P. M., Davis, J. M., Fegal, A. R., and Mahaffey, K. R., 1990. Indirect Health Effects Associated with Acidic Deposition. NAPAP Report 23, Acidic Deposition: State of Science and Technology, National Acid Precipitation Assessment Program, Washington.

Hamilton, L. D., ed. 1974. The Health and Environmental Effects of Electricity Generation-A Preliminary Report by the Biomedical and Environmental Group. BEAG-HE/EE, Brookhaven National Laboratory, Upton, N.Y.

Holdren, J. P., 1987. "Global Environmental Issues Related to Energy Supply: The Environmental Case for Increased Efficiency of Energy Use," Energy 12(10/11), 975-992.

House, P. W., Coleman, J. A., Shull, R. D., Matheny, R. W., and Hock,J. C., 1981. Comparing Energy Technology Alternatives for an Environmental Perspective, DOE/EV-0109.

Inhaber, H. 1979. "Risk of Energy from Conventional and Nonconventional Sources," Science 203, 718-723 (1979).

Jones, T. D., Walsh, P. J., Watson, A. P., Owen, B. A., Barnthouse, L. W., and Sanders, D. A., 1988. "Chemical Scoring by A Rapid Screening of Hazard (RASH) Method," Risk Analysis 8(1), 99-118.

Jones, T. D., Griffin, G. D., and Walsh, P. J., 1983. "A Unifying Concept for Carcinogenic Risk Assessments," J. Theor. Biol. 105, 35-61. 
Jones, T. D. and Walsh, P. J., 1990. "Cancer Models for B[a]P, Benzene, Benzidine, and Chromium," ASCE J. of Energy Engineering 116(3), 211-230.

Kazantzis, G., 1978. "The Role of Hypersensitivity and the Immune Response in Influencing Susceptibility to Metal Toxicity," Environ. Health Perspect. $25,111-18$.

Lave, L. B. and Seskin, E. P., 1970. "An analysis of the Association Between U.S. Mortality and Air Pollution, J. Am Stast. Assoc. 68:284-290.

Lilienfeld, A. M. and Lilienfeld, D. E., 1980. Foundations of Epidemiology, 2nd ed, Oxford University Press, N.Y.

Mendelsohn, R. and Orcutt, G., 1979. "An Empirical Analysis of Air Pollution Dose-Response Curves," J. Environ. Econ. Managmt. 6, 85-106.

Morgan, M. G., Morris, S. C., Meier, A. K., and Shenk, D. L., 1978. "A Probabilistic Methodology for Estimating Air Pollution Health Effects from Coal-Fired Power Plants," Energy Systems and Policy 2(3), 287-310.

Morris, S. C., Moskowitz, P. D., Sevian, W. A., Silberstein, S., and Hamilton, L. D., 1979. "Coal Conversion Technologies: Some Health and Environmental Effects," Science 206, 654-662.

NAPAP, 1990. "National Acid Precipitation Assessment Program State of Science and Technology Report 22," Washington.

NAS-NRC (National Academy of Science/National Research Council), Committee on Risk and Decision-Making, Assembly of Behavioral and Social Science, 1982. Risk and Decision Making: Perspectives and Research, Washington.

NCRP, 1989. Comparative Carcinogenicity of Ionizing Radiation and Chemicals, Report 96 Bethesda, M.D.

Needleman, H. L., 1989. "The Persistent Threat of Lead: A Singular Opportunity," commentaries in Am. J. Pub. Health 79(5), 643-645.

Novak, K. M., Bozzo, S. R., and Hamilton, L. D., 1984. Nitrogen Oxides: Health and Environmental Effects Document III, Brookhaven National Laboratory. 
OSTP (Office of Science and Technology Policy), 1979. Identification, Characterization and Control of Potential Human Carcinogens: $A$ Framework for Federal Decision-Making, Washington.

OTA (Office of Technology Assessment), 1979. The Direct Use of Coal: Prospects and Problems of Production and Combustion, PB-295-797 (NTIS), U.S. Congress, Washington.

OECD (Organization for Economic Cooperation and Development), 1982. "Part I: Comparative Assessment Methodology and Its Application to Policy," 82(17), Paris.

Ottinger, R. L., Wooley, D. R., Robinson, N. A., Hodas, D. R., and Babb, S. E., 1990. Environmental Costs of Electricity, Oceana, N.Y.

Owen, B. A., 1990. "Literature-Derived Absorption Coefficient Estimates for 39 Chemicals Via Oral and Inhalation Routes of Exposure," Regul. Toxicol. and Pharm. 11, 237-252.

Owen, B. A., Dudney, C. S., Tan, E. L., and Easterly, C. E., 1990. "Formaldehyde in Drinking Water: Comparative Hazard Evaluation and An Approach to Regulation.," Regul. Toxicol Pharm. 11, 220-236.

Owen, B. A. and Jones, T. D., 1990. "Hazard Evaluation for Complex Mixtures: Relative Comparisons to Improve Regulatory Consistency," Regul. Toxicol. and Pharm. 11, 132-148.

Ozkaynak, H. and Spengler, J. D., 1985. "Analysis of Health Effects Resulting from Population Exposures to Acid Precipitation Precursors," EHP Environ. Hlth. Perspect. 63, 45-55.

Ozkaynak, H. and Thurston, G. D., 1987. "Associations between 1980 U.S. Mortality Rates and Alternative Measures of Airborne Particle Concentration," Risk Anal. 7, 449-461.

Penn, A., 1989. "Molecular Alterations Critical to the Development of Arteriosclerotic Plaques: A Role for Environmental Agents," Env. Health Perspectives 81, 189-192.

Pope, C. A., 1989. "Respiratory Disease Associated with Community Air Pollution and a Steel Mill,Utah Valley," Am. J. Public Health 79(5):623628. 
Ricci, P. F. and Molton, L., 1981. "Risk-Benefit in Environmental Law," Science 214, 1096-1100.

Ricci, P. F., 1990. "Mortality, Air-Pollution, and Energy Production:Uncertainty and Cause," J. of Energv Engineering 116(3),148.

Schlesinger, R. B., Driscoll, K. E., Gunnison, A. F., and Zelikoff, J. T., 1990. "Pulmonary Arachidonic Acid Metabolism Following Acute Exposures to Ozone and Nitrogen Dioxide," J. Toxicol. Environ. Health 31:275-290.

Schrag, S. D., and Dixon, R. L., 1985. Occupational exposure associated with male reproductive dysfunction. Annu. Rev. Pharmacol. Toxicol., 25:56792.

Senior Expert Symposium, 1991. Comparative Environmental and Health Effects of Different Energy Systems for Electricity Generation, Key Issues Paper No. 3, Senior Expert Symposium on Electricity and the Environment, Helsinki, Finland 133-17, May 1991, SM-232/3, sponsored by the World Health Organization.

Schwartz, J., 1991. "Lead, Blood Pressure, and Cardiovascular Diseases in Men and Women," Env. Hlth Perspectives 91, 71-75.

Stjernsward, J., 1966. "Effect of Noncarcinogenic and Carcinogenic Hydrocarbons on Antibody-Forming Cells Measured at the Cellular Level In Vitro," J. Natl Cancer Inst. 36, 1189-95.

Tennant, R. W., Margolin, B. H., Shelby, M. D., Zeiger, E., Haseman, J. K., Spalding, J., Caspary, W. Resnick, M., Stasiewicz, S., Anderson, B., and Minor, R, 1987. "Prediction of Chemical Carcinogenicity in Rodents from In Vitro Genetic Toxicity Assays," Science 236, 933-941.

Thatcher, R. W., Lester, M. L., McAlaster, R., and Horst, R., 1982. "Effects of Low Levels of Cadmium and Lead on Cognitive Functioning in Children," Arch. Env. Hlth 37(3), 159-166.

Travis, C. C., Holton, G. A., Etnier, E. L., Cook, C., O'Donnell, F. R., Hetrick, D. M., and Dixon, E., 1986. "Assessment of Inhalation and Ingestion Population Exposures from Incinerated Hazardous Wastes," Environmental International 12, 533-540. 
DHHS (U.S. Department of Health and Human Services), 1989. Fifth Annual Report on Carcinogens (prepared by the National Toxicology Program, U.S. Public Health Service, and issued by the Secretary of the Department of Health and Human Services), pursuant to Pub. L 95-622 of November 9, 1978.

US EPA (U.S. Environmental Protection Agency), 1986a. Federal Register, 51(189): 34836-62.

US EPA (U.S. Environmental Protection Agency), 1986b. 40 CFR P. 261, 271, and 302. Federal Register 51(114): 21648-93.

US EPA (U.S. Environmental Protection Agency), 1988. Acid Aerosols Issue Paper, EPA-600/8-88-005A, Office of Health and Environmental Assessment, Washington.

US EPA (U.S. Environmental Protection Agency), 1988a. Summary of Selected New Information on Effects of Ozone on Health and Vegetation: Draft Supplement of Air Quality Criteria for Ozone and other Photochemical Oxidants, EPA/600/8-88/105A, Office of Health and Environmental Assessment, Washington.

US EPA (U.S. Environmental Protection Agency), 1990. Direct Health Effects of Air Pollutants associated with Acidic Precursor Emissions Report 22.

US EPA (U.S. Environmental Protection Agency), 1990a. Air Quality Criteria for Carbon Monoxide, EPA/600-8-90-045A, Office of Health and Environmental Assessment, Washington.

Watson, A. P., 1984. "Energy Analysis of the Coal Fuel Cycle in an Appalachian Coal County," Human Ecology 12(1), 65-86.

Winneke G., Brockhaus, A., Ewers, U., Kramer, U., and Neuf, M., 1990. "Results from the European Multicenter Study on Lead Neurotoxicity in Children: Implications for Risk Assessment," Neurotoxicology and Teratology 12, 553-559.

Wierda, D., Irons, R. D., and Greenlee, W. F., 1981. Immunotoxicity in C57BL/6 mice exposed to benzene and Aroclor 1254. Toxicol. Appl. Pharmacol., 60, 41-17. 


\section{ECONOMIC VALUATION FOR FUEL CYCLE ANALYSIS}

The purpose of this chapter is to provide preliminary guidance to other members of the project team and to other interested parties on issues related to valuing endpoints for all fuel cycles. Potential endpoints for valuation were identified in the previous chapter, with particular reference to the coal cycle. We begin with a discussion of approaches to valuing these endpoints in general and then specific to each endpoint. The relative success of these approaches in estimating values for specific endpoints, the limitations of these approaches, and research needs are then briefly summarized. Next, a number of special issues in benefits estimation for this project are discussed: transferability, aggregation, non-linearities in damage functions, temporal perspectives, and discounting. Finally, we consider matching endpoints to values and suggest an implementation plan for the external costs of air emissions to illustrate how the impact and valuation components are combined to derive damages. Appendices to the coal fuel cycle document provide greater detail on these issues.

\subsection{THEORY OF VALUE}

All of the valuation approaches to be discussed here have been crafted from a notion of value based on decades of research in neoclassical microeconomic analysis. At the core of this notion is consumer sovereignty-i.e., that each individual in society is the best judge of value. These judgements, incidentally, are not restricted to goods bought in the marketplace or even those "consumed" by the individual. If individuals are bothered by visibility degradation, for instance, then improved visibility may have value. Or, if individuals get a feeling of satisfaction from others' consumption or reduced damage (e.g., from expected improvements to someone else's health through the cleanup of an abandoned waste site), then this situation may also have value.

We use the word "may" to emphasize that however strongly someone may feel about some "good," unless they are willing to pay something for it, it has no value. That is, value is intimately connected to opportunity costs i.e., the concept that there is no free lunch, that something must be given up to gain something else. Thus, values are determined in the context of constraints, be they money, time, health, or something else that is valued. These constraints imply that a thing has value to the extent that individuals are willing to pay for it - the so-called WTP criterion in economics that 
underlies all modern benefit-cost analysis. ${ }^{1}$ Specifically, the value of a thing is what we would have to take away from an individual to leave him as well off without the good as with it. If values are being expressed in the context of income constraints, use of the WTP criterion implicitly sanctions the existing distribution of income as acceptable.

So far, what has been said about value is completely general, applying to shoes as well as environmental goods, such as visibility or the "existence value" of a whooping crane. But, in some important respects, environmental goods are not like marketed goods. For instance, the consumption of an environmental good by one person doesn't generally diminish its availability to another. This implies that the value for such a good is obtained by summing individual values rather than taking the value for that good expressed by the "marginal individual," as in a good traded in a market.

More important and controversial is the fact that many types of nonmarketed goods are generally not well understood by or familiar to individuals because they do not have opportunities to learn about such goods through repeated purchases. Irrespective of the claims about a product (say a coffee maker) made by an advertiser or friend, repeated purchase and use of coffee makers will reveal the combinations of product characteristics and cost that maximize a given individual's utility from this type of product. Compare this to the value of avoiding increased risk of chronic disease or the value of preserving a wilderness area. Most individuals have little knowledge and experience with such goods and little opportunity to become more experienced. If asked questions pertaining to the values they hold or if responding to situations that might reveal their values, such individuals might, indeed, be able to reveal a value. But, could such values be trusted? In other words, what is the appropriate amount of experience and information that individuals must have before they can exercise consumer sovereignty?

There are two extreme positions. One, the traditional view, holds that consumer sovereignty can be exercised irrespective of information quality or

\footnotetext{
${ }^{1}$ The values of concern are of two types: the individual's willingness to pay (WTP) for an improvement in the state of nature (in terms of reductions in pollution or its physical consequences) and the individual's (WTA) compensation to tolerate worsening of the state of nature. Because the former is constrained by income and the latter is not, one assumes that WTA > WTP, ceteris paribus. The theoretical expectation that the difference between these two measures should be small (Willig 1976) has not been born out by some studies of environmental goods. Hanemann (1991) showed that WTP could differ substantially from WTA for goods lacking close substitutes even after income constraints were taken into account. For goods with close substitutes, such as a lake in the Adirondacks, WTP and WTA estimates should be much closer.
} 
quantity; it is not the business of economists or anyone else to invalidate someone's values just because these values do not correspond to someone else's view of rationality or appear to be based on erroneous information. People used to smoke cigarettes and buy cars because they think it makes them alluring: some may see this as irrational, but by what standard? The other position is that because many nonmarketed goods are so complex and unfamiliar, only "well-informed" or expert views can be used to generate values for use in subsequent analysis.

Irrespective of these positions, it is generally agreed that values can be legitimately based on perception, emotion, education, family status, and other factors in addition to "facts." Controversy involves not so much how facts are processed (although a good bit of research is ongoing to discern this) but whether information about a commodity or service is accurate.

This controversy has spawned much current research effort in the estimation of benefits, most examining the effect of different levels or qualities of information or even of different ordering of information on values for nonmarketed goods. While no firm conclusions have been reached, a fairness standard is emerging, where information provided to respondents in WTP surveys should be finely enough balanced so that such respondents are as likely to believe that the survey was financed by "polluter" interests as by "public" interests.

\subsection{VALUATION APPROACHES}

Methods to estimate the damages associated with the impacts that were discussed in previous chapters have gained broader acceptance in the last two decades as theoretical valuation issues have been resolved and the body of literature pertaining to specific applications has grown. It is noted that the early literature on estimating environmental benefits or costs stressed a distinction between behavioral and "engineering" approaches, with the damage function approach classified in the latter category. Now it is generally recognized that the damage function approach is behavioral as long as the estimates of value are based on WTP. It is also recognized, however, that simply multiplying some estimate of physical damage by some estimate of WTP to avoid the damage may not capture the full range of behavior that is possible when individuals are confronted with risks of injury or other types of damage. Estimates of the physical damage to health will not capture the value of activities that are foregone because people avoid certain activities to protect their health (e.g., asthmatics who give up tennis on smoggy days to avoid asthma attacks). 
With all of this research activity, it remains that success and effort have been unevenly distributed among the benefit categories. The most effort has clearly gone into the theory and estimation of recreation and mortality benefits. Mortality benefit studies have derived values for reducing risks of death that are quite consistent with one another. However, very few studies have obtained values for reducing mortality risks arising from environmental improvements. Substantial research has also addressed the valuation of pollution effects on health, visibility, and economic production, particularly on the effects of ozone exposure on field crops. Valuation of damages to materials and to ecosystems (including endangered species) is largely unexplored, although even here much effort has recently been placed on the natural resources damage assessment process applied to the Exxon Valdez spill and other like events.

When impacts appear in marketed products, standard approaches to valuing changes in welfare may be taken. Scientific information is used to estimate the shift in the supply of the affected commodity as a result of pollution exposure. Then, with additional estimates of the elasticity of demand for the affected commodity, the effect on price and ipuantity sold can be estimated. With this information, social costs can be computer, measured as the reduction in consumer plus producer surplus. Losses co consumers occur because the prices of these products increase, reducing the gap between individuals' willingness to pay for these products and what they have to pay, i.e., consumer surplus decreases. Losses to producers occur because of losses in rents as a result of higher production costs to obtain any given yield. Rents are money returns received by factors of production (land, labor, capital, entrepreneurship) beyond the value of their contribution to the value of the product. They are analogous to consumer surplus - the value consumers receive from consuming a product minus what they pay for a product - and arise for the same reason. In markets, value (i.e., price) is determined by the marginal consumer as willingness to pay and the cost of producing the marginal unit of output. With this price established, nonmarginal consumers (who were willing to pay more for the product than they had to) receive a benefit (consumer surplus), just as nonmarginal factors of production (which were able to be employed to produce the product at a lower cost than the factors used to produce the marginal unit) receive a benefit (rent).

When impacts occur in nonmarketed commodities, two broad approaches have been developed to estimate damages: the contingent value (CV) and indirect approaches. Both of these approaches have been 
developed over decades and continue to evolve and improve, although significant problems remain and significant types of impacts have yet to be credibly valued.

The CV methods involve asking either open- or closed-ended questions of individuals for their willingness to pay in response to hypothetical scenarios involving reductions in health or environmental risks or effects. ${ }^{2}$ The major advantages of these approaches are that they can be designed for ex ante situations, ${ }^{3}$ the good being valued can be specified exactly to match other information available to the analyst (such as the endpoint specified in a D-R function), and the survey can be administered to a sample appropriate for the good being valued (whether representative of the general population or of some other group; such as older people). Further, for some types of values, such as existence values, there are no other means of obtaining values. On the other hand, the hypothetical and often complicated nature of the scenarios raises serious concerns about whether individuals can process the information provided and have enough motivation and familiarity with the "goods" being valued to respond as if they were in a real situation. Cr ncern over strategic bias $^{4}$ appears to have been overcome and much recent research has attempted to systematize and standardize the development and conduct of these surveys (Mitchell and Carson 1989; Cummings, Brookshire, and Schulze 1986), in terms of payment vehicle, treatment of risk in the scenarios, openversus closed-ended questions, and other issues such as how questions are phrased. Additional research has attempted to compare values elicited from $\mathrm{CV}$ surveys to values obtained by indirect methods (see below), generally finding close agreement. It should be recognized, however, that such comparisons are possible only for certain classes of nonmarketed goods. For obtaining existence values, for instance, $\mathrm{CV}$ methods are the only available approach.

\footnotetext{
${ }^{2}$ Open-ended questions ask individuals for their WTP, either in a bid format, on a payment card, or some other method that seeks a best estimate from the individual. Closed-ended questions involve asking individuals whether they would be willing to pay as much as or more than a given amount. This approach is less demanding of individuals, while still permitting recovery of values for the group.

${ }^{3}$ This means that WTP for some future change in the state of nature can be elicited. As discussed below (see the section on Temporal Perspectives in Analysis), this is the appropriate perspective for valuation. In contrast, other methods must rely on realized (or ex post) information to infer ex ante values.
}

This is the term for the act of willfully offering misleading answers in the hopes of influencing the outcome of the survey and, ultimately, of policy. 
The indirect approaches (sometimes called revealed preference approaches) seek to uncover values for the nonmarketed environmental goods by examining market or other types of behavior that are related to the environment as substitutes or complements. For instance, treating money (in the form of a wage premium) as a substitute for on-the-job safety, the relationship between wage rates and accidental death rates in different occupations has been statistically examined, with the finding that such premia do exist. These premia represent a value for reducing risks of premature death that can be used to value occupational health and safety risks posed by alternative fuel cycles and, with appropriate caveats (see below), to value risks to life posed by environmental pollution from these fuel cycles. As another example, environmental quality and recreation are complementary in the sense that more visits will be made to recreation sites with better environmental quality. Observing behavior in the choice of recreation sites and the frequency of visits to sites of different levels of water quality and relating this behavior to miles and time for travel to the site has revealed willingness to pay for improvements in water quality at recreation sites.

As a third example, when costs are incurred to avoid impacts, these goods may be viewed as substitutes for environmental quality. By tracking spending on goods used to avoid pollution or its effects, one can gain some idea of WTP. For instance, if people buy bottled water solely to protect themselves from toxics in their tap water, we know that their willingness to pay for avoiding health risks from these toxics is at least equal to the cost differential between bottled and tap water. As pain, suffering, and other nonpecuniary costs are omitted from consideration, this approach provides underestimates of willingness to pay, assuming the other problems with this approach have been avoided. Unfortunately, if the substitute good provides other benefits, the estimates could be too large.

\subsubsection{Comparison of Approaches}

There are a growing number of attempts to compare the results of CV and indirect approaches to valuing the same commodity. One of the most interesting and comprehensive of the earlier studies [Bishop, Heberlein, and Kealy (BHK) 1983] compared estimates for the value of a hunting permits (both in terms of the willingness to pay for a permit and the willingness to accept payment for giving up a permit) for Canadian geese using a CV, travel cost, and simulated market experiment. CV responses varied from $\$ 11$ to $\$ 101$, with the travel cost model yielding a value of $\$ 32$ and the simulated market experiment (WTA) yielding a value of $\$ 63$. The artificiality of the CV approach was cited as a likely hypothesis for these divergences. Mitchell and Carson (1989) take issue with the BHK approach on a variety of 
methodological grounds and point to a more recent study by the same authors on deer hunting permits, which has fewer methodological problems and shows a much closer association between a closed-ended WTP CV result and the simulated market result ( $\$ 35$ vs. $\$ 31$ ), the latter based on WTP instead of WTA as in the goose-hunting study. Sellar, Stoll, and Chavas (1985) also found closed-ended WTP CV estimates and travel cost estimates roughly comparable. Cummings, Brookshire, and Schulze (1986) concluded after reviewing many of the studies comparing $\mathrm{CV}$ and indirect valuation results, that the approaches yielded estimates within $60 \%$ of one another, witit many closer. Mitchell and Carson (1989) reviewed CV studies to determine the extent to which regression analysis of the responses corresponds with $a$ priori expectations. They conclude that such results generally are consistent with expectations.

Attempts at validating the $\mathrm{CV}$ approach by comparing its results to those of other approaches suffer from the problem that the comparison is for a set of commodities restricted to those that can be valued by multiple approaches. Even if CV results lined up perfectly with those of other approaches for these commodities, one could not conclude that CV offered valid measures of value for commodities for which no such comparisons are possible. However, the existence of logical patterns in WTP responses, even to questions about existence values, does offer some evidence for the validity of CV in these situations.

\subsection{SPECIFIC ENDPOINTS ${ }^{5}$}

\subsubsection{Mortality Risk Reductions to Individuals}

Of the categories of benefits to individuals, reductions in the risk of premature mortality are of central concern to the public and environmental policy makers. Nearly all of the research has been directed toward an individual's valuation of reducing his or her own mortality risks. ${ }^{6}$ Research

\footnotetext{
${ }^{5}$ See Appendix $\mathrm{F}$ of the Coal Fuel Cycle Study for detailed literature reviews on valuation of mortality, morbidity, visibility and recreation.

Some studies have examined whether family status affects "own-risk" valuation, with the conclusion that married people may be willing to pay more than unmarried people to reduce their own risk of death.
} 
on the WTP to reduce risks to one's family, friends, or coworkers is virtually non-existent, as are studies of altruism.?

Focusing on "own-risk" valuation, a variety of approaches have been used to monetize reductions in mortality risks. Perhaps the most common method has been to examine pay differentials across a sample of occupations posing different annual mortality risks. By holding constant other attributes of the occupations and the workers, it is possible to estimate how much extra compensation is required to induce people to accept slight increases in job risk. These wage premia are often used to measure individuals' WTP for reduced environmental risks. ${ }^{8}$ By dividing average WTP by the risk reduction being valued, one arrives at what is termed "the value of a statistical life (VSL)." For example, if the WTP for a reduction in risk of 1 in 10,000 is $\$ 100$, then the VSL is $\$ 1$ million. ${ }^{9}$

Reduced mortality risks have also been translated into dollars using the contingent valuation method, i.e. by asking individuals directly through survey means what they would be willing to pay for the reductions in risk of dying in highway accidents (Jones-Lee, Hammerton, Philips 1985).

Two recent surveys of the mortality valuation literature attempt to narrow the range of VSL estimates. Fisher, Chestnut, and Violette (1989) review 21 mostly wage studies, concluding that the "most defensible range for the VSL estimates is $\$ 1.6$ to $\$ 8.5$ million (1986\$s)" for risks in the one to 10

\footnotetext{
7Viscusi, Magat, and Forrest (1988) are an exception, although they examine altruism with respect to morbidity (see below).
}

${ }^{8}$ For obvious reasons, the measures are not perfect. To take but one example, occupational risks are borne more voluntarily than are risks arising from air pollution. This must be factored into the valuation of risks. Another problem is that if workers lack information about their true risks, the wage premia will reflect their perceived risks rather than the true risks. This is acceptable so long as the researchers incorporate perceived risks in their estimations. One study (Gegax, Gerking, and Schulze 1985) has done just this.

'It is unfortunate that VSL nomenclature implies that a life is being valued: many people, including economists, are uncomfortable with such a prospect. An incorrect response to such concerns, but one frequently heard, is that a statistical life rather than a real life is being valued, the distinction being that of whether one knows in advance who will die prematurely. The appropriate response is that reducing one's risk of death is being valued, with the VSL measure being a convenient form in which to express both WTP and the size of the risk change in one measure. Evidence that people are willing to pay to reduce their risk of death can be seen in many everyday activities. Reducing the speed of one's car in rainy conditions shows a trade-off between saving travel time and reducing mortality (plus morbidity) risks. Translation of time into dollars makes the money-risk tradeoff explicit. 
in 10,000 range. They put more faith in the lower end of this range. Miller (1990) reviews forty-seven "good quality" mortality risk valuation studies and adjusts their results to be more consistent with economic theory (using aftertax instead of before-tax rates, for instance), with the definition of risks they used, the value of travel time (for the motor fatality studies), and for other problems. Miller finds a mean VSL of $\$ 2.2$ million (1988 \$) with a reasonable range of $\pm 30 \%$. He also finds no discernable trend in the VSL's as a function of the size of the risk change (see below).

Because nearly the entire literature addresses risks of accidental death taken voluntarily, its use to value mortality risks from environmental causes is problematic. The WTP to reduce accidental death caused by voluntary activities (in doing one's job or while driving a vehicle, for instance) may be viewed differently from death caused by environmental pollution exposure (such as cancer from pollution exposure) that is largely of an involuntary nature. Even if the nature of the death were unimportant to valuation, other factors would argue for hesitancy in applying this literature to environmental problems: the presence of differences in the life-years lost (fewer with environmental risks than with work-place risks, for instance), in the age at which changes in risks are experienced (older people with environmental risks), and in latency.

Few CV studies have attempted to estimate WTP for reducing mortality risks in an environmental context. Mitchell and Carson (1986) examined WTP for various size reductions in cancer risks from reduced exposure to trihalomethanes in drinking water. In its questions, this study incorporates a latency period between exposure and possible realization of the cancer (assumed to be 20 years). It finds that for a 4 in 1 million change in latent cancer risks, the value of a statistical life is about $\$ 2.5$ million (1986 \$), but for risk reductions in the range of wage-risk studies ( 1 in 10,000), the VSL is only $\$ 167,000$. The latency consideration should result in lower estimates of VSL relative to the literature on accidental death (where latency is zero). Yet, there is a supposition that VSLs for environmental types of death (nonaccidental and involuntary) are likely to exceed those of worker or auto deaths. Thus, some doubt is cast on the Mitchell and Carson survey instrument (in particular, whether respondents could understand the extremely small changes in health risks they were asked to value).

Another study (Smith and Devousges 1987) asked individuals in Boston and Acton, Massachussetts (the latter because of recent incidents of drinking water contamination), their (household) WTP (in terms of tax and price increases) for reductions in the risks of mortality from exposure to hazardous wastes at a hypothetical dump site three miles from their home. They found, 
surprisingly, that WTP was not particularly sensitive to the baseline risks assumed or the size of the risk reduction. Bids were in the range of $\$ 8$ to $\$ 30$ for assumed risk changes ranging from $1 / 100$ to $2 / 300,000$. Given this relative constancy and the dramatic difference in risk changes, the VSL is much larger for smaller risk changes, ranging from only about $\$ 2,000$ for the $1 / 100$ risk change to $\$ 2$ million for a 2 in 300,000 risk change. Of course, baseline risks are also very different - 1 in 50 in the former case and 1 in 120,000 in the latter.

Unfortunately, this disquieting finding may be an artifact of the means used to communicate risks - a risk circle. From the pictures in the article, it is impossible to discern differences in risks across the various scenarios. Thus, one might expect bids to be little different from one another, as well. Another important finding - that WTP for a further reduction in risks increases with baseline risks ${ }^{10}$ (rather than decreasing as might be expected from diminishing returns) - is then also called into question.

Other methods have been used to value reductions in mortality risks. For instance, in some cases individuals living near hazardous waste sites take measures to reduce perceived carcinogenic and other risks to health. By observing the amounts they spend on such means - buying bottled water, for instance - and asking them the amount of risks they think they are avoiding, it is possible to make tentative inferences about the minimum amounts they are willing to pay to reduce perceived risks. The benefit of this approach is that whether the residents know the "objective" risks they face are irrelevant for the valuation problem (although there is still an issue about whether, in a new context, such values can be applied to the objective risks). One problem with this approach is that such measures reduce morbidity as well as mortality risks. Thus, it is not correct to attribute the entire averting cost to the mortality risk reduction.

It was common a number of years ago to value premature mortality using the so-called "foregone earnings" or resource cost approach, in which deaths were valued according to the wage or salary income that would be lost as a result of premature death. This approach is no longer viewed as acceptable for modern benefit-cost analysis (BCA). Not only does it fail to assign any value to the prevention of mortality among the elderly and the retired (who have no current wages), but it is also inconsistent with the basic fundamentals of economics from which BCA sprung. This is because it

\footnotetext{
${ }^{10}$ Thus, WTP for the first risk reduction of 1 per 100,000 is less than WTP for the second 1 per 100,000 reduction.
} 
ignores individuals' WTP for reductions in their own - as well as others' mortality risks. Thus, WTP may bear little relationship to income loss.

\subsubsection{Morbidity Reductions}

Health benefits can also take the form of reduced morbidity (both acute and chronic illness). CV approaches have been used with some success to value reductions in acute respiratory symptoms and asthma attacks. The resource cost approach has also been used. For instance, work-loss days are typically valued at the wage rate or some fraction thereof, with literature examining how time in non-work situations (for homemakers and children, and the value of leisure time) should be valued. Some literature also attempts to infer morbidity values from observing avoidance behavior - for instance, the purchase of air conditioners. Thus, if reducing air pollution means fewer doctor and hospital visits, less money spent on medicine, less work loss, etc., when appropriately valued these reduced costs of illness help establish a lower bound on WTP for reduced morbidity risks. (We say lower bound because there are nonmonetary components to illness, such as pain, from which individuals would surely be willing to pay to be free.)

Very little literature addresses the total value of reducing chronic illness, such as hypertension, learning disabilities (Schwartz et al. 1985), and the incidence of chronic respiratory diseases, such as chronic bronchitis (Viscusi, Magat, and Huber, 1988 and 1991; Krupnick and Cropper 1992). Other literature has investigated just the medical cost and the labor market implications (in lower wages, or reduced work hours) of having various types of chronic diseases. Other effects that might be loosely termed health effects that individuals may be willing to pay to avoid include the reduced risk of mutagenic and teratogenic effects and anxiety. Very limited research has been conducted on valuation of these effects.

Acute illness occurs frequently and therefore may be valued more credibly and easily than other morbidity endpoints. Because acute illness is frequently experienced, people are familiar with the good being valued; questions on its valuation need not be phrased to incorporate risks (as they must be where developing chronic disease or dying prematurely is at issue). Rather, one can straightforwardly ask for WTP for a reduction in a day of symptoms. Three CV studies have estimated values for respiratory symptom days, with estimates ranging from $\$ 1$ to $\$ 25$ and more, on average (see Krupnick 1987 for a complete review of the relevant studies for valuing respiratory symptoms). 
Chronic illness is probably the most difficult morbidity endpoint to value because the commodity one is valuing is so complex and its realization so uncertain. Researchers have had some success valuing the risks of chronic respiratory disease (the value of a statistical case - VSC) using contingent behavior and CV questions. People were asked to choose between living in one of two cities identical in all respects except the risk of developing chronic disease and either (in separate questions) the risk of dying in an auto accident or the cost of living (a money measure). With an interactive computer program driving their choices to a point of indifference between the cities, the VSCs for the risk-risk trade were converted to dollars using the above wage premia literature, and the VSCs for the risk-cost-of-living trade were obtained directly. The studies find VSCs in the lower range of VSLs, with Krupnick and Cropper's (1992) best estimate of $\$ 1$ million, obtained from a sample of people who, while being themselves healthy, each had relatives with chronic respiratory disease. Hence, they were familiar (to varying degrees) with the complex consequences of this disease.

Altruistic values for reducing non-fatal risks of poisonings caused by insecticide handling were obtained in a CV study of 785 individuals in Greensboro, North Carolina, by Viscusi, Magat, and Forrest (1988). Average values of a statistical case avoided ranged between $\$ 2,100$ and $\$ 3,700$ for a scenario involving risks reduced $5 / 10,000$ by a new, safer product than the hypothetical product presented. WTP was elicited for an advertising campaign in North Carolina and in the United States to result in the same risk reductions (2,000 statistical cases in North Carolina) through improved handling of insecticides. When aggregated across the population of North Carolina, the value of a statistical case avoided $(\$ 10,000-\$ 18,000)$ was more than five times that obtained through private risk valuations. A similar result was derived for the U.S. campaign, although respondents were not willing to pay for a campaign that would only benefit residents of another state (e.g., Georgia).

Caution in using this study is urged because of (1) the relatively unsophisticated nature of the survey design of this study, (2) the possibility that private valuations are spilling over into the altruistic responses, and (3) failure to probe the deeper issue of whether respondents would change their "altruistic" bids upon learning how high their value per case was relative to a value obtained through private risk reductions. The authors urge caution for any use of this study outside of the commodities it examined.

\subsubsection{Occupational Health and Safety}

The effects of fuel cycle activities on occupational health and safety include both mortality and morbidity risks, whether from exposure to 
pollutants or from accidents. These would be valued using wage premia studies. However, the major question is whether such effects are externalities. Unlike the risks from fuel cycle activities borne by the general public, occupational risks are likely to be at least partly internisized in production activities - for example, in wage premia paid for particularly risky jobs and in health insurance given to employees as a benefit. To the extent such externalities are internalized, the estimated damages would not be added to the private cost of electricity generation (see the forthcoming Coal Fuel Cycle document). The extent to which occupational risks associated with fuel cycles are internalized is a topic for research in the course of this project. Note, however, that it is the premise of the wage premia literature that occupational health and safety effects are internalized into wages. To the extent they are not, VSLs for the general public are being underestimated by these studies.

Another issue for using these studies is whether the information about job risks held by workers is too imperfect to be reliable. That is, even if perceived job risks were fully internalized into wages, wages might not fully (or might excessively) reflect actual job risks, leaving uninternalized (or overinternalized) externalities.

In any event, with the wage-mortality risk literature already reviewed, it remains to consider the wage-injury literature. Viscusi (1986) reviews this literature on values of preventing non-fatal injury to conclude that they range between $\$ 20,000$ and $\$ 30,000$ per case.

\subsubsection{Production Impacts}

Individuals are not the only parties harmed by emissions from the fuel cycles. There are also damages to manufacturing and commercial enterprises (including those providing recreational services) as well." ${ }^{11}$ For instance, the food processing industry uses vast amounts of fresh water for its production process. Contamination of those waters means that alternative supplies have to be identified or the intake water must be given special and often expensive treatment before it can be used. Thus, one benefit from reduced emissions to water bodies may be the reduction in costs to water-using industries. This same point holds for municipalities using contaminated waters for drinking water supplies. Individuals who switched to an uncontaminated but more expensive water supply after the discovery of contamination in their historical source of supply will pay higher prices for their water. The benefits of

\footnotetext{
${ }^{11}$ Ultimately all costs and benefits are borne by individuals. The damages/benefits discussed in this section accrue in the first instance to business.
} 
reduced contamination (assuming constant marginal costs of providing water at each source of supply) ars related to the reduction in water price from returning to the historical supply. They include cost savings from being able to use the same quantity of water at a cheaper price plus a benefit from increased water consumption due to the fall in price. Note that if people do not switch back to the historical supply (because they still doubt its safety, for instance), the benefits of the switch would be zero (and may even be negative if individuals purchase expensive alternatives to tap water).

The most well understood production effect associated with fuel cycles is that of air pollution, particularly ozone, on crops. Consumer plus producer surplus gains from an increase in agricultural productivity have been estimated in several large-scale studies using the ozone dose-response literature, primarily that developed by EPA's National Crop Loss Assessment Network program. Kopp (1985) and Adams, Hamilton, and McCarl (1985) have constructed models of the damage to field crops from reductions in ambient ozone, and there are several studies of ozone damage to a variety of fruit and vegetable crops in California. Benefits of 10 to $20 \%$ reductions in seasonal average ozone levels are about $\$ 1$ billion annually for the major field crops.

The effects of acid deposition on crops and commercial forests are other potentially important effects of fossil-fuel cycles, although the National Acid Precipitation Assessment Program (NAPAP) (EPA et al. 1989) concluded that there have been no crop effects and, with the exception of red spruce at high elevations, there is no evidence that acid deposition has caused a general decline in U.S. forests. NAPAP discusses one study that estimated timber losses as a function of hypothetical growth reductions.

\subsubsection{Benefits to Economic Assets}

The stock of economic assets can also be harmed by emissions. The benefits of avoiding such impacts are measured by the increased value of the stream of economic services that these assets deliver. One example would be acidic leachate from a coal mining site that, through intake of water for use by residences or commercial establishments, was responsible for corroding tanks, pipes, and other surfaces with which it came in contact. Other effects besides corrosion are possible. In these cases, as with those above, the impacts to third parties that would be prevented or reversed through any cleanup action represent lower-bound estimates of economic benefits. This is because those currently bearing the costs of this corrosion would be willing to pay at least this much for the improvement. 
To the extent that hazardous waste sites are involved in the fuel cycle, the effects on economic assets may be more subtle. For example, because of the perception (if not the reality) of health risks, aesthetic impairment, and other unpleasantness associated with such sites, houses and other properties adjoining such sites are depressed in value. In other words, problems perceived to be associated with hazardous waste sites are said to be "capitalized" into property values.

Using a technique known as hedonic estimation (in which the market price of a home or other property is viewed as being composed of a number of individual implicit prices for its various site and house characteristics), it is possible to make predictions about the decline in property values that might result from waste accumulation at a site. Where otherwise desirable residential or commercial properties are located close to the site, the hedonic approach may be quite useful for estimating benefits. ${ }^{12}$

A few studies have attempted to value the benefits of reduced particulate emissions on soiling and painted surfaces, and materials affected by acid rain. These estimates suffer from incomplete data on the materials inventory and economic models and data that fail to appropriately capture avoidance and mitigation behavior. For instance, Lipfert (1987) assesses and values damages to materials from acid deposition in the New Haven, Conn., region. He uses damage functions and unit cost factors and a materials inventory for the region to estimate that the benefits of a $50 \%$ reduction in acid deposition would be $\$ 4.25$ per person per year. However, Lipfert's unit values do not reflect the frequency and types of responses made by building owners to signs or prospects of materials effects.

\subsubsection{Impacts to Environmental Assets}

Fuel cycle activities may also affect natural, "environmental" assets. These include recreation sites and other natural resources that yield valuable services from use (the latter, quite apart from their value for recreation) and also provide value even to those who do not use them (what economists call "existence" values, described later in this section).

\footnotetext{
${ }^{12}$ The change in local property values is generally not considered to be an independent benefit category. Rather, it is a proxy for changes in site characteristics (such as health risks) that would be affected (or perceived to be affected) by site remediation.
} 


\section{Recreation}

Studies addressing the nonmarketed services of recreation are by far the most prevalent, owing to the early insight on valuation methods offered by the Clawson travel cost model, the theoretical complexities of estimating benefits in this area, many government funders, and widely available data. Smith and Kaoru (1990) performed a meta-analysis on 77 studies of recreation demand, and Walsh, Johnson, and McKean (1988) reviewed 120 studies of the value of various types of recreation-activity days. Most of these studies are on individual sites or clusters of sites in a region. Some seek estimates of national recreation benefits.

The recreation literature may be split into two contexts: the value of adding or eliminating one or more recreation sites (quantity) and the value of changing quality characteristics (e.g., water quality or catch rates) at one or more sites (quality). While the former may conceptually be considered the logical extreme of the latter (i.e., when pollution is bad enough the site is effectively eliminated) in practice, approaches to valuation in each context are quite different in the details.

For this project, the site quantity studies are most relevant for considering the effects of a new hydroelectric facility. Such a facility may eliminate a recreation area downstream while, perhaps, creating a new recreation area behind the dam (albeit of a very different character than the free-flowing river it replaced).

In the quality context, the NAPAP studies compose perhaps the most relevant and empirically complete literature on the effects of air emissions on recreation. While these studies considered the effect of acid deposition on both the quality and quantity of recreation sites in the northeastern United States, they considered only the quantity context in the region associated with our southeast reference environment (EPA et al. 1989, SOS 27; Krupnick, Harrington, and Radin 1990). Surprisingly, while there are several comprehensive reviews of the quantity studies, there are no recent reviews of the quality studies.

As a consequence of the research activity in this area, there are a variety of valuation approaches ranging from the very simple to the esoteric (consult Smith 1989 for a summary). But, to obtain benefit estimates, all of these approaches need estimates from the physical sciences of a long chain of effects. For instance, to estimate the benefits of reducing $\mathrm{SO}_{2}$ and $\mathrm{NO}_{x}$ emissionc along the "acid deposition pathway," at a minimum one would need information on the effects of these emissions on acid deposition by location 
and the effects of deposition on stream and lake quality. Some economic valuation models use these quality changes as a starting point: others use changes in catch rate. For the latter models, additional scientific information includes the effects of quality change on fish populations and the effects of changes in fish populations on catch rate. Somehow, the ideal economic model would also need to capture the effects of worse fishing at some sites on recreation choices at all sites and the effects (in the case of environmental improvements) on current nonparticipants that might be induced to participate. In the same model, consistent with welfare maximization, the value recreators place on these changes would also need to be captured.

The simplest valuation approach, called the "unit-day" value approach, is a two-step procedure in which (1) effects of the change in recreation site characteristics (such as water quality) on recreation participation are estimated, and (2) from numerous studies in the literature, "prices" for a day of recreation are multiplied by the change in recreational participation to obtain an estimate of benefits. Walsh, Johnson, and McKean (1988) offer a 20 year review of 102 studies using travel cost and CV approaches to produce unit values (per activity day) for camping; picnicking; swimming; hiking; boating; hunting; cold, salt, warm, and anadromous fishing, non-consumptive fishing and wildlife; and wilderness. Some of the values are available for the eastern and western United States.

As the affected sites may have unique characteristics, "average" unit values drawn from the literature may be inappropriate. In particular, the participation choice and valuation are really two sides of the same coin that cannot be neatly separated, as is implied by the unit-day value approach.

Better approaches are those that examine these two aspects together. Each of these approaches takes as its point of departure the insight that the WTP for improvements in recreation quality characteristics can be determined by examining recreation choices across sites that have different levels of quality and are located at different distances from recreators (i.e., one can estimate the trade-off between quality and quantity of recreation experience and the travel costs and time needed to obtain these experiences).

The three major approaches are multiple site demand models, discrete choice models, and hedonic travel cost models (see Bockstael, Hanemann, and Kling 1987). All have advantages and disadvantages. The first, also called a varying parameters model, estimates a system of demand equations for all sites in the area, with travel costs, personal characteristics, and site characteristics as arguments (the last indirectly in a second stage). The consumer surplus associated with a change in a site characteristics (the 
willingness to pay for this change) can then be computed. The drawbacks of this approach are that non-participation and substitution possibilities across sites are not handled very well.

The discrete choice approach addresses both of these drawbacks by seeking to explain recreator choices per occasion (i.e., the allocation of participation across sites). It explicitly allows for an individual to participate at some sites but not at others. A drawback of this approach is that it assumes total participation in the area. ${ }^{13}$ In practice, additional analyses are appended to explain overall participation, using results of the site allocation model as input to the appended analysis. A recent study of swimming visits at 30 Boston beaches is a successful application of this approach that yields benefits in terms of water quality characteristics (Bockstael, Hanemann, and Kling 1987).

The final approach, the hedonic travel cost model (Brown and Mendelsohn 1984) assumes that each individual can choose among sites with many different bundles of attributes and can trade off some of one attribute for more of another. By observing the sites individuals choose, the price and, ultimately, the demand for each attribute can be recovered. The basic assumptions of this model, like the others, have been criticized. For instance, Bockstael, Hanemann, and Kling (1987) note that there is no market for providing alternative attributes of sites the way there is for houses (an application of hedonic techniques that is theoretically more satisfying), and thus it is questionable how much meaning one should attach to estimates of such prices as estimates of marginal valuation of an attribute. Indeed, values of desirable attributes estimated by this technique have frequently been negative. Smith, Palmquist, and Jackus (1990) have made a series of modifications to this approach that improve its theoretical and empirical performance, however. They estimate benefits per trip for a $60 \%$ increase in catch rate of boat fishing parties in Albermarle-Pamlico Estuary in North Carolina of about $\$ 1$, in the range found by others for sportfishing in Florida using a discrete choice model (Bockstael, McConnell, and Strand 1989).

In spite of the vitality of research on recreation benefits, a convincing case has not been made that recreation choice is highly sensitive to changes in site quality or characteristics and, therefore, that changes in quality are highly valued. For instance, a study of the recreation benefits of pollution reductions at 30 Boston beaches (Bockstael, Hanemann, and Kling 1987) finds per recreator per season benefits from a $10 \%$ reduction in oil, chemical

\footnotetext{
${ }^{13}$ Additional drawbacks include the assumption of independence of choice occasions and degeneration of constant marginal costs of trips.
} 
oxygen demand (COD), or fecal coliform ranging from $\$ .50$ (fecal coliform) to $\$ 6.70$ (COD) (1989 \$). As another example, a 20\% increase in the number of striped bass caught in the Maryland portion of the Chesapeake Bay was estimated to result in annual benefits to bass fisherman of only $\$ 2.50$ per person, while benefits to beach users of a $20 \%$ reduction in nutrients in the Maryland portion of the Bay results in estimated benefits of $\$ 17$ per trip. Such changes in nutrients of fish populations are far greater that those that might result from a new power plant.

More pertinent to the fuel cycle for coal are results from studies linking reductions in acid deposition to the benefits to recreational fishing in the Adirondacks (see Krupnick, Harrington, and Radin 1990 for a survey and NAPAP, SOS 27 1990). One study (Morey and Shaw, forthcoming) is useful for environmental costing of these damages because it values explicitly changes in fishable acres and catch rates for most preferred fish types affected by acidity instead of treating quality changes implicitly, as other studies do. Using a relatively unsophisticated version of the discrete choice model, Morey and Shaw find a WTP for a $25 \%$ improvement in catch of $\$ 8.70$ per fisherman per visit. One drawback is that total trips are assumed. ${ }^{14}$

It is possible that the major benefits of reducing pollution of recreation assets may well be in non-use values (see below), not because such values may be large per capita but because so many people may have them. A companion CV study of user and nonuser benefits to improving water quality in the Chesapeake Bay finds use values per household three times nonuse values ( $\$ 94$ per household per year versus $\$ 33$ ) for those living in the Bay border states. If non-use values extend to people living in other states, total nonuse values could easily exceed total use values. Of course, the Bay is a unique environmental asset. One would be surprised to find high existence values for common types of assets. In what is probably an amazing coincidence, a study asking for use and nonuse values for improving Minnesota lakes (Welle 1985) found the same result as the above Chesapeake Bay study: the average user's WTP was about three times the WTP of the average nonuser. As all Minnesota lakes are included in the scenario, this group of assets may be viewed as unique in a way similar to that of the Chesapeake Bay.

\footnotetext{
${ }^{14}$ Many other studies have estimated the WTP for changes in catch rate, but not in the context of acid deposition and lakes. For instance, Bockstael, McConnell, and Strand (1987) estimated that fishermen would be WTP from $\$ 2$ to $\$ 6$ per trip if they could increase their catch of striped bass from the Chesapeake Bay by $25 \%$.
} 
An important complication for valuing recreational benefits of environmental improvements concerns the appropriate means of accounting for baseline conditions. Valuation studies of impacts to lakes from acid rain assume that the historical, rather than the current, baseline is appropriate and that impacts already observed and related to a certain amount of deposition are a reasonable estimate of the benefits to be gained by reducing deposition (or slowing its increase) by the same amount. Estimates of the value of avoiding further deposition to lakes would be far more useful to environmental costing in the context of the DOE study. ${ }^{15}$

Visibility

Visibility benefits are a particularly important type of benefit associated with reduced emissions from electricity generation. Such benefits could be obtained in rural settings, where a plume marred an otherwise clear vista, or contributed to regional haze and reduced visual range, or in an urban setting, where visual range was restricted. The most important problems in this literature are in the linkage from emissions to some measure of visibility and the inconsistencies between measures of visibility used by scientists and those by economists attempting to value visibility in CV surveys.

Researchers on visibility in urban settings have estimated an order of magnitude range for the individual WTP for a one-mile change in visual range (\$7 - \$70) (Regional Economic Research 1990) using both CV and hedonic property value studies. Rowe et al. (1986) found that a $30 \%$ increase in visual range in four air basins in California generated benefits of about $\$ 26$ per person per year. In Denver, for a $25 \%$ improvement in range, annual per capita benefits were $\$ 17$.

Additional research has been conducted on users' and nonusers' visibility values in major national recreation areas (e.g., the Grand Canyon). Non-use values for visibility were $90 \%$ of total value (Schulze et al. 1983). Visibility benefits generally have been found to be lower than health benefits (15\% in Rowe et al. 1986) in studies that examine air pollution control scenarios affecting both endpoints.

Both the $\mathrm{CV}$ and property value techniques as applied to the visibility endpoint suffer from the inability to rule out other types of damages (such as health) in these estimates.

\footnotetext{
${ }^{15}$ If our project were considering the benefits from reducing emissions below the current baseline, then the concept of irreversibilities would also need to be incorporated in the analysis.
} 


\section{Other Use Values}

Environmental assets also provide use values beyond those directly affecting recreation. For instance, estuaries and rivers serve as spawning grounds for fish species that have both market and recreational value. Similarly, biological processes in water bodies can help assimilate waste products. Estimating these benefits requires a combination of scientific information on dose-response, as well as values for the services affected, and is subject to other types of uncertainties described earlier.

\section{Nonuse Values}

What are referred to as "nonuse" values associated with environmental assets are probably the most controversial of all the benefit categories. Survey after survey has shown that many people are willing to pay something for the knowledge that environmental assets are being protected or improved, even though they may have no intention of themselves ever using these assets for recreation. These so-called existence values may be related to wise stewardship, bequest motives, or perhaps even vicarious consumption. In addition, some people may feel that protecting certain assets is a moral and ethical imperative. To the extent such imperatives affect willingness to pay, a benefit-cost assessment could incorporate moral or ethical concerns.

The definition of existence values is fuzzier than it may appear. One's physical presense at a site clearly indicates use. But, if elephants in a wildlife refuge are observed on television, does this constitute use, or may it be considered as information contributing to formation of nonuse values? What if the television program was made ten years ago and the elephants are no longer in the region depicted in the pregram?

However defined, existence values on an environmental asset may be large relative to use values, at least for unique assets. This inference is made because, to the degree the good is a pure public good (e.g., to the degree individual values are unaffected by distance from the site), very large numbers of people may hold values for the site. Even if individual values are small relative to use values, the large numbers of individuals holding the former relative to the latter can potentially cause existence values to dominate.

Yet, tile value of such improvements remains elusive for several reasons. First, many surveys ask about concerns for environmental assets in general, rather than for specific assets. Local WTP may be affected by the types and variety of environmental assets present in a region. Individuals may care less about improving certain assets (such as a local river) if there are 
many other, unaffected rivers nearby. Second, the presence of substitutes creates an addition problem; for example, the sum of WTP for each marsh taken separately is likely to be far larger than the WTP for all marshes. Third, only contingent valuation approaches can be used to obtain such values. Thus, their results cannot be proved or disproved, although regressions of WTP on a set of variables thought $a$ priori to exert influence on WTP can act as a reliability check. Fourth, these approaches have a number of inherent limitations. Given the economist's bias toward observing what people do, rather than what they say, the most important of these is the hypothetical nature of this approach and the difficulty of making the scenario credible and understandable. In addition, careful analyses of responses to such surveys indicate that the responses are quite sensitive to question wording, the method of eliciting responses (such as by using a card with various dollar amounts on it), and the hypothetical means of payment (such as an increase in income taxes).

Several recent papers on the nonuse value debate clarify the issues. One side in the debate over whether such values can be credibly estimated asserts that lack of familiarity with the "goods" at issue (such as an ecosystem, an endangered species, or a wilderness area) and the embedding effect (i.e., where WTP is sensitive to whether a good is valued by itself or as part of many other goods) make it inherently impossible to reliably estimate the WTP for such goods through hypothetical questioning. It is asserted (Kahneman and Knetch 1992) that observed WTP values are for the purchase of "moral satisfaction" not a WTP for marginal changes in the good. The other side suggests the studies relied upon for these conclusions are faulty and that normal economic behavior can explain most of the observed, allegedly inconsistent, patterns of WTP responses (Smith 1992). Similar conclusions have also been reached about an Exxon-funcied effort that concluded CV was an unreliable tool for eliciting non-use values. For example, one of the studies purporting to show that individual bids for saving ducks were insensitive to the number of ducks being saved (i.e., from 2,000 to 200,000 ducks annually (Desvousges et al 1992)) has been criticized for defining scenarios that involve, in fact, a very nearly identical percentage of ducks being saved (from $1 \%$ to $2 \%$ of ducks on the flyway). In such a case, it may be unremarkable that WTP estimates for a group of individuals responding to one scenario are very similar to those from a group responding to a different scenario.

One of the knottiest problems with studies of existence values is disentangling use from nonuse values. Mitchell and Carson (1989) suggest dividing the sample of respondents into users and nonusers, counting only the values of nonusers as existence values, even though users may also hold such values. Boyle and Bishop (1987) and Bennett (1984) defined scenarios to 
preclude use (e.g., valuing eagles living in an inaccessible region of Wisconsin). Another approach is to value a good for which there is no use (e.g., the striped shiner).

One example of a particularly good existence value study is Boyle and Bishop (1987), who valued eagle and striped shiner preservation in Wisconsin. Using closed-ended WTP questions asked only of Wisconsin taxpayers, they estimated the average WTP for striped shiner preservation to be $\$ 4$, and the median to be less than $\$ 1$. Average existence values for preserving the bald eagle in Wisconsin were about $\$ 11$ for nonviewers who never contributed to a special Wisconsin endangered species fund and $\$ 31$ for nonviewers who did. For the noncontributors, existence values are $38 \%$ of use values, while use and nonuse values for contributors are about equal. Median values are always less than mean values, indicating the presence of a number of very high values. These results are quite similar to those of other studies noted in the recreation section above.

In using such studies in our reference environment and investment approach, there are at least two important problems. First, the studies are very specific to species or ecosystem types and regions and, therefore, will not be easily transferable. Second, many of the studies we have examined so far estimate existence values for a change from the current state of nature to elimination of habitat, etc. This drastic change is not likely to be compatible with the marginal increase in emissions caused by an investment in new generation.

Finally, efforts are now under way to value the consequences of a variety of possible effects of global warming. We anticipate that this class of effects will prove particularly difficult to value. For conceptual reasons (see Chapter 2), we do not anticipate using costs of reducing greenhouse gases as a proxy for the benefits of such reductions.

\subsection{SUMMARY AND RESEARCH ISSUES}

Progress in the area of environmental benefit estimation over the last fifteen years has been remarkable. Benefit analysis has gone from an afterthought in a cost-effectiveness analysis to being an integral part of environmental economics and government decisionmaking. Consider the first professional examination of the benefits literature (Fisher and Peterson 1976), which concluded that benefit estimates should be taken with a "grain of salt." Yet, three years later, Freeman (1979) provided the first compendium of benefit estimation methods. Now, environmental benefit analysis has been 
institutionalized in the Regulatory Impact Assessment process under E012291; the natural resource damage assessment provisions of the Superfund Act; and State Implementation Plan decisions of a number of states, notably California. The newest survey of the field (Cropper and Oates 1990) depicts the enormous energy, success, and popularity of the field.

Most of the research effort has clearly gone into the theory and estimation of recreation and mortality benefits. Recently, major efforts have used discrete choice models for valuing recreation quality change, but these have been generally applied to saltwater-based recreation rather than the freshwater setting appropriate to our southeast reference environment. For this DOE study, the empirical importance of estimating these benefits for changes in the fuel cycle is also debatable. The extent to which small improvements in water quality or visibility at a group of sites that could result in substantial numbers of new participants is a key issue.

In the other major area of research effort, mortality benefit studies have derived values of a statistical life that are quite consistent with one another. However, very few studies have obtained values for reducing mortality risks arising from environmental improvements, and few have examined a person's WTP for reducing risks to others; such studies are sorely needed.

Substantial research has also addressed the relatively straightforward estimation of benefits of environmental improvements to economic output, concentrating on the effects of ozone exposure on field crops. Limitations in the availability of dose-response functions for other pollutants and for various types of products (e.g., forestry and row crops) have limited the interests of economists in this area of valuation. Few studies have valued producer surplus losses to firms using recreation assets as an input.

The field of benefit estimation is wide open in the other areas. We would guess that morbidity from air pollution and visibility effects would be of most importance to the coal cycle. Materials damage might also be important.

The literature on valuing morbidity effects is exceedingly thin, using mostly CV techniques and confined primarily to the valuation of reductions in acute symptom days. Each of the studies has methodological drawbacks, but the values they find for a similar endpoint are close to one another and the a priori ranking of symptoms by severity mirrors the ranking produced by the WTP estimates. A definitive acute morbidity valuation study using the CV 
approach could be done given current knowledge and should be a high priority.

In spite of a number of attempts to estimate the WTP for visibility improvements in urban areas, much uncertainty still exists about the magnitude of these values, the appropriate unit of measurement, and how people even think about such values. Literature on nonuse visibility values and visibility values for recreation is even less clear.

Research on benefits to materials, both as economic assets and as cultural objects, has been very slow to develop after a fast start on household soiling. This slow development is primarily because of empirical considerations for the former and the difficult problems posed by nonuse value estimation of the latter. Only the most limited materials inventories exit for cities that would permit even engineering based estimates of damages. In addition, surveys upon which to estimate the behavioral responses to materials damage are sorely lacking.

Finally, the full range of existence values (including ecosystem effects) remains largely unexplored. Much research effort has been placed on the natural resources damage assessment process applied to the Exxon Valdez spill under the provisions of the Superfund law. If and when the methodologies and results are released, valuation in this area should benefit.

\subsection{SPECIAL ISSUES IN VALUATION}

\subsubsection{Transferability}

There are three distinct research strategies for obtaining estimates of environmental costs of fuel cycles specific to reference environments. The first is to estimate values for the specific environments from the "bottom up" using the damage function approach. By coincidence, there may be valuation studies in the literature specific to one of the reference environments. In this case, such studies can be used directly. The second is to obtain "top down" estimates, starting with national-level benefit estimates and using some method to allocate these estimates to the specific reference environment. The third is to transfer the results of valuation studies for sites at one location to the reference environment.

We anticipate that the first and third approaches will be used in the fuel cycle project. The second approach, essentially that adopted by Hohmeyer (1988), is less credible than the others. Because of the location 
specificity of environmental damage, it is difficult to imagine how one can estimate national benefits without estimating local damages first and then aggregating. This is not to say that national benefit studies are useless to the project. Rather, to be useful they need to have explicitly aggregated local benefits in the process of developing national estimates. ${ }^{16}$

As most of this paper addresses the first approach, we focus below on the third approach - the issue of transferability. The papers published in Water Resources Research (1992) as well as the participants in the Spring 1992 Association of Environmental and Resource Economics (AERE) Workshop on Benefits Transfers are in close agreement on general protocols for conducting a benefits transfer. The care and effort used in conducting a benefit transfer, and indeed whether one should attempt it at all, depend on the commodity being valued, differences in regional, site and personal characteristics, and the nature of the original literature being relied upon for the benefit transfer. Given that a benefit transfer is called for, much emphasis is placed on the use of demand or value functions where possible, as opposed to the use of average unit values - be they for a day of recreation or a day of coughing avoided. Using the function approach puts some additional burden on the analyst (data must be gathered on the variables found by the original study to affect willingness to pay, for instance); indeed, without careful reporting of results in the original study, this approach may be impossible.

An example of transferring a function would be an estimated regression equation that specifies household willingness to pay for reductions in drinking water contaminants as a function of existing concentrations of various pollutants in the drinking water (or baseline perceived risk levels), real income, age, sex, number of children, gallons consumed per day, baseline health status, smoking status, etc. The function approach involves obtaining estimates of the average values of the regression variables for the reference environments (income levels, for example) and inserting these values into the WTP function. Where such information is unavailable, the average values for such characteristics might be taken from the study generating the function.

The unit value approach is applied by simply multiplying a unit value by the relevant estimate of physical changes (e.g., value of a fishing day times the change in fishing days predicted in the reference environment). Natural

\footnotetext{
${ }^{16}$ Carson and Mitchell 1988 is an example of a national study used to estimate local benefits. The authors conducted a national $\mathrm{CV}$ survey of the recreational and nonuse benefits of improved water quality and used the resulting WTP function to estimate the benefits of similar water qualiiy improvements to individuals living near the Monongahela River.
} 
scientists typically stop far short of measuring changes in fishing days, and instead, estimate the effects of pollution concentrations on fish populations or the effects of emissions on water quality variables (e.g., fecal coliform, dissolved oxygen). Therefore, use of the unit value approach usually requires separate estimates of the link between the measures addressed by natural scientists and unit values.

The average values and the functions need not be taken from only one study of one location. The study itself may consider many locations, or even the nation, thereby providing unit values that average over very different environments or providing functions that result from observations on a wide range of environments. Whether one chooses a value or function from a study on a particular environment or on many environments depends on judgment about the degree of similarity between the reference environment and the environment or environments examined in the study. In general, the multienvironment study that reports WTP as a function of location-specific characteristics provides the most flexibility.

Finally, there may be studies that integrate results of other studies into a "meta-analysis." This type of statistical analysis combines the results of many studies on the same endpoint to obtain functional relationships that are the best fitting over the results of each of the studies. Smith and Kaoru 1990 is an example of such a study, where the authors seek to explain differences in average WTP for recreation experiences obtained in 77 studies.

\section{Transferability by endpoint}

How is one to judge when a reference environment is similar to a studied environment? At least one should be aware of important ways in which environments can differ. There are several types of location-specific characteristics that would apfear to be important: region-specific, site-specific, and individual characteristics. Region-specific characteristics might include overall environmental quality levels, the number and type of recreation opportunities available and the location of recreators relative to these sites, and the quality of ecological systems. Site-specific characteristics might include baseline levels of pollution at specific recreation sites and baseline catch levels at a site. Individual characteristics might include income, sex, age, household size, recreation participation rates by activity type, and education levels.

The degree to which transferability can be credibly carried out depends on the nature of the endpoint in question and the features of the valuation literature for that endpoint. Values for reducing health effects are perhaps 
relatively easy to transfer, both because of the presumption and some empirical evidence that region and site characteristics do not affect such values. If individuals in regions of poor air quality valued improvements in health effects more or less highly than those in other regions (say, because of lower health status of the former group), this would be reason for caution in transfer of values or functions. There is more evidence that individual characteristics affect values. Here, there are a number of mortality and morbidity studies that provide functions explaining variation in WTP by individual characteristics, but without a location component.

Studies of commercial damages (crops, forests, and fisheries) are highly location specific, for the simple reason that damages depend, in oart, on the specific species being harvested and baseline productivity (whick depends on climate, soil, and other location-specific factors). Transferability may not be critical to estimate benefits for these endpoints, however. A new investment in electric power may cause localized reductions in yields but other than in farmer's markets, is unlikely to cause large enough damages to increase prices. In this case, current product prices can be multiplied by the change in harvest (estimated from dose-response functions) to arrive at a measure of revenue loss. Information on profitability of the sector can then be used to measure loss in producer surplus (Harrington, Krupnick, and Spofford 1989).

The benefits of reducing materials damages depend critically on the stock of materials being damaged. Given how little data exist on such stocks, it is unlikely that damage estimates can be made. Thus, the issue of transferability of valuation estimates may not come up.

Recreation is one area where region and site-specificity are likely to be important and where the literature is rich enough to possibly apply the function approach to valuation. It will be necessary to characterize the availability of recreation opportunities in the reference region, as well as participation, and compare these to their counterparts in the particular regions examined in the literature.

Judgments on the transferability of results on existence, visibility, and other values will be made after more information is obtained from the literature.

\section{Scaling}

Where transferability is possible, it will still be necessary to apply scaling factors of various types. For instance, valuation of aquatic damages from a study of a group of lakes may need to be adjusted, say for the different 
surface area of lakes in the reference environment. Damages to materials estimated in one city may be crudely adjusted by the ratio of the population in the city with that of the reference environment. All of these measures have problems, of course. Population may be a poor proxy for materials to be found in a city of different size than the city for which an inventory is available, particularly if climate or city age differs.

\subsubsection{Aggregation}

The aggregation problem is a common one to empirical economics. It simply means that one may not be able to simply add up values across components to obtain total values. Linearity in all components of the damage function calculations is a sufficient condition to avoid certain aggregation problems. However, if there are nonlinearities or thresholds in any component of the damage function estimation, then simply adding up values becomes questionable. Aggregation issues in valuation arise in four contexts: across infrastructure, across location, across endpoints, and across individuals.

\section{Across the infrastructure}

Increases in generation capacity lead to increased damages from generation, but also increased damages from the infrastructure components supporting this capacity change. These components may or may not be located within the same reference environment as the new generation unit. The model should be capable of handling either case. The emissions from infrastructure located within the reference environment can simply be added to like emissions from generation in the calculation of damages so long as the concentration of the pollutant is unaffected by differences in the location of emissions within the reference environment. Location-specific air quality models would be needed otherwise. Local damages from emissions from infrastructure outside the reference environment require a separate estimation procedure from that for damages created within the reference environment; but the two estimates are additive. Regional or global damages can be computed by taking into account emissions from the various locations of the infrastructure components.

\section{Across the same endpoint at different locations}

Much discussion appears in the literature on whether values for water quality improvements at one recreation site, or existence values estimated for one asset, can be added together over many sites or assets. The conclusions are that under a variety of reasonable conditions, such adding up will overestimate benefits and that values attached to individual sites are sensitive 
to the order in which respondents are asked for values in a study involving multiple sites.

\section{Across endpoints}

The major theoretical issue is whether estimates of benefits for more than one type of endpoint can be aggregated to obtain a total benefit. Hoehn and Randall (1982) show that, if the endpoints are substitutes (water quality improvements that affect a site in the mountains and a site at the seashore), adding up separable benefit estimates overestimates total benefits. If the endpoints are complements (e.g., visibility improvements and water quality improvements), adding up the separate components underestimates benefits. Hoehn and Randall argue that the substitution case is the general case because, with a (time and money) budget constraint all goods are substitutes. However, the empirical importance of these offsetting influences on bias in aggregation has not been demonstrated.

Another example of this endpoint aggregation problem arises when values taken from property value studies are treated additively to other values. Assuming the value of neighborhood externalities is capitalized into property markets, economists have sought to identify the implied WTP for air quality improvements by estimating models that explain variation in housing prices with variables on housing characteristics, air quality, public good availability, etc. This approach short-circuits the damage chain by linking air quality effects directly to dollars. Individuals in the property market are implicitly completing the chain in their decisions to buy and sell property.

The problem with these studies is that they offer WTP estimates that aggregate over many types of air pollution damage endpoints (health, visibility, vegetation damage, soiling, etc.) and perhaps include other correlated neighborhood effects (e.g., noise and smell). Exactly which endpoints are included is impossible to determine. Therefore, one may use either property value studies or studies on discrete endpoints to estimate damages, but not both. As we have argued above, because the short-circuit approach ignores the scientific literature, we will emphasize the damage function path in this project. A host of problems with the property value studies (Polinsky and Shavell 1976) also argues against this approach.

A more tractable and specialized set of aggregation problems can be illustrated by considering those involving the daily symptom and restricted activity day effects of ambient ozone exposure (an area where good information exists on dose-response and values). Two specific aggregation problems exist: how to treat multiple symptoms experienced by a person on 
the same day and how to treat overlap between symptoms (whether singly or in multiples) experienced at the same time as a restricted activity day.

The multiple symptom problem involves consideration of the individual's health production function and utility function. For most people, symptoms are often jointly produced: certain types of symptoms bear a cause and effect relationship to others (e.g., certain types of coughing are induced by hest congestion or a runny nose) and certain symptom combinations often appear together as indicators of a condition, such as symptoms commonly associated with the common cold and flu (e.g., headache, runny nose, cough, and chest congestion).

Whether the value of avoiding a day of multiple symptoms is different than the sum of the values for avoiding a day of each symptom depends on whether symptoms are separable in the utility function. If they are separable then the values of avoiding each day of a type of symptom can be added together irrespective of whether different types of symptoms occur on the same day or not. Put another way, symptom jointness in the health production function as well as separability of symptoms in the utility function are necessary but not sufficient conditions for the existence of a multiple symptom aggregation problem. Thus, jointness and separability are both needed to have a multiple symptom problem.

What is the evidence on jointness and separability? Evidence on jointness is mixed. Animal studies find that exposure to ozone reduces resistance to infection. If this were true for humans then it would be important to capture the types of symptom combinations associated with colds, flu, and other types of respiratory infections. Clinical and epidemiological studies find that ozone exposure causes the more direct respiratory responses. If these are the only effects of ozone, the multiple symptom problem as related to conditions is probably insignificant.

Using a detailed microdata base (Flesh, Riha, and Miller 1982) on 13 types of daily symptoms, it appears that some symptoms are experienced fairly often in combination with other symptoms. For instance, with 4514 headache days in total, $61 \%$ of these (2759) were experienced without eye irritation or upper respiratory symptoms (2-8) while at least ${ }^{17} 27 \%$ were experienced with one other upper respiratory symptom or eye irritation.

\footnotetext{
${ }^{17}$ The phrase "at least" is used because headache does appear in combination with two or more symptoms.
} 
5. Economic Valuation

How reasonable is the separability assumption? There is evidence from Tolley et al. 1986 that assuming separability would result in an overestimate of benefits. Tolley finds that a day of multiple symptoms is valued at less than the sum of the values for a day of each symptom. Specifically, a day of "coughing-throat congestion-stuffed sinuses" is valued at only $74 \%$ of these symptoms valued separately.

The second specific aggregation problem (one related to impacts not value) involves the overlap between symptoms and restricted activity days (RADs). A priori, it is reasonable to assume that one or more respiratory symptom must be present for a RAD to be registered and that not all respiratory-related symptoms lead to a $R A D$. The issue, then, is how to identify and eliminate double-counting of symptoms and RADs. One approach would be to use a micro data set (Flesh, Riha, and Miller 1982) to compute the conditional probability of each symptom being present when a RAD is present and using this probability to identify the overlap of each symptom with a RAD.

\section{Across individuals}

The problem of assessing the benefits of moving from one to another state of the world (because of a change in policy or a new project, for example) (i.e., the problem of measuring welfare) is one of the most basic problems in neoclassical economics. The key issue is the relationship between changes in the welfare of individuals and changes in the welfare of society as a whole.

The clearest criterion for stating unambiguously that one state is preferred to another is the Pareto criterion: that social welfare increases if at least one person is made better off without making anyone worse off. As any project or policy is likely to reduce someone's welfare. In its place, the potential Pareto criterion was developed: that as long as income could be redistributed to make at least one person better off without making anyone else worse off, the project had social benefit.

Unfortunately, it has been shown that this criterion can produce inconsistent rankings, where a change to state $B$ from state $A$ is welfare improving but once one was in state $B$ a change back to state $A$ also appears welfare improving. This intransitivity can be avoided by assuming that all individuals have identical preferences, but this has the far-fetched implication that "the social value of a dollar is equal for every member of society" (Blackorby 1990). 
An alternative criterion is the aggregate willingness to pay criterion: the compensation that each member of society requires (or the payment they need to make) to be indifferent to a change from state $A$ to $B$ is added up. If the sum across all of the members of society is positive, the change is socially beneficial. Unfortunately, as Boadway (1974) and others have shown, this criterion also can lead to intransitivity under certain conditions, such as where there are differences in prices between the two states.

\subsubsection{Nonlinearities}

One of the most difficult problems with the reference environment approach is how to deal with nonlinear marginal damage valuation functions. Nonlinearities may be caused by physical processes (such as ozone formation from $\mathrm{NO}_{\mathrm{x}}$ precursors and health responses that are increasingly severe for larger doses), cumulative pollution effects, and nonlinear valuation functions (such as where the willingness to pay for a given reduction in health risk is less the lower the baseline risk i.e., state dependence). Because we treat each increment to generation capacity as a discrete event, the assumption about the baseline level of environmental quality (i.e., where one is on the damage function) is crucial to the damage estimate.

Currently, we plan to put the most effort into estimating the baseline conditions at the reference environment and estimating incremental damage that would arise from a new plant at this point. Any nonlinearities associated with this incremental pollution would be captured in the analysis, at least in principle. In addition, we plan to search for reasonable alternative baseline conditions that would provide very different estimates of incremental damage. For instance, ambient ozone concentrations are related to volatile organic compounds (VOC) and $\mathrm{NO}_{\mathrm{x}}$ concentrations in a highly nonlinear way. If VOCs in the ambient air are very plentiful relative to $\mathrm{NO}_{x}$ then changes in NOx will have a relatively large effect on ambient ozone concentrations.

\subsubsection{Temporal Perspective in Analysis}

Estimates of environmental costs can take either an ex post or an ex ante perspective. In an ex ante context, costs are prospective (i.e., estimates are made before an investment is chosen). The pre-investment state is hypothetical (because individuals who might be affected do not know in advance exactly what will happen following the investment). A probability distribution of alternative states may be posited to describe this uncertainty. This context is the appropriate one for environmental costing. 
However, many values are derived from ex post analysis. In an ex post (or after-the-fact) context, the actual (realized) costs associated with some activity are tallied. Then these estimates are used as a surrogate for the expected costs of a hypothetical activity. These estimates do not account for uncertainty or the degree of risk aversion.

\subsubsection{Discounting}

The issue of adjusting social cost estimates for the period of occurrence - use of discount rates - pervades all cost analyses. Some preliminary thoughts on the appropriate discount rate are included in the position papers on discounting prepared by the U.S. and EC teams. The positions resolve to the choice of a $3 \%$ real rate of discount for the base case, with sensitivity analyses using one percent and ten percent. New survey research on discounting human lives (Cropper, Aydede and Portney 1992) will be examined for its relevance to this debate.

\subsection{MATCHING IMPACT ENDPOINTS AND ECONOMIC VALUES}

The matching problem involves matching predictions about the effect of a pollutant on an endpoint to an available unit value or function for monetizing that endpoint. An intractable example of this problem concerns ozone and the lung function endpoint. There are numerous studies relating ozone exposure to lung function. While a perceived decrement in lung function may be something that a rational person would be willing to pay to avoid, there are no economic studies that directly attempt to place a value on lung function. Moreover, it is far from clear that such a study is even possible, given that lung function measurements have no meaning for the average person. Further, small changes in lung function are not always perceived. Thus, studies of the response of this endpoint to ozone are not directly useful for our study.

A more tractable example of the matching problem concerns symptom endpoints. Here, the definition of a symptom examined by a concentrationresponse (C-R) function may differ from that used by a valuation study. For example, a $\mathrm{C}-\mathrm{R}$ function may be defined for chest tightness while the closest match for this end-point in the valuation literature may be chest congestion. These two endpoints may overlap but treating them as identical obviously introduces error.

Endpoints and values have time dimensions that also should match. An example is matching 2-hour symptom incidences from ozone exposure to 
the valuation literature that provides values only for a symptom day. To convert incidences to days requires an estimate of the average number of 2hour incidents in a "day" of symptoms. Unfortunately, no such information is available. Krupnick (1987) used an arbitrary set of conversion factors: 1.0 (each 2-hour incident is counted as a symptom day), 0.5 (i.e., symptoms would need to be experienced during 4 waking hours (two 2-hour periods) to qualify as a symptom-day), and 0.125 (symptoms would need to be experienced during all 16 waking hours to qualify as a symptom-day).

A final, but highly important issue is the interface between impact endpoints and economic valuation. A problematic example is the recreation endpoint. Natural scientists may be able to offer estimates of the effects of pollutants on a lake or stream, or even effects on the population of certain types of highly valued fish living in the lake. However, the effect of reduced fish populations on catch rate has been traditionally seen as in neither the scientist's nor the economist's domain, although the last step - the effect of reduced catch on participation and value - is the economist's responsibility.

What is critical for this study is the provision of arguments to redefine physical resources in the social context. Any resource changes, for the purposes of economic valuation, must have some social meaning in either a use or existence sense. Further research is recommended for areas where physical changes cannot be redefined into social resource changes on the basis of existing literature or credible expert judgment.

\subsection{REFERENCES}

Adams, R.M., Hamilton, S.A., and McCarl, B.A., 1985. "An Assessment of the Economic Effects of Ozone on U.S. Agriculture," J Air Pollu Control Assoc 35, 938-943. (Based on The Economic Effects of Ozone on Agriculture, report to the U.S. Environmental Protection Agency, EPA-600/3-84-090).

Bennett, J.W., 1984. "Using Direct Questioning to Value the Existence Benefits of Preserved Natural Areas," Australian J Ag Econ 28(2, 3), 136-150.

Bishop, R. C., Heberlein, T. A., and Kealy, M. J., 1983. "Hypothetical Bias in Contingent Valuation: Results from a Simulated Market," Natural Resources Journal 23(3), 619-633. 
Blackorby, C., 1990. "Economic Policy in a Second-best Environment." Canadian J Econ, 748-771.

Broadway, R., 1974. "The Welfare Foundations of Cost-Benefit Analysis." Econ J 84, 926-939.

Bockstael, N. E., Hanemann, W. M., and Kling, C. L., 1987. "Estimating the Value of Water Quality Improvements in a Recreational Demand Framework," Water Resources Research 23(5), 951-960.

Bockstael, N. E., McConnell, K. E., and Strand, I. E., 1987. "Benefits From Improvements in Chesapeake Bay Water Quality," Volume II of Benefit Analysis Using Indirect or Imputed Market Measures, report prepared for U.S. Environmental Protection Agency, CR-811043- 01-0.

Bockstael, N. E., McConnell, K. E., and Strand, I., 1989. "Recreation," in Braden, J. B. and C. D. Kolstad, eds., Measuring the Demand for Environmental Improvement (Urbana, Illinois, Institute for Environmental Studies), Chapter 8.

Boyle, K. J. and Bishop, R. C., 1987. "Valuing Wildlife in Benefit- Cost Analysis: A Case Study Involving Endangered Species," Water Resources Research 23(5), 943-950.

Brown, G. and Mendelsohn, R., 1984. "The Hedonic Travel Cost Method," Rev Econ Stat 66(3), 427-433.

Carson, R. T. and Mitchell, R. C., 1988. "The Value of Clean Water: The Public's Willingness to Pay For Boatable, Fishable, and Swimmable Quality Water," final draft report.

Cropper, M. L., Aydede, S. K., and Portney, P. R., 1992. "Public Preferences for Life Saving," Resources for the Future Discussion Paper, CRM-9201.

Cropper, M. L. and Oates, W. E., 1990. "Environmental Economics: A Survey," Resources for the Future Discussion Paper QE90-12 (forthcoming in J Econ Lit).

Cummings, R. G., Brookshire, D. S., and Schulze, W. D., eds. 1986. Valuing Environmental Goods: A State of the Arts Assessment of the Contingent Valuation Method, Totowa, N.J., Rowman and Allanheld. 
Desvousges, W. H., et al. 1992. "Measuring Natural Resource Damages with Contingent Valuation: Tests of Validity and Reliability," presented at the Contingent Valuation: A Critical Assessment Conference April 2 and 3, Washington, D.C.

Fisher, A., Chestnut, L. G., and Violette, D. M., 1989. "The Value of Reducing Risks of Death: A Note on New Evidence," J Policy Analysis Manage 8(1), 88-100.

Fisher, A., and Peterson, F. M., 1976. "The Environment in Economics: A Survey," J Econ Lit 14(1), 1-33.

Flesh, R. D., Riha, M. L., and Miller, M. F., 1982. "Effects of Short-term Intermittant Air Pollutants on Incidence and Severity of Acute Respiratory Disease: Data Collection and Quality Assurance," EPA-600/S1-81-065, project summary, U.S. Environmental Protection Agency, Health Effects Research Laboratory, Research Triangle Park, N.C.

Freeman, A. M. III, 1979. The Benefits of Environmental Improvement, Resources for the Future, Inc., Johns Hopkins University Press, Baltimore.

Gegax, D., Gerking, S., and Schulze, W. D., 1985. "Estimating Evaluations of Safety From Labor Market Data: A New Measure of Risk," Gesellschaft Fur Regionalforschung 22, 81-108.

Hanemann, W. M. 1991. "Willingness to Pay and Willingness to Accept: How Much Can They Differ?" Amer Econ Rev 81(3), 635-647.

Harrington, W., Krupnick, A. J., and Spofford, W. O., Jr., 1989. "The Economic Losses of a Waterborne Disease Outbreak," J Urban Econ 25(1), 116-137.

Hoehn, J. P. and Randall, A., 1982. "Aggregation and Disaggregation of Program Benefits in a Complex Policy Environment: A Theoretical Framework and Critique of Estimation Methods," presented at the American Agricultural and Economics Association summer meetings, Logan, Utah.

Hohmeyer, O. 1988. Social Costs of Energy Consumption: External Effects of Electricity Generation in the Federal Republic of Germany, SpringerVerlag, Berlin. 
Jones-Lee, M. W., Hammerton, M., and Philips, P. R., 1985. "The Value of Safety: Results of a National Sample Survey," Econ J 95, 49-72, March.

Kahneman, D. and Knetsch, J. L., 1990. "Valuing Public Goods: The Purchase of Moral Satisfaction," J. Environ Econom. Management 22(1), 57-70.

Kopp, R. J., 1985. "Implications of Environmental Policy for U.S. Agriculture: The Case of Ambient Ozone Standards," J Environ Manage 20, 321-331.

Krupnick, A. J., 1987. "A Health Benefit Analysis of Reductions in Photochemical Oxidants in the Northeastern United States," draft interm report for the U.S. Environmental Protection Agency.

Krupnick, A. J. and Cropper, M. L. 1992. "The Effect of Information on Health Risk Valuations," $J$ Risk and Uncertainty 5(1), 29-48; also RFF Discussion Paper QE980-13.

Krupnick, A. J., Harrington, W., and Radin, S., 1990. "Externality Costs by Emission: Acid Deposition," pp. 229-263 in Ottinger, R. et al., eds., Environmental Costs of Electricity, Oceana Publications, Inc., N.Y.

Lipfert, F., 1987. "Effects of Acidic Deposition on the Atmospheric Deterioration of Materials," Materials Performance.

Magat, W., Viscusi, K., and Huber, J. forthcoming. "Valuing Chronic Morbidity Damages," J Environ Econ Manage.

Miller, T. R., 1990. "The Plausible Range for the Value of Life - Red Herrings Among the Mackerel," J Forensic Econ.

Mitchell, R. C., and Carson, R. T., 1986. "Valuing Drinking Water Risk Reductions Using the Contingent Valuation Method: A Methodological Study of Risks From THM and Giardia," report for the U.S. Environmental Protection Agency.

Mitchell, R. C. and Carson, R. T., 1989. Using Surveys to Value Public Goods: The Contingent Valuation Method, Resources for the Future, Washington, D.C. 
Morey, E. and Shaw, W. forthcoming. "An Economic Model to Assess the Impact of Acid Rain: A Characteristics Approach to Estimating the Demand for and Benefits from Recreational Fishing," in V. Smith and A. Witte, eds., Advancies in Applied Microeconomics Theory, vol. 8, JAI Press Inc., Greenwich, Conn.

Polinsky, A. M., and Shavell, S., 1976. "Amenities and Property Values in a Model of an Urban Area," J Public Econ 5, 119-129.

Regional Economic Research, Inc., 1990. "Estimating the Air Quality Impacts of Alternative Energy Resources," Phase II Report prepared for California Energy Commission.

Rowe, R. D., et al. 1986. "The Benefits of Air Pollution Control in California," prepared for the California Air Resources Board.

Schulze, W. D. et al. 1983. "The Economic Benefits of Preserving Visibility in the National Parklands of the Southwest," Nat Resources J 23, 149-173.

Schwartz, J., et al. 1985. "Costs and Benefits of Reducing Lead in Gasoline: Final Regulatory Impact Analysis," final report for the U.S. Environmental Protection Agency.

Sellar, C., Stoll, J. R., and Chavas, J. P., 1985. "Validation of Empirical Measures of Welfare Change: A Comparison of Nonmarket Techniques," Land Economics 61(2), 156-175.

Smith, V. K., 1989. "Household Production Functions and Environmental Benefit Estimation," Resources for the Future Discussion Paper QE9004.

Smith, V. K., 1992. "Arbitrary Values, Good Causes, and Premature Verdicts," J. Environ. Econom. Management 22(1), 71-89.

Smith, V. K. and Desvousges, W. H., Feb. 1987. "An Empirical Analysis of the Economic Value of a Risk Change," J Political Econ.

Smith, V. K., and Kaoru, Y., 1990. "Signals or Noise? Explaining the Variation in Recreation Benefit Estimates," Amer J Ag Econ, 419-433.

Smith, V. K., Palmquist, R. and Jackus, P., 1990. "Combining Farrell Frontier and Hedonic Travel Cost Models for Valuing Estuarine Quality," unpublished paper. 
Tolley, G., et al. 1986. "Valuation of Reductions in Human Health Symptoms and Risks," final report for the U.S. Environmental Protection Agency, CR-811053-01-0.

U.S. Environmental Protection Agency, et al. 1989 and 1990. "National Acid Precipitation Assessment Program (NAPAP)," State of Science/Technology, various reports, including SOS \#27 on Economic Issues, Washington.

Viscusi, W. K., 1986 "The Valuation of Risks to Life and Health: Guidelines for Policy Analysis," pp. 193-210 in J.D. Bentkover et al., eds., Benefits Assessment: The State of the Art, D. Reidel Publishing Company, Dordrecht.

Viscusi, W. K., Magat, W. A., and Forrest, A., 1988. "Altruistic and Private Valuations of Risk Reductions," J Policy Analysis Manage 7(2), 227-245.

Viscusi, W. K., Magat, W. A., and Huber, J., 1991. "Pricing Environmental Health Risks: Survey Assessments of Risk-Risk and Risk-Dollar Trade-Offs for Chronic Bronchitis," J Envir Econ Management 21(1), 32-51.

Walsh, R. G., Johnson, D. M., and McKean, J. R., 1988. "Review of Outdoor Recreation Economic Demand Studies with Nonmarket Benefit Estimates, 1968-1988," unpublished manuscript, Department of Agricultural and Resource Economics, Colorado State University, Fort Collins, Colorado for U.S. Forest Service.

Welle, P., 1985. "Potential Economic Impacts of Acid Rain in Minnesota: The Minnesota Acid Rain Survey," unpublished manuscript, Department of Economics, Bemidji State University, Bemidji, Minnesota.

Willig, R. D., 1976. "Consumer's Surplus Without Apology," Amer Econ Rev 66(4), 587-597. 


\section{APPENDIX A}

Typical Environmental Interactions

of the Coal Fuel Cycle for

Electricity Production 
㐫

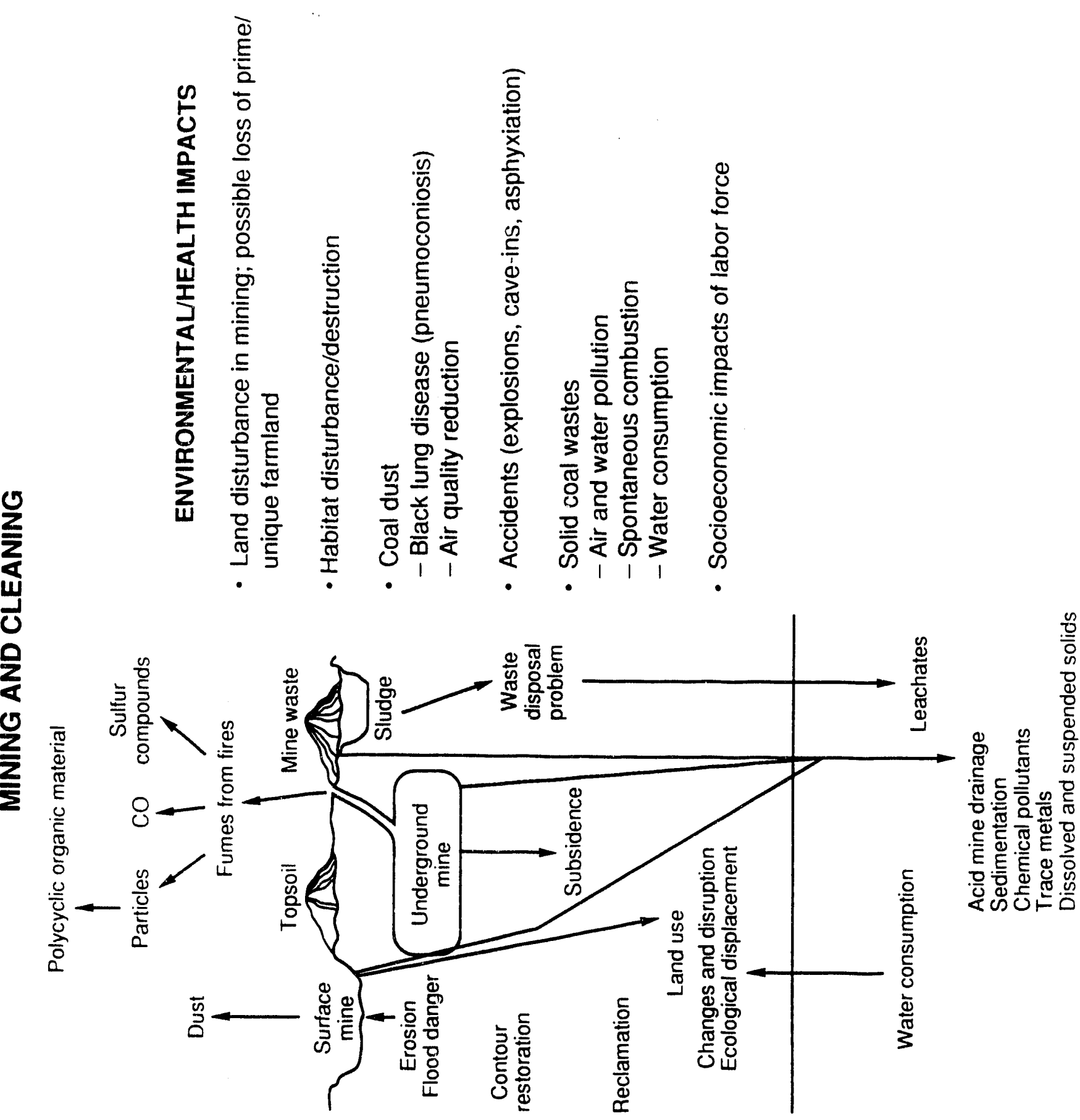

$\frac{a}{\alpha}$ 


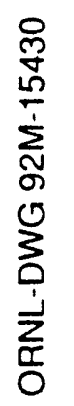

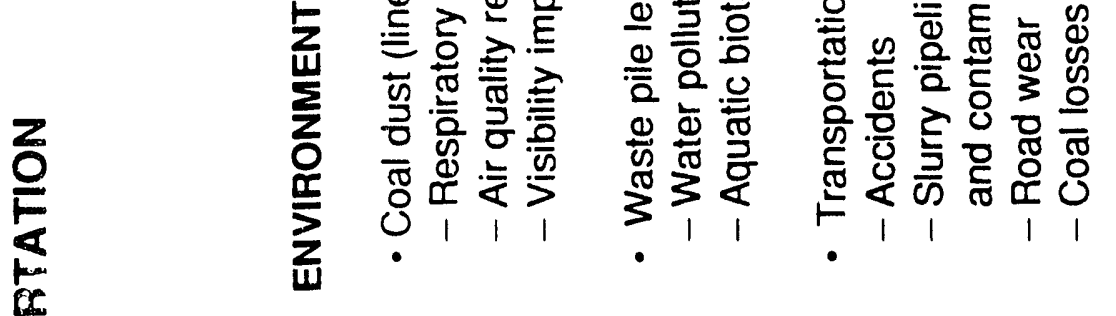

응

क

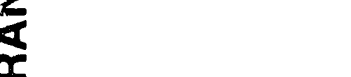

之

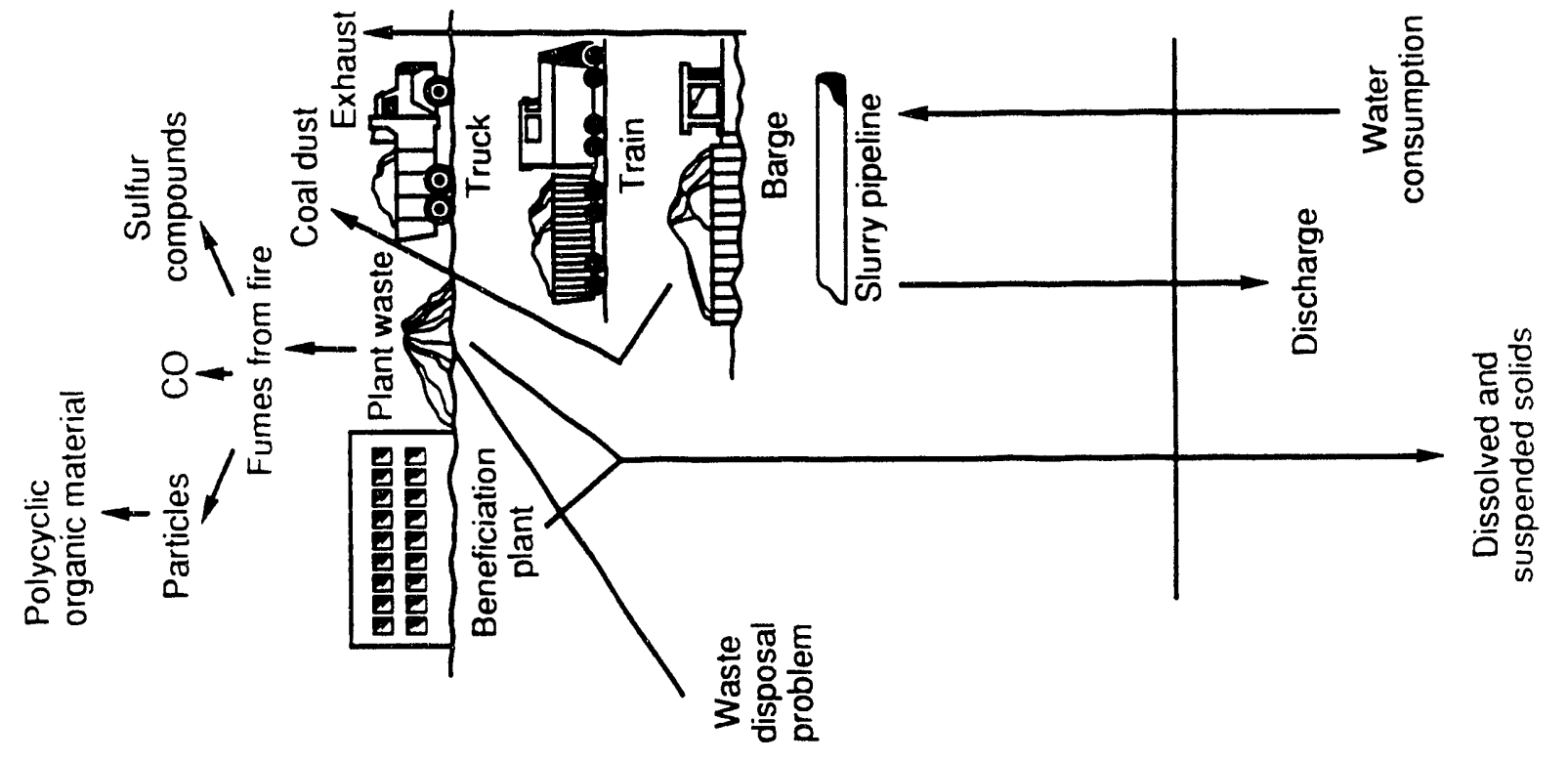

$\frac{\Upsilon}{\alpha}$

亨

$\frac{\sqrt[r]{4}}{3}$ 

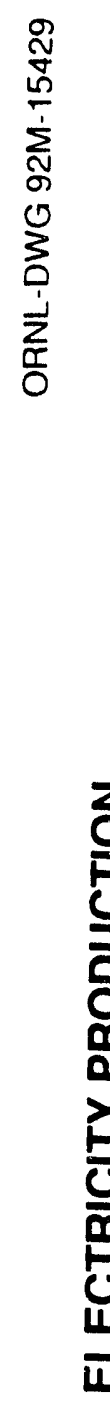

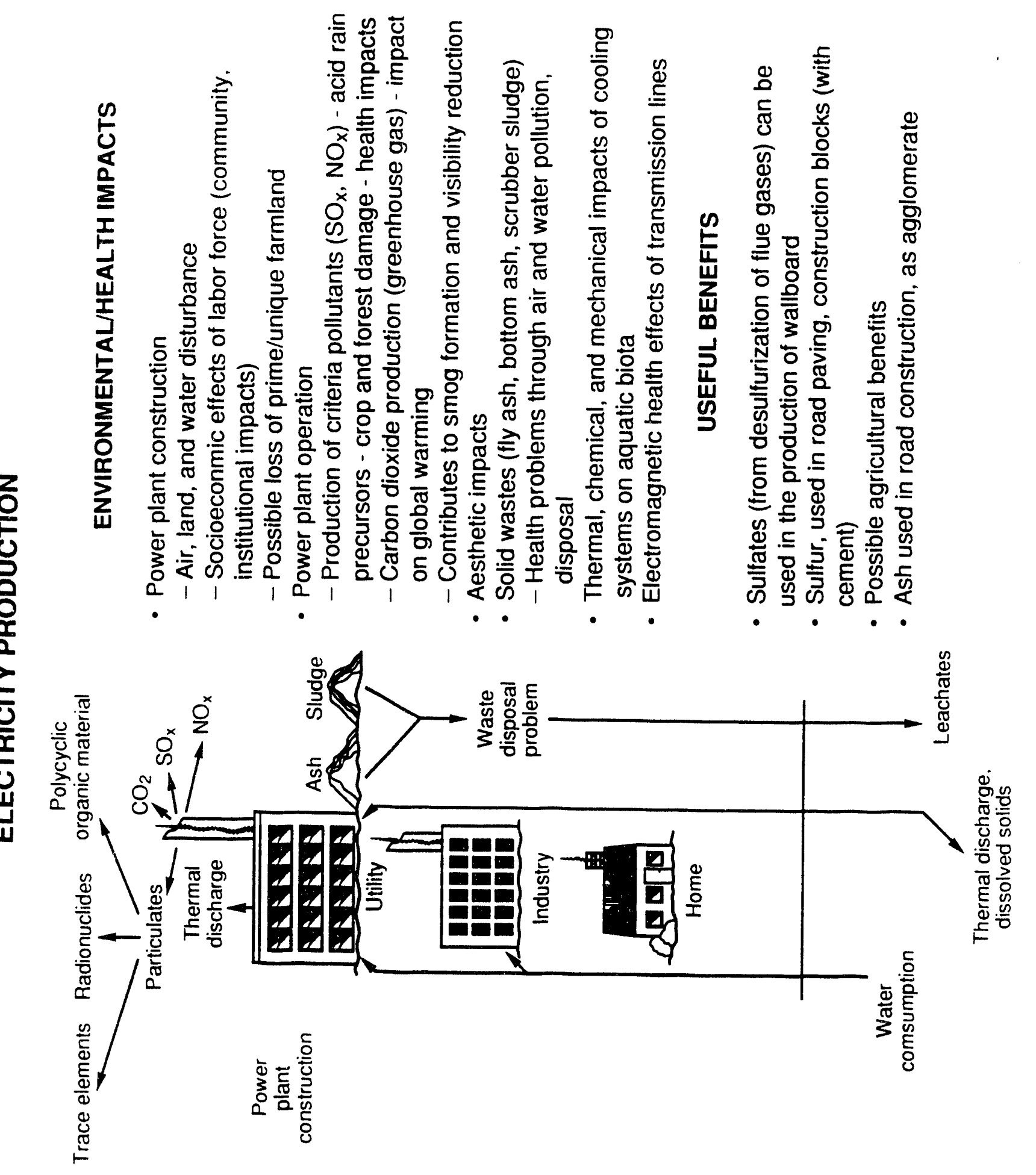




\section{APPENDIX B}

\section{Accounting Framework Matrices}

for the Coal Fuel Cycle 
Appendix B

B-1

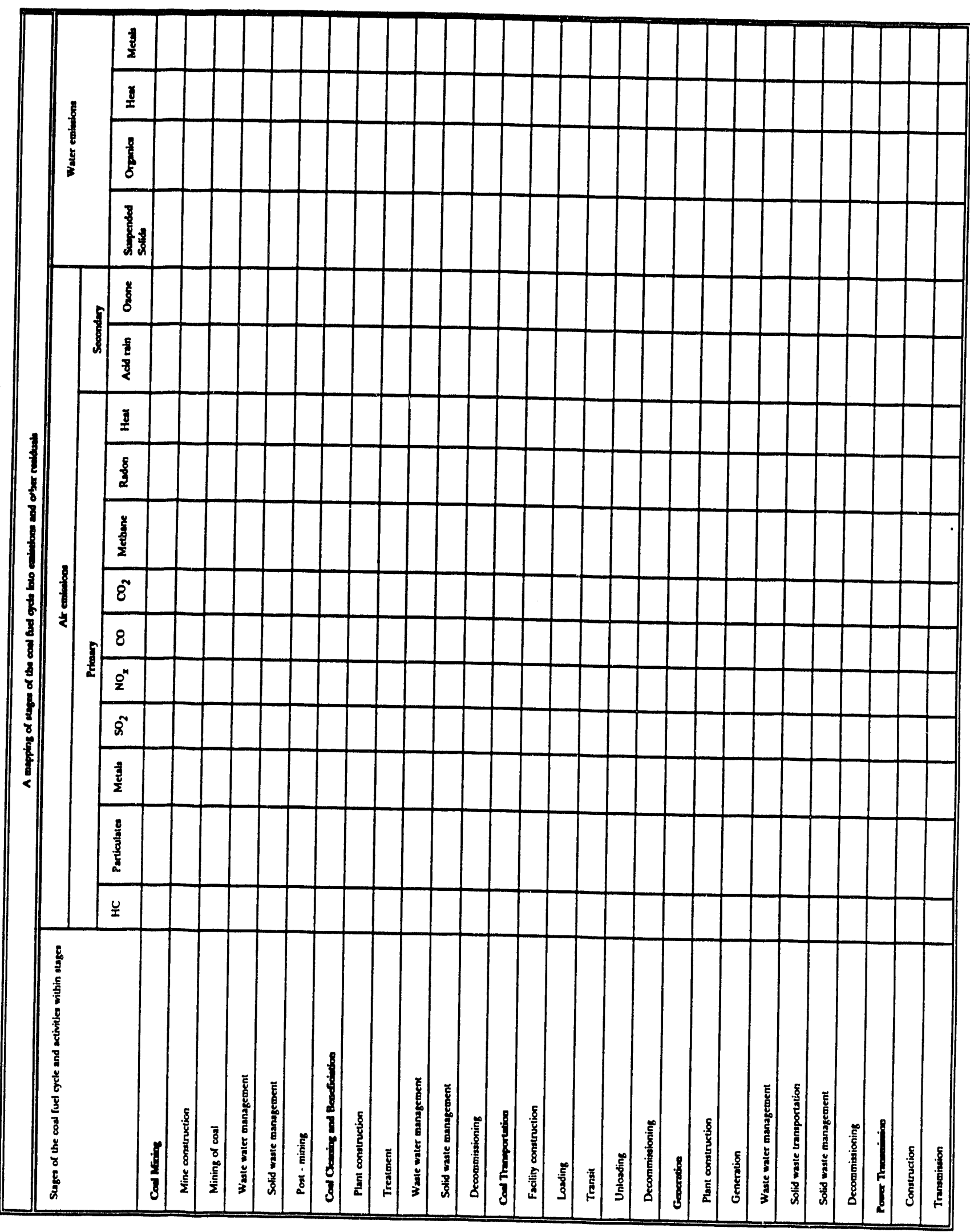




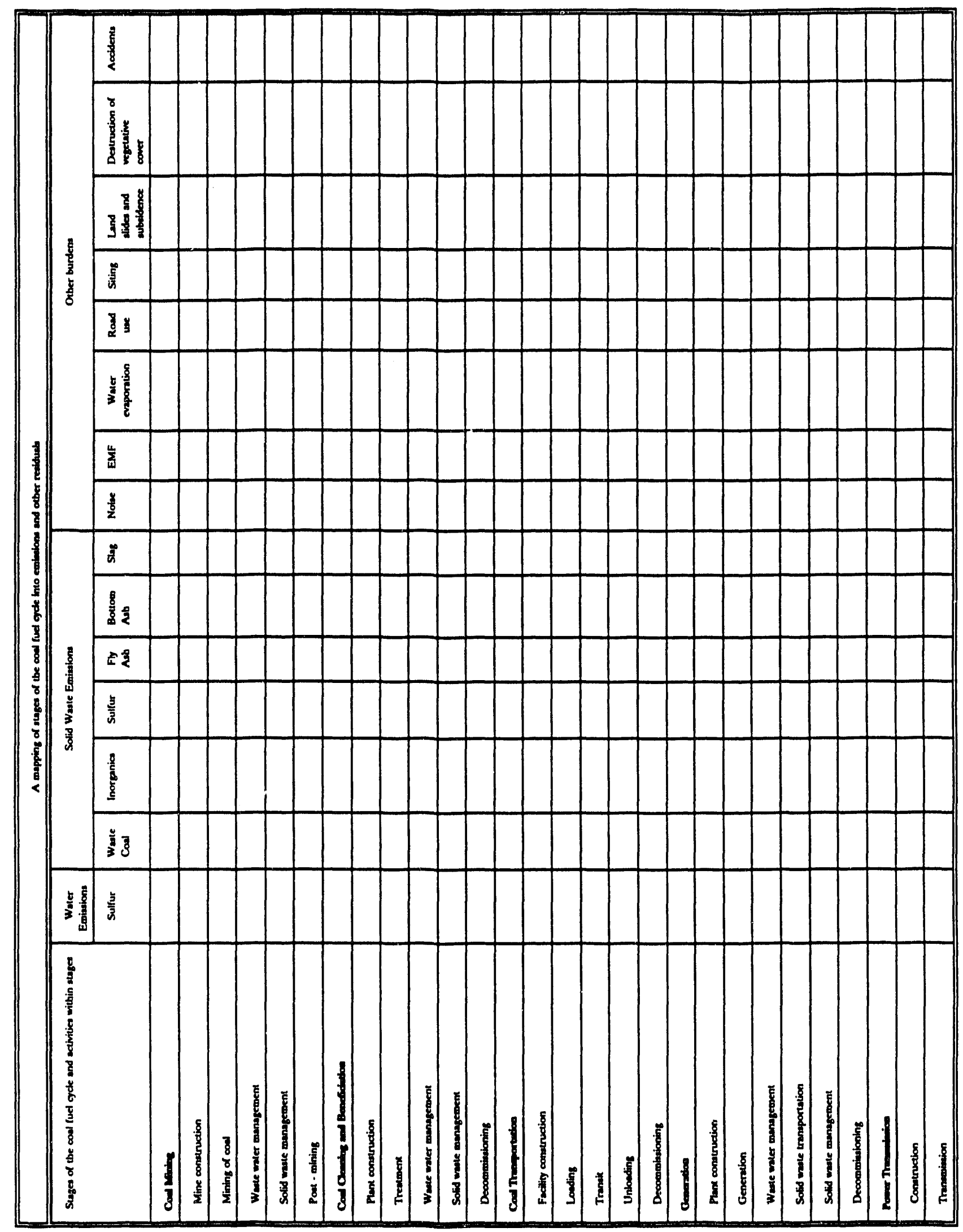




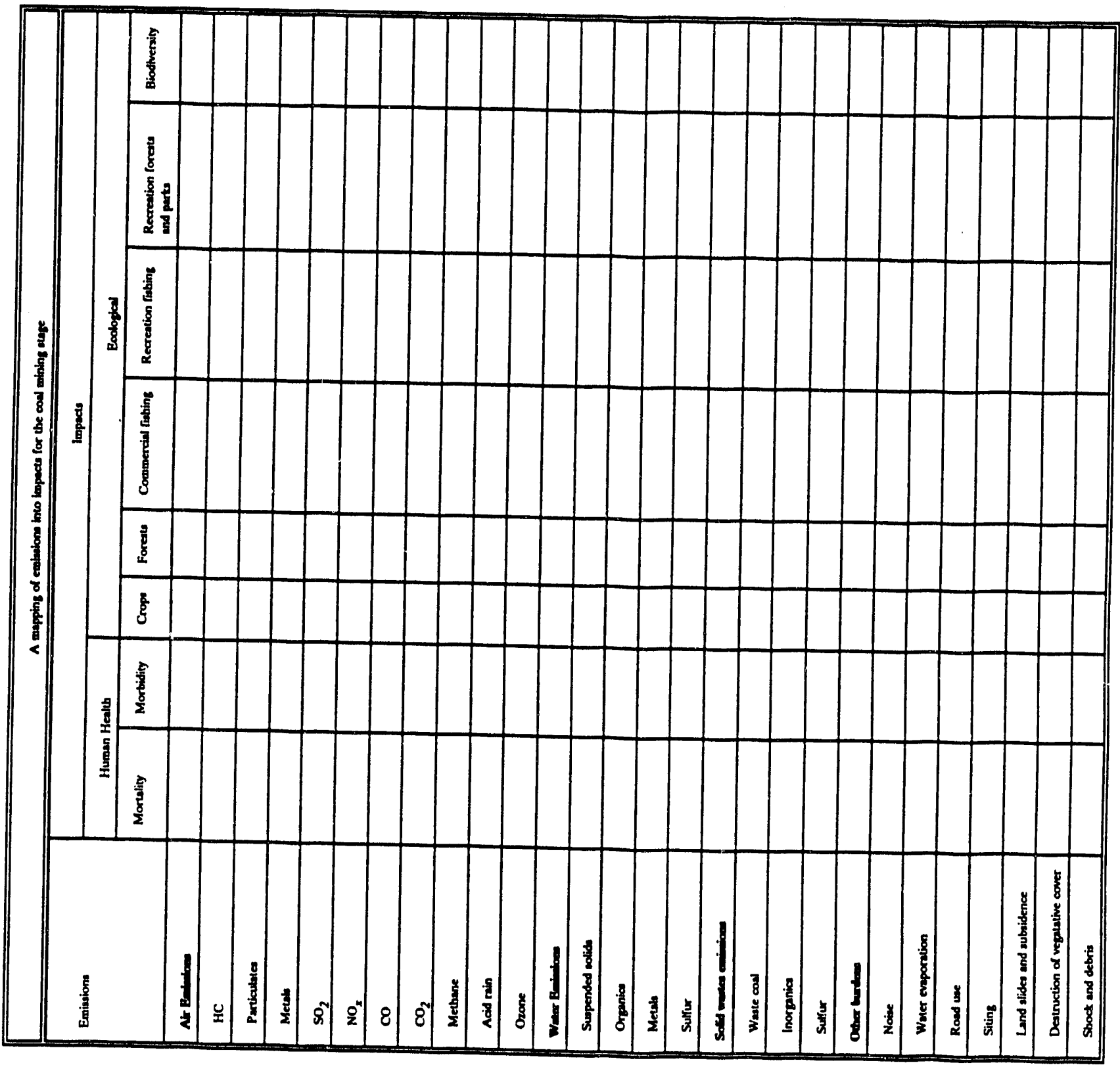




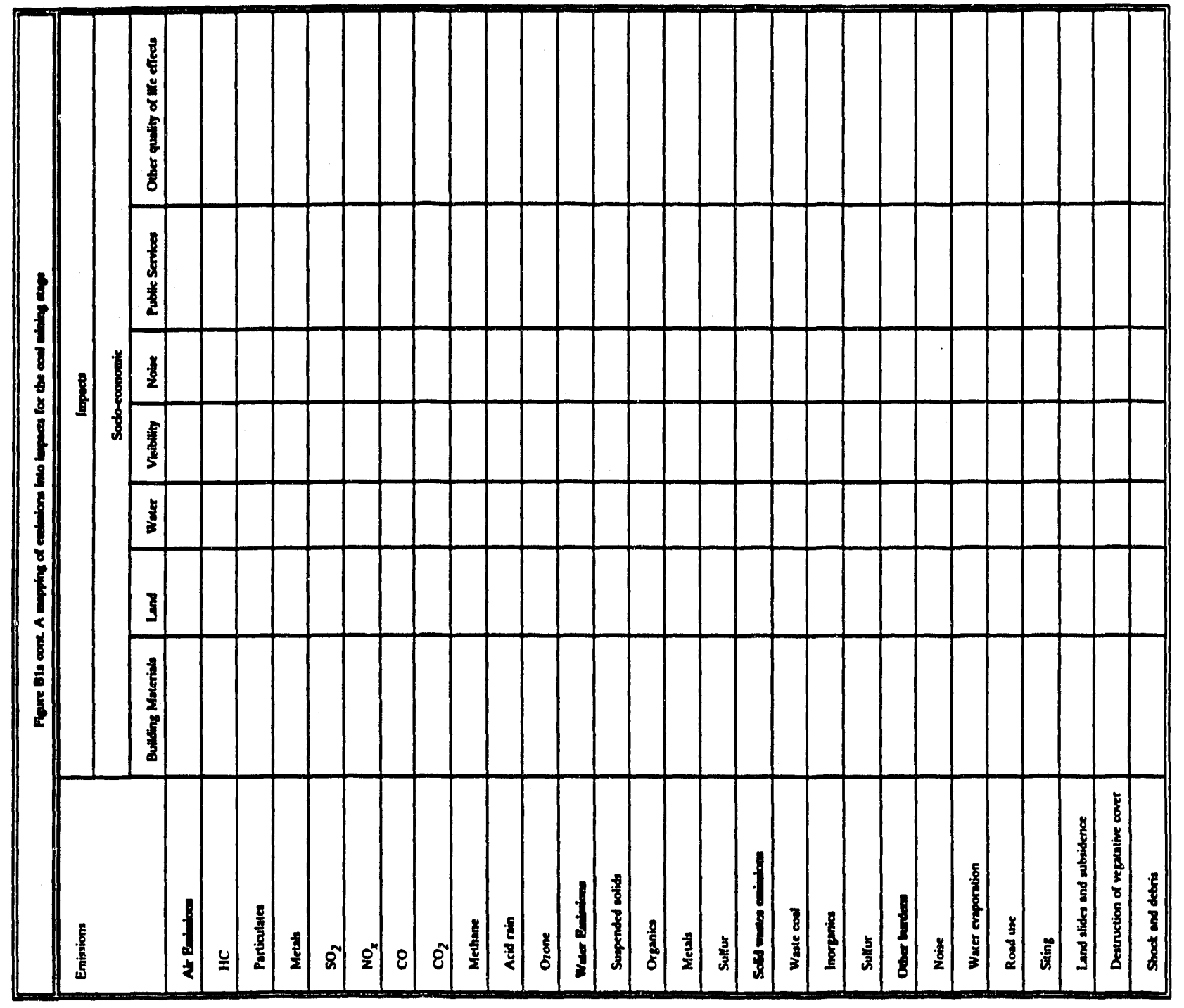




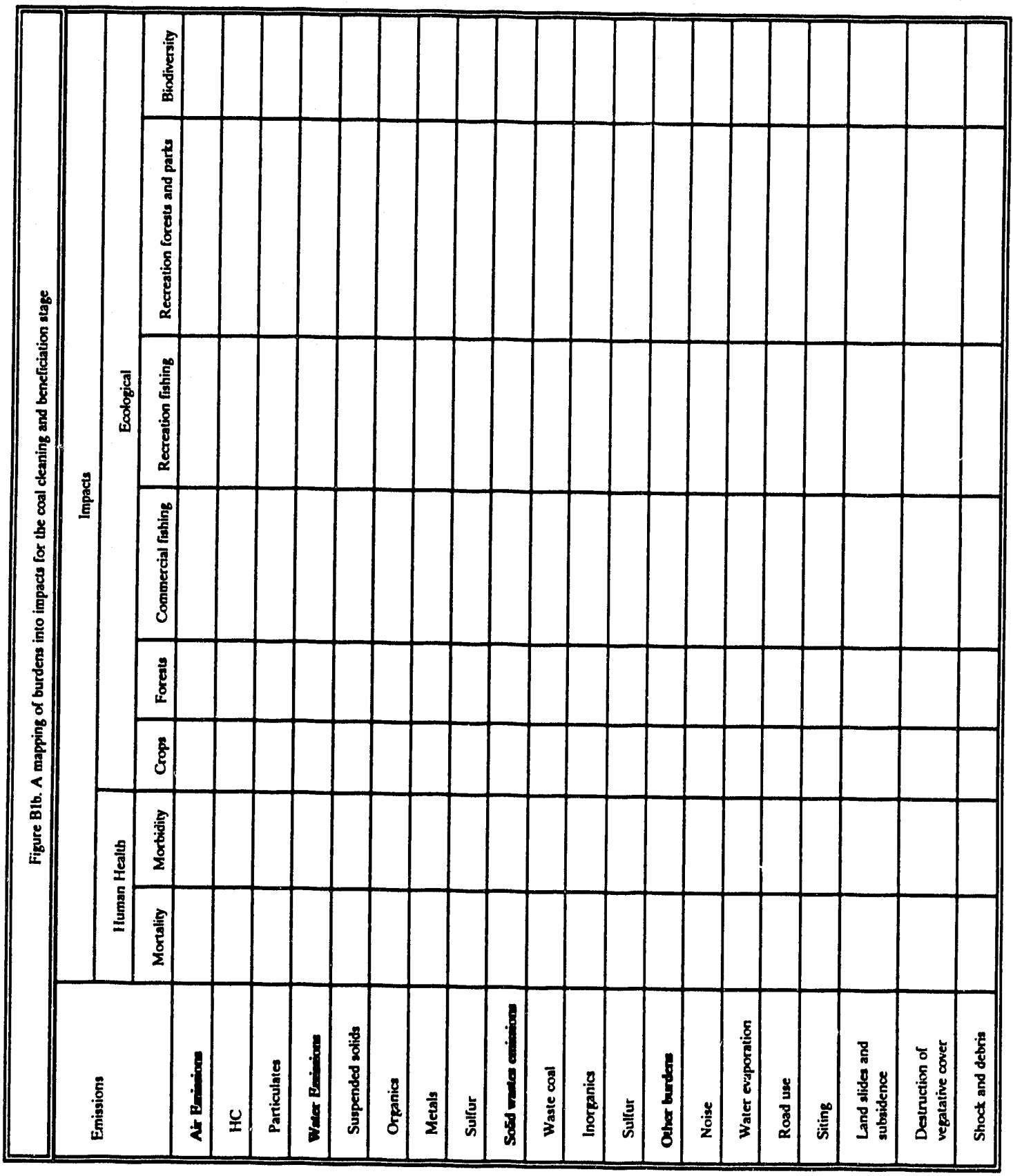


B- 6

Appendix B

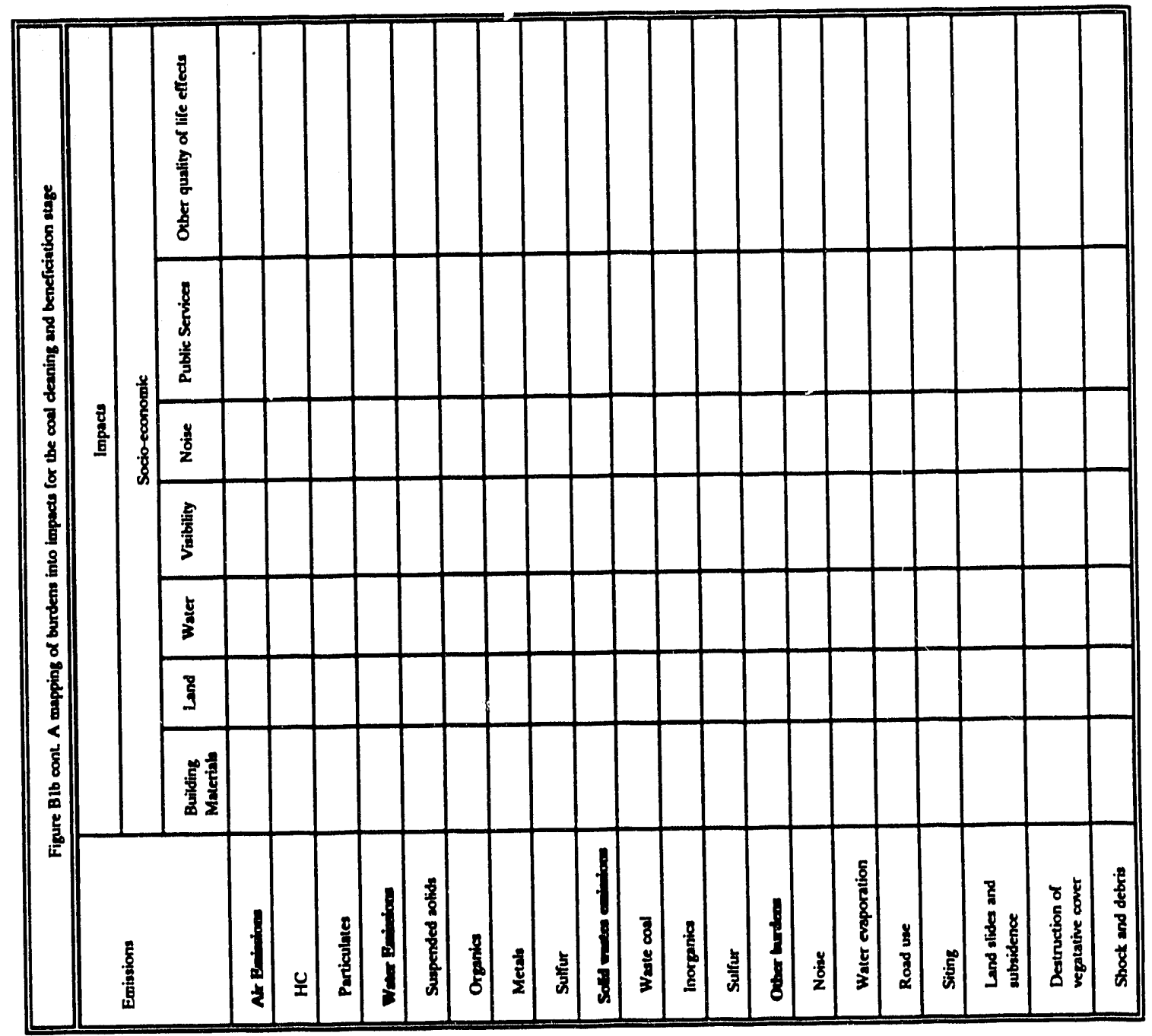




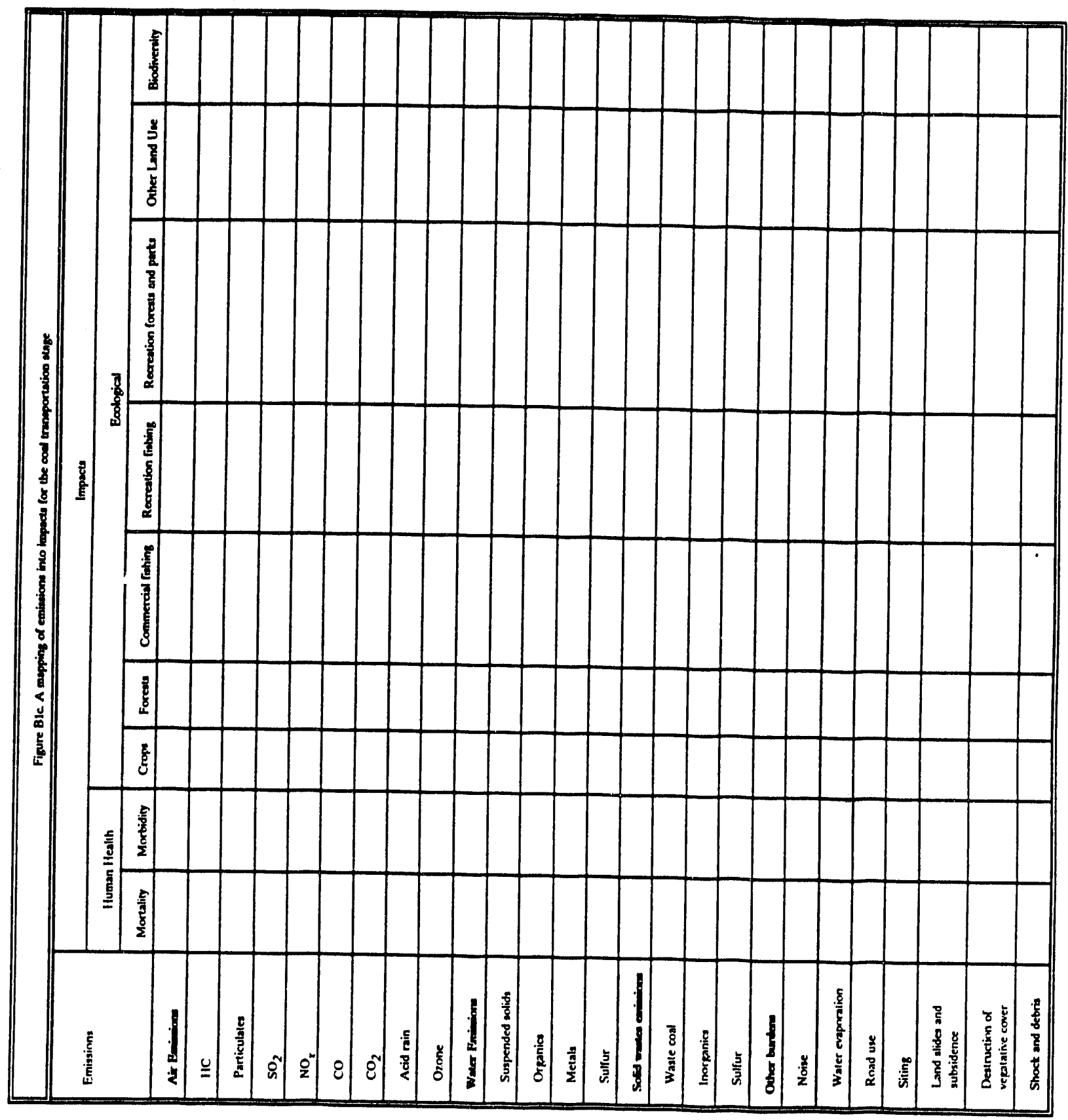




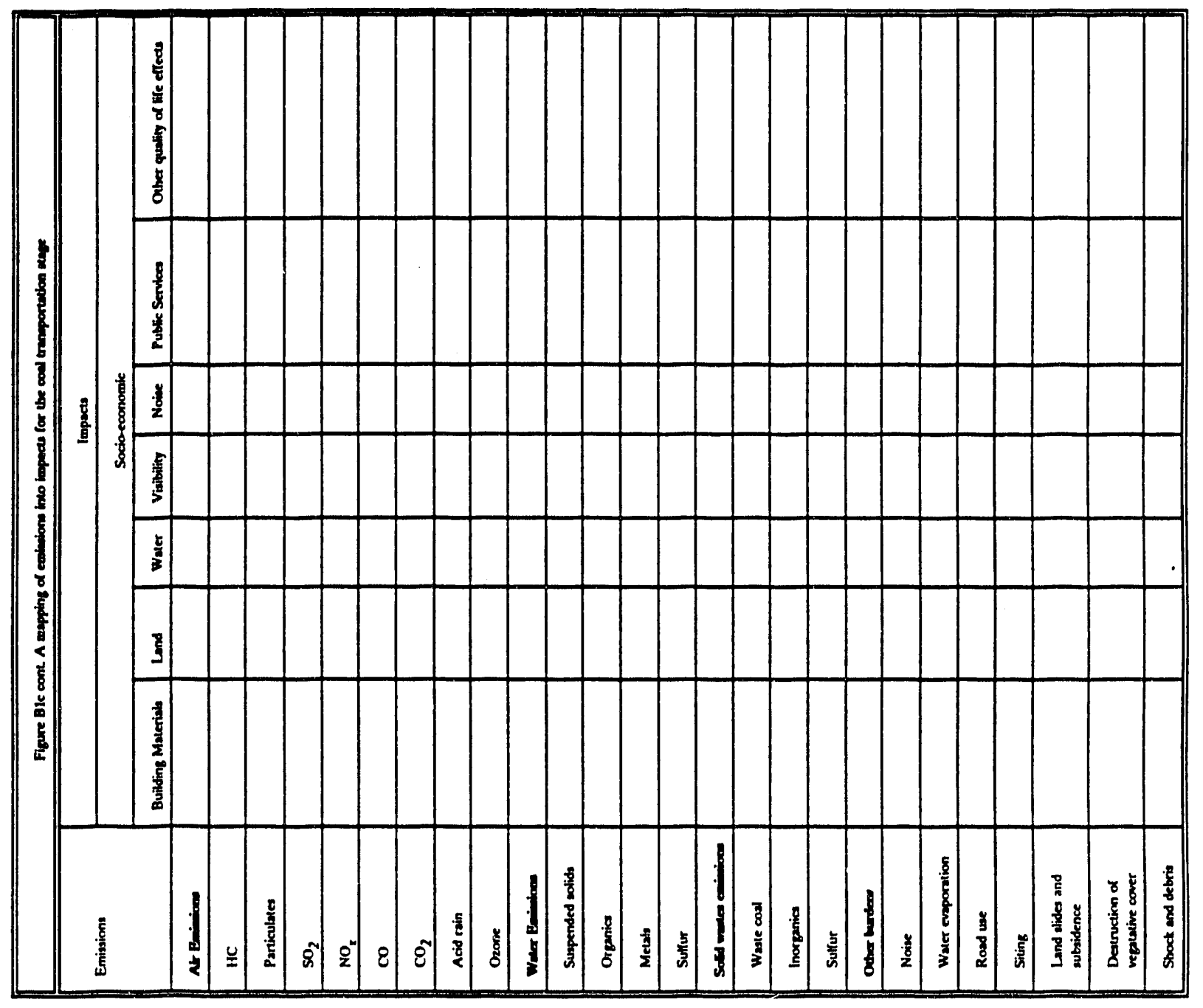




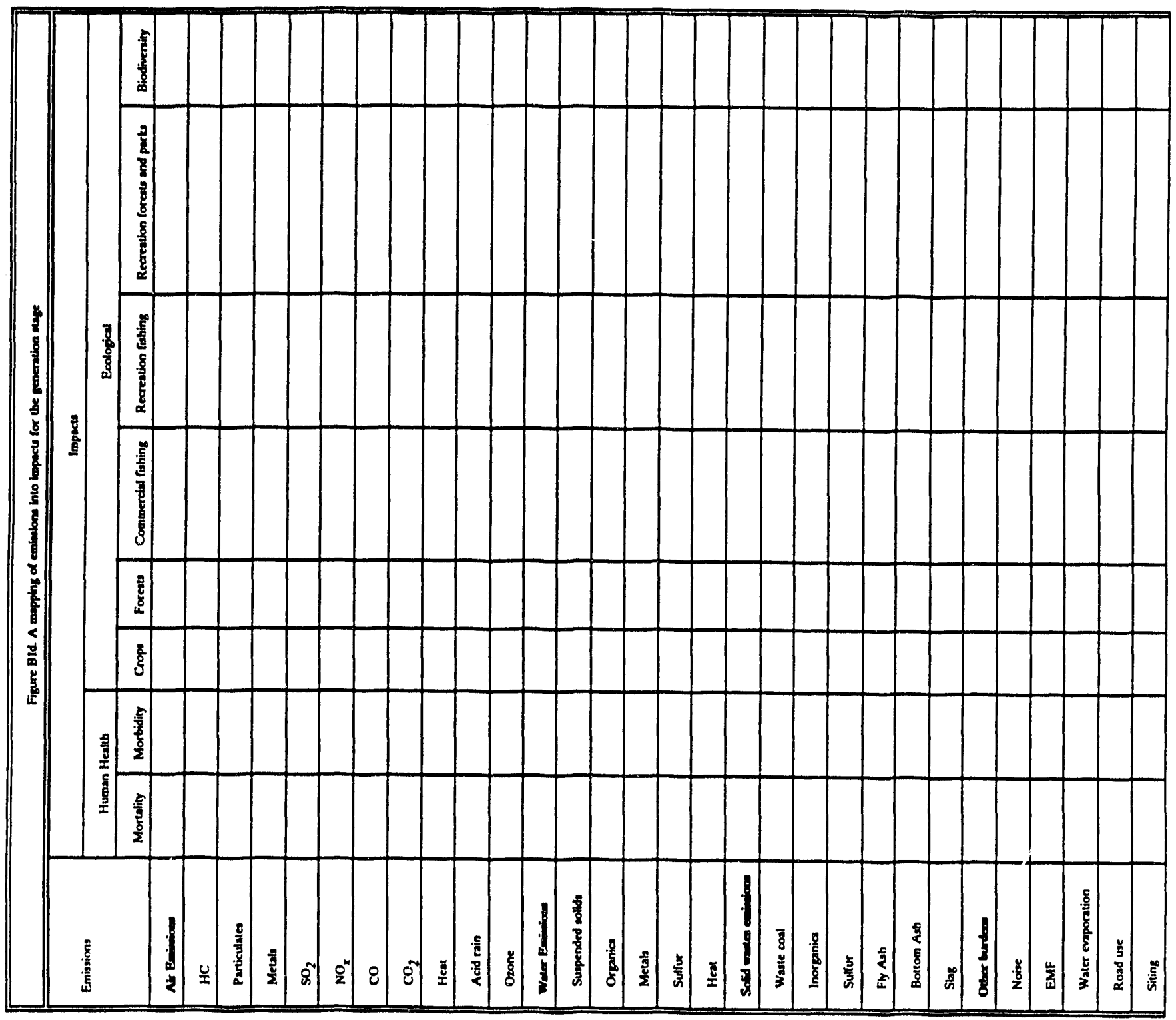




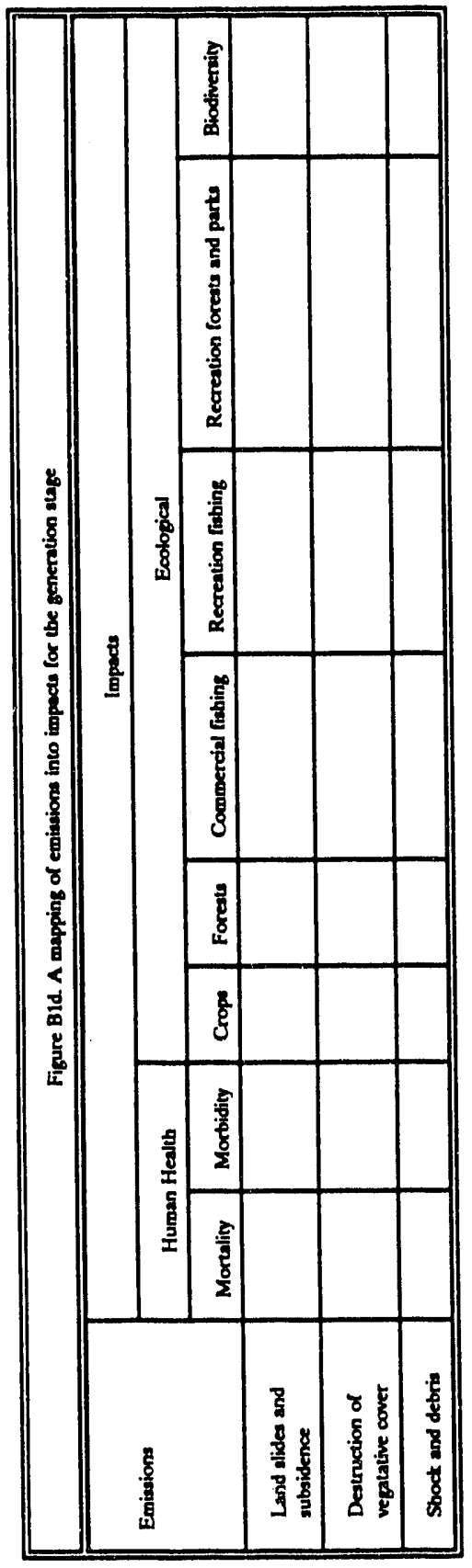




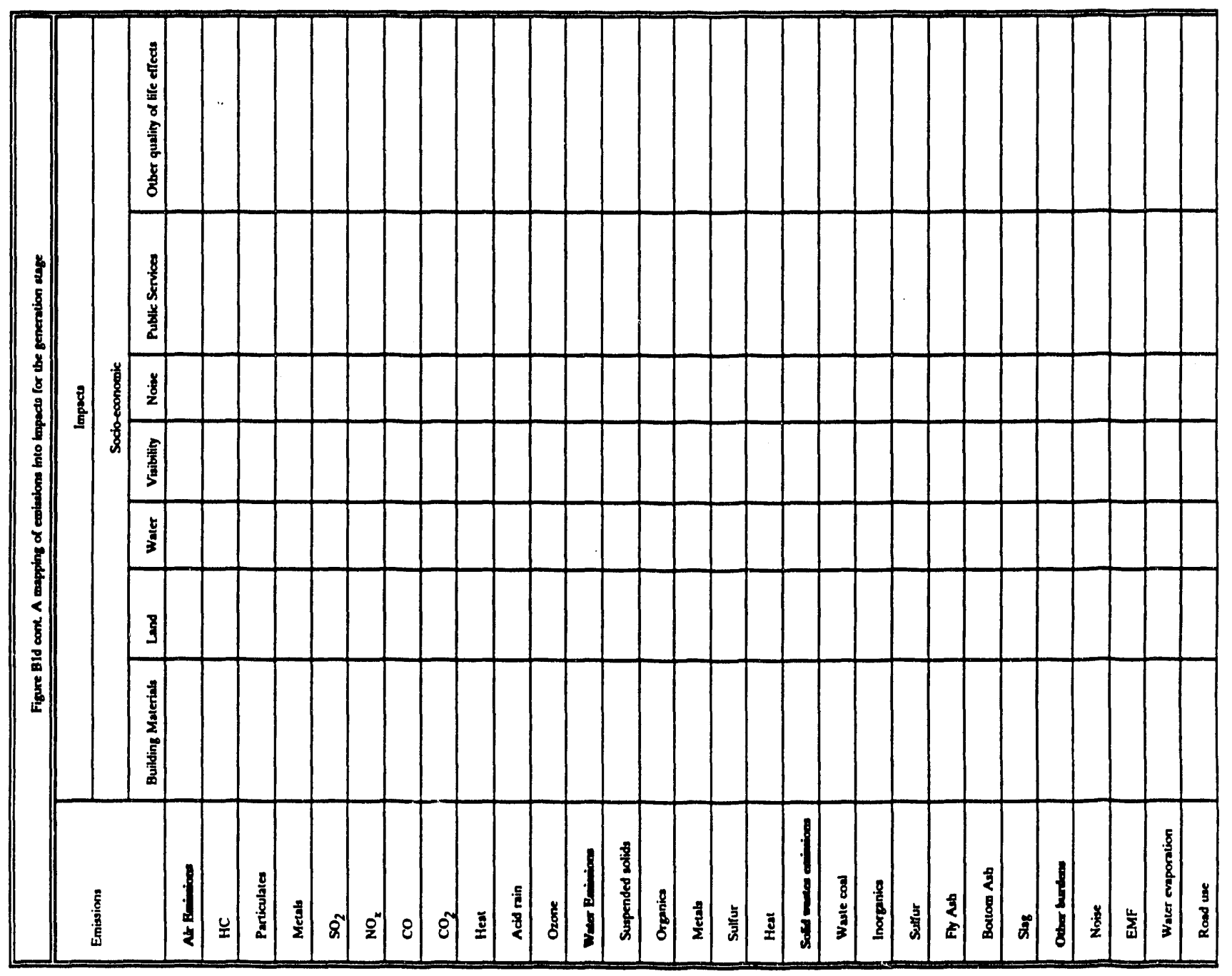




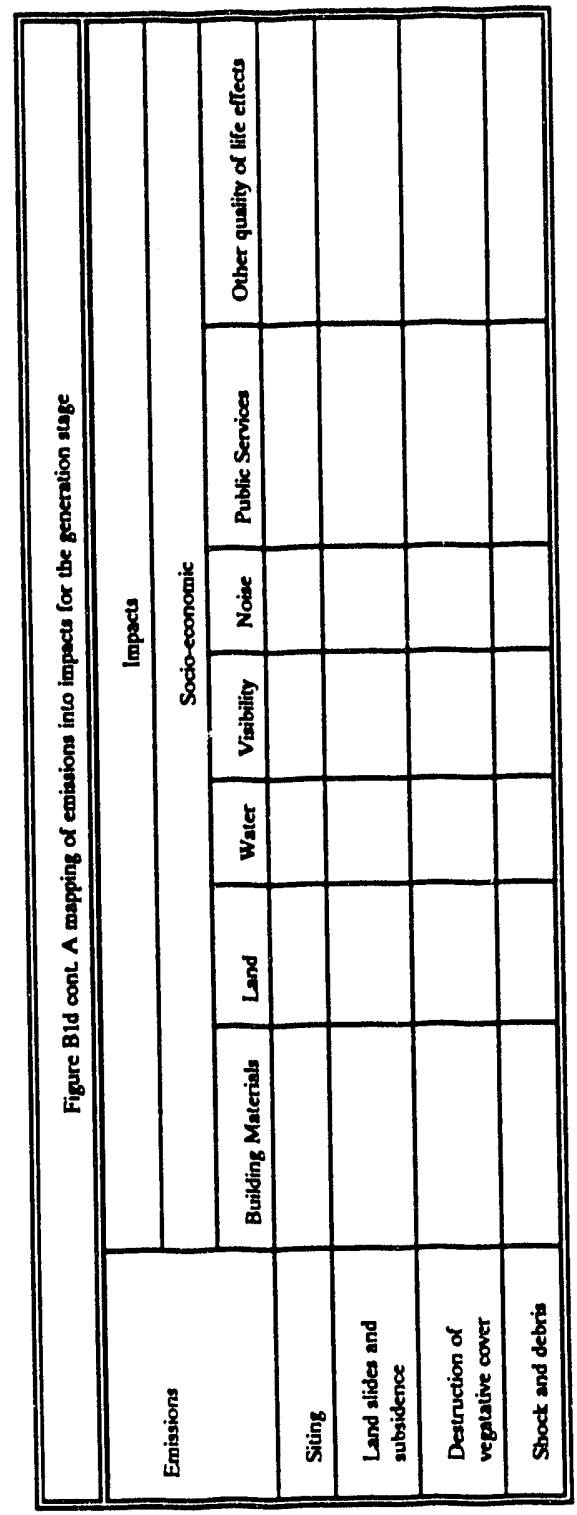




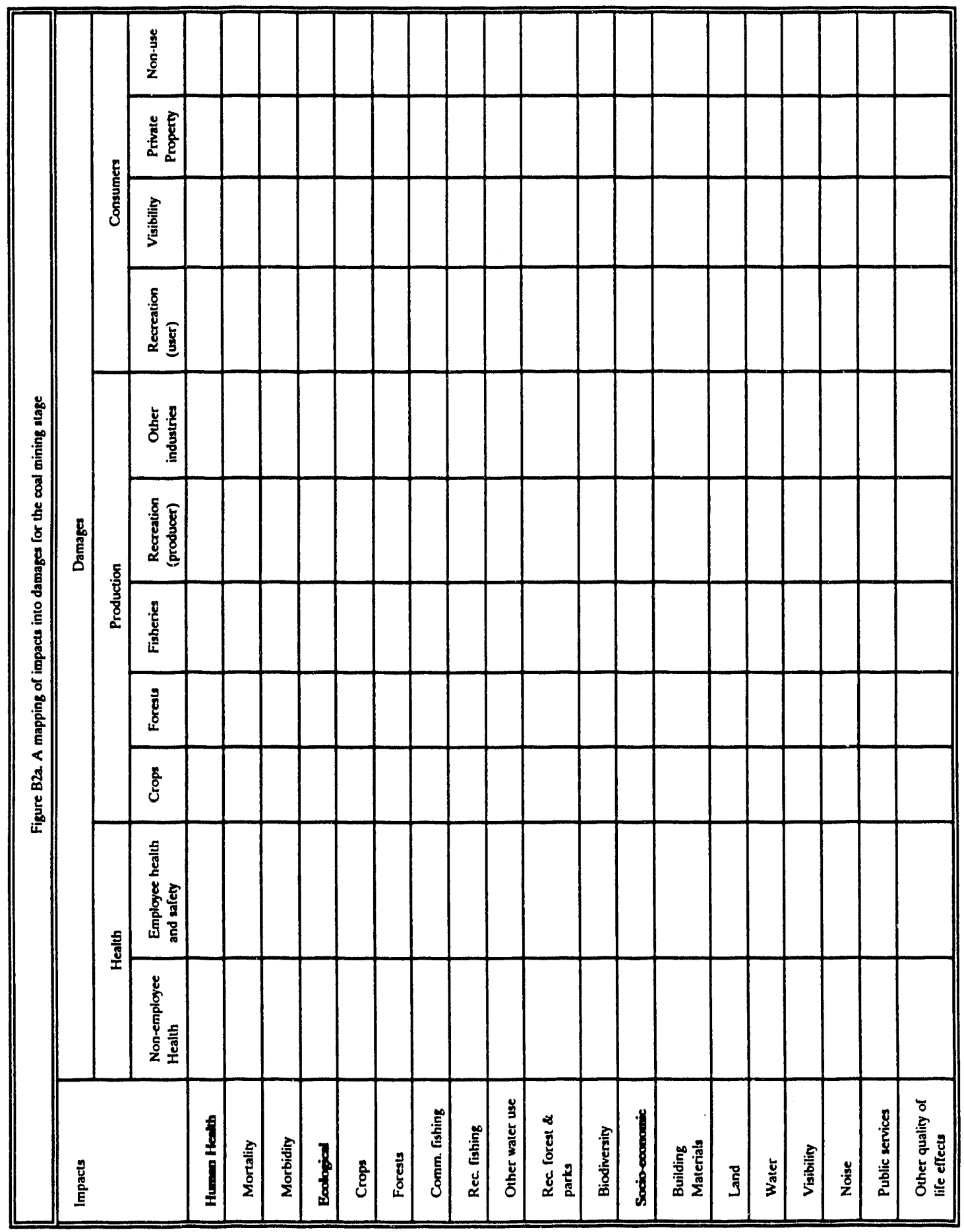




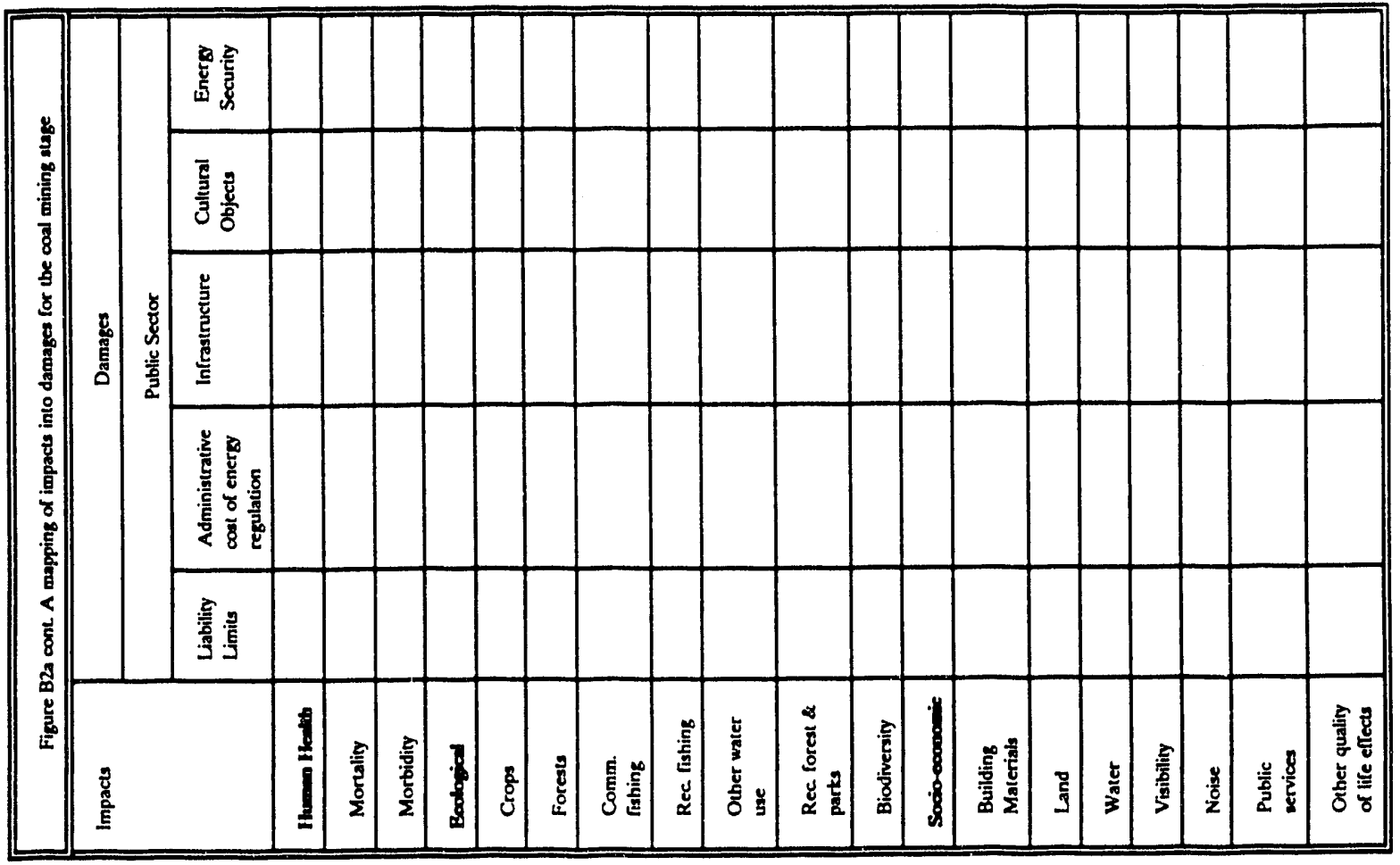


Appendix B

B-15

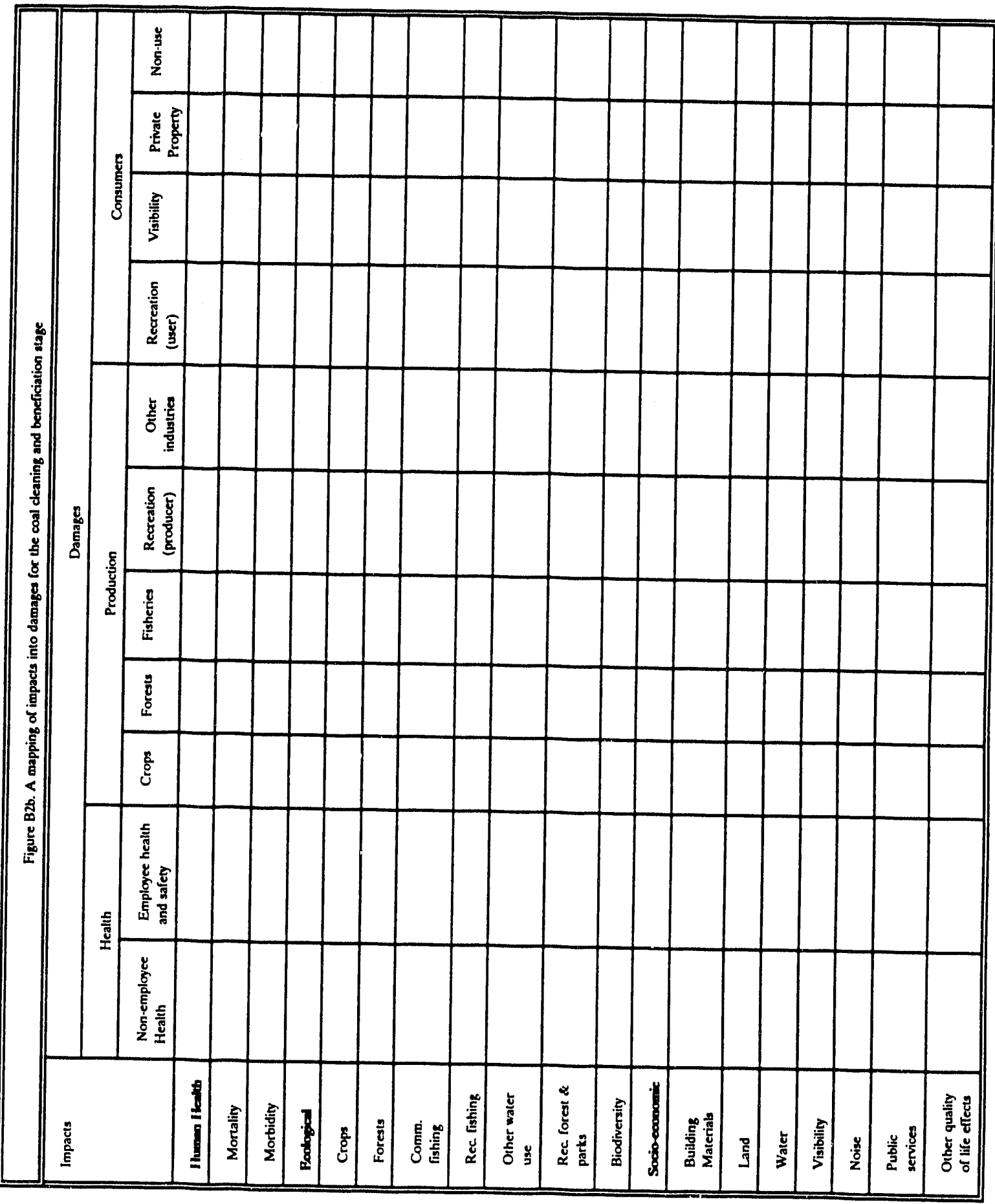




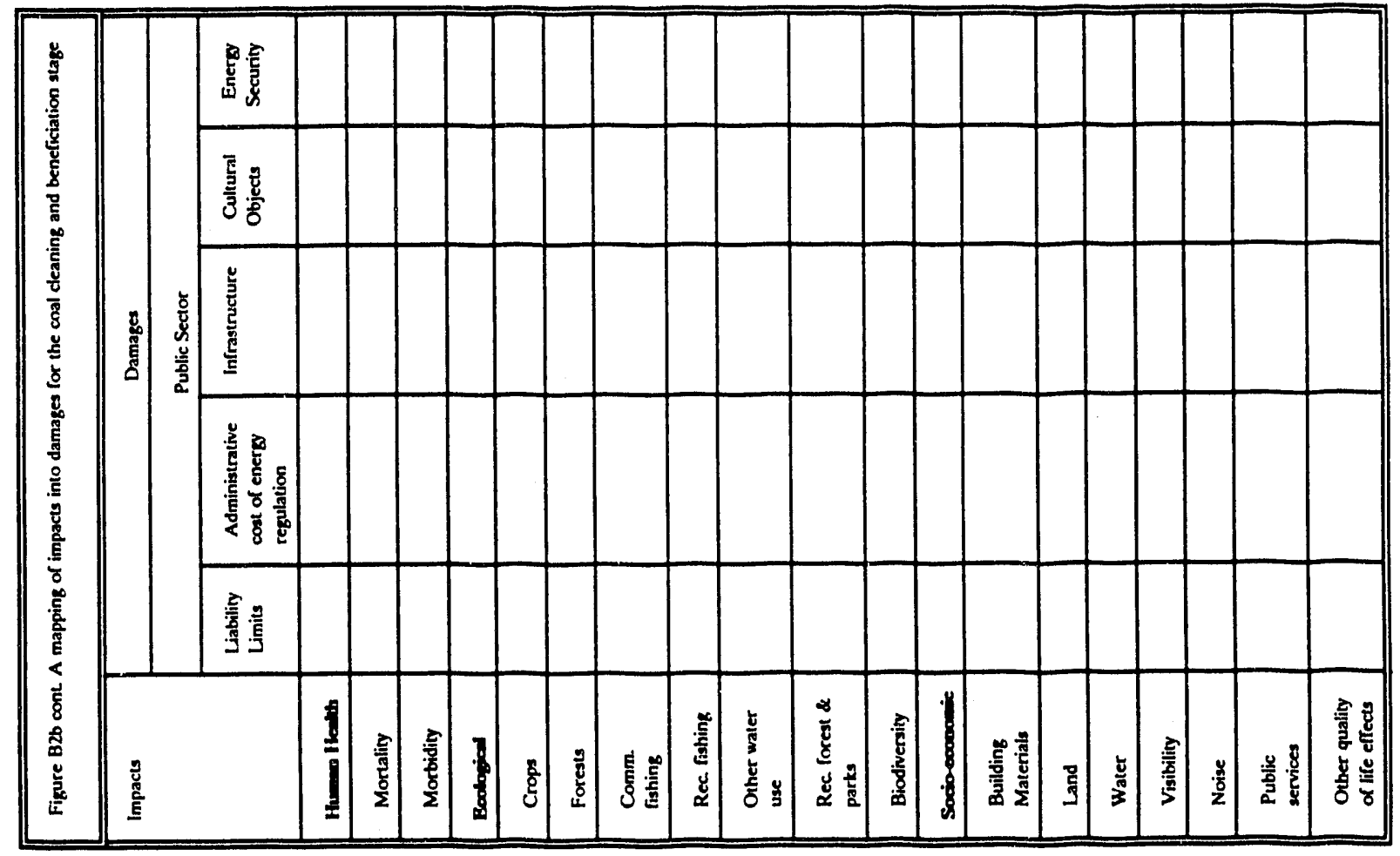




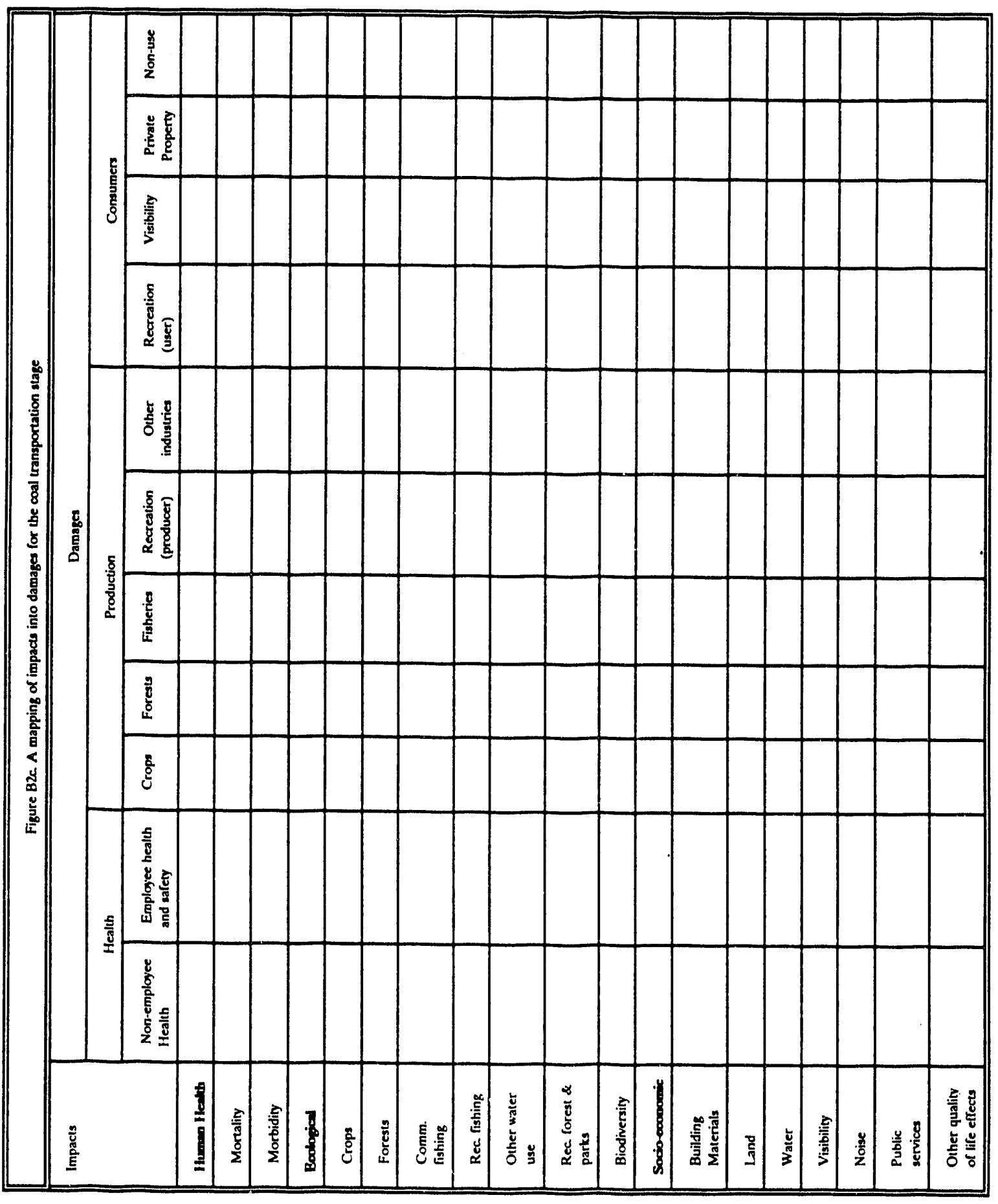




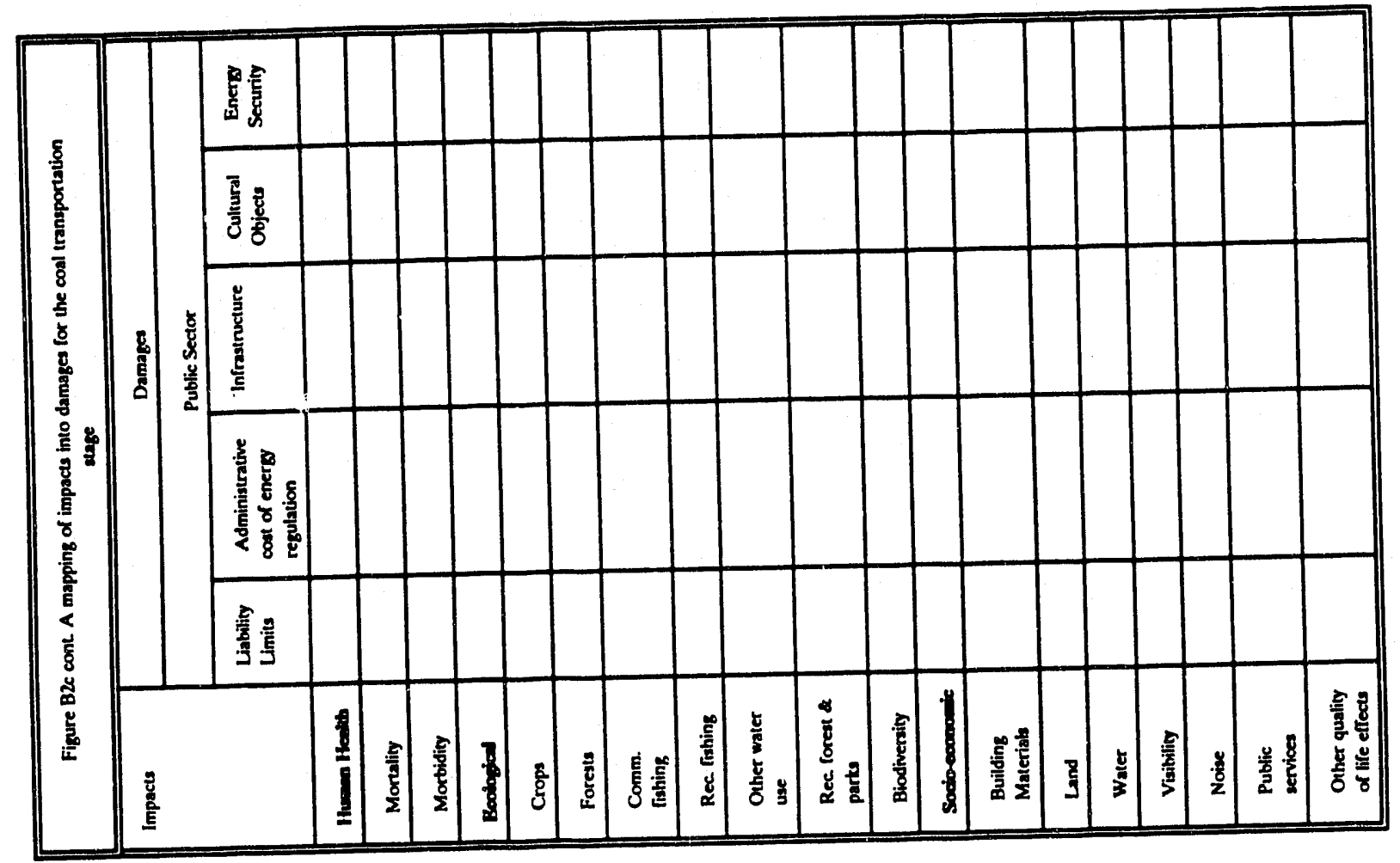




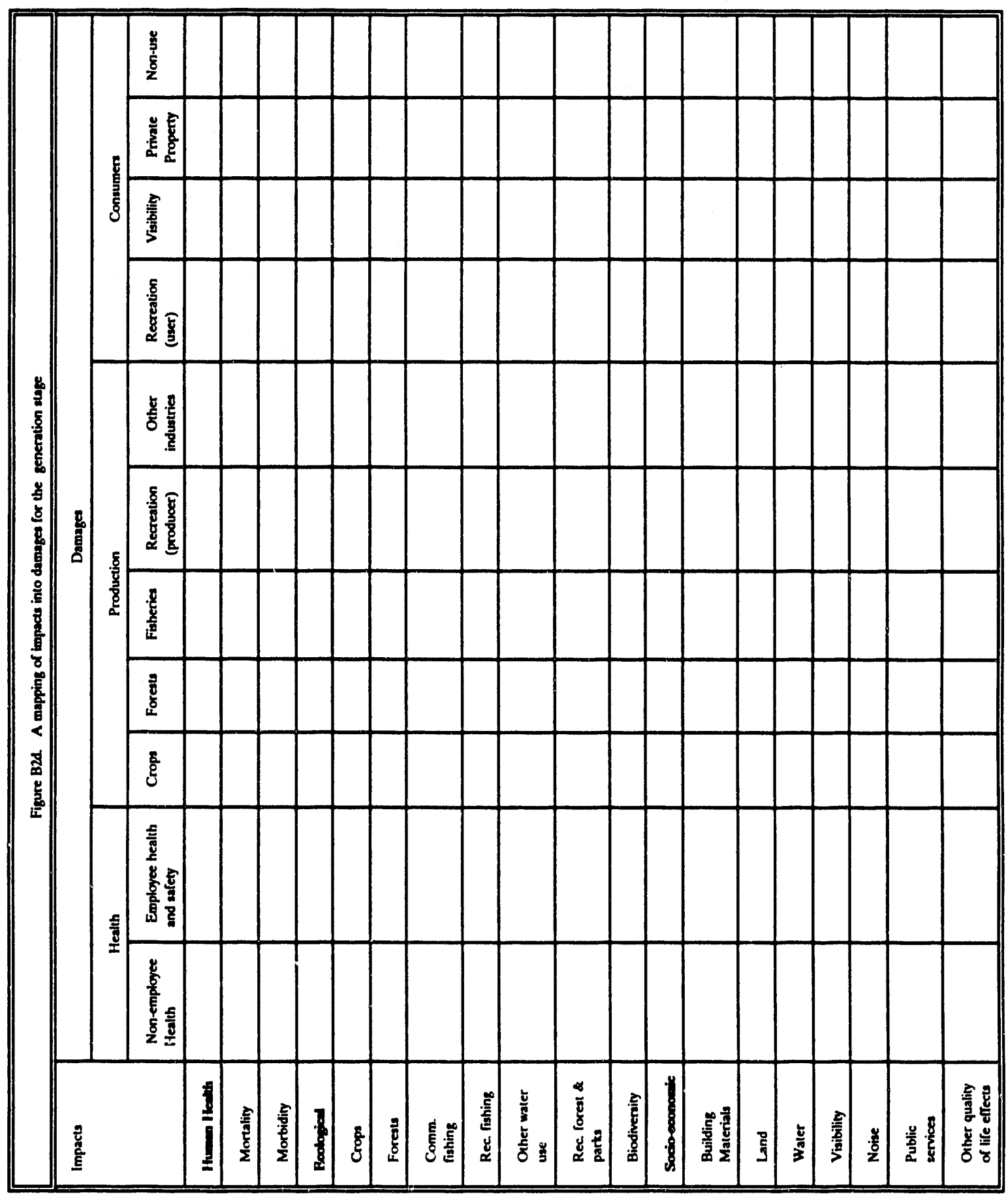




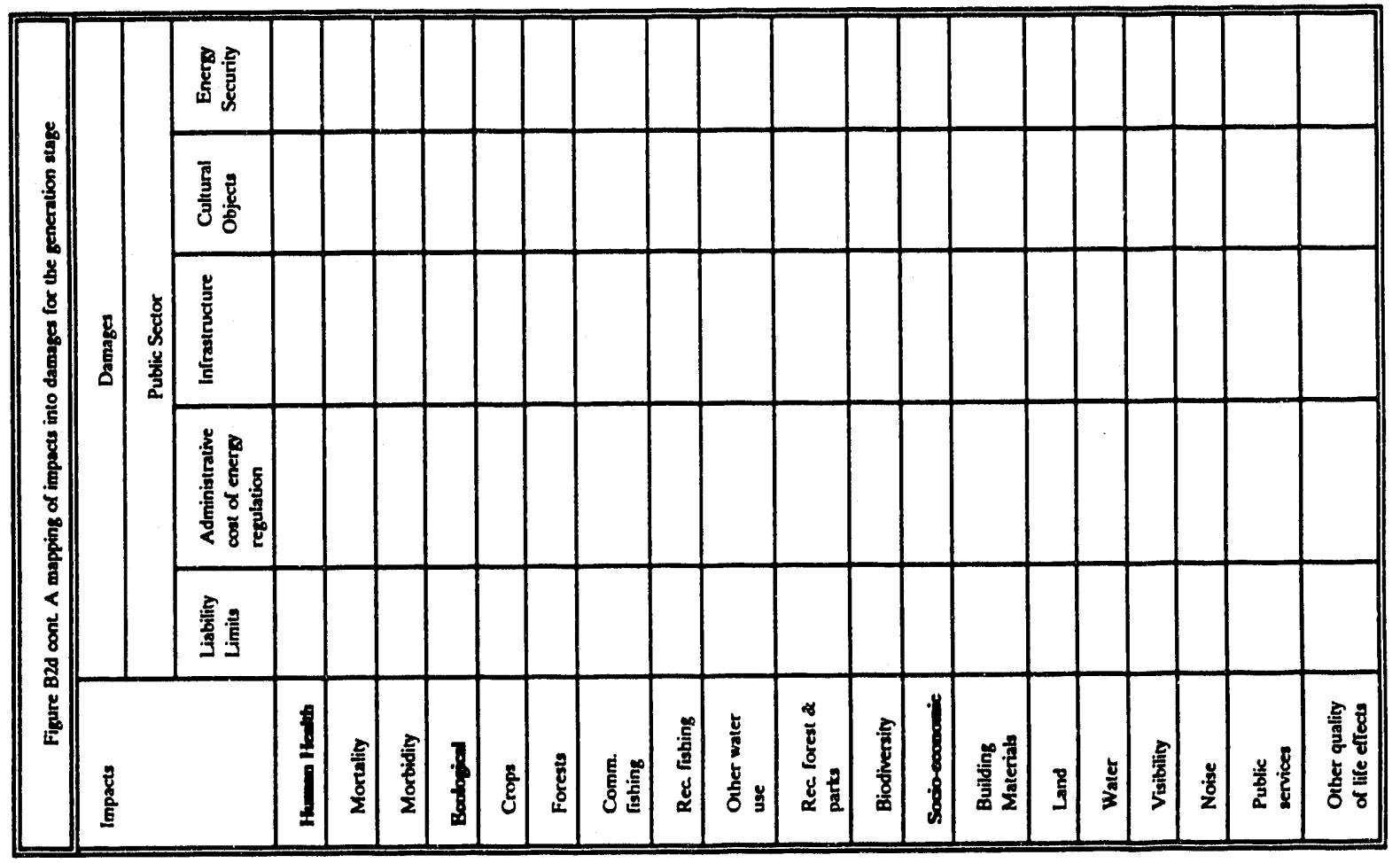




\section{APPENDIX C}

The Social Costing Debate:

Issues and Resolutions 


\section{APPENDIX C}

\section{THE SOCIAL COSTING DEBATE: ISSUES AND RESOLUTIONS*}

This appendix is meant to provide guidance to Public Utility Commissions (PUC's) and to other parties interested in the social costing debate, although it will also yield useful information to those concerned with improving environmental policy in general. ${ }^{1}$

Indeed, we begin with the basic theory of environmental policy before turning to issues specific to the social costing of electricity. We view these two types of policies very differently. The first is fundamentally about seeking optimal, first-best policies for controlling pollution and other third party consequences of economic activity (in this are electric utilities) through equating costs of control and their benefits at the margin. The second is about cost-effective, second-best policies--to choose new investment or plant operating characteristics optimally (i.e. that minimize social costs) given policies and regulations faced by the utility.

Within the issues specific to social costing, we identify and examine four: (i) Is social costing a good idea, (ii) How should damages be measured, (iii) When is damage an externality (and therefore an effect in need of an "adder", and (iv) How should such externality estimates be implemented by PUC's? Issue (ii) is primarily taken up directly in the Fuel Cycle Study. Here, some supplementary issues in damage measurement specific to social costing are taken up. Considerable attention is devoted to issue (iii), presenting first a "rule of thumb" analysis that distinguishes between damage and externality in the case of a competitive industry unable to influence electricity price, while in the second part, results of a more sophisticated mode of utility behavior are reviewed to examine how the rules of thumb will hold up. Issue (iv) presents simulation model results for the effects of given "adders" on utility investments, output, and prices. Damages and net welfare effects associated with four alternative "regimes" for implementing social costing--social cost investment, no fees; investment with fees; social cost dispatch; and social cost pricing--are examined.

\footnotetext{
Most of the material in the appendix is drawn from research produced with support from the Department of Energy, The Electric Power Research Institute, the New York State Energy Research and Development Administration, and Resources for the Future. This material appears in Burtraw and Krupnick (1992); Burtraw, Harrington, Freeman, and Krupnick (1992); Freeman and Krupnick (1992); Freeman, Burtraw, Harrington, and Krupnick (1992); Palmer and Krupnick (1991); and Palmer and Dowlatabadi (1991).
} 


\section{C.1 THE BASIC THEORY OF ENVIRONMENTAL POLICY}

In this section we explain the terminology to be used in this appendix and review the basic economics of market failure and pollution control. The context is the electric utility industry which "manufactures" electricity for sale to consumers and other firms.

An emission is a by-product of generating energy services which has an impact, usually adverse, on third parties. By third parties we mean any economic agents who are not engaged in the market exchange. "Emissions" is a generic term referring not just to air pollutants but to any third party impacts.

The impact of an emission on third parties can have the effect of either decreasing the welfare of individuals or increasing the costs of production of other firms. We use the term damage to refer to a monetary measure of this impact. The damage is the sum of money which exactly offsets or compensates for the harm caused by the emission. Since emissions reach third parties primarily through one or more environmental media, the damages are sometimes referred to as environmental damages.

An externality exists when one agent's activity (in this case, the utility) has an effect (either positive or negative) on the welfare or cost of another economic agent and the utility insufficiently takes account of that impact in its own private decision making. Since emissions cause impacts on third parties, they can be the source of negative externalities or external costs.

Economic efficiency (Pareto optimality) requires that the levels of production and consumption of all things that matter directly (or indirectly through their effects on firms and profits) be set so that the marginal social value of the thing equal its marginal social cost, where social value (cost) is defined as the sum of private and external value (cost). For the remainder of this discussion we will focus on external cost. For goods consumed by individuals, economic efficiency requires that each individual's marginal willingness to pay for the good be equal to the marginal social cost of producing it. An equivalent statement for "bads" such as emissions is that the marginal benefit of producing more of the bad equal the marginal social cost of the bad. Since the benefit of producing more of a bad is the avoidance of the cost of controlling or reducing the production of the bad, another equivalent statement is that the marginal cost of control for each emission equal the marginal damage that the emission causes. 
The efficient level of emissions is shown in Figure C-1 as $\mathrm{E}^{*}$. In this figure, MCC is the aggregate marginal control cost curve. It shows the marginal cost of reducing emissions assuming that the responsibility for controlling emissions is allocated anong firms so as to minimize the total cost of control. MD is the marginal damage of emissions.

For firms generating electricity, an externality exists if firms insufficiently take into account in their business decisions the damage imposed on others by their emissions. The result is market failure and an inefficient allocation of resources in the economy. This inefficiency shows up in two places. First, the condition for the optimum level of production of the emission will not be satisfied. The marginal damage of the emission will exceed the marginal cost of controlling it. This is shown in Figure C-1 where EMAX is the aggregate level of emissions chosen by firms when they do not take into account the effect of their emissions on third parties. The other place the inefficiency shows up is in the market for electricity. Part of the social cost of generating electricity is the damage caused by the emissions on third parties. But because of the externality, these costs are not recognized by the firm as part of its private costs. This is shown in Figure C-2. The market for electricity clears at $\mathrm{e} 1$ where the demand or marginal willingness to pay for electricity (MWTPe) is equal to the marginal private cost of electricity (MPCe), but MWTPe is less than the marginal social cost of electricity (MSCe).

There are several ways in which the inefficiency can be corrected and economic efficiency can be achieved. First, it might be possible to create enforceable property rights such that firms cannot generate emissions unless they have obtained the permission of those who feel the impact of the emissions. This would create a market where one was missing before. The MD curve of Figure C-1 would become the market supply curve of rights to generate emissions. As long as the market was competitive, it would clear at a price of $t^{*}$, and the efficient level of emissions $E^{*}$ would be achieved.

The second way of correcting the market failure is for the government to create a pseudo-price or a charge on emissions by firms. Again, the appropriate charge would be $t^{*}$ in Figure A-1. The tax has the effect of forcing firms to take account of the level of their emissions in private decision making. If the tax is set equal to the marginal damage at the optimum point, $\mathrm{t}^{*}$, then firms will limit emissions to the optimum level, $\mathrm{E}^{*}$, and pay total tax revenues of $t^{*} E^{*}$. What was an externality has now been internalized in the firm's decision making. Third parties would still experience harm or damage equal to the shaded area under the marginal damage curve to the left of $E^{*}$. These are sometimes known as residual damages, since they 
remain even after the implementation of a policy to restrict emissions. Efficiency does not require that third parties be compensated out of the tax revenues for these residual damages (Baumol and Oates 1988).

The third alternative is some form of tradable emission permit system (TEP). Permits equal in number to $E^{*}$ are either sold to firms or given away on some arbitrary basis. As long as those whose willingness to pay for an additional permit ${ }^{2}$ exceeds the offering price of other permit holders, permits will be exchanged until the market equilibrium is achieved at a price per ticket equal to $t^{*}$. The opportunity cost of an emission of one unit for a firm is the price of a permit. Firms must take account of this cost in their private decision making so again, the externality would be internalized.

All three of these methods for dealing with externalities have an effect on the market for the good. The required compensation, the tax on emissions, or the price of emissions permits becomes part of the private cost of production. If the costs associated with emissions are correctly internalized to firms, the MPCe shifts up to coincide with MSCe. And the market clears at the optimal level of electricity, $e^{*}$ in Figure $\mathrm{C}-2$. The residual damage can also be measured in Figure C-2. It is the shaded area below the MSCe curve. The residual damages are irrelevant and there is no need to compensate those who experience the damages in order to achieve economic efficiency. The presence of residual environmental damages does not mean that there is an externality.

\section{C.2 OPTIMALENVIRONMENTAL POLICY VS SOCIAL COSTING AS COST-EFFECTIVE POLICY}

A diagram such as Figure $\mathrm{C}-1$ in the preceding section is sometimes used to justify statements that externality cost adders are unnecessa.y when pollution is being optimally controlled at level $\mathrm{E}^{*}$, or even potentially overcontrolled. But as we will now show, these diagrams do not capture the essence of the problem of choosing the most economical way 'sf increasing the supply of electricity under alternative forms of environmental policy.

For the most part, U. S. environmental policy does not make use of any of the three approaches to internalizing externalities discussed previously. Rather, the most common policy instrument is specific quantitative restrictions on the level of emissions from each firm through direct regulation, also known as command and control (CAC) regulation. In principle, it would be possible to establish a set of quantitative restrictions at emissions level $E^{*}$. But even if this level of total emissions was achieved in a cost effective way, it would not 
be Pareto optimal. This is because the CAC approach to limiting emissions does not deal with the second dimension of market failure, the divergence between MWTPe and MSCe in the market for electricity. The effect of "optimal" CAC regulation of emissions would be to shift the MPCe of Figure C-2 up part way toward MSCe. However, the new equilibrium would have a price below $\mathrm{Pe}^{*}$ and a quantity above $\mathrm{e}^{*}$. So, the CA.C policy does not fully internalize the externality into the price of electricity. The presence of residual damages does have economic significance in this case. Since firms pay nothing for the emissions up to $E^{*}$, they have no reason to take them into account in private decision making. This can be particularly important in utility capacity planning decisions, wherein major new investments could be made without properly considering the full social costs of each alternative.

All of this has been a prelude to the issue at hand. Social costing has been proposed as a means to deal with decision making when we anticipate an increase in the demand for electricity and must plan for an increase in capacity (or encourage a decrease in demand) so that the market will clear and price will equal marginal social cost. Any increase in capacity will be represented by a rightward shift of the MPCe and MSCe in Figure C-2 and an upward shift of the marginal control cost curve in Figure $C-1$. The magnitude of these shifts will depend on the means chosen to increase capacity, for example, the fuel type, combustion technology, and location of the facilities. For nonmarginal increases in capacity, these factors could also affect the shape of the marginal damage curve.

In a first best world, the PUC and the environmental agency would work together to achieve a Pareto optimum. The new equilibrium would require adjustments to the pollution charge or the number of TEPs to be consistent with the intersection of the new MCC and MD curves of Figure C1. However, making optimal adjustments to the environmental policy instruments is beyond the power of the PUC. Rather, the PUC should evaluate the alternative supply options taking existing pollution control policy as given. This is a problem of the second best, to which we now turn.

\section{C.3 IS SOCIAL COSTING A GOOD IDEA?}

It is a good idea but not a great idea. A great idea is to internalize externalities throughout society by replacing our patchwork of command and control policies with economic incentive policies that inherently force internalization. Given that this is unlikely to happen, a second-best option is to seek cost-effective choices of electricity investment and generation, given the policies and regulations in place, where cost-effectiveness here means 
choosing technologies with the lowest social cost to meet new electricity demand.

Once one makes a distinction between optimal regulation and enters the second-best world of social costing, much of the confusion in the social costing debate dissolves. For instance, economists who feel that social costing is a bad idea justify this position in a way that mischaracterizes the objectives of social costing as a first-best policy. For instance, Joskow says, "their (PUC's) reliance on numerical "adders" to reflect environmental impacts will not achieve the goal of improving the environment at the lowest reasonable cost to society (Joskow 1992 p.1) [emphasis added]." And "States such as Massachusetts, Nevada, New York, and California have decided they can 'fix' what ails existing environmental regulations by appending various externality "adders" to the private costs of new utility resource options (Joskow 1992 p.12) [emphasis added]."

We believe that in many instances PUC's will not have the authority or the expertise required to set environmental policies and standards. And for those externalities regulated by environmental agencies, PUC's have no business trying to second guess or correct the perceived errors of these other agencies. However, internalizing externalities in electricity system planning is consistent with a much more limited objective, an objective which is entirely appropriate to PUC's. This objective is to minimize the increment to social cost associated with meeting a given increase in the demand for electricity.

We wish to emphasize three points about this objective:

(i) In pursuing this objective, PUC's must take existing environmental policy as given. Therefore, pursuit to this objective does not involve second guessing environmental agencies or attempts to "fix" existing environmental policy. But it does require a concern for the environmental impacts of the electricity supply and demand side management (DSM) choices made by the PUC.

(ii) This objective can be interpreted as a straightforward extension of the traditional rationale for PUC regulation of electricity prices, namely concern for the impact of prices on consumer welfare. A low price for electricity is not a fundamental goal of policy; rather it is one of several instruments to be used to promote the fundamental objective of improving consumers' economic welfare. Since environmental quality also affects consumer welfare, PUC's should be aware of the effects of their decisions on environmental quality. Choosing the electricity supply option with the lowest private cost helps to keep the price of electricity low. But a PUC does consumers no favor by choosing the 
alternative with the lowest private cost if this choice imposes a hidden "tax" on consumers through its environmental damages.

(iii) The PUC that wants to promote consumer welfare must take account of both the private costs and the external costs of alternatives in its decision making. This will often require some form of "adder".

However one feels about the objectives of social costing, there is universal agreement about the existence of a "piecemeal problem" - i.e. the possible losses of efficiency associated with singling out the electricity sector for social costing. (The likely application of this approach in some, but not all, states may also be a kind of "piecemeal problem", to be dealt with in the next section).

These efficiency losses could arise because of distortions introduced in relative prices. Limiting use of social cost adders to the utility industry puts the utility's electricity at a competitive disadvantage relative to self-generation or purchasing power directly from an independent power producer (IPP). Some IPPs may find it advantageous to deal directly with customers rather than go through the PUC review process of bids to connect to the grid. This is the so-called "by-pass" problem. If these potential sources have uninternalized environmental costs associated with them, social welfare could be reduced by requiring externality adders only in the utility system. Electricity, in general, may be inappropriately disadvantaged next to other forms of energy.

The two problems of incorrect electricity price signals and by-pass arise not because social costing is wrong, but rather because it is incomplete in its coverage. PUCs do not presently have jurisdiction over electricity sources that do not connect to the grid. They may not have the authority to set the price of electricity above its private cost in an effort to "pass through" uninternalized environmental costs to electricity consumers. The solution to these problems is to develop a comprehensive system for internalizing environmental costs not only on utilities but on other sources of these emissions as well.

Nonetheless, concern about the piecemeal approach begs the question: why are utilities being picked on? One opinion that is often stated as a justification for singling out utilities is the view that "electric utilities are a major source of our environmental ills and are dragging their feet on demand-side management." The reality is that electric utilities are already more scrutinized and controlled than most industries. 
On the other hand is the viewpoint represented by the following: "The utility industry should earn credits for the superior value provided by electricity." The problem with this viewpoint is that the value of electricity is already accounted for in the price. Consumers make consumption decisions based on the marginal value and the marginal price of the product. Since price is fixed from the consumer's perspective, one can vary the quantity one purchases until at the margin the value just equals its price. A fundamental tenet of the economic approach is that we are concerned about the effects of marginal decisions, rather than inframarginal decisions. No one is suggesting that one possibility is to de-electrify America or any such thing. Instead, we are concerned with marginal decisions that may involve new investment, the dispatch of existing capacity, or the proper pricing of energy services. We are concerned with the choice among the various fuel cycles for the delivery of energy services.

The reality as to why utilities have been singled out probably begins with the observation that utilities are an easy target and still an important source of pollution. The belief among certain regulators and their constituencies that social costing will speed penetration of renewables and demand-side management options into utility operations is also an important factor. In any event, electric utilities may not be alone for long. Increased attention already is being directed toward other sectors of the economy, the transportation sector in particular.

Note also the historic role of economic regulation of electric utilities. These organizations have been granted an exclusive franchise, and have accepted along with that a commensurate obligation to serve their communities. The aim of this form of economic regulation has been to improve consumer welfare, with the justification that historically the industry enjoys a declining average cost technology.

There are special responsibilities for a regulated industry and the consideration of full social costs appears to be one. Indeed, the consideration of social costs in utility regulation is nothing new. The historic partnership between regulators and utilities has been interpreted broadly to include social issues such as regional economic development, and this approach has been sanctioned in the courts.

Furthermore, environmental concerns are nothing new to utilities. They are residents of a local area and citizens in their community, just like everyone else. They have always had to comply with relevant environmental laws. And most recognize that regional economic development depends on environmental quality in the first place. 
Seen in this light, the concern with full social costs is just an extension of the historic mandate to consider consumer welfare in this regulated industry. Today, analysts recognize that consumer welfare depends not just on the price of electricity, or even on regional economic development, but on the full array of social costs and benefits that attend the delivery of energy services. Consumer welfare achieves a maximum if energy services are delivered not at their least private cost, but at their least social cost.

\section{C.4 HOW SHOULD DAMAGES BE MEASURED?}

First, one should consider all damages and benefits from the entire fuel cycle. For example, in the evaluation of a proposed hydroelectric facility one should consider environmental damages, such as lost trout habitat and associated lost recreation opportunities. In addition, there may be environmental benefits such as the creation of bass habitat behind the reservoir and new recreation opportunities. There may be nonenvironmental damages such as infrastructure costs associated with the damage to roadways done by heavy trucks in the construction of the dam; and, there may be nonenvironmental benefits such as net new job creation, to the extent that previously there existed under-employed labor. All of these effects should be considered on an equal footing.

Second, damages and benefits are generally location specific. Things that differ between locations include ambient concentrations, relevant populations, population density, specific dose-response functions, geology and stream flows, transport conditions, along with nonenvironmental variables such as the local labor market. Furthermore, the conditions that apply throughout the plant's life must be considered. These wide-ranging considerations lead to the determination of the "baseline" from which the marginal facility will have its impact.

The location specificity of damage implies a point which many people have failed to appreciate: there never will be a "big book of values" in which one can look up numbers for the external damage or benefit associated with a kilowatt hour of electricity produced from a fuel cycle. What is important is that analysts use common methods, not common values, in the estimation of these location-specific social costs.

\section{C.5 WHEN IS DAMAGE OR BENEFIT AN EXTERNALITY?}

Given that damages and benefits can be measured, we move to their evaluation with reievance to the policy process in mind. In this section we 
introduce several criteria that should be useful in circumscribing the set of issues that should be of genuine concern. These criteria are suggested by economic theory, but their precise formulation is sometimes a fundamentally political issue. If regulators first resolve the issues embodied in these criteria, they can serve as rigorous filters to guide analysis.

\section{C.5.1. CRITERIA}

The first criterion is a fundamentally political question: How should the analysis treat transboundary effects? Transboundary effects pertain to effects of pollution and other impacts that cross over borders to other jurisdictions. One has to decide whether one is altruistic, or hard-nosed and self-interested, in one's approach. That is, should damages to the residents of one's service territory be counted exclusively, or should damages to the state, to the entire U.S., or even to the world be counted as well?

Sometimes it is said that an individual utility can have no impact on a transboundary problem. This is incorrect. One utility has the opportunity to reduce a transboundary problem, such as the global warming problem, to the precise extent of its contribution to the problem. The reason that one might argue that consideration of global warming is inappropriate from an economic perspective is that most of the benefits from individual action to reduce global warming accrue to others. This observation applies to many other issues as well. Whether or not the costs that spill-over to other jurisdictions are to be counted will affect significantly the estimate of social cost.

Treating all transboundary effects as costs may have unfortunate consequences. Not only may ratepayers pay more than the benefits they personally receive from the consideration of all costs, but this approach may exacerbate the problems of bypass or industrial flight. If a noncaptive customer decides to bypass the utility's system it may have the opportunity to capture the environmental benefits of the utility's benevolent policies and avoid the cost, even achieving a cost advantage compared to its competitors. Consequently, from an economic perspective one can complain legitimately that state public utility commissions are an inappropriate forum for addressing issues such as global warming. Political analysis can vary from that, to the extent that legislatures want to consider strategic and political issues or to try to prompt federal leadership. But it seems to us that as important as transboundary problems may be, they lie outside the purview of utility regulators absent direction from state or federal governments.

A second criterion asks: What is marginal in the decision at hand? If an increment in capacity is being considered (i.e., the external costs of one 
additional plant), many potential external costs will be irrelevant. For example, it is often pointed out that historic subsidies to research and development have given certain fuel cycles a price advantage. But, clearly, these are sunk costs and not marginal to the decision at hand. Energy security externalities identified with the military dimensions of foreign policy and the costs of the Strategic Petroleum Reserve are not relevant because these national policies are invariant with the decision of an isolated utility. Considering the 1991 Persian Gulf War, it is unlikely that the U.S. response would have been different if even $20 \%$ of imported oil demands were reduced (let alone the addition or deletion of a single facility). As with the case of transboundary issues, many social costs are fixed from the perspective of individual utilities and properly should be the subject of policy debate in a different forum.

A third criterion is whether the candidate externality would differentiate between fuel cycles. If an externality affects all fuel cycles in a comparable manner, then it is not worthy of extended consideration in many policy contexts because it is not helpful in differentiating the options according to social cost. One example of such a possible externality is the macroeconomic costs that may result from the shori-run inflexibility of prices of electricity, which results from price regulation. This inflexibility may lead to dislocations in the economy when resource prices change but electricity prices do not reflect these changing costs. However, since all fuel cycles are afflicted in a similar manner, what is sometimes called the regulatory externality of fixed prices is not a useful criteria in a siting decision.

A fourth criterion asks: what is the relevant regulatory environment? In the case of environmental pollution, two general regulatory environments are relevant in the U.S. One is command-and-control, which describes the approach of setting minimum technology performance standards for polluters. Command-and-control is by far the most common type of pollution control in the U.S. A second approach is marketable permits, which describes the imposition of a quantity constraint on the total amount of pollution that can be released and allows polluters to buy and sell pollution permits among themselves.

In a command-and-control regime, the rule of thumb we recommend is that the relevant externality is any residual marginal damage that is observed after the firm has complied with all applicable environmental laws.

The second approach to environmental regulation that we consider is tradable emissions permits (TEPs). This is the approach that is embodied in the 1990 Clean Air Act Amendments pertaining to the regulation of sulfur 
dioxide and the control of acid rain. In this case the quantity of sulfur dioxide emissions is constrained on a national basis.

The most important issue concerning tradable permits is whether the pollutant in question is "uniformly mixing." This means that within an air shed or a water basin the concentration of the pollutant and its impact does not vary with the location of the emission.

If the pollutant in question is uniformly mixing then no marginal damage can occur as the result of operating a new facility or changing the dispatch of existing facilities. The reason is that there is a quantity constraint on the total amount of pollution that can be emitted. In order to emit pollution at the new facility, the utility must obtain offsetting permits at another facility. Consequently, the marginal impact is zero, marginal damage is zero, and there is no externality. On the other hand, if the pollutant is not uniformly mixing (or at least approximately so) then there may be a change in local environmental quality that should be addressed.

To appreciate these results more fully, the next section provides a detailed presentation of the underlying logic and the following section a more rigorous and realistic model yielding a somewhat more qualified conclusion regarding externalities vs damages in a command and control regime.

\section{C.5.2 RULES OF THUMB}

We make the following assumptions about the PUC. First, the PUC has no control over environmental policy, per se. It must take such things as emission standards, pollution tax rates, or numbers of TEPs as given. Despite the absence of power over environmental policy, we assume the PUC has the objective of minimizing the increment to social cost (inclusive of environmental concerns) associated with meeting the increase in the demand for electricity. ${ }^{3}$ It achieves this objective through its choice of the mix of new capacity.

We assume that the PUC has before it a set of proposals from a utility and (perhaps) IPPs. Each proposal is characterized by a quantity of electricity, a price or bid which we take to represent private cost, and a description of its emissions. In the presence of CAC regulation, private cost will include only the costs of controlling emissions to meet standards. In the presence of other appr vaches to regulation the private cost will also include the pollution taxes to be paid, the cost of permits, etc. The PUC wishes to rank the proposals by social costs, so any external cost should be added to each proposal's private cost to determine its social cost. This external cost is the "adder." In the rest of this section we identify the correct adder under 
case, we also consider the possibility that environmental regulation may not be optimal. We will show that in some circumstances, the magnitude of the adder will depend on whether existing environmental policy is optimal, overcontrolling, or under-controlling.

\section{Command and Control Regulation}

The CAC case is the simplest of the three that we consider. With $\mathrm{CAC}$, there is no mechanism for internalizing the marginal damages in the private cost or bid of each option. Thus, the adder should be equal to the marginal damages for each source. Whether the CAC policy is over-controlling or under-controlling is irrelevant because the PUC cannot do anything to make matters better. In fact, any effort on the part of the PUC to adjust its ranking of supply options in an effort to "correct" for inappropriate environmental policy will necessarily make things even worse.

Suppose that the FUC has two alternatives, a clean source (no environmental damages) and a dirty source in the sense that it has large environmental damages even with the presently required controls on emissions. For the clean source, $\mathrm{MSC}($ clean $)=\mathrm{MPC}($ clean $)$. And for the dirty source, MSC(dirty) $=\mathrm{MPC}$ (dirty) $+\mathrm{MD}$ (dirty). Finally, suppose that their marginal private and social costs are related in such a way that the marginal social cost of the clean source is greater than the marginal private cost of the dirty source, but less than the marginal social cost of the dirty source:

$\operatorname{MSC}($ clean $)>\operatorname{MPC}($ dirty $)$

MSC(clean) < MSC(dirty)

The utility or PUC looking only at private costs would choose the dirty source. But since the PUC wishes to minimize the social cost of the new capacity, it should choose the clean source. Including an adder equal to the marginal damage of the dirty source reverses their ranking on the basis of cost. Alternatively, if MSC(dirty) < MSC(clean), the PUC should choose the dirty source.

Could the PUC "correct" for the effects bad environmental policy by using a different adder? The answer is "no." The PUC can do no better than to choose the source with the lowest social cost. Suppose that environmental policy involves setting emissions standards that are too strict from an economic efficiency perspective. If the PUC ignores or discounts the adder in an effort to tilt the scale in favor of the dirty source, it winds up choosing a source that imposes additional external damages and excessive abatement costs on society. 
Now consider the case where existing emissions standards are not strict enough. Can the PUC "correct" for this under-control by choosing the clean source even though its marginal social cost exceeds that of the dirty source? Again, the answer is "no." Given that a dollar of private cost has the same significance for economic efficiency and welfare as a dollar of external cost, the PUC should choose the source with the lowest social cost.

The bottom line of this discussion is that if the PUC is trying to minimize social cost the PUC should treat the costs imposed on society by inappropriate environmental standards for existing sources as sunk costs. There is nothing the PUC can do about them. They should be ignored. However, the environmental consequences (given existing environmental regulation) are not sunk but variable with an incremental investment in capacity. If excessive control cost exists it is already built into the bid or private cost, so the PUC should find the external cost and add it to the private cost. The appropriate adder is marginal damage.

\section{A Tax on Emissions ${ }^{4}$}

With an emissions tax system, a potential new source's bid will be based on the sum of production cost and the tax on the remaining emissions. The production cost will include any cost associated with controlling emissions in response to the incentives created by the tax. The PUC will wish to rank the supply options by marginal social cost, which will be the sum of the production costs (including costs of control) and the marginal damages imposed by the remaining emissions. Marginal social costs will differ from bids to the extent that marginal damages differ from the tax on emissions. The PUC should adjust the bid by including an adder equal to MD - t. ${ }^{5}$

If existing environmental policy is too strict, the emissions tax is greater than marginal damages. The PUC should correct for this by incorporating a negative adder equal to MD-t. This negative adder corrects for the fact that the part of the tax included in the private cost or bid is not reflective of a social cost, but rather it is just a transfer payment. Similarly, if the environmental policy is not strict enough, the PUC should adjust the bid upward by an amou'lt equal to the excess of marginal damage over the emission tax.

Some adjustment may be necessary even if the emissions tax is just equal to marginal damage at the existing equilibrium. Suppose the marginal damage function is upward sloping and the proposed increment to supply involves a nonmarginal change in emissions. In a first best world, the emissions tax would be adjusted upward to reflect this fact. And the bid would be based on the anticipated higher emissions tax rate. But in the 
second best world, bidders and the PUC take the emissions tax rate as given. Therefore the PUC should include an adder equal to the excess of marginal damages in the new equilibrium over the unchanged emissions tax rate.

\section{Tradable Emissions Permits}

This case is of special interest because of the offset requirements for new sources in air pollution non-attainment areas and the $\mathrm{SO}_{2}$ allowance trading system being established under the Clean Air Act Amendments of $1990 .{ }^{\circ}$ The calculation of the correct adder in the case of tradable emissions permits depends on whether the marginal damage per unit of emission varies across sources, and if so, the extent to which the rules which determine how permits are traded reflect any variation in marginal damages. In general, the marginal damage per unit of emission depends both on the effect of emissions on ambient environmental quality and on the marginal damage associated with a decrease in ambient quality. Both of these relationships can vary significantly across sources of emissions at different locations. The origins of this variation include differences in the ability of the environment to absorb emissions, differences in the characteristics and numbers of agents experiencing the impacts of the emissions (e.g.., urban vs. rural areas), and nonlinearities in the damage function.

We first consider a simple case where the marginal damage per unit of emission is same for all sources. An example would be a globally or regionally well-mixed pollutant with a uniform ambient concentration. The effect of a one unit increase in emissions on ambient concentration and damages is therefore independent of the location of the source of the emission. The key feature of this case is that any new source must purchase permits for every unit of emission, and since the total number of permits available is fixed, emissions from other sources are reduced by an equal amount as they sell permits to the new source.

Given these assumptions, the marginal social cost of a new source is the sum represented in the following Table C-1. If the pollutant is uniformly mixed the two marginal damage terms are equal and cancel out. ${ }^{7}$ In equilibrium, the price of a permit will equal the marginal control cost at the source selling permits. The new source must include the price of its permits in its bid. So the bid will equal the sum of marginal production cost and the cost of permits, and this will be equal to the marginal social cost of the new source. In other words, the price of permits internalizes the cost of reducing emissions by an equal amount at other sources. The appropriate adder is zero. This is true regardless of whether the number of permits available in the market is optimal, too large, or too small. 
Appendix C

\section{Table C-1}

MARGINAL SOCIAL COSTS OF PRODUCTION AT A NEW SOURCE IN THE CASE OF TRADABLE EMISSIONS PERMTTS WHEN THE POLLUTANT IS UNIFORMLY-MIXING

1. Marginal production cost at the new source including its control costs. $(t)$

2. Marginal control cost at the source selling permits to the new source. $(t)$

3. Marginal damage of emissions at the new source. (+)

4. Marginal damages avoided at the source selling permits and reducing emissions. (-)

We now turn to the case where the marginal damage per unit of emission varies across sources. We will first assume that the environmental agency has adopted optimal trading rules to reflect this variation. These rules will require that any source $i$ which desires to increase its emissions by purchasing permits from source $j$ must purchase $d_{i j}$ permits per unit of its emission where $d_{i j}$ is the ratio of its marginal damages to marginal damages at source $j\left(M D_{i} / M D_{j}\right)$. We will then examine how our results change if the environmental agency has not adopted the optimal trading rules.

Suppose that it is known that the proposed new source i would purchase its required permits from existing source $j$ and that the ratio of the marginal damages from the two sources is three. In other words, $d_{i j}=M D_{i} / M D_{j}=$ 3 . Let the present price of permits sold by source $\mathrm{j}$ be $\mathrm{P}^{*}$; and suppose that the incremental demand of the new source is small enough that $\mathrm{P}^{*}$ can be assumed to be constant. Given this ratio of marginal damages between the new and existing source, the optimal trading rules will require that the new source purchase three permits from source $j$ for every one additional unit of emission. Thus the price of one unit of emissions at the new source, $P_{i}$, is $3 \mathrm{P}^{*}$. The new source will optimize by purchasing enough permits so that its marginal control cost is equal to the price must pay $\left(\mathrm{P}_{\mathrm{i}}=3 \mathrm{P}^{*}\right)$. As in the case of the well-mixed pollutant, the marginal social cost of the new source is the sum represented in the following Table C-2. 


\section{Table C-2}

\section{MARGINAL SOCIAL COSTS OF PRODUCTION AT A NEW SOURCE IN THE CASE OF TRADABLE EMISSIONS PERMITS WHEN THE POLLUTANT IS NOT UNIFORMLY-MIXING}

1. Marginal production cost at the new source including its control costs. $(+)$

2. Marginal control cost at the source selling permits to the new source. $(+)$

3. Marginal damage of emissions at the new source. $\left(+M D_{i}\right)$

4. Marginal damages of emissions at the source selling permits and reducing emissions. $\left(-3 \mathrm{MD}_{\mathrm{j}}\right)$

Since the optimal trading rules require that the new source purchase 3 permits for each unit of its emissions, the last two components are equal to each other and cancel out. And the marginal control cost at the source selling the permits is internalized in the bid of the new source through the necessity to purchase permits at $P_{i}=3 \mathrm{P}^{*}$. So, the adder is zero in the case of a permit system with optimally designed trading rules.

Note that this result was obtained without making any assumption about the optimality of the pattern of environmental quality or the number of permits issued for trading. As long as the permit trading ratio is equal to the ratio of marginal damages, the last two components of the above summation cancel out. And the private bid of the new source internalizes the marginal control cost at the source selling permits.

Now let us see what happens when the trading rules are not optimal. Suppose that in the above example, permits traded one for one, even though $M D_{i}=3 \mathrm{MD}_{\mathrm{j}}$. Then, the last two components of the above summation would not cancel out. Although the private bid would internalize the marginal control costs imposed on the selling source through the permit price, the difference between the marginal damages at the two sources would have to be added to the bid to reach the correct marginal social cost. In other words, the environmental cost adder would be the difference between the marginal damages at the new source and the old source. If the marginal damages at the selling source were greater than the marginal damage at the new source, the adder would be negative.

Alternatively, suppose that the marginal damages per unit of emissions are the same at both sources but that permits do not trade on a one for one basis. For example, suppose that the new source must purchase more than 
one permit for each unit of its emissions so that there will be a reduction in total emissions. Then, the correct adder is based on the

product of marginal damages and the net change in emissions. If total emissions are reduced, the adder is negative.

Conclusions

We can summarize the results of our analysis in the Table C-3.

Table C-3

LEVEL OF ENVIRONMENTAL CONTROL

Environmental Policy

Instrument

Under-Control

Optimal Control

Over-Control

Emission tax

Adder $=M D-t>0$

Adder $=M D-t=0$

Adder $=M D-t<0$

TEPs: Optimal

Trading Rules

Adder $=0$

TEPs: NonOptimal

Trading Rules

Adder $=M D(n e w)-M D($ old $)$

Command and

Control

Adder $=M D$

Table C-3 shows that the correct adder depends on the nature of the environmental policy instrument and the details of the implementation of that instrument. The adder will be zero only when the true costs of the new source, broadly construed, are fully internalized in the private cost calculus of the bidder. For example, with a TEP system and optimal trading rules, the adder is always zero because the cost that the new source imposes on society is the additional control cost at the selling source and this cost is already internalized through the cost of permits. But with a TEP system and trading rules that are not optimal, the differences in marginal damages across sources 
are not properly internalized. Nonetheless the correct costs to be internalized are not necessarily the external damages.

\section{C.5.3. A MORE SOPHISTICATED APPROACH}

The previous section offered an informal analysis of the issue of social costing for planning purposes, and the relationship between an optimal adder and exogenous, preexisting policies. In the case of command-and-control regulation, we suggested rules of thumb for approximating these relationships. In other cases we suggested how an optimal adder would relate to marginal damages.

In this section, we offer results based on a simple but fairly general formal model of social welfare maximization (see Burtraw et al. 1992), under the assumption that the goal of the PUC is to maximize social welfare, within its ability to do so. In this paper, we investigate the design of an optimal adder that could be used for either planning or dispatch purposes (depending on the definition of the cost functions). We consider two technology options for the regulated utility, and one option for utility customers to bypass the grid and generate their own energy services (including fuel substitution) which would have its own externalities. Within the formal model, however, we do not consider the possibility of substitution away from energy services to other factors of production such as capital, labor, or resources.

We find that the optimal (second-best) adder depends on the market structure of the industry, that is, whether the firms are subject to cost-recovery rate setting and whether prices deviate from marginal costs. Since we assume average cost pricing is already second-best, the optimal adder is zero when there are no external damages. However, in the presence of external damages such as environmental pollution, the calculation of the optimal adder must take into account the ramifications of moving toward or further away from marginal cost pricing.

Second, we formally model an opportunity for bypass of the electricity grid by the utility's customers. This opportunity may have deleterious environmental effects which must also be taken into account. In some special cases the optimal adder is shown to approximately equal marginal damage. One such case is when the opportunity for bypass is nonexistent, or when emissions from independently generated energy services are zero. In this case, whenever price and marginal social cost are within $40 \%$ of each other, and elasticity is greater than or equal to -0.7 , the optimal adder is within about $25 \%$ of marginal damages. The difference between the optimal adder and marginal damage is smaller the smaller is the elasticity of demand and the smaller the deviation between price and marginal social cost. 
In a competitive market, such as may characterize the independent power sector supplying power from various technologies to a regulated utility for transmission and distribution, and against a backdrop of command-andcontrol environmental regulation at the federal or state level, the optimal adder differs from marginal damage only due to potential emissions and associated damage resulting from bypass of the electricity grid. The smaller are either these emissions or the potential for bypass, the closer is the optimal adder to marginal damage. In the absence of an opportunity for bypass, the optimal adder precisely equals the marginal damage from the residual pollution that occurs after the firms have complied with all relevant environmental laws.

The command-and-control setting is the most important for the consideration of environmental issues because it is the form taken by most existing federal and state environmental regulations in this country. The rules we identify for these adders are invariant with regard to the rigor of preexisting regulation, that is whether emissions are over-controlled or undercontrolled from the standpoint of economic theory. Against the backdrop of command-and-control regulation, the simple rule of thumb that an adder be set equal to marginal damages has the potential to be quite robust. In further research we intend to determine whether this rule can be a useful guideline for the use of adders for planning or dispatch decisions.

Setting the fee equal to the marginal damages appears to be a standard result in the economics literature, as found in Baumol and Oates (1988) and elsewhere. Note this important difference, however. In the standard model, where there is no preexisting environmental standard that must be met, the optimum effluent fee must be set equal to what the marginal damages would be at the optimum. If one starts at a nonoptimal point hoping to use the fee instrument to reach optimality, the proper fee is not obvious. This analysis establishes that the optimal adder does not depend on whether existing regulation is inefficient or efficient, and offers a theoretical framework for comparison of the optinial adder with observed marginal damage given existing regulation. While environmental damage estimation is not easy under any circumstances, it is at any rate easier to estimate marginal damages than to estimate what damages would be at some as-yet-unattained optimum.

\section{C.6 IMPLEMENTATION ISSUES}

Proposed and existing social costing regulations--both of which focus primarily on the selection of new sources of generating capacity--require utilities to invest in the project(s) with the lowest social costs of electricity 
supply, but do not require them to actually pay the environmental damage costs of electricity generation. Ranking potential sources of new supply by social cost per unit of electricity produced is referred to as "ranking with grandfathering." This is because new generation facilities, but not existing ones, are covered by this form of regulation.

Another possible approach to social costing would be to impose the environmental costs of power production at new generating units on a utility by means of a tax on emissions. The tax rate would be set equal to the marginal damage cost associated with an additional unit of pollution. This form of social costing, referred to as "taxation with grandfathering," would pass to consumers the full social cost of generating electricity at new generating units only.

Under a third form of social costing, a utility would be required to internalize the external costs of emissions from both new and existing generating units. This regulatory regime would govern not only investment behavior, but also the schedule of use or dispatch of all generating units. When a utility has to consider the complete social cost of each kwh of electricity generated, it will dispatch all units in order of unit social cost, a practice referred to as "social cost dispatch."

\section{Modeling utility decision making}

To explore the effects of imposing each of these three social costing regimes on a utility's investment and dispatch decisions, researchers at Resources for the Future (RFF) developed and simulated a model of utility planning and dispatch for a representative mid-Atlantic utility. The objective of this hypothetical utility which uses nuclear, coal steam, oil steam, gas steam, gas turbine and hydro technologies to generate electricity was to build and operate generating units in a way that minimizes the cost of satisfying a given expected level of demand for eleciricity plus a 20 percent reserve margin. The model allowed for demand to vary over time and specified a realistic load duration curve which depicts the time duration of electricity demand at or above a particular level. In the simulation, the utility had to increase its generating capacity by deferring retirements and by investing in new generating units to meet increased demand. The range of technologies available for investment included four fossil-fueled technologies and three renewable technologies: hydro electric, solar and wind. Ranked from least expensive to most expensive in terms of private cost per kwh generated, the technologies are hydro-electric, integrated gasification combined cycle (IGCC), gas turbine combined cycle (GTCC), pulverized goal with wet flue gas desulfurization (PC/FGD), atmospheric fluidized bed coal (AFBC), wind and solar. 
To simulate how the hypothetical utility would respond to social costing in its investment and dispatch decisions, the RFF study inserted estimates of the environmental costs associated with three pollutants that are emitted when fossil fuel is burned to generate electricity: sulfur dioxide $\left(\mathrm{SO}_{2}\right)$, nitrogen oxides (NOx), and carbon dioxide $\left(\mathrm{CO}_{2}\right)$.

The RFF study considered four sets of illustrative estimates of the unit environmental costs of $\mathrm{NOx}$ and $\mathrm{SO}_{2}$ emissions. In the first set of estimates based on illustrative estimates of environmental damage costs, NOx emissions are valued at $\$ 0.25$ per pound and $\mathrm{SO}_{2}$ emissions at $\$ 0.50$ per pound. $\mathrm{A}$ second set of estimates multiplies these values by a factor of 10 . In a third set of estimates, based on abatement costs, $\mathrm{NO}_{\mathrm{x}}$ emissions are valued at $\$ 3.25$ per pound and $\mathrm{SO}_{2}$ emissions at $\$ 0.75$ per pound, while the fourth set multiplies these values by 10 . The social costs of $\mathrm{CO}_{2}$ emissions were not based on estimates of environmental damage or abatement costs, but on two tax rates proposed for limiting these emissions: $\$ 25$ per metric ton (MT) and $\$ 100$ per MT of carbon content of the fuel which translates to $\$ 6.82$ per MT and $\$ 27.27$ per MT respectively of $\mathrm{CO}_{2}$ emitted. The RFF study considered the effects of social costing both with and without valuing $\mathrm{CO}_{2}$ emissions.

Results of the model simulations

The RFF study compared the utility's investment decisions, its dispatch of generating units, and the related social costs under the various social costing regimes to a base case scenario with no environmental costing. With no social costing, the utility builds new IGCC and GTCC generating capacity and uses these new generating units to generate 27 percent of its total electricity output. The utility builds a small amount of new hydro capacity and runs its existing hydro unit at capacity throughout much of the year. It does make some life-extending investment in its aging coal-fired units, but allows its expiring oil-fired unit to shut down.

Under this base scenario, the social costs of the utility's investment and operating plan depend on the environmental cost assumptions adopted. Using relatively high external costs for $\mathrm{SO}_{2}$, the study revealed that the ratio of social costs to private costs is 1.2 in the absence of a carbon tax. With a $\mathrm{CO}_{2} \operatorname{tax}$ of $\$ 6.82 / \mathrm{MT}$, the ratio rises to 1.3 . With a tax of $\$ 27.27 / \mathrm{MT}$, the ratio is 1.8 . At ten times the relatively high $\mathrm{SO}_{2}$ cost level, the ratio is 2.6 . Using relatively high $\mathrm{NO}_{\mathrm{x}}$ costs, the ratio of social costs to private costs is 1.7 in the absence of a $\mathrm{CO}_{2} \operatorname{tax}, 1.9$ with a $\mathrm{CO}_{2} \operatorname{tax}$ of $\$ 6.82 / \mathrm{MT}$, and 2.4 with a $\mathrm{CO}_{2} \operatorname{tax}$ of $\$ 27.27 / \mathrm{MT}$. At ten times the relatively high $\mathrm{NO}_{x}$ external cost levels, the ratio rises to 8.4 . 
Under a social cost program in which new electricity generating units are ranked by the social cost per unit of electricity produced (ranking with grandfathering), the utility's dispatch and investment behavior is unaffected unless $\mathrm{CO}_{2}$ is assigned an external cost

of \$27.27/MT. Under this set of scenarios, new units using renewable energy are built, but account for less than 3 percent of the electricity generated. Under any environmental cost assumptions, this regulatory regime does not decrease the social costs of electricity generation.

As compared with ranking, a social cost program in which emissions from new generating units are taxed (taxation with grandfathering) has a more substartial effect on the utility's investment behavior and on how generating units are dispatched. The impart on dispatch is especially pronounced when carbon emissions are taxed, leading the utility to increase significantly its reliance on existing fossil- fueled units. This tendency to avoid new generating units may lead to an increase in social costs, because the assymetric tax creates a stronger incentive to substitute existing sources of electricity for new sources. The social costs of electricity generation never fall under taxation with gra-sitathering.

Under a social cost dispatch program, the utility's investment and dispatch decisions vary depending on the environmental costs adopted. With the high $\mathrm{SO}_{2}$ set of external costs, the utility's investment and operating behavior is not changed substantially from the base case unless $\mathrm{CO}_{2}$ emissions are assigned a cost of $\$ 27.27 / \mathrm{MT}$, in which case existing gas stream units are employed more intensely, or external costs for $\mathrm{SO}_{2}$ and $\mathrm{NOx}$ emissions are set at $\$ 7.50$ and $\$ 32.50$ per pound respectively, in which case the utility shuts down all of its existing coal units and relies heavily on new coal-burning units. (See Figure C-3.)

With relatively high $\mathrm{NO}_{x}$ the utility shuts down its existing coal- fired boilers at the lowest external cost levels and increases its reliance on new coalfired units. When $\mathrm{CO}_{2}$ emissions are included, the utility increases its reliance $\backsim n$ renewables and reduces its use of existing oil steam units. Social cost dispatch never leads to an increase in social costs. Under all of the illustrative environmertal cost assumptions, the utility chooses generating resources that result in lover social costs than in the base case. As the assumed marginal environmental cost estimates increase, the social cost savings from the imposition of social cost dispatch rise.

\section{Implications of environmental costing for electricity prices}

The effect of social costing on electricity prices varies with the environmental cost assumptions and the scope of the regulatory regime. The 
average cost of generating a kilowatt-hour of electricity with no social costing is $\$ 0.052$. This unit cost estimate includes the embedded capital cost of using existing generating units but does not include the overhead costs of operating the utility.

Assuming that demand for electricity does not change, the findings of the RFF study suggest that the unit generation cost and the consumer price for electricity would rise between 0 and 0.05 cents under a social costing program of ranking with grandfathering. This virtually non-existent price effect reflects how little a requirement to invest in new sources of generating capacity with the lowest social costs of electricity supply would affect a utility's employment of generating resources, given the range of illustrative environmental cost estimates for the included pollutants.

Under a social cost program of emissions taxation with grandfathering, the size of the electricity price effect depends on the asso 1 level of environmental costs. With relatively high $\mathrm{SO}_{2}$ costs, the price is not affected unless $\mathrm{CO}_{2}$ emissions are taxed. At a tax of $\$ 27.27 / \mathrm{MT}$, the price could be expected to rise by as much as 0.5 cents. With relatively high $\mathrm{NO}_{x}$ costs, the price could rise if only NOx, and $\mathrm{SO}_{2}$ emissions are taxed; however, it is likely to rise by more when $\mathrm{CO}_{2}$ emissions are taxed.

The potential price increases under social cost dispatch depend on whether or not the utility is required to pay the external costs of generation in the form of emission taxes or to simply dispatch units according to full social costs. With relatively high $\mathrm{SO}_{2}$ costs, the consumer price would rise by from 1 to 3 cents per kwh if emissions are taxed, but only up to .75 cents per kwh if only shadow prices are used. With relatively high $\mathrm{NO}_{\mathrm{x}}$ costs, the increase in price is smaller because the utility significantly reduces its environmental tax bill when it shuts down its existing coal-fired units. However, with environmental taxes set at ten times the basic abatement cost level, the price could rise by as much as 3.5 cents per kwh with emission taxes and 1.25 cents per kwh with no emission taxes.

\section{Limitations and results of the RFF simulation analysis}

The findings of the RFF simulation study represent neither a universal prediction of utility behavior under environmental costing regulation nor a characterization of the expected behavior of a particular existing utility. Instead, the RFF study provides an empirical example of the response of a representative mid-western utility to illustrative environmental costs. The applicability of the findings of this study to either the general class of electric utilities or to a specific utility is restricted by the limited range of 
environmental externalities that are included in the analysis and by the specification of environmental costs.

With respect to externalities, the study focused only on emissions of a small number of air pollutants and, therefore, failed to include other environmental externalities, such as emissions of water and soil pollutants or environmental damages associated with the construction of various types of power plants. Moreover, a constant emission factor for each pollutant at each type of generating unit was used to estimate the levels of those emissions that were considered. While this assumption is accurate for some pollutants, $\mathrm{NO}_{\mathbf{x}}$ emission rates vary with the level of capacity utilization at each generating unit.

With respect to environmental costs, the illustrative external cost estimates adopted in this study were intended to indicate a range of possible environmental costs that might be used for implementing EC regulation. However, these costs do not reflect state-of- the-art estimates for environmental damages for the selected pollutants. If the studies of environmental damages of electricity generation currently underway in several states estimate damages that lie outside of the ranges included in this study, then a particular utility's response to a social costing regime based on these estimates may be at variance to the responses suggested in the simulation study.

Keeping these limitations in mind, the RFF study indicates that the outcome of a social cost program depends on the breadth of the program and on the environmental cost estimates on which it is based. The most effective environmental costing regime is social cost dispatch. Such a regime causes utilities to internalize the environmental damage costs of all the electricity they generate and, thus, leads them to reduce the social costs of electricity generation. A less comprehensive regime, such as ranking with grandfathering or taxation with grandfathering, could lead to higher emissions levels than those that would occur in the absence of environmental costing. Under partial environmental costing, utilities may not have an incentive to invest in cleaner technologies as long as the lives of existing generating units that use more polluting technologies may be extended with no regulatory penalties. Indeed, in RFF's empirical analysis, social costs never decrease under partial environmental costing, whereas they never increase under social cost dispatch. The incentive to substitute existing dirty units for new clean units can be even stronger when emissions from new supply sources are taxed than when utilities are required to invest in new sources with the lowest social cost per unit of electricity produced. 
A striking result of the RFF study is that social cost dispatch, based on the study's illustrative relatively high $\mathrm{SO}_{2}$ environmental cost estimates, leads to no change in the utility's investment and dispatch decisions unless high $\mathrm{CO}_{2}$ costs are assigned or unless the external costs of $\mathrm{SO}_{2}$ and $\mathrm{NO}_{\mathrm{x}}$ are set at ten times their initial levels. While these results reflect only a limited range of environmental externalities, they suggest that comprehensive social costing based on air pollution damage costs may have only a small effect on utility investment and dispatch behavior.

\section{C.7 CONCLUSION}

Introducing social costs into utility decision making is not the first best policy for internalizing damages associated with energy use. If this approach is applied to electric utilities only, energy markets could become distorted. It introduces possible anti-new source bias if applied to only new sources. It requires that other policies, such as potentially inefficient environmental laws, be taken as a given. It offers an inappropriate jurisdictional control for many issues, such as global warming or foreign policy, which will be a source of frustration for many advocates. And it could even result in increases in pollution. It would be preferable for federal and state laws to be set and designed efficiently affecting all sectors of the economy.

Nonetheless, application and investment of the concept of social costing of electricity can lead to more efficient electricity generation choices. While the piecemeal problem is potentially significant, so are the benefits of social costing. 


\section{C.8 REFERENCES}

Agathan, Paul A., 1992. "Dealing with Environmental Externalities," Public Utilities Fortnightly, pp. 23-24.

Baumol, William J. and Wallace E. Oates, 1988. The Theory of Environmental Policy, Cambridge and New York, Cambridge University Press.

Bohm, Peter, and Clifford S. Russell, 1985. "Comparative Analysis of Alternative Policy Instruments," in Allen V. Kneese and James L. Sweeney, eds., Handbook of Environment and Resource Economics vol.1, New York, North Holland.

Burtraw, Dallas, Winston Harrington, A. Myrick Freeman III, and Alan J. Krupnick, 1992. "The Analytics of Social Costing in a Regulated Industry," unpublished manuscript Washington, D.C., Resources for the Future.

Burtraw,1 Dallas, and Alan J. Krupnick, 1992. "The Social Costs of Electricity: How Much of the Camel to Let into the Tent?" Quality of the Environment Division Discussion Paper QE92-15, Washington, D.C., Resources for the Future.

Freeman, A. Myrick, Dallas Burtraw, Winston Harrington, and Alan J. Krupnick, "Externalities - How to Do it Right", The Electricity Joumal 5(7) p. 18.

Freeman, A. Myrick and Alan J. Krupnick, 1992. "Response to Joskow's 'Dealing with Environmental Externalities: Let's Do It Right' Paper," The Electricity Journal 5(7) p.61.

Joskow, Paul L, 1992. "Dealing with Environmental Externalities: Let's Do It Right!" Edision Electric Institute Issues and Trends Briefing Paper No. 61.

Organisation for Economic Co-operation and Development [OECD], 1991. Economic Instruments for Environmental Protection, Paris, OECD. 
Palmer, Karen L. and Alan J. Krupnick, 1991. "Environmental Costing and Electric Utilities' Planning and Investment," Resources, 105, Washington, D.C., Resources for the Future, based on Palmer, Karen L. and Hadi Dowlatabadi, "Implementing Environmental Costing in the Electric Utility Industry," Quality of the Environment Discussion Paper QE91-13 Washington, D.C., Resources for the Future.

Tietenberg, Thomas H., 1985. Emissions Trading: An Exercise in Reforming Pollution Policy, Washington, D.C., Resources for the Future. 


\section{NOTES}

1. Public debate about externalities has primarily been about external costs. Thus, in that context, this appendix focuses on costs and damages. Notwithstanding, it is important to realize that some externalities are benefits.

2. Willingness to pay is equal to MCC because it is this cost that is avoided through the purchase of an additional permit.

3. For a different view of responsibilities and objectives of public utility regulation, see Agathan (1992).

4. Currently there are no examples of these in the U.S., although they are prevalent in Europe (OECD, 1989).

5. The statement that the adder is equal to $M D-t$ is an over simplification. MD and $t$ are usually expressed in units of $\$ / E$, while the adder is expressed in units $\$ / \mathrm{kwh}$ (or $\$ / \mathrm{mw}$ ). So the adder is calculated as (MD t)E/kwh.

6. Proposed new sources of air emission in regions presently not attaining primary national air quality standards must certify offsetting reductions in emissions from other sources as a condition for obtaining an emissions license. They may obtain offsets by purchasing reductions in emissions from other sources.

7. There is a change in the incidence of damages. Some gain as their damages are reduced while others lose. But the net effect is zero. 


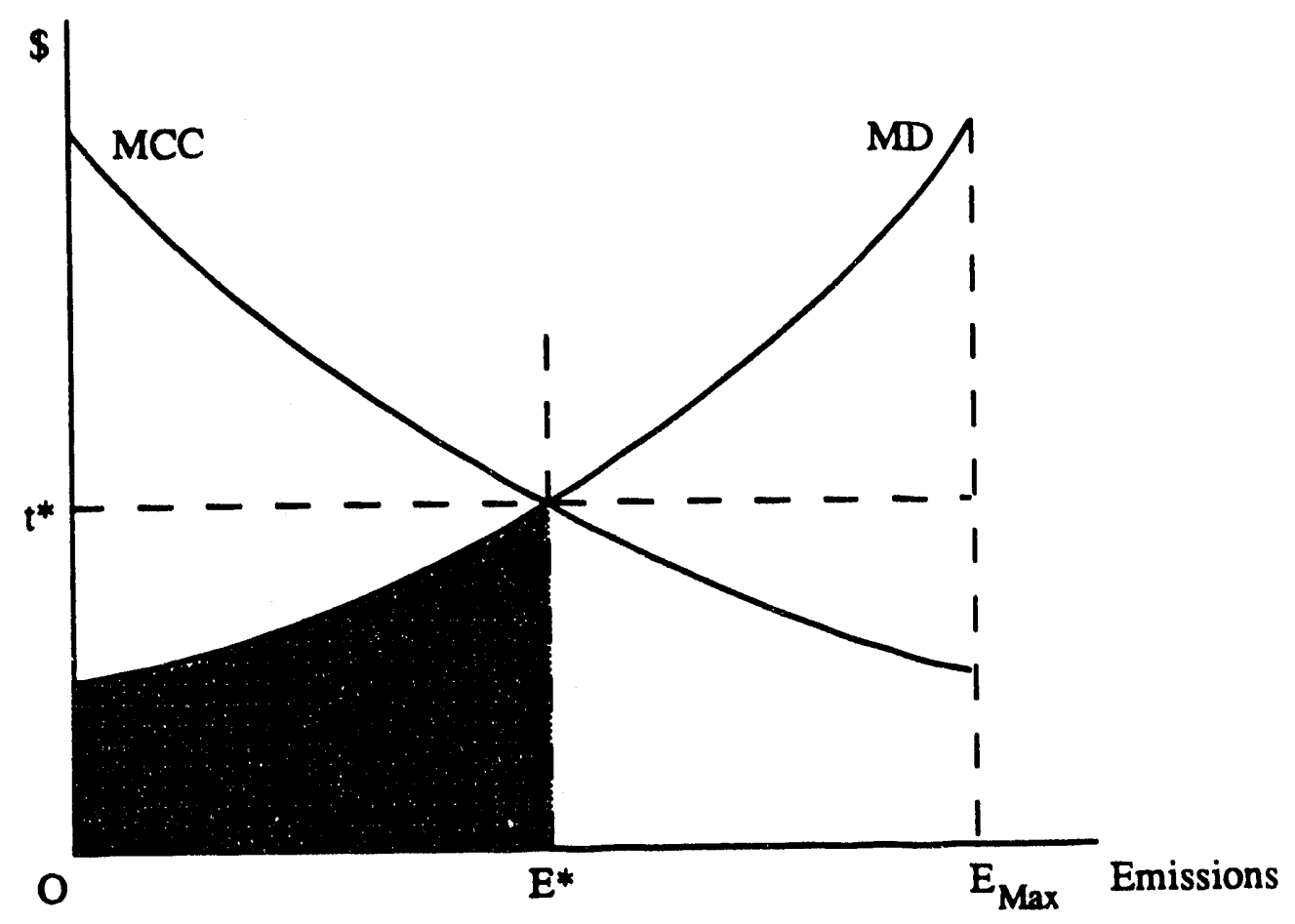

Fig. C-1 Optimal Emissions Control 


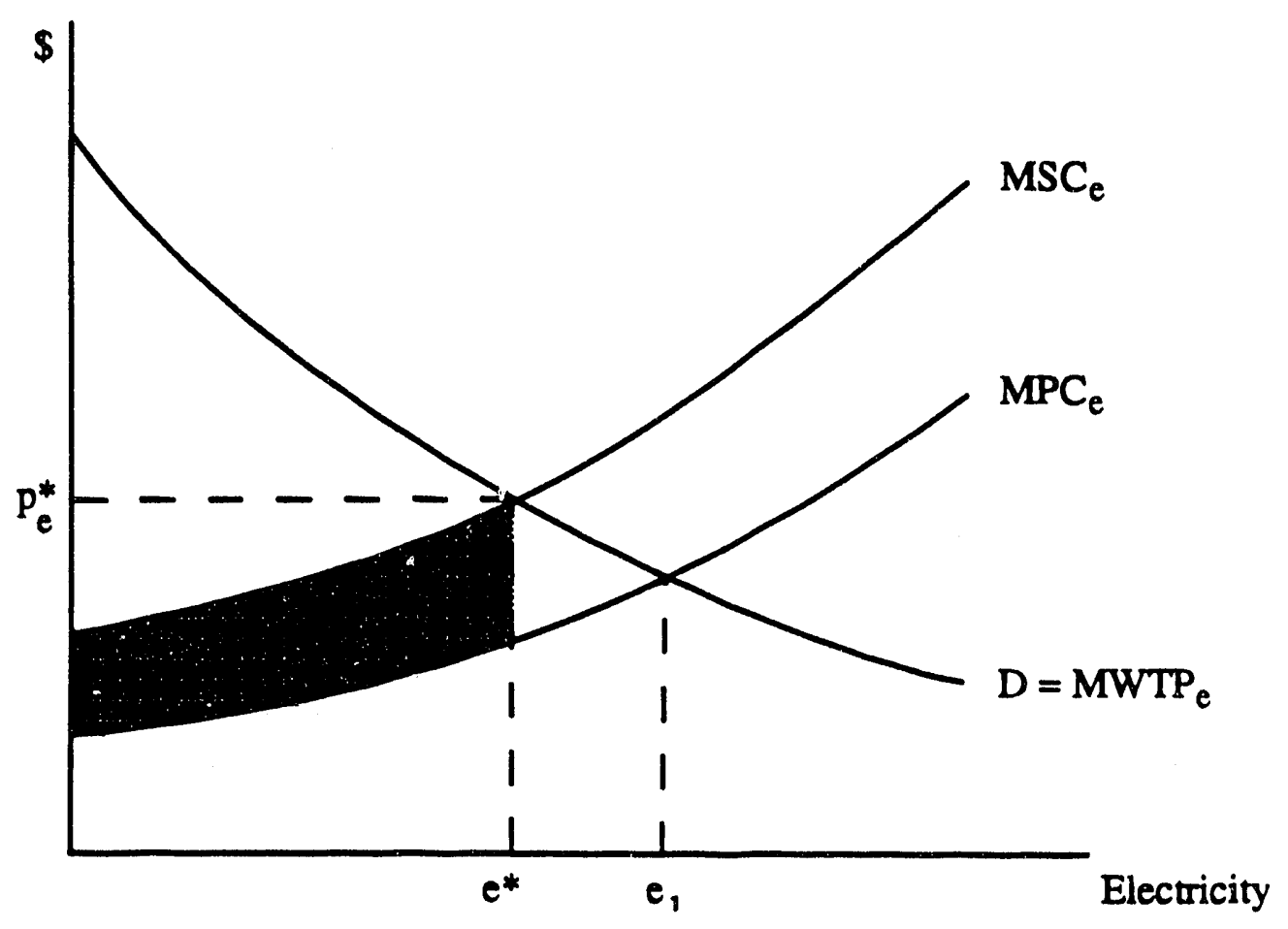

Fig. C-2 The Market for Electricity 
Fig. C-3

A Hypothetical Utility's Sources of Electricity Generation under an Environmental Costing Program of Social Cost Dispatch

Percentage of Electricity

Produced
100

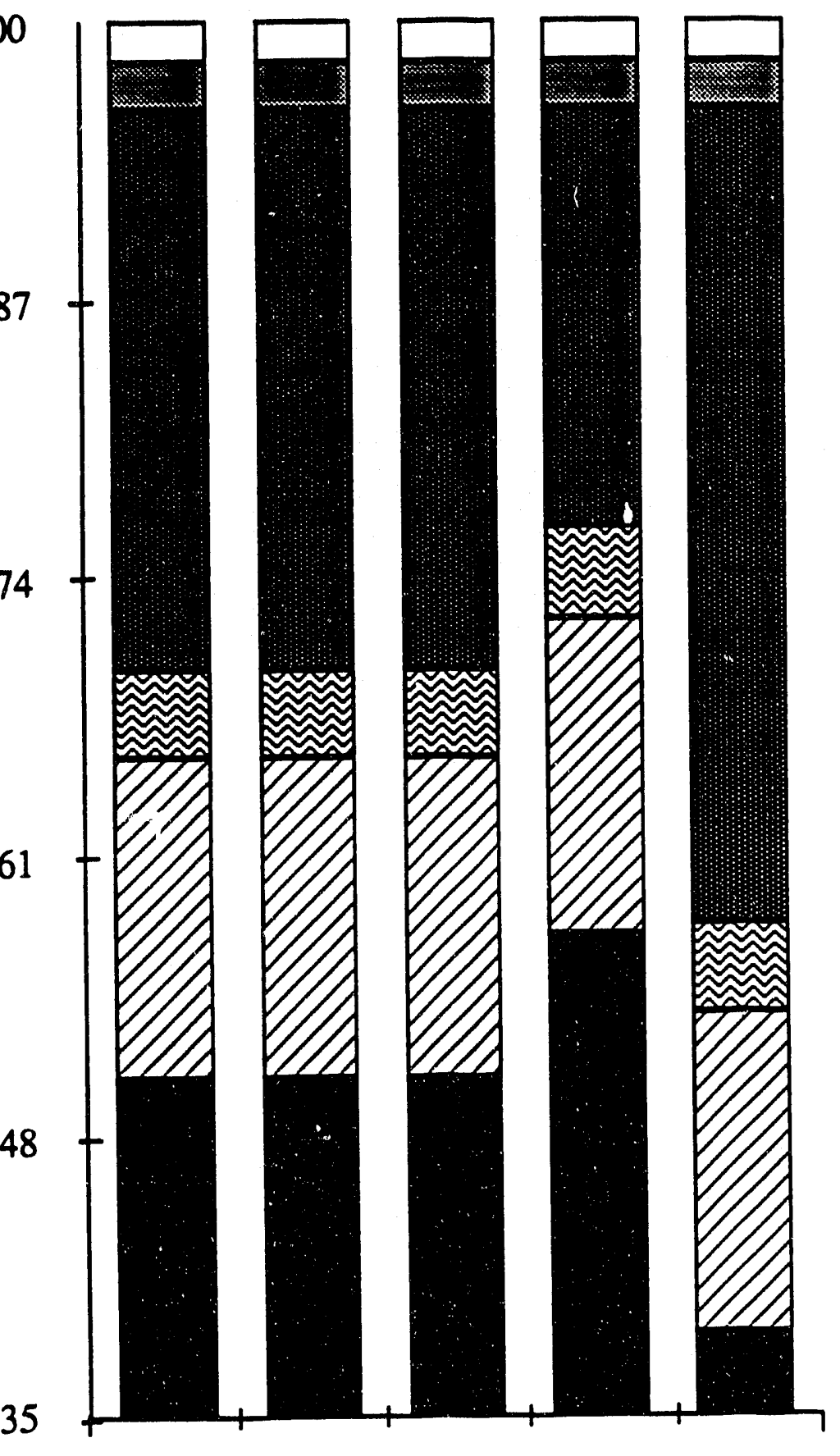

Base NOx cost $=$ Plus CO2 Plus CO2 NOx cost = Case $\quad \$ 0.25 / \mathrm{b} ; \quad$ cost $=\quad$ cost $=\quad \$ 2.50 / \mathrm{b}$; SO2 cost $=\$ 6.82 / \mathrm{MT} \quad \$ 27.27 / \mathrm{MT} \quad$ SO $\times$ cost $=$ $\$ 0.50 \mathrm{Ab}$ No $\operatorname{CO} 2$ cost $\$ 5.00 / \mathrm{b}$; No $\mathrm{CO} 2$ cost. $\square$ NEW RENEW

NEW GAS

NEW COAL

因 EXISTING HYDRO

$\square$ NUCLEAR

EXISTING FOSSIL 

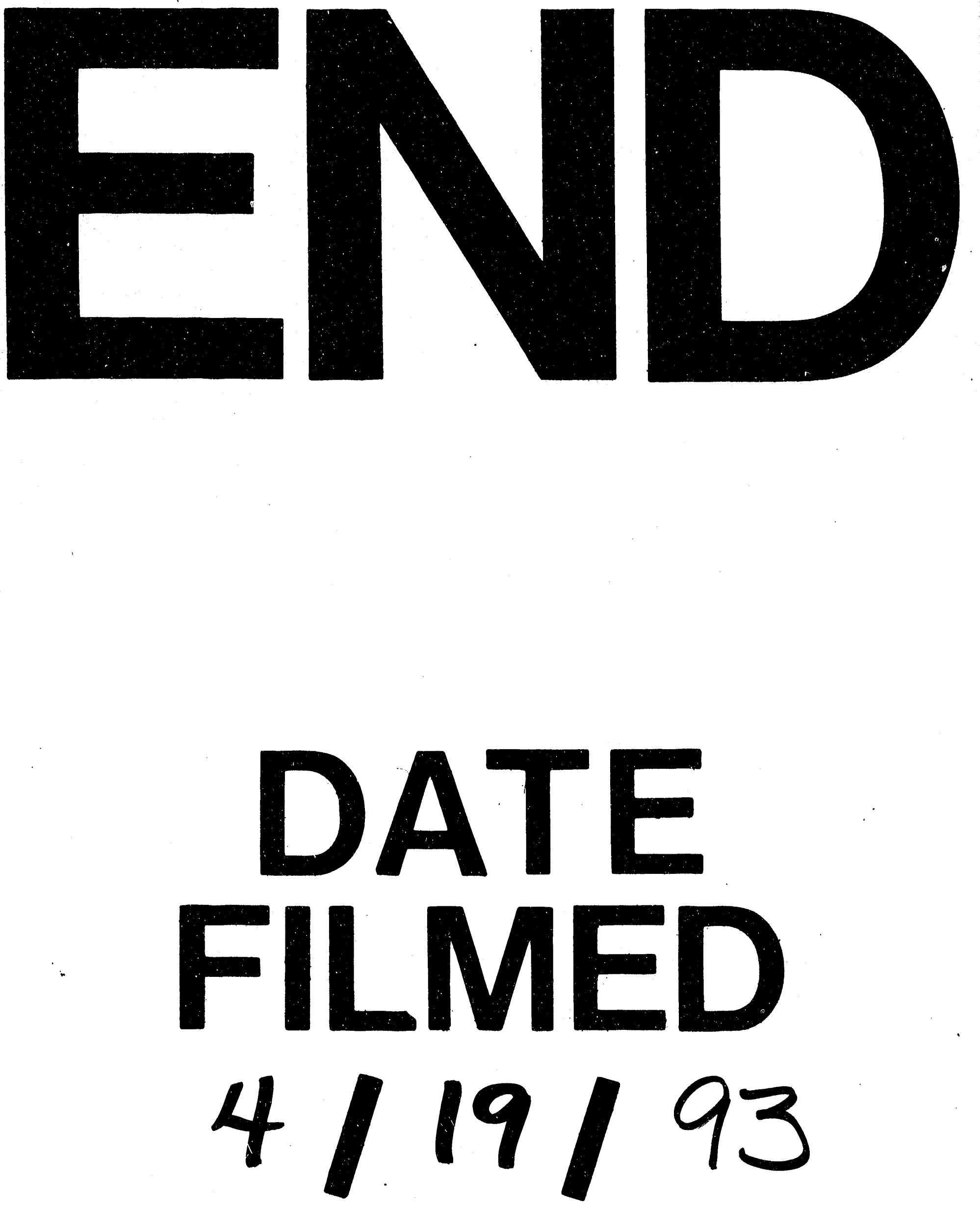

1 
